\title{
An Assessment of the Risk of Transporting Plutonium Oxide and Liquid Plutonium Nitrate by Truck
}

August 1975

Prepared for the U.S. Energy Research and Development Administration under Contract E(45-1): 1830 


\section{NOTICE}

This report was prepared as an account of work sponsored by the United States Government. Neither the United States nor the United States Energy Research and Development Administration, nor any of their employees,

nor any of their contractors, subcontractors, or their employees, makes any warranty, express or implied. or assumes any legal liability or responsibility for the accuracy, completeness or usefulness of any intormation. apparatus, product or process disclosed, or represents that its use would not infringe privately owned rights.

\section{PACIFIC NORTHWEST LABORATORY}

operated by

BATTELLE

for the

U.S. ENERGY RESEARCH AND DEVELOPMENT ADMINISTRATION

Under Contract E(45-1)-1830 
BNWL-1846

UC-71

33679000487209

\author{
AN ASSESSMENT OF THE RISK OF TRANSPORTING \\ PLUTONIUM OXIDE AND LIQUID PLUTONIUM \\ NITRATE BY TRUCK.
}

Program Coordinators

T. I. McSweeney R. J. Hall

Technical Contributors
C. L. Brown
W. S. Kelly
J. M. Creer -
D. A. Kottwitz
D. K. Davis
S. N. Liu
J. G. Desteese
T. I. McSweeney
J. G. Droppo
J. Mishima
R. J. Hall
E. C. Watson
S. W. Heaberl in
L. D. Williams

August 1975

BATTELLE

PACIFIC NORTHWEST LABORATORIES

RICHLAND, WASHINGTON 99352 


\section{CONTENTS}

LIST OF FIGURES. . . . . . . . . . . . . . . . . . . . . iv LIST OF TABLES . . . . . . . . . . . . . . . . . . . . vii

1. INTRODUCTION . . . . . . . . . . . . . . . . . . . 1.1

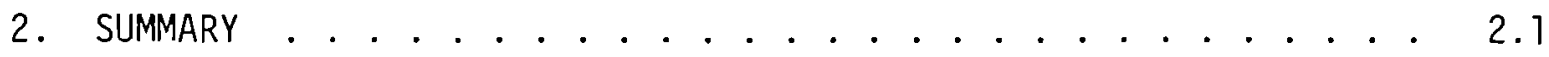

3. RISK ANALYSIS MODEL . . . . . . . . . . . . . . . . 3.1

3.1 BACKGROUND ON RISK METHODOLOGY . . . . . . . . . . . . 3.1

3.2 RISK MODEL DEVELOPMENT . . . . . . . . . . . . . 3.4

4. PLUTONIUM SHIPPING REQUIREMENTS . . . . . . . . . . . . . . 4.1

4.1 NUCLEAR INDUSTRY ASSUMPTIONS . . . . . . . . . . . . 4.1

4.2 FUEL REPROCESSORS ................... . . . 4.2

4.3 FUEL FABRICATORS ..................... 4.2

4.4 PLUTONIUM SHIPPING DISTANCES . . . . . . . . . . . . . 4.2

5. TRANSPORT ACCIDENT ENVIRONMENT . . . . . . . . . . . . . . . 5.1

6. PACKAGE FAILURE THRESHCLLDS . . . . . . . . . . . . . . 6.1

6.1 RESULTS OF ANALYSIS - L-10 CONTAINER . . . . . . . . . 6.2

6.2 RESULTS OF ANALYSIS - 6M CONTAINER . . . . . . . . . . 6.5

6.3 DISCUSSION OF STRESS ANALYSIS . . . . . . . . . . . . 6.6

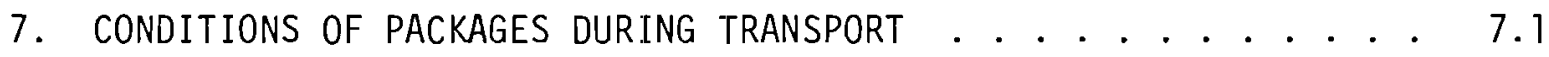

7.1 SCOPE OF SURVEY ...................... 7.1

7.2 RESULTS OF SURVEY . . . . . . . . . . . . . . 7.6

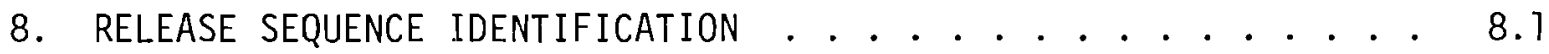

8.1 SAFETY ANALYSIS TREE CONSTRUCTION . . . . . . . . . . 8.1

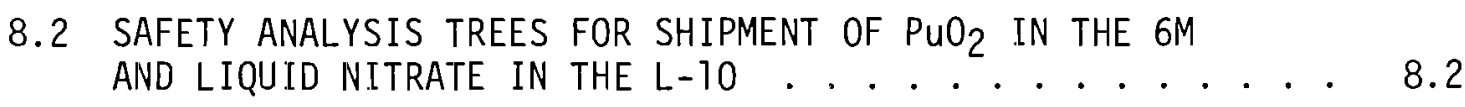


8.3 BARRIER RELEASE SEQUENCES . . . . . . . . . 8.10

9. ReleASe Sequence EVAuATION . . . . . . . . . . . . 9.1

9.1 BASIC EVENT PROBABILITIES . . . . . . . . . . . . 9.3

9.2 BARRIER RELEASE SEQUENCE PROBABILITIILS . . . . . . 9.27

9.3 RELEASE FRACTIONS . . . . . . . . . . . . . . . 9.28

9.4 SUMMARY OF RELEASE SEqUence EVAlUations . . . . . . . . 9.35

10. EVALUATION OF ENVIRONMENTAL CONSEQUENCES . . . . . . . 10.1

10.1 QUANTITY AIRBORNE .................. 10.1

10.2 METEOROLOGY . . . . . . . . . . . . 10.10

10.3 DEMOGRAPHY ......................... 10.11

10.4 INDIVIDUAL AND POPULATION DOSE FACTORS . . . . . 10.19

10.5 POPULATION HEALTH EFFECTS . . . . . . . . 10.29

10.6 ESTIMATEd EXPOSURE FREQUENCY . . . . . . . . . . . 10.32

11. THE RISK OF SHIPPING PLUTONIUM OXIDE AND LIQUID NITRATE

BY TRUCK . . . . . . . . . . . . . . . 11.1

11.1 SYSTEM DESCRIPTION . . . . . . . . . . . . . 11.1

11.2 RISK EVALUATIONS FOR PLUTONIUM OXIDE AND LIQUID

PLUTONIUM NITRATE SHIPMENTS ............... . . . 11.4

11.3 RISK CALCULATIONAL UNCERTAINTIES . . . . . . . 11.12

11.4 RISK SENSITIVITY EVALUATIONS . . . . . . . . . 11.20 $\therefore$ PPPEIDIX A - DESCRIPTIN: OF PACKAGES USED TO SHIP

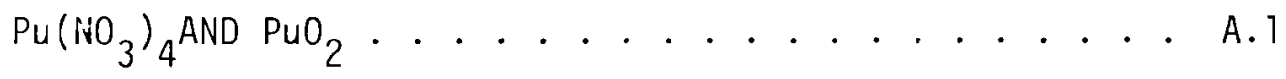

APPENDIX B - QUESTIONS USED IN SURVEY TO DETERMINE PACKAGING CONDITION DURING TRANSPORT . . . . . . . . . . . . B. 1

APPENDIX C - CONSIDERATIONS IN EVALUATION OF THE AIRBORNE RELEASE AND DISPERSION OF PLUTONIUH:1 . . . . . . . . .

APPENDIX D - PHYSICAL AND CHEMICAL PROPERTIES OF PLUTONIUM DIOXIDE AND PLUTONIUM NITRATE SOLUTION . . . . . . . . D.T 


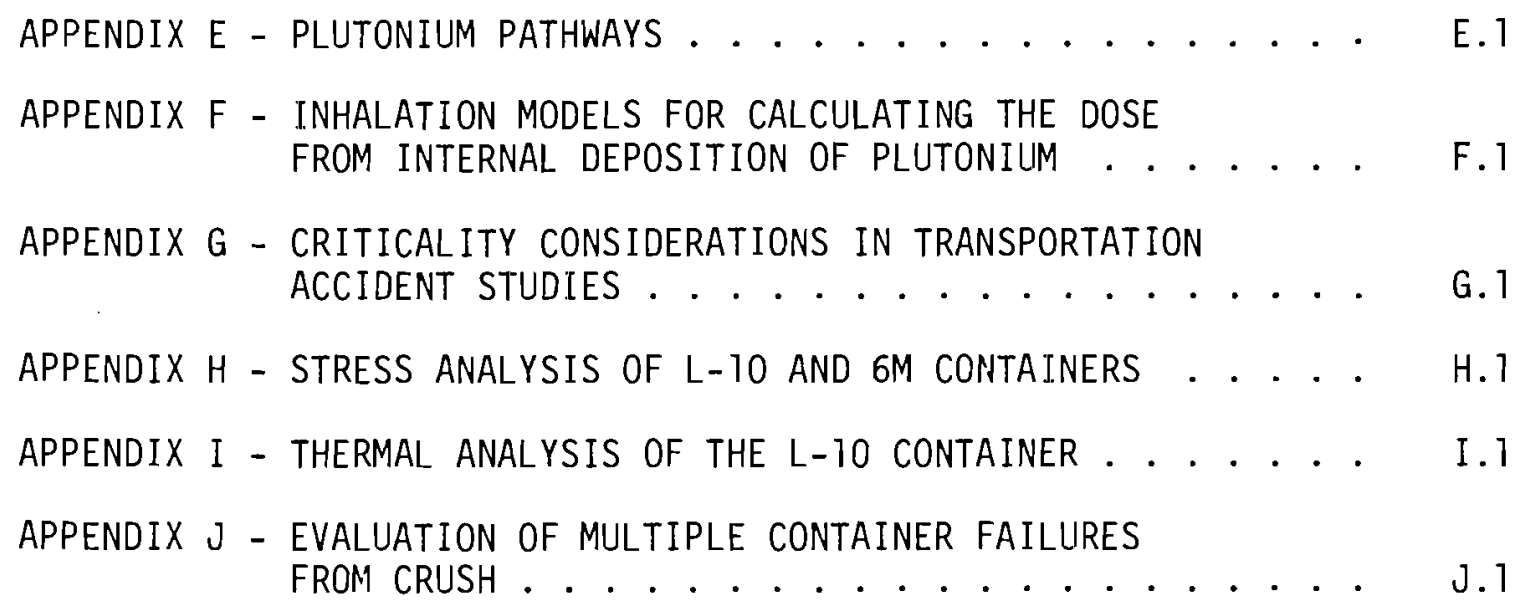




\section{LIST OF FIGURES}

2.1 Risk Spectra for Plutonium Shipments in the Early 1980 's for the Entire U.S. . . . . . . . . . . 2.3

3.1 Model to Calculate the Risk of Shipping Nuclear Material .................. 3.5

3.2 Information Required to Describe Transport System . . . 3.8

3.3 Information Required to Define Scope of Evaluation... . 3.11

5.1 Expected Severity of Cargo Decelerations in the Truck Accident Environment . . . . . . . . . . 5.3

5.2 Expected Severity of Puncture Forces in the Truck Accident Environment .. . . . . . . . . . . 5.4

5.3 Expected Duration of Fires for Accidents Involving a Truck with Nonflammable Cargo .. . . . . . . . 5.5

7.1A Fault Tree for L-10 Plutonium Nitrate Solution

Package Closure Analysis . . . . . . . . . . 7.3

7.1B Fault Tree for L-10 Plutonium Nitrate Solution Package Closure Analys is (Part 2) .......... 7.4

7.2 Fault Tree for 6M Plutonium 0xide Package Closure Analysis................ 7.5

8.1 Fault Tree for the Shipment of Plutonium Oxide Powder in the $6 \mathrm{M}$ Container . . . . . . . . . . . 8.3

8.2 Fault Tree for the Shipment of Liquid Plutonium
Nitrate in L-10 Containers . . . . . . . . . 8.6

9.1 Release Sequence Evaluation Steps . . . . . . . . 9.2

10.1 Release Sequence Evaluation Steps . . . . . . . . 10.2

10.2 Aerodynamic Entrainment of Uranium Dioxide Powder from Smooth Sandy Soil at an Air Velocity of . . $2.5 \mathrm{mph}$

10.3 Aerodynamic Entrainment of Uranium Dioxide Powder from Smooth, Sandy Soil at an Air Velocity of $20 \mathrm{mph}$

10.4 Fuel Reprocessing Sites and Plutonium Fuel Fabrication Facility Locations. 
11.1 Risk Spectrum for Shipping One Metric Ton of Plutonium 1500 Miles Across the North Central and Southeastern U.S. . . . . . . . . . . . 11.8

11.2 Risk Spectrum for Plutonium Shipments in the Early 1980 's for the Entire U.S. ............. 11.10

11.3 Risk Spectra for Liquid Plutonium Nitrate Sinipments in the Early 1980's for Four Zones in U.S.

11.4 Risk Spectra for Plutonium 0xide Shipments in the Early 1980's for Four Zones in U.S. . . . . . . . . . 11.13

11.5 Risk Spectrum Evaluation of Single and Multiple Container Failure from Crush Forces Imposed on the L-10 Container in the Accident Environment . . . . . . 11.19

11.6 Sensitivity of the Risk Spectrum Curves to Several Parameters for Liquid Plutonium Nitrate Shipments in the L-10 Container.

11.7 Sensitivity of the Risk Spectrum Curves to Several Parameters for the Plutonium Oxide Shipments in the 6M Container

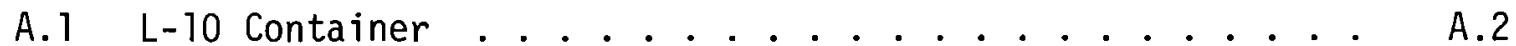

A.2 6M Container .................... A.

A.3 LLD-1 Container . . . . . . . . . . . . . . . A.6

D.1 Plutonium Dioxide Particle Size Distribution Formed by Calcination of Plutonium Oxalate D.4

E.1 Exposure Pathways and Discrimination Factors for Plutonium in the Biosphere ........... E.2

F.1 Schematic Diagram of the Task Group Lung Model . . . . . F.3

G.1 Pre-Accident Truck Loading Patterns . . . . . . . . . . G.4

G.2 Vessel Compaction Assumed in Analysis . . . . . . . G.6

G.3 Actual and Model 2R Container........... G.7

H.1 She11 Deformation from Impact Versus Drop Height for an L-10 Container. . . . . . . . . . . . H.4

H.2 Change in She11 Circumference as a Function of Drop Height for the L-10 Container 
H.3 Pressure-Temperature Relationships for the

L-10 Container.............. . H.6

H.4 Distance Between L-10 Inner and Outer Containers

After Impact as a Function of Drop Height . . . . . H.8

H.5 Relative Distance Between Inner and Outer

Containers after Case II Drop ............ H.9

H.6 Deceleration of Inner Container and Outer Shell

During Impact as a Function of Drop Height. . . . . . . H.9

H.7 She11 Deformation from Impact versus Drop Height

for the 6M Container............... H.11

H.8 Deformation of Inner Vessel from Impact as a

Function of Drop Height - 6M Container ......... H.13

I.1 L-10 Case I Geometry . . . . . . . . . . . . I.6

I.2 L-10 Case II Geometry . . . . . . . . . . . I.6

I.3 L-10 Case III Geometry . . . . . . . . . . . I.6

I.4 L-10 Case II Vermiculite Model . . . . . . . . . I.8

I.5 L-10 Case I Temperature versus Time of Pressure Housing Exposed Directly to $1475^{\circ} \mathrm{F}$ Fire ... . . . . . I.14

I.6 L-10 Case II Nodal Temperatures after 50 min.

Fire Exposure .............. I.15

I.7 L-10 Case II Temperature versus Time of Pressure
Housing in Crushed Container Exposed to $1475^{\circ} \mathrm{F}$ Fire . . . . I.16

I.8 L-10 Case III Temperature versus Time of Pressure Housing with $1475^{\circ} \mathrm{F}$ Fire Inside Container ....... I.17

I.9 L-10 Case III Time for Pressure Housing Failure versus Vermiculite Insulation Thickness ........ I.18

J.1 Risk Spectrum Evaluation of the Independent and Multiple Container Failure Evaluation from Crush Forces Imposed on the L-10 Container in the Accident Environment 


\section{LIST OF TABLES}

3.1 Important Physical and Chemical Properties of

Materials Used in Assessing Shipment Risks . . . . . 3.9

4.1 Assumed Industry Characteristics (One Year Period) . . . . 4.1

4.2 Assumed Fuel Fabrication Facilities . . . . . . . . 4.2

4.3 Estimated Route Distances Between Fuel Reprocessors and Fuel Fabricators (mi) ........... 4.3

6.1 Calculated Failure Thresholds for L-10 and 6M Shipping Containers ........... 6.6

7.1 Fault Tree Symbolism . . . . . . . . . . 7.2

7.2 Estimated Number of Shipments and Packages Included in Survey. . . . . . . . . . . 7.7

7.3 Data Bank - Package Closure Experience Obtained by Survey (For Period 1970-1974) . . . . . . . . 7.9

8.1 Listing of Basic Events for 6M Analysis . . . . . . . . 8.9

8.2 Listing of Basic Events in L-10 Analysis . . . . . . . 8.10

8.3 Barrier Release Sequences Developed for the 6 M Container............... 8.12

8.4 Listing of Input Labels for Rectangles for 6M Container Analysis.............. 8.13

8.5 Barrier Release Sequences Developed for the $L-10$ Container ............... . . 8.14

8.6 Listing of Input Labels for Rectangles for L-10 . . . . . 8.15
Container Analysis . . . . . . . .

9.1 Surmary of Barrier Release Sequences and Basic Element Occurrence Frequencies Used in the Evaluation of Plutonium Oxide Shipments in the 6M Container . . . . . 9.28

9.2 Summary of Barrier Release Sequences and Basic Element Occurrence Frequencies Used in Evaluation of Liquid Plutonium Nitrate Shipments in the L-10 Container. . . . . 9.29 
9.3 Summary of Barrier Release Sequences, Basic Element Frequencies and Barrier Release Fractions for Shipping Plutonium Oxide Powder a Distance of 1500 Miles in the 6M Container ............ 9.36

9.4 Summary of Barrier Release Sequences, Basic Element Frequencies and Barrier Release Fractions for Shipping Liquid Plutonium Nitrate a Distance of 1500 Miles in the $\mathrm{L}-10$ Container . . . . . . . . . 9.37

10.1 Average Windspeed/Stability Characteristics . . . . . . 10.12

10.2 New Jersey Population Characteristics-1960 . . . . . . 10.14

10.3 Massachusetts Population Characteristics-1960 . . . . 10.15

10.4 Missouri Population Characteristics-1960 . . . . . . . 10.15

10.5 Washington Population Characteristics-1960 . . . . . . 10.15

10.6 Projected Population Density and Land Area by Zone and Population Classes ........... . 10.17

10.7 Average Population Densities by Zone (People/mi2)................... 10.18

10.8 Projected Land Area of Urban Areas in the

Four Zones of the U.S. . . . . . . . . . . . 10.18

10.9 Fractional Shipping Route Mileage by

Population Zones................. 10.19

10.10 Dose Conversion Factors for Inhalation of Plutonium and Americium-241 Isotopes (Standard Man) . . . . . . 10.23

10.11 Reference Mixture of Plutonium and Americium . . . . . . 10.24

10.12 Dose Conversion Factors for Inhalation of Reference Plutonium Mixture (Standard Man) . . . . . . . . 10.24

10.13 Values of $\sigma_{y}$ for Pasquill Stability Categories . . . . . 10.26

10.14 Values of $\sigma_{z}$ for Pasquill Stability Categories . . . . . 10.26

10.15 Land Areas Within Isopleths of a Release Plume and More than $100 \mathrm{~m}$ from the Release Point....... . 10.28

10.16 Land Area Contaminated Within $100 \mathrm{~m}$ of Accident Scene and Centerline Value of EU/Q at $100 \mathrm{~m}$ versus Pasquil1 Stability Classification ............. . 10.28 
10.17 Estimated Numbers of Deaths Per Year in the U.S.

Population Attributable to Continual Exposure at a

Rate of $0.1 \mathrm{rem} / \mathrm{yr}$, Based on Mortality from Leukemia

and from all Other Malignancies Combined . . . . . . 10.30

10.18 Assumed Values Used in Calculating Estimates of

Risk Shown in Table 10.17 .......... . 10.31

10.19 Cancer Risk Estimates for Plutonium in Man . . . . . . 10.32

11.1 Shipping Characteristics for L-10 and 611 Assumed for

Analysis (Based on the Shipment of 1 Metric Ton of Pu) . . 11.2

11.2 Characteristics of a Composite U.S. Route for

Plutonium Transport in the Early 1980's . . . . . . 11.4

11.3 Risk Sensitivity Cases for Liquid Nitrate

Shipments for U.S. in the Early 1980's......... 11.21

11.4 Risk Sensitivity Cases for Oxide Shipments

in the U.S. in the Early 1980's ........... 11.24

C.1 Fractional Airborne Release of Plutonium Dioxide--

Summary (Fraction of Source Airborne as Particles

Less Than $10 \mathrm{um}$ Aerodynamic Equivalent Diameter) . . . . C.3

C.2 Fractional Airborne Release of Plutonium Nitrate

Under Thermal and Aerodynamic Stress-Summary . . . . . . C.6

C.3 Comparison of Fractional Airborne Release of

Dioxide Powder and Nitrate Solution under Simulated

Accident Conditions .............. . C.9

D. 1 Summary of $\mathrm{PuO}_{2}$ Properties ............... D. 1

D.2 Specifications for Plutonium Nitrate to be

Purchased by the AEC ................ D.3

D.3 Effect of Nitric Acid and Plutonium Nitrate

Concentration on the Value of $\mathrm{G}_{\mathrm{T}}$........... . D.8

E.1 Discrimination Factors for Plutonium Pathways . . . . . E.3

F.1 Values of the Clearance Parameters for the

Task Group Lung Mode1 ................ F.5

G.1 Loading Pattern for Plutonium Shipping Packages . . . . G.3

G.2 Plutonium Shipping Package Dimensions . . . . . . . G.3 
G.3 Keff for Deformed Plutonium Oxide Shipping Package Arrays under the Assumed Conditions ......... G.8

I.1 Radial Material Distribution for all Cáses . . . . . . I.7

I.2 Material Description Data . . . . . . . . . I.9

I.3 Radiation Heat Transfer Coefficient for

Transient Fire Conditions . . . . . . . . . . I.12

J.1 Crush Force Required for Lid Removal of the L-10 and 6M Containers ............ J.2

J.2 Accident Severity Spectrum for Crush Failure in the Accident Environment . . . . . . . . . J.4

J.3 Comparison of Occurrence Frequencies for Single Container and Shipment Crush Sequence Evaluation . . . J.6

J.4 Summary of Multiple Container Failure from Crush, Lost from Van and Subsequent Fire . . . . . . J.9 


\section{INTRODUCTION}

Radioactive materials, in a variety of physical and chemical forms, are routinely transported between nuclear facilities. The safety record for these shipments has been excellent. As the nuclear industry grows, it is expected that the number of shipments made annually will increase. In the interest of continuing to insure the health and safety of the general public, the nuclear industry and government regulatory agencies are continually improving their level of understanding of the safety-related aspects of transporting radioactive materials.

Research programs are one method of improving the level of understanding. Such a research program is being conducted by Battelle-Northwest for the Transportation Branch of the ERDA. Division of Environmental Control Technology The objective of this continuing program is to develop a methodology for quantitatively assessing the safety of transporting radioactive materials and apply it to current and future shipping systems. Risk analysis was the technique selected for this assessment. Through analys is of risk, consequences of postulated releases of radioactive material during transport can be put into perspective by viewing the events relative to their expected frequency of occurrence.

Risk, as used in the context of this report, is the product of the magnitude of a possible loss and the expected frequency of occurrence of the loss. There are two measures of the risk that are of importance in a risk assessment. The first is the total risk, obtained by summing the risk associated with each particular loss. In order to perform the summation, all risks have to be expressed with respect to the same time interval (e.g., per year). Although the total risk is an important measure, it gives only the loss that would be expected on the average during the reference time interval. The range of losses which could be experienced is not discernable. For e:ample, the risk associated with an accident that occurs once a year and results in one fatality is the same (i.e., one fatality/year) as that from an accident which occurs once in ten years but results in ten fatalities. In a plot of the expected frequency of $\mathrm{N}$ or 
more fatalities as a function of $\mathrm{N}$, these two accidents would appear as discrete points. The second measure of risk is a curve called a risk spectrum, which is generated by connecting such points. The risks associated with two activities are truly similar only if they have the same total risk (risk magnitude) and the same risk spectrum. Both risk measures are used in this report.

This risk methodology was initially applied to the truck shipment of plutonium in two forms: liquid nitrate shipped in L-10 containers and oxide powder in 6M containers. This report offers both a description of the general risk methodology and a risk assessment of plutonium shipment by truck. 


\section{SUMMARY}

This report presents both a methodology for assessing the risk in transporting radioactive materials and the results of the initial application of the methodology to shipment of plutonium by truck.

The risk assessment methodology is described in section 3 of this report. The methodology is manifested in a model that relates the functional steps in the assessment. Data needs and analysis procedures are explicitly defined in the mode1. The model is constructed for ease of periodic updating of the data base to maintain the risk assessment current as additional data become available.

The remainder of the report treats the application of the model to the risk assessment of the truck shipment of plutonium in two forms - liquid nitrate $\left[\mathrm{Pu}\left(\mathrm{NO}_{3}\right)_{4}\right]$ and oxide powder $\left(\mathrm{PuO}_{2}\right)$. The scope of the assessment encompasses the risk of plutonium releases due to transportation accidents and package misclosure and degradation.

The report is sectioned to correspond to specific analysis steps identified in the model. The transport system and accident environment are described in sections 4 through 7 . Release sequences are postulated in section 8 and evaluated in sections 9 through 11 to determine both the likelihood and the possible consequences of a release. Supportive data and analyses are given in the appendices.

The risk assessment results have been related to a future time - the early 1980's - when plutonium shipments are expected to be more frequent. To conduct the risk assessments certain assumptions about the nuclear economy and transport system in the early 1980's were required. The assumptions used for the analysis are:

- A total of 18 metric tons of plutonium is shipped by truck (exclusive carrier).

- $100 \mathrm{~kg}$ of plutonium are transported per shipment and the average shipment distance is 1,474 miles. 
- Shipping systems and regulations are the same as in 1974.

- $\mathrm{PuO}_{2}$ is shipped in $6 \mathrm{M}$ containers and 1 iquid $\mathrm{Pu}\left(\mathrm{NO}_{3}\right)_{4}$ in $\mathrm{L}-10$ containers.

Other shipping conditions (e.g., different shipping regulations) could result in different risks than reported herein. However, the developed methodology is capable of analyzing the risks under any shipping conditions.

Based on the shipping assumptions, the likelihood that plutonium truck shipments will be involved in an accident is estimated to be about once in $11 / 2$ years. Most accidents will result in no release of plutonium. For the projected shipping rate in the early 1980's, the likelihood of a release of plutonium as a result of shipment by truck is about one in 60 years for liquid nitrate in the L-10 container and one in 330 years for oxide powder in the $6 \mathrm{M}$ container. The consequences of these postulated releases were estimated based on the amount of plutonium released to the environs, the probable weather conditions at the time of the accident, and the population density downwind from the accident scene. The likelihood and the consequences for these postulated releases have been coupled and expressed as risk spectra.

Risk spectra for the two plutonium forms are shown in Figure 2.1 for the plutonium shipments projected for the United States in the early 1980's. These curves can be compared to similar risk curves which are presented in the Rasmussen Report. (1) Inspection of the curves indicates that the risks of shipping plutonium are small relative to other societal risks. For example, the risk curve for transporting chlorine is several orders of magnitude greater than that of transporting 1 iquid plutonilin nitrate. The risk curve for the liquid nitrate shipment is similar to the risk curve for being killed by meteorites. The curves also indicate that the likelihood of a plutonium release resulting in cancer death is one in 7,000 years for the shipment of liquid plutonium nitrate in L-10 containers and one in 200,000 years for $\mathrm{PuO}_{2}$ shipments in 6M containers. 


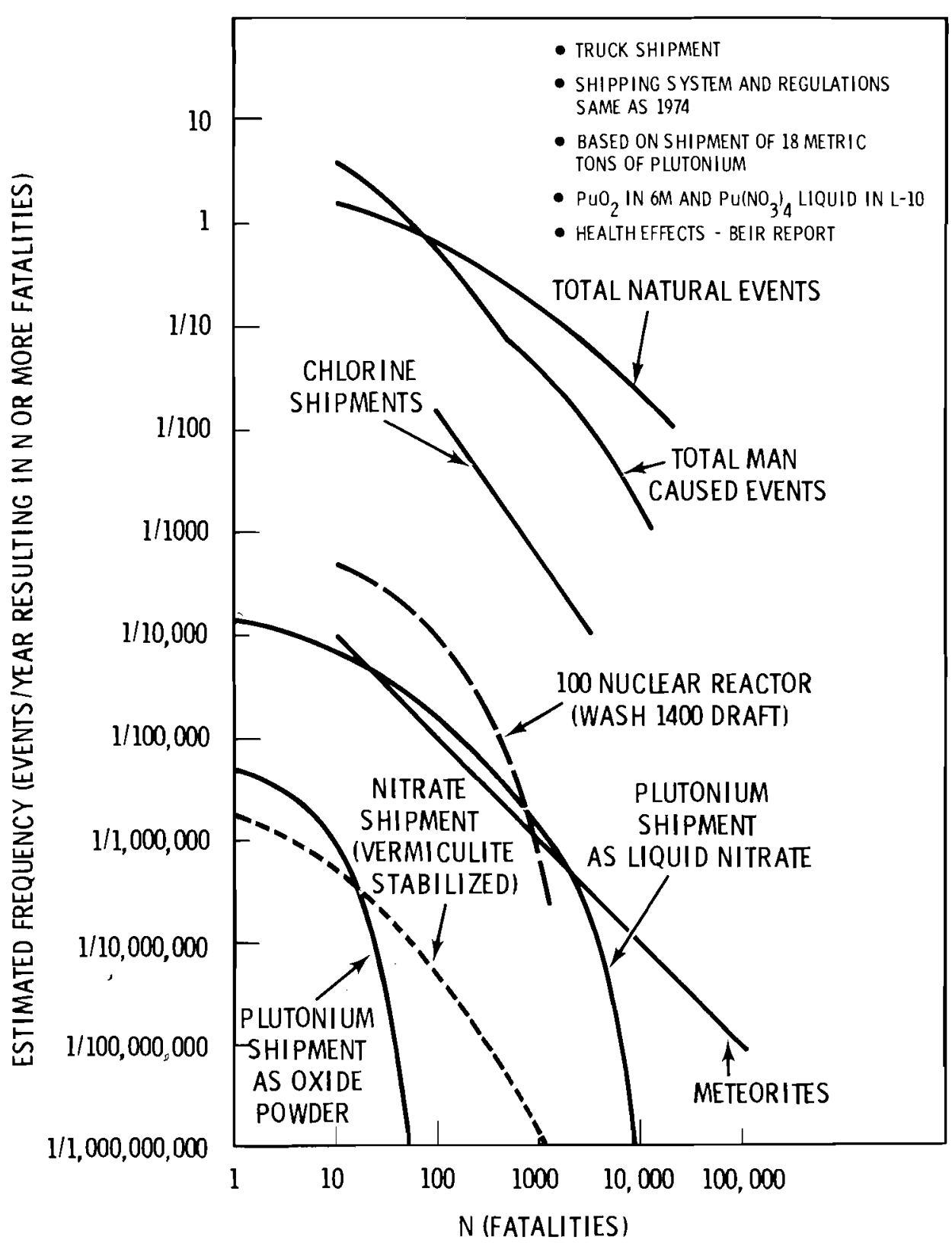

FIGURE 2.1 Risk Spectra for Plutonium Shipments in the Early 1980 's for the Entire U.S. 
Sensitivity studies were performed to determine the most important contributors to the risk. These studies are described in section 11. Loss of the thermal insulation followed by exposure to a fire was found to be the most significant risk contributor for the liquid plutonium nitrate shipments. A risk curve developed assuming stabilized vermiculite insulation is included in Figure 2.1 to show the importance of the insulation.

\section{REFERENCE}

1. "Reactor Safety Study - An Assessment of the Accident Risks in U.S. Commercial Nuclear Power Plants," WASH-1400 (DRAFT) U.S. Atomic Energy Commission, Washington, D.C., August 1974. 


\section{RISK ANALYSIS MODEL}

The risk analysis model described in this section was developed from methodologies used in prior risk assessments. This section first briefly summarizes prior risk assessment methods and then presents a detailed description of the model used in assessing the risk of plutonium shipments.

\subsection{BACKGROUND ON RISK METHODOLOGY}

The risk methodology was initially suggested by Farmer as a method of selecting an acceptable site for a nuclear reactor. (1) Farmer analyzed a series of postulated accidental releases and determined both the probability and the consequences for each release. The probability was expressed in terms of reactor years between releases, and the consequences were expressed in terms of curies of ${ }^{131}$ I released. Each accidental release was a point on a graph with the probabilities as the ordinate and the consequences as the abscissa. Putting all the points on the plot permitted showing the relationship between more probable accidents releasing small quantities of iodine and less frequent releases of larger amounts.

Otway and Erdmann ${ }^{(2)}$ and Meleis and Erdmarn ${ }^{(3)}$ further developed this methodology. The analysis by 0tway and Erdmann used individual mortality as the measurement of release consequences, and the units of risk then became the probability of an individual mortality in any operating year. In order to select the exclusion radius around the plant, they suggested that the individual risk of mortality from living at the plant boundary should be less than $10^{-7} /$ year. Based on this risk leve 1 , the required exclusion radius could then be calculated.

These analyses were further expanded by Starr ${ }^{(4)}$ and Starr, Greenfield and Hausknecht. ${ }^{(5)}$ Starr demonstrated that the risk level individuals are willing to accept is related to the benefits received by the individual. For small benefits, an individual will accept risk levels with a probability of resulting in death lower than $10^{-7} /$ year. If the benefits are significantly higher, then the risk level the individual is willing to accept is higher. The article by Starr, Greenfield and 
Hausknecht showed how the risk methodology could be applied to compare the public health risks from operating nuclear versus oil-fueled power plants. This analysis was also based on risk units expressed in deaths/year.

This last article shows the advantages gained by expressing the risk in terms of health effects. Use of these terms allows a variety of technologies to be meaningfully compared. Such comparison is the ultimate goal of any risk assessment.

The risk assessment methodology discussed above has been limited to an analys is of fixed facilities. Evaluating the risk of transporting radioactive materials brings up some very unique problems. For a fixed site, there is complete control of the population density within the exclusion area, whereas during transportation, the population density varies over several orders of magnitude. For a fixed site, the accident environment is largely generated within the facility, whereas the accident environment during transportation is highly variable and frequently interactive. For a fixed site, the individuals at risk are located within zones surrounding the facility and are liable to the risks from al1 accidents. In transportation, the individuals at risk are located adjacent to the route, and the probability of an individual being exposed to multiple releases is extremely smal1. A11 these factors make risk assessment for transportation basically more complex than evaluations for fixed sites.

The desirability of assessing the risk for hazardous material transport has been discussed in a special study of the National Transportation Safety Board. (6) In this study, members pointed out the variety and inconsistency of current regulations governing the transport of hazardous materials via various transport modes. The desirability of determining the levels of risk for various commodities was clearly shown. The factors which must be considered were identified. In addition, the report showed how such calculations would aid regulators in deciding what shipment forms and containers should be allowed. Concurrent and subsequent studies have used many of the concepts suggested in the Safety Board study.

A Department of Transportation (DOT) study carried out by the University of Southern California ${ }^{(7)}$ describes a methodology applicable to 
transport of hazardous chemicals. It is based on accident case histories for shipment by various modes. This technique, however, cannot be applied to radioactive material shipments because the accident experience is extremely limited. The major concern rests in the future projected shipment requirements. Will they pose an undue risk to the general public?

A study witi greater relevancy to radioactive material shiprents was carried out by Holmes and Narver for the Department of Defense. (8) This study developed a risk model for the transport of hazardous materials. They then applied the model to the transport of bioweapon systems.

The model developed by Holmes and Narver begins by selecting a route and then looks at the risk of shipping one bioweapon along that route. For each link, the population density, vehicle type, vehicle speed, link length and weather conditions along the link are specified. The model then evaluates the probability that a member of the general public will become infected as a result of the transport of the bioweapons system along the selected route.

The methodology was also used by Holmes and Narver to evaluate the risk of a radioactive material shipment. (9) The summation of all shipments required in a particular year gives the total annual risk for the population. This latter work was carried out under an EPA contract.

The limitation of this methodology is that one average number is obtained. In evaluating a particular route, one would like to know not only the average risk but also the variability of risk with route, weather, population, material form, and accident severity. For example forms that "on the average" have little dispersibility upon release would be shown to have less risk than another form under the same average conditions. However, under a set of less probable circumstances the most desirable form under average conditions might exhibit hundreds of times the hazard of an alternative form. The same discussion could be directed at shipment mode. One should rightly be concerned not only with the average risk but also the variability of the average risk with possible transport conditions. 
The model developed for this study will simultaneously evaluate both the risk and the risk spectrum associated with a given transport route.

\subsection{RISK MODEL DEVELOPMENT}

The model used in assessing the risk of plutonium shipments is described in this section. This model, still undergoing development, is applicable to the shipment of radioactive materials in general. The description here is an overview of the model. It is shown schematically in Figure 3.1. More detailed discussion of its components and application to plutonium shipments are given in subsequent sections.

The risk assessment model provides a systematic method for handling the data germane to analysis of the safety of the transport environment. The model uses one fundamental equation:

$$
R=\sum_{i} R_{i}
$$

The tota 1 system risk $R$ is the sum of the risks of all accidental releases as denoted by the subscript $i$. Only accidental releases are considered in the model. The risk of an individual release is the product of the consequences of the release and the probability of its occurrence. This equation could be expanded into a sirigle, long, complex equation. In the current formulation of the mode1, each term in Equation (1) is expanded into two expressions which have more physical significance. The expanded equation for $R_{j}$ is:

$$
R_{i}=\left(\begin{array}{llll}
A & F_{R_{i}} & \times P_{R_{i}}
\end{array}\right) \times \underset{q}{\Sigma}\left(\begin{array}{lll}
C_{E_{i, q}} & \left.\times P_{E_{q}}\right)
\end{array}\right.
$$

The first factor, $A F_{R_{j}}$, is the product of the amount of material present in a shipment times the fraction of that material lost to the environment in the $i^{\text {th }}$ release sequence. This factor can be thought of as a source term for the $i^{\text {th }}$ chain of events or failures which end with a release of radioactive material. The second factor, $P_{R_{i}}$, is the probability that the 


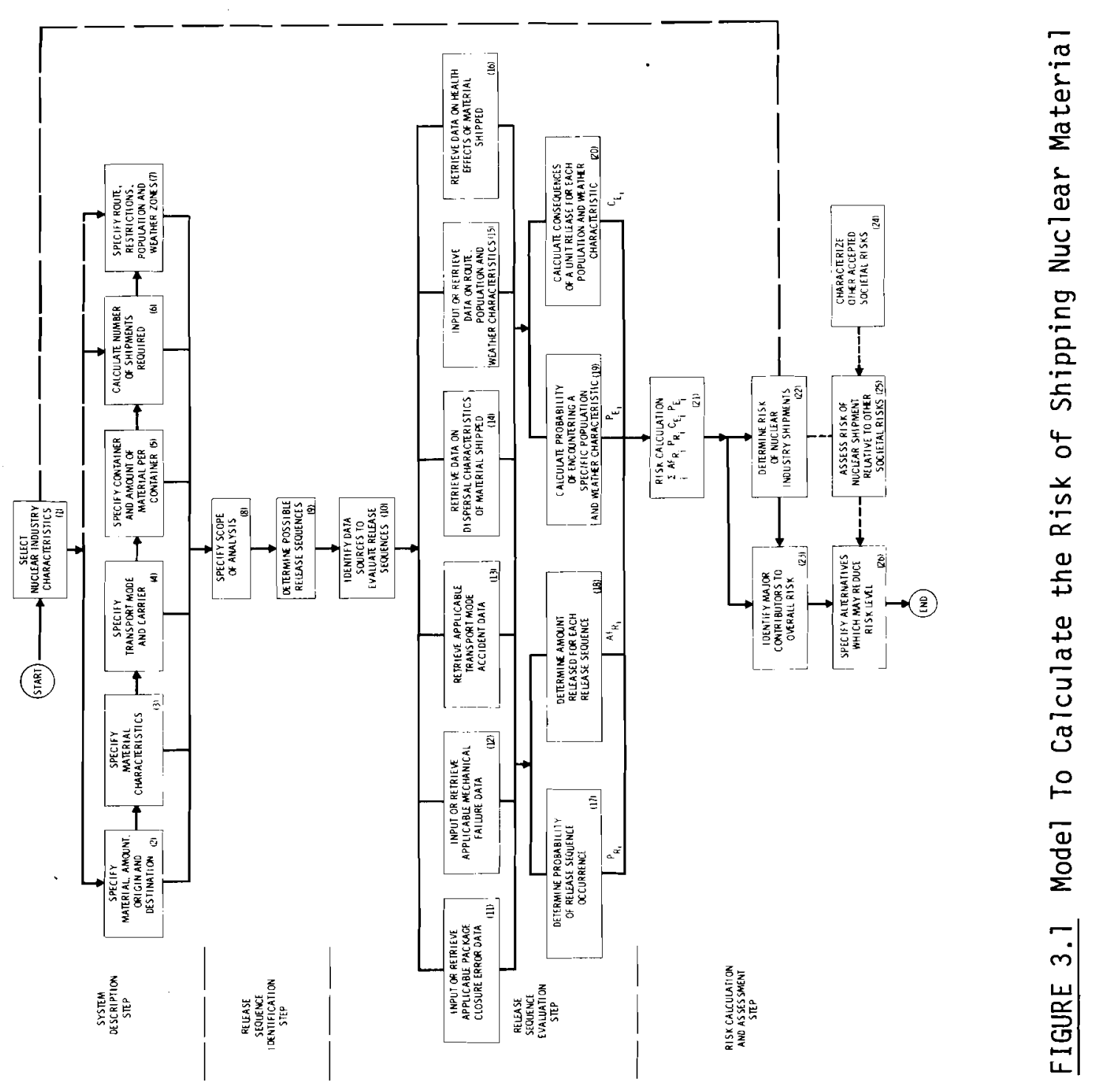


release sequence will happen during transport. The first expression, $A F_{R_{i}} \times P_{R_{j}}$, can be thought of as a probabilistic source term for each identified release sequence.

The factor $C_{E_{i, q}}$ in the second part of Equation 2 is the consequences of a unit release. The subscript $q$ is added to show that the factor is a function of the specific weather conditions existing at the time of the release and the population exposed to the release. The factor represents the effect of a unit release on the exposed population in terms of either a whole body dose to man or to a specific organ. The final factor, $\mathrm{P}_{\mathrm{E}_{\mathrm{q}}}$ is the probability of encountering a particular set of weather conditions within a specific population zone. The expression $\sum_{q}\left(C_{E_{i, q}} \times P_{E_{q}}\right)$ can be thought of as the consequences of a unit release of radioactive material (unit source term) under probabilistically weighted weather conditions and population distributions.

For this plutonium transportation analysis, the risk formulation given by Equation 2 considers only material dispersed to the atmosphere. Formulation for the other exposure pathways is not given since the air pathway would be the major contributor to the dose from plutonium releases. (See Appendix E.)

Equation 2 is the pivotal equation in the risk model. Two preparatory steps are needed before the terms can be evaluated. These are the system description and the release sequence identification steps. Following these two steps is the release sequence evaluation step which utilizes Equations 1 and 2. The final step is to evaluate or assess the significance of the risk level determined for the transport system being evaluated. The relationship between these four steps is shown in Figure 3.1. In the remainder of this section each step will be broken down into its important components to provide a detailed description of the model.

\subsubsection{System Description}

As shown in Figure 3.1 , the system description step has seven components:

1) Projected Nuclear Industry Characteristics

2) Specify Materia1, Amount, Origin and Destination 
3) Specify Material Characteristics

4) Specify Transport Mode and Carrier

5) Specify Container and Amount of Material per Container

6) Calculate Number of Shipments Required

7) Specify Route, Restrictions, Population and Weather Zones

Figure 3.2 and the following paragraphs provide an expanded description of each of these components.

Projected Nuclear Industry Characteristics (1) This component uses a data file of projected nuclear industry characteristics including a description of projected sites for nuclear fuel cycle facilities and also projected shipments between facilities. The only input into the model required is the reference year and an indication of whether the analysis is to consider all material shipments or just those between two facilities. In Figure 3.2 the reference year is 1980 and the analysis considers only the shipment between two facilities.

Specify Material, Amount, Origin and Destination (2) This component specifies the material shipment being considered in the analysis. If component 1 has not already described the origin and destination of the shipments and the quantity of material being shipped, then they are specified under component 2. In the case shown in Figure 3.2, the risk is being calculated for shipments totaling one metric ton of plutonium between facilities $A$ and B.

Specify Material Characteristics (3) This component describes the important chemical and physical characteristics of the material. Table 3.1 lists the types of physical and chemical properties which must be considered. When comparing plutonium oxide powder shipments with plutonium nitrate solution shipments, an important property of the plutonium nitrate is the vapor pressure exerted by the liquid as a result of elevated temperatures in an accident environment. An important characteristic of oxide is the particle size distribution. In addition to the physical and chemical description of the material, its isotopic composition must be specified. 


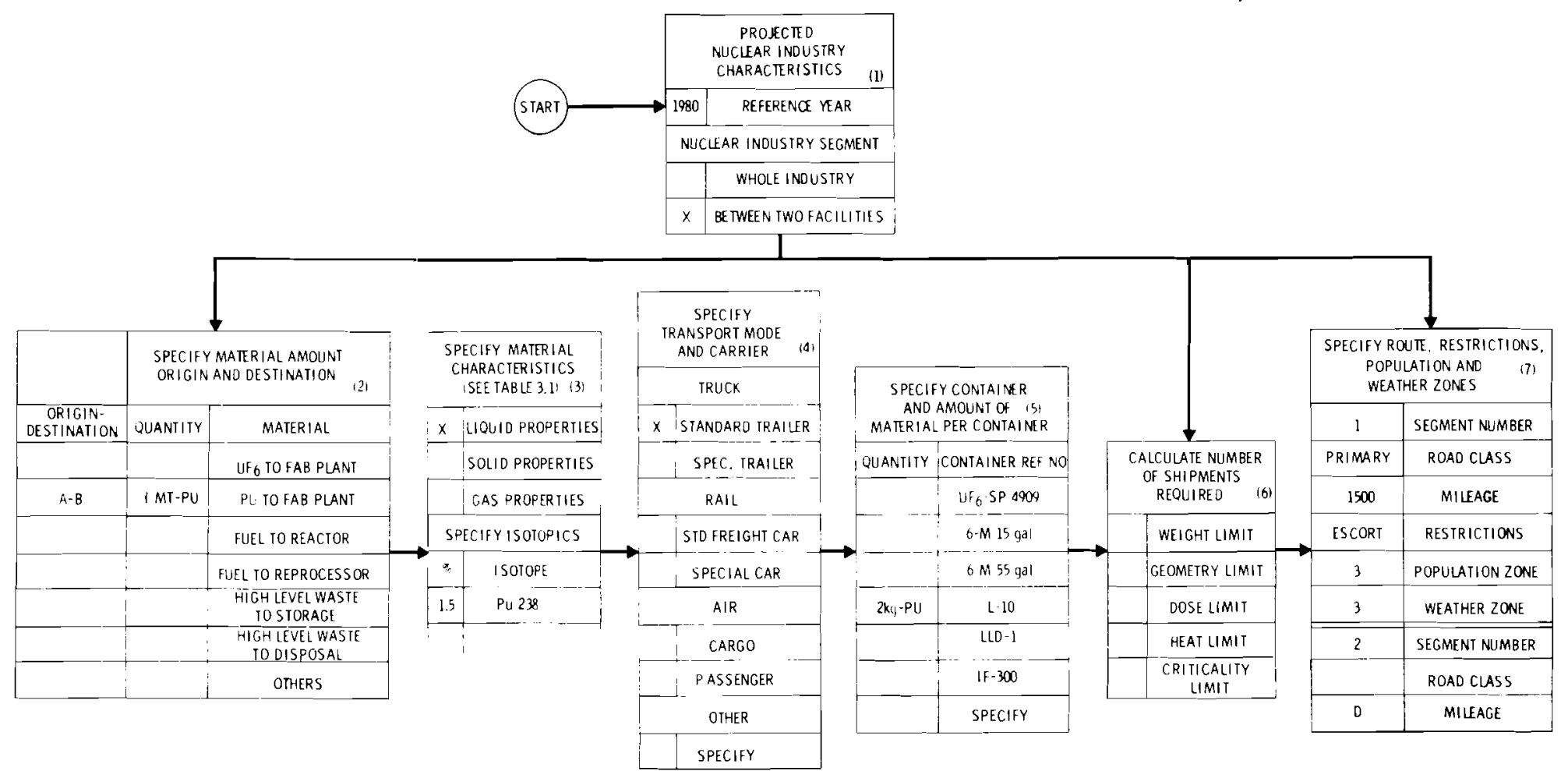

\section{FIGURE 3.2 Information Required to Described Transport System}


TABLE 3.1 Important Physical and Chemical Properties of Materials Used in Assessing Shipment Risks

General Characteristics

Reaction with Air

Reaction with water

Reaction with Acids/Bases

Reaction with Hydrocarbons

Reaction with Metals/Nonmetals

Radiolytic Gas Generation Rate and Composition

Equation of State (Pressure, Volume, Temperature Relationships)

Decomposition Temperature and Reactions

Characteristics of Solid Materials

Impact Strength

Particle Size Distribution upon Fracture Characteristics of Solid Materials in Powder Form

Size Distribution

Sintering Temperature

Characteristics of Liquids

Solubility in water

Viscosity

Density

Surface Tension

Characteristics of Gases

Density Relative to Air

Specify Transport Mode and Carrier (4) The common transport modes are truck, rail and air. The vehicle or cask being used to hold the containers of radioactive material must also be described. Weight, heat, dose, space and criticality limits must be included in the description in order to calculate the number of shipments required in component 6 . 
Specify Container and Amount of Material Per Container (5) The container specification for common approved containers is generally straightforward; a11 that is needed is the container designation to completely describe the container. Non-standard containers, however, require sufficient input to permit specification of failure paths in later parts of the analysis. The case outlined in Figure 3.2 shows that the container selected is the L-10 and that $2 \mathrm{~kg}$ of plutonium are to be shipped in each container.

Calculate Number of Shipments Required (6) This first calculational step determines the number of shipments required. This is done by dividing the number of containers which can be shipped on one truck into the total number of containers to be shipped. The number of containers which may be shipped on one truck is constrained by weight, geometry, heat, dose, and/or criticality limits. The most restrictive limit determines the amount being shipped. In the plutonium analysis, the dose limit was the most restrictive variable when using presently licensed containers.

Specify Route, Restrictions, and Population and Weather Zones (7) This component segments the route and then describes each segment in terms of the type of route, restrictions, population and weather characteristics. In the example shown in Figure 3.2, the route description indicates that the first segment is an escorted shipment over 1500 miles of primary roads in population zone 3 and weather zone 3 . The population and weather zone descriptions are characterized in the model; thus only the zone numbers need to be specified.

These seven components completely describe the system being evaluated.

\subsubsection{Release Sequence Identification}

Although it might seem that the system description provides alf the information needed to evaluate the risk, one further component titled Select Scope of Risk Assessment is required before applicable release sequences are identified in component 9 . The relationship of these two components to the rest of the model is shown in Figure 3.1. Figure 3.3 


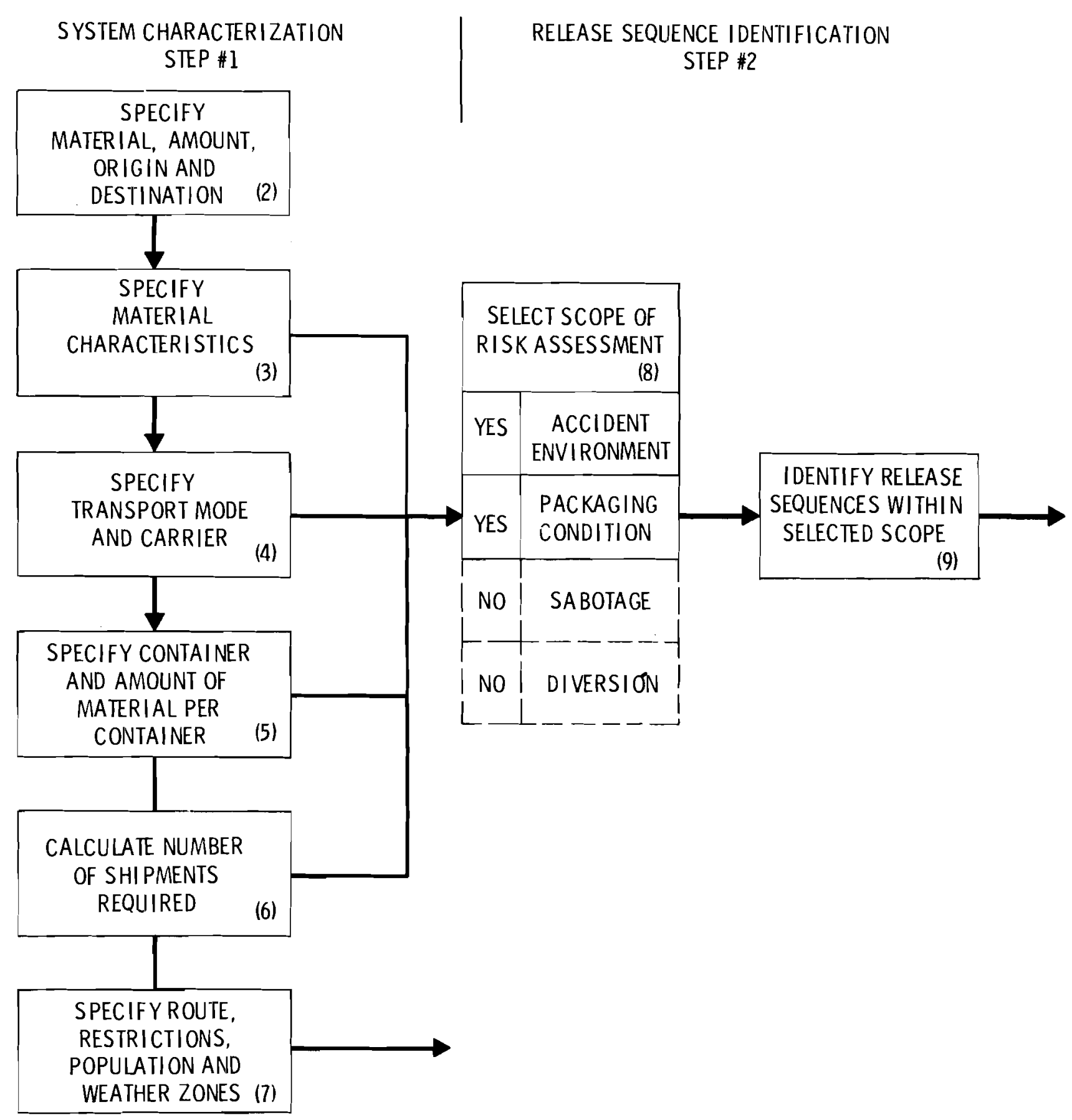

FIGURE 3.3 Information Required to Define Scope of Evaluation 
and the following paragraphs provide an expanded description of these two components in the Release Sequence Identification Step.

Select Scope of Risk Assessment (8) Only those failure sequences within the scope of the analysis are evaluated. Thus this step more than any other clearly delineates the limits of the analysis. In this study, the failures associated with the accident environment and with packaging conditions are being considered. This last category includes failures resulting from package closure quality control, and any deterioration in package integrity resulting from normal transport. Fallures associated with deliberate sabotage or diversion efforts are not included although it is felt that the techniques used in the model are general enough to consider such events.

Identify Release Sequences Within Selected Scope (9) The selected scope, component 8 , and the system description steps 1 through 7 completely specify the information needed to identify applicable release sequences. Although many techniques are used to identify release sequences, the most complete listing is obtained by working backwards from a release through chains of events or failures required to breach the barriers between the material and man's environment. This process uses both inductive and deductive reasoning to evaluate the correctness of each small step in the chain of events needed for a release.

The best known technique for working backwards from a release to a set of identifiable component failures is called fault tree analysis. This technique is used in this risk assessment model to identify release sequences.

\subsubsection{Release Sequence Evaluation}

The release sequence evaluation step considers each release sequence identified in the previous step and determines the factors in Equation 2. The assembly of this data will be described in the following subsections entitled Source Term Evaluation and Environmental Consequences Evaluation. 
Source Term Evaluation The release sequence factors in Equation 2, denoted by the subscript "R," represent the probability that a source of material will be released and the amount of material released. The evaluation of these factors requires the input of four data bases, shown in Figure 3.1 as components 11-14. These data bases are:

- Input or Retrieve Applicable Package Closure Error Data (11)

- Input or Retrieve Applicable Mechanical Failure Data (12)

- Retrieve Applicable Transport Mode Accident Data (13)

- Retrieve Data on Dispersal Characteristics of Material Shipped (14)

Section 7 of this report discusses the package closure data used in component 11. Mechanical failure analyses for component 12 are given in Section 6 . The results of analyses of truck accident environment used in component 13 are summarized in Section 5. Data relevant to the dispersal characteristics of plutonium dioxide powder and plutonium nitrate solution is given in Appendix $C$. This forms the data base for component 14 .

With the information from components 11 to 14, the model evaluates the probability of a release and the source term, shown as components 17 and 18 in Figure 3.1. The probability of a release sequence occurring is evaluated first. Then the source term is evaluated for the release sequences which have non-zero probabilities. The source term must be expressed in equation form so that the source can be related to environmental conditions. The $F_{R_{i}}$ factors of source term expression used for various release sequences and environmental conditions are discussed in Section 9.

The "A" factor in Equation 2 includes terms which relate the total amount of material shipped to the fraction that is potentially dispers ible. The fraction is a function of the number of containers damaged and the amount of material spilled from the damaged containers. When these terms have been evaluated for each release sequence, this part of the analysis is complete.

Environmental Consequences Evaluation The environmental terms in Equation 2 are denoted by a subscript $E$. The factor $P_{E}$ represents the probability 
that a given set of weather and population density characteristics will be encountered. The factor $C_{E_{j}}$ represents the consequences of a unit release from an accident when it occurs in the region characterized by the weather and population density used to determine $P_{E}$. The consequences of the unit release are initially calculated as a population dose expressed in units of man-rem to a selected organ of reference. The population dose is then converted to health effects using commonly accepted methods. The evaluation of the two factors in Equation 2 requires the input from three data bases, shown in Figure 3.1 as components 14 to 16 . These data bases are:

- Retrieve Data on Dispersal Characteristics of Material Shipped (14)

- Input or Retrieve Data on Route, Population and Weather Characteristics (15)

- Retrieve Data on Health Effects of Material Shipped (16)

As mentioned previously, data relevant to the dispersal characteristics of plutonium nitrate and dioxide are given in Appendix $C$. Health effects of plutonium are discussed in Section 10. Data for component 15 are available from many compilations. These include U. S. Census data $(10)$ and summaries of regional weather data compiled by the U. S. Weather Bureau. (11)

The model uses relevant information from components 14 to 16 to evaluate the probability of experiencing a given set of weather conditions and population characteristics. These evaluations are shown as components 19 and 20 in Figure 3.1. The method used to calculate the $C_{E_{j}}$ term is discussed in Section 10. The PE term in Equation 2 is the probability associated with the weather and population characteristics. The expanded form of this term is given:

$$
P_{E_{j, k, 1}}=P_{j / k} \times P_{k} \times P_{1} .
$$

The subscripts $j, k$ and 1 refer to the multiplicity of environmental conditions which could exist at the location of the accident. The variable $\mathrm{P}_{\mathrm{j} / \mathrm{k}}$ is the probability of experiencing the $j^{\text {th }}$ atmospheric stability 
classification when the $k^{\text {th }}$ windspeed exists. The variable $P_{k}$ is the probability of encountering the $k^{\text {th }}$ windspeed category. The variable $P_{1}$ is the probability of encountering a specified population distribution.

This data completes the description of the four terms in the risk equation. Once all of these variables are specified, the risk calculation and assessment step, the last step, can be completed.

\subsubsection{Risk Calculation and Assessment}

The final step in the risk assessment is to sum and evaluate the risks associated with all the applicable release sequences. As shown in Figure 3.1 , this final step consists of six components numbered 21 to 26 :

- Risk Calculation (21)

- Determine Risk of Nuclear Industry Shipments (22)

- Identify Major Contributors to Overal1 Risk (23)

- Characterize Other Accepted Societal Risks (24)

- Assess Risk of Nuclear Shipments Relative to Other Societal Risks (25)

- Specify Alternatives Which May Reduce Risk Level (26)

The major contribution from each of these components is summarized below. Risk Calculation (21) The overall risk calculation is described by Equations 1 and 2 . Sorting the risk numbers during the summation for the total risk permits obtaining some of the statistical parameters useful in analyzing the significance of the results.

Determine Risk of Nuclear Industry Shipments (22) The overall risk from the entire nuclear industry is the summation of the risks from individual routes weighted by the amount of material shipped along those routes. If the evaluation is being made along many routes, then the summation (component 21 ) is continued until all designated routes have been included. Identify Major Contributors to Overall Risk (23) The major contributors are obtained during the summation operations described by components 21 and 22. Changes which will greatly reduce the risk are those that head 
the list of major contributors. Without this component much of the significance associated with an overall risk value is lost.

Characterize Other Accepted Societal Risks (24) A comparison of the risk levels obtained in components 21 and 22 with the accepted risk levels imposed either by other technologies or by our natural environment places the calculated risk levels in perspective. Component 24 provides the data on the other accepted risk levels.

Assess Risk of Nuclear Shipment Relative to Other Societal Risks (25) This operation is a comparative procedure to determine whether the reduction of risk levels is warranted. Risks not associated with the nuclear shipments are placed on the 1 ist to put the overall risk level determined in components 21 and 22 in perspective.

Specify Alternatives Which May Reduce Risk Level (26) Based on the 1ist of major risk contributors generated by component 23, the controlling variables are very evident. If, for example, the top ten risk contributors have all occurred in the same population zone on one route, then the analysis suggests that the selection of an alternate route might be warranted. If one component failure is in each element in the list of contributors, then a design change eliminating that variable from the list may be worthwhile. Such decisions can be based on information provided from evaluations carried out under this last component in the model.

The application of this model to assessment of the risks of shipping solid plutonium oxide and liquid plutonium nitrate is demonstrated in the remainder of this report. 


\section{$\underline{\text { REFERENCES }}$}

1. F. R. Farmer, "Reactor Safety and Siting: A Proposed Risk Criterion," Nuclear Safety, Vol. 8, p. 539, 1967.

2. H. J. Otway and R. C. Erdmann, "Reactor Siting and Design From a Risk Viewpoint," Nuclear Engineering and Design, vol. 13, p. 365, 1970.

3. M. Meleis and R. C. Erdmann, "The Development of Reactor Siting Criteria Based Upon Risk Probability," Nuclear Safety, vol. 13, p. 22, 1972.

4. C. Starr, "Benefit-Cost Studies in Socio-Technical Systems," Proceedings of Conference on Hazard Evaluation and Risk Analys is, Houston, Texas, 18-19, August 1971, Nationa1 Academy of Sciences, Washington, D.C.

5. C. Starr, M. A. Greenfield and D. F. Hausknecht, "A Comparison of Public Health Risks: Nuclear vs. $0 i 1$ Fired Power Plants," Nuclear News, vol. 15, no. 10, p. 37, 1972.

6. National Transportation Safety Board Special Study, "Risk Concepts in Dangerous Goods Transportation Regulations," Report no. NTSB-STS-71-1, Department of Transportation, Washington, D.C.: 1971.

7. G. P. Jones and R. H. Barrow, "Risk Analysis in Hazardous Materials Transportation," RAP0-72-106, U. S. Department of Transportaton, Office of Hazardous Materials, Hashington, D.C., November 1972.

8. B. J. Garrick, W. C. Gekler, 0. C. Baldonado, H. K. Elder and J. E. Shapley, A Risk Model for the Transport of Hazardous Materials, HN-204, Holmes and Narver, Inc., Los Angeles, CA, August 1969.

9. C. V. Hodge and 0. C. Baldonado, "Risk Analys is of Shipments in the Huclear Power Industry," Proceedings of the 4th International Symposium on Packaging and Transportation of Radioactive Materials, September 22-27, 1974, CONF-740901.

10. U.S. Bureau of the Census, County and City Data Book, 1967, (A Statistical Abstract Supplement), U.S. Department of Commerce, Washington, D.C., 1967.

11. U.S. Weather Bureau, Climatological Data Summaries, U.S. Department of Commerce National Climatic Center, Ashevil1e, NC. 


\section{PLUTONIUM SHIPPING REQUIREMENTS}

As discussed in Section 3, the risk assessment model is designed to use a plutonium shipping requirements model which projects the amount, number, origin and destination of plutonium shipments to future years. Using such a shipping requirements mode 1 a 11 that is required in the shipping requirements input specification is the year of interest. However, current conditions (energy crisis, plant financing problems, administrative and regulatory process changes, etc) make it difficult to predict the plutonium shipment scheduling which is needed to develop the shipping requirements model. Because of these uncertainties the plutonium shipping requirements model used for the present evaluation is related to the number of operating power reactors rather than the year.

\subsection{NUCLEAR INDUSTRY ASSUMPTIONS}

The present evaluation is based on the plutonium shipping requirements for an industry of 100 power reactors. It is felt that this assumption is reasonably representative of the stage of growth that will be reached in the early 1980's. It is assumed that plutonium recycle will be used in the industry. The industry characteristics assumptions used in the evaluation are given in Table 4.1.

\section{TABLE 4.1 Assumed Industry Characteristics (One Year Period)}

Number of Operating Power Reactors

Power Leve 1

Number Shipping Spent Fuel to Reprocessors

Fuel Reprocessed

Total Pu Recovered and Shipped to Fabricators
100 $1000 \mathrm{MW}(\mathrm{e})$

75* 30 MT per reactor 2250 MT total 18 MT

*The other 25 have not begun to discharge fuel.

It is assumed that each fuel fabricator will receive an equal amount of the plutonium recovered by each of the reprocessors. Assumptions on the number and location of fuel reprocessors are given in the following paragraphs. 


\subsection{FUEL REPROCESSORS}

It is assumed that there will be two fuel reprocessors operating at the reference time when the 100 nuclear power plants will be on line. These reprocessors are AGNS at Barnwel1, South Carolina, and NFS at West Valley, New York. It is assumed that the Barnwell plant will have a capacity to reprocess 1500 MT fuel/year; the West Valley plant, a capacity of 750 MT fuel/year. This result in a total capacity of 2250 MT fuel. It is assumed that the plants will recover and ship 18 MT plutonium/year.

\subsection{FUEL FABRICATORS}

It is assumed that at the reference time there will be five fabricators receiving plutonium for the production of mixed oxide fuel. The locations of these facilities are given in Table 4.2.

TABLE 4.2 Assumed Fuel Fabrication Facilities

\section{Company}

Exxon

Genera1 Electric

Kerr-McGee

Westinghouse

NUMEC

\section{Location}

Richland, WA

Pleasanton, $C A$

Crescent, OK

Cheswick, PA

Apol10, PA

Each of the fabricators will receive during a one year period, 3.6 MT of Pu; 2.4 MT from Barnwell, S.C., and 1.2 MT from West Valley, N.Y.

\subsection{PLUTONIUM SHIPPING DISTANCES}

It is assumed that each fuel reprocessor will ship plutonium equally to each of the five fuel fabricators. Estimated shipping distances between the locations are shown in Table 4.3. 
TABLE 4.3 Estimated Route Distances Between Fuel Reprocessors and Fuel Fabricators (mi)

Fuel Fabricator Location

1. Richland, WA

2. Pleasanton, $C A$

3. Crescent, OK

4. Cheswick, PA

5. Apol10, PA

\section{Fuel Reprocessor Location}

1. Barnwe11, S.C. 2. West Valley, N.Y.

2692
2645
1061
658
649

2423

2677

1240

187

174

It is felt that this plutonium shipment model will result in some overestimation of the expected frequency of a transport accident. The expected frequency is closely proportional to shipment distance. It is expected that, in general, more plutonium will be shipped to fabricators located fairly close to reprocessors than to those located a significantly further distance away. This would reduce the average shipment distance and thus the likelihood of an accident. 


\section{TRANSPORT ACCIDENT ENVIRONMENT}

Failure of a container during an accident occurs when the forces generated in an accident exceed the mechanical strength of a container. This section discusses the forces or stresses which may be generated in a truck accident environment and their likelihood of occurrence. Section 6 discusses the estimated mechanical strength of the L-10 and 6M containers. The use of the results from Sections 5 and 6 to estimate the likelihood of container failure in an accident is demonstrated in Section 9.

The truck accident environment data summarized here were developed by Sandia Laboratories. (1) These data represent the most comprehensive accident environment information currently available. In Sandia's analysis the accident environment is categorized by five accident stresses: impact, crush, puncture, fire, and immersion. Impact and crush are distinguished by the duration and direction of the force. Impact forces act over periods of a few milliseconds whereas crush forces can exist for several seconds following the accident. Impact forces are applied to one side whereas crush forces are applied from several directions. Impact and crush forces are adequately differentiated by comparing the force exerted by a hammer blow to the same force exerted by a press.

Of the five truck accident stresses evaluated by Sandia, probable immersion and impact stresses were found to be several times less severe than the stresses imposed during qualification tests for the L-10 and $6 \mathrm{M}$ packages. Because package designs have passed the qualification tests, which are more severe, these stresses were not included in the evaluation. The remaining three, crush, puncture, and fire, are summarized below:

Crush: The crush force exerted on a container is dependent on both the accident severity and the location of the container in the shipment. A first row of containers at the front of a trailer experiences a high crush force from a head-on collision because the deceleration of a 11 the containers is accomplished by forces transmitted through the front row. The back row of containers experiences a very small crush force since only the deceleration 
of the container itself generates any force. In a rear-end collision the situation is reversed, and the back row experiences the high crush forces. Side collisions give intermediate results. The actual magnitude of these forces is strongly dependent on the container arrangement in the trailer, and the relationship is described in detail in Appendix $J$. The magnitude of the force exerted on any container arrangement is also dependent on the rate of deceleration. Figure 5.1 shows the probability that an entire shipment will experience a deceleration in excess of a given level. Deceleration in this figure is expressed in multiples of the normal gravitational acceleration. Figure 5.1 was generated from data developed by Sandia. (1) The analysis used the Sandia data on accident probabilities for truck collisions with 1) another truck, 2) a fixed object and 3) a car. For each class of accidents Sandia presented data on the relative decelerations for various relative collision velocities. To obtain Figure 5.1 this data was combined with their data on the expected frequency of accidents with greater than a specific relative collision velocity.

The curve shown in Figure 5.1 is applicable for decelerations in the range of 9 to 20 times normal gravity. The curve bends rapidly downward at lower "g" levels. Thus the average accident generates much lower "g" forces than would be indicated by linear extrapolation of the curve. Data above $18 \mathrm{~g}$ is lacking. Since it is conceivable that accidents more severe than $18 \mathrm{~g}$ could occur, they have been included in the analysis at the $20 \mathrm{~g}$ leve1. The analysis of multiple container failures, presented in Appendix $\mathrm{J}$, considers the $20 \mathrm{~g}$ collisions. Use of higher " $\mathrm{g}$ " forces at the same expected frequency of occurrence would not significantly affect the risk spectrum. For these reasons a11 analyses consider a maximum cargo deceleration of $20 \mathrm{~g}$. 


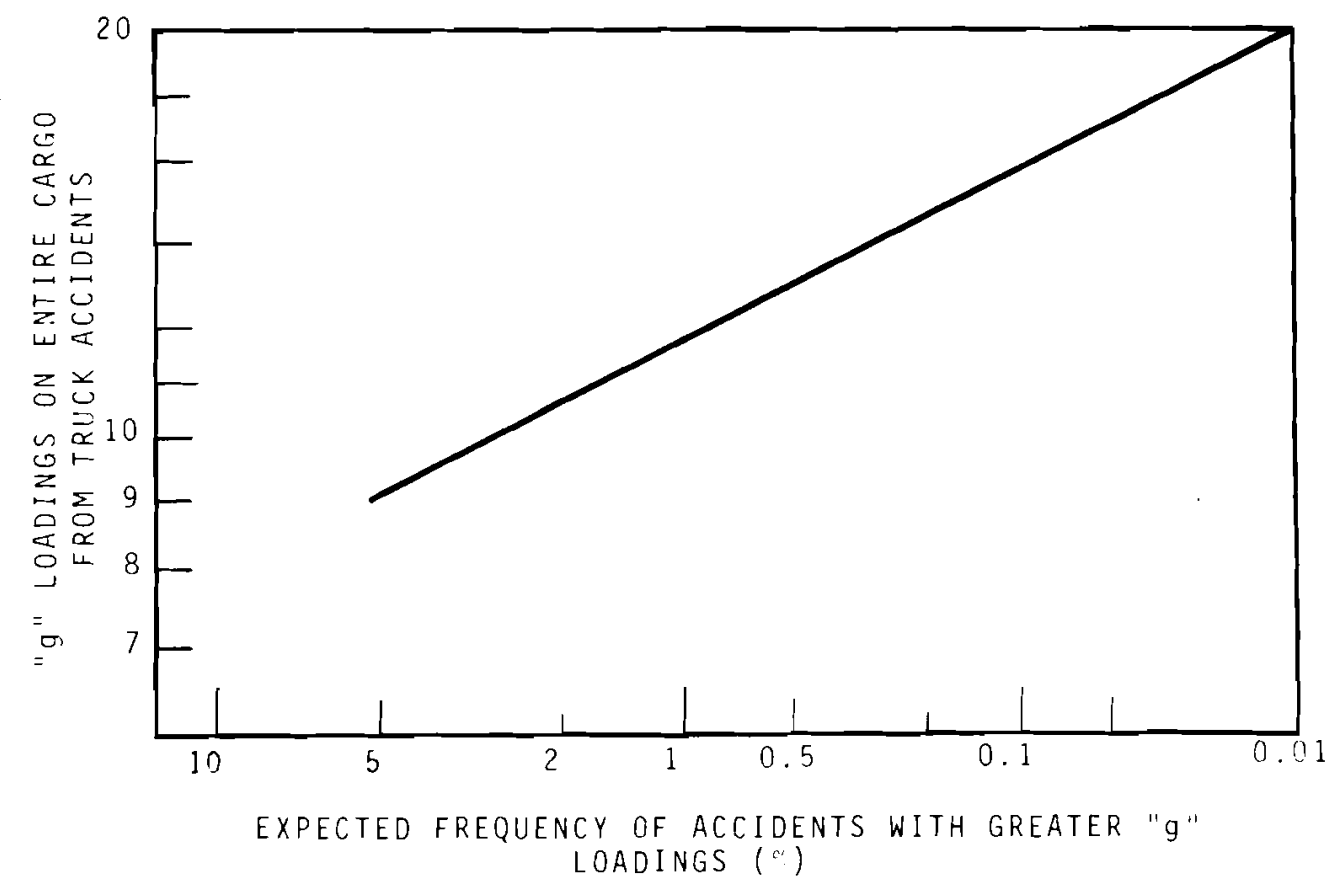

FIGURE 5.1. Expected Severity of Cargo Decelerations in the Truck Accident Environment

Puncture: The puncture environment, shown in Figure 5.2, was found to be somewhat dependent on the cargo load but to a lesser extent than crush. The parameter $V / R$ on the horizontal axis has units of $(\mathrm{sec})^{-1}$ and represents the relative velocity of the container and probe divided by the radius of the probe. The parameter on the vertical axis represents the probability that a container will be struck by a probe with a higher V/R. Not included in the graph is the expected frequency of puncture probes striking a container in an accident. Sandia estimates that puncture probes are generated in only $20 \%$ of a 11 truck accidents. In addition, it is estimated by Sandia that on $1 y 6.8 \%$ of the cargo wil1 see a puncture probe. Thus, the expected frequency of puncture probes striking one container is $0.068 \times 0.2=0.0136$ per accident. 


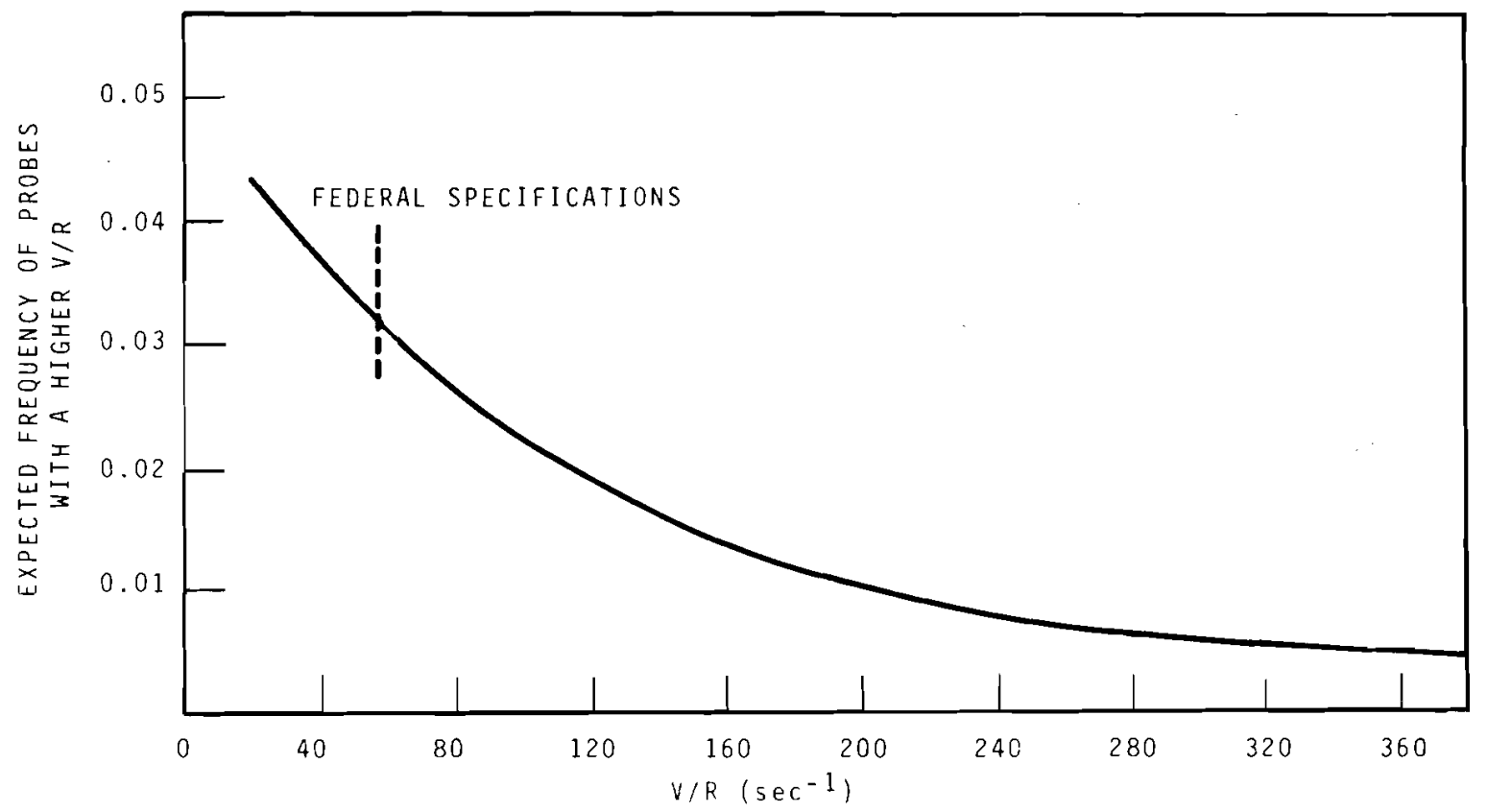

FIGURE 5.2. Expected Severity of Puncture Forces in the Truck Accident Environment.

Fire: Based on the Sandia compilation of the truck accident environment, fire can be expected to occur in $1.6 \%$ of a 11 truck accidents, the mean fire temperature is $1850^{\circ} \mathrm{F}$, and the duration of the fire can range from a few minutes to several hours. The expected duration of fires for the plutonium shipments is shown in Figure 5.3. This curve was prepared by Sandia ${ }^{(2)}$ as a special case since in the general truck accident environment the cargo may be flammable. The analysis includes the response time and effect of fire fighting teams. The analysis does not consider the probability of exposure of a package in the truck to the fire environment. This exposure probability is a function of the fire duration; the longer the fire the more probable that the package will be exposed. (1) In the risk analysis it was conservatively assumed that, if a fire occurred, the package would be exposed to the full fire environment. 


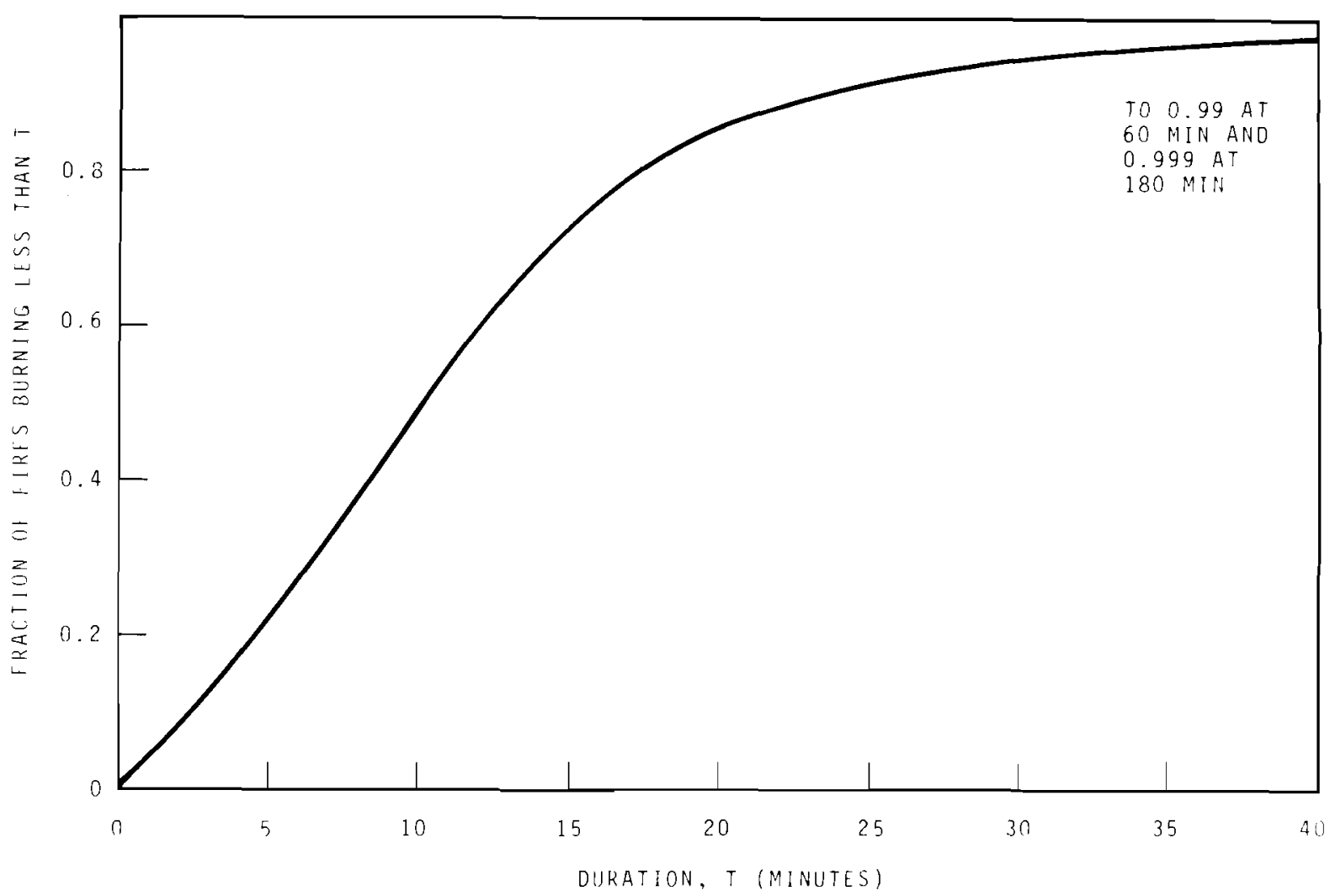

FIGURE 5.3. Expected Duration of Fires for Accidents Involving a Truck with Nonflammable Cargo

\section{REFERENCES}

1. R. K. Clarke, J. T. Foley, W. F. Hartman and D. W. Larson, Severities of Transport Accidents, Volume III - Motor Carriers, SLA-74-001, Sandia Laboratories, Albuquerque, N. M. (to be published).

2. W. F. Hartman, Sandia, "Fire Duration Data in Trucks Carrying Combustible Cargo," personal communication to T. McSweeney, Battelle-Northwest, June 1974. 


\section{PACKAGE FAILURE THRESHOLDS}

The previous section described the environment imposed on containers during truck accidents. Estimates of the failure thresholds for the $6 \mathrm{M}$ and L-10 packages are presented in this section. The concept of a failure threshold (a point below which all "identical" packages will survive and above which they will all fail) is a simplification of this application of the risk model. Mechanical failure points of containers are distributed in stress leve1. There is a most probable level that will result in failure, but in any group of "identical" containers there are some that will fail above or below this most probable value. However, it is felt that the simplifications in this section are consistent with the detail in the knowledge of the accident environment and that the analysis gives a reasonable estimate of the risk of package failure in an accident. The results of this section must be used in conjunction with other information on the stresses to which the package may be exposed in order to assess whether or not the package will fail in the accident environment. These assessments are made in Sections 9 and 11 .

The package failure thresholds reported here were not obtained by destructive testing. Experimental tests were beyond the scope of this evaluation. The results represent estimates of failure thresholds obtained in using the elastic theory of structure behavior. The analysis is limited to cases of side drop or loading (i.e., the axis of the package perpendicular to the direction of the applied load). Side loading is assumed to be the predominate orientation in an accident environment. The failure points obtained using elastic theory are also believed to be less than the actual strength of the container if tests to failure had been performed. The degree of conservatism is unknown.

The $6 \mathrm{M}$ and L-10 containers are shown schematically in Figures A.2 and A.1, respectively. The detailed calculations performed on these containers are given in Appendix H (Stress Analysis of L-10 and 6M Containers) and in Appendix I (Thermal Analysis of L-10 Container). The pertinent results of these analyses are summarized in this section. 
The detailed analyses enabled the direct evaluation of the following accident sequences:

$\mathrm{L}-10$

- Side impact followed by fire

- Puncture

$6 \mathrm{M}$

- Side Impact

- Puncture

The results from analysis of these accident sequences can be applied to other conditions. For example, analyzing container impact using elastic theory neglects the time variable. This means that the results of crushing can be inferred from the impact results. This can be accomplished by equating the energy in the container prior to impact to the work performed on the container in deformation. Thus:

$$
E=1 / 2 m v_{2}^{2}=m g h_{1}=F d
$$

where: $m$ is the mass of the container

$V_{2}$ is the velocity of the container at impact

$\mathrm{h}_{1}$ is the initial drop height

$d$ is the deformation of the container after impact

$F$ is the force representing an equivalent crush force.

The kinetic energy just before impact, $1 / 2 \mathrm{mv}_{2}^{2}$, was initially potential energy represented by the term "mgh ${ }_{1}$. " This energy is dissipated by deforming the container an amount " $d$ " using a force " $F$." The force in this equation represents a crush force. In the case of crushing, the force can come from many directions whereas the impact is imposed on one side. This represents the major distinction between crush and impact analyses.

\section{1 RESULTS OF ANALYSIS - L-10 CONTAINER}

\subsubsection{Impact Plus Fire}

The first accident scenario was the impact failure of the outer container of the L-10 followed by a fire which pressurized and ruptured the 
inner pressure vesse1. The first step in the analysis was to determine the drop height (or impacting velocity) that could result in loss of the vermiculite insulation located between the inner and outer containers. It was assumed that the L-10 container was subjected to a side drop onto an unyielding surface, with all the energy absorbed by the container in an elastic deformation mode.* The analysis showed that loss of vermiculite would occur due to the 1 id coming off. The assumption was made that the lid would come off when the perimeter of the lid in the deformed state was smaller than the undeformed inside circumference of the clamp ring. * Based on this assumption, the drop height that could cause loss of vermiculite material was calculated to be between 130 and $180 \mathrm{ft}$ in a side drop. The lower number, which ignores the effect of the vermiculite insulating material and the inner pressure vessel supporting frames, was used in the risk analysis (see Section 9).

The rupture of the inner pressure vessel, which is a 5 -in. Schedule 80 stainless steel 304 pipe, was determined under fire conditions from two sets of calculations: (a) rupture pressure versus temperature (which reflects the decrease in the rupture strength of the vessel as a function of temperature) and (b) vessel internal pressure versus temperature when it contained 10 liters of plutonium nitrate. Threshold failure temperature was determined from the intersections of the curve resulting from these calculations. This temperature was found to be $610^{\circ} \mathrm{F}$. Failure of the inner pressure vessel can occur as a combination of yielding of the bolts and the flange at the closure end. Failure was defined as the point where any leakage of contents of the pressure vessel takes place.

Following the determination that the pressure vessel will fail when the temperature reaches $610^{\circ} \mathrm{F}$, calculations were performed to determine the time needed to heat the inner container to this point for a range of conditions. If the pressure vessel were exposed directly to a $1475^{\circ} \mathrm{F}$

* For a discussion of these assumptions see Appendix $\mathrm{H}$. 
fire, rupture was calculated to occur 6 min after exposure to the fire.* If all the insulation is present, the pressure vessel can maintain its integrity for $240 \mathrm{~min}$. If the container remains upright and part of the insulation is missing, then the rate of heat up can be calculated by considering the insulated path and the direct radiant path in parallel. Thus for a container which is upright and has lost half its insulation, the heat up time is $12 \mathrm{~min}$ instead of 6 for no insulation. Calculations were also performed on the effectiveness of vermiculite with the container deformed or on its side and some of the vermiculite lost. A 0.38 in. vermiculite thickness was found to be sufficient to prevent pressure vessel failure for 30 min exposure to the postulated fire. The conclusion reached from this calculation is that vermiculite is effective as long as the pressure vessel is covered.

\section{1 .2 Puncture}

The next analysis carried out was the theoretical determination of the drop height onto a 6-in. diam pin required to puncture both the inner and outer shells of the L-10 container. The drop height required to puncture the outer shell was shown to be approximately $42 \mathrm{in}$.

The minimum drop height required to cause puncture of the inner vesse 1 alone when dropped on a 6-in. diam pin was calculated as approximately $4000 \mathrm{in.}$ This failure mode, which takes no cognizance of the energy absorption properties of the outer container and vermiculite material, is one which for the conditions described cannot occur; the vesse1 would fail in some other mode long before the energy required for puncture could be generated. The most likely mode would be that of the inner vessel bending over the pin upon impact, resulting in the skin of the vessel being stretched until cracking occurs. If one considers the inner vessel alone, with no support from the outer container or space frame or energy absorbing properties of the vermiculite, then incipient cracking could occur in the inner vessel wall at a minimum drop height of 58 in. This

\footnotetext{
* For a discussion of these results see Appendix I.
} 
figure was used in subsequent evaluations and represents a lower bound of the drop height; the actual drop height would be much higher due to the reinforcing effect of the neglected structural components of the $L-10$ container.

\subsection{RESULTS OF ANALYSIS - 6M CONTAINER}

\subsubsection{Impact}

An analysis was made on a 15 gallon 6M container to determine the drop height which would result in rupture of the outer container. Again a side drop onto an unyielding surface was assumed. The drop height required to pop the lid off the outer container was $194 \mathrm{ft}$. Again failure or loss of the lid was assumed to occur when the perimeter of the lid in the deformed state was smaller than the undeformed inside circumference of the clamp ring.

An attempt was made to determine the drop height which would cause rupture of the inner container of the 6M. It was assumed that the inner pressure vessel would not deform until the outer shell and inner shell came into contact. The drop height required to cause this contact was calculated to be approximately $260 \mathrm{ft}$. Inner container deformation would occur from drop heights greater than this. The point at which rupture would occur due to such deformation cannot be readily calculated. The solution could best be found by physical tests. Therefore for this study the threshold failure point for the inner container was assumed to be $260 \mathrm{ft}$.

\subsubsection{Puncture}

Calculations for the 15 gallon 6M showed the total drop height required to puncture both the inner and outer containers is $170 \mathrm{in}$. Just as with the $L-10$, the inner container of the $6 \mathrm{M}$ would fail in bending rather than by puncture. Failure thresholds are summarized in Table 6.1. 
TABLE 6.1. Calculated Failure Thresholds for L-10 and 6M Shipping Containers

\begin{tabular}{|c|c|c|c|c|c|c|}
\hline \multirow{2}{*}{$\begin{array}{l}\text { CONTAINER: } \\
\text { BARRIER: }\end{array}$} & \multicolumn{3}{|c|}{$L-10$} & \multicolumn{3}{|c|}{$6 \mathrm{M}$} \\
\hline & Outer & Inner & Inner + Outer & Outer & Inner & Inner + Outer \\
\hline $\begin{array}{l}\text { Failure } \\
\text { Mode } \\
\end{array}$ & \multicolumn{6}{|c|}{ Drop Height Required To Cause Failure* } \\
\hline Impact & $130 \mathrm{ft}$ & ---- & $>130 \mathrm{ft}$ & $190 \mathrm{ft}$ & ---- & $>260 \mathrm{ft}$ \\
\hline Puncture & 42 in. & $58 \mathrm{in.}$ & 100 in. $^{\star \star}$ & $133 \mathrm{in.}$ & $37 \mathrm{in.}$ & 170 in. \\
\hline \multicolumn{2}{|c|}{ Fire After Impact } & \multicolumn{5}{|c|}{ Time to Failure } \\
\hline \multicolumn{2}{|c|}{ (a) no insulation } & \multicolumn{5}{|c|}{$6 \min$} \\
\hline \multicolumn{2}{|c|}{$\begin{array}{l}\text { (b) } 0.4 \text { in. of } \\
\text { insulation } \\
\text { remaining }\end{array}$} & \multicolumn{5}{|c|}{$30 \mathrm{~min}$} \\
\hline $\begin{array}{l}\text { (c) } 180 \\
5 \text { in } \\
\text { of ou } \\
\text { no } 10\end{array}$ & $\begin{array}{l}\text { drop - } \\
\text { deformat } \\
\text { er conta } \\
\text { s of ins }\end{array}$ & $\begin{array}{l}\text { on } \\
\text { ner, } \\
\text { latic }\end{array}$ & & $\min$ & & \\
\hline
\end{tabular}

* For side impact.

**Inner vessel failure occurs in bending.

\subsection{DISCUSSION OF STRESS ANALYSIS}

The stress analysis used in this study was based primarily on elastic behavior of the materials. It did not include the effects of larger deformation and plastic behavior. Inclusion of such effects would give calculated results as drop heights greater than those calculated and shown in Table 6.1. Elementary mechanics show that a structure of ductile material, such as most grades of steel, absorbs so much energy that it undergoes large plastic deformations many times greater than that absorbed by the same structure in a purely elastic mode. Though some of the equations applied in this study are empirical in nature, being based on model tests, the basic mathematical theory employed was still that of linear elasticity. Such a treatment is inherently conservative, giving drop height figures that should be used as lower bounds rather than being completely definitive. The failure thresholds reported here should be used in correlation with the forces expected to exist during accidents. 


\section{CONDITIONS OF PACKAGES DURING TRANSPORT}

To obtain a data bank of package conditions during transport for use in the risk analysis, a survey was conducted of companies and laboratories who routinely receive plutonium. This section presents the results of this survey.

\subsection{SCOPE OF SURVEY}

\subsubsection{Information Needed}

To determine the package condition information which should be in the data bank, fault trees were constructed for the $L-10$ and the $6 \mathrm{M}$ packages. Fault tree terminology and symbolism are shown in Table 7.1. Fault trees are shown in Figures 7.1 and 7.2.

The fault trees traced each step of package loading and closure and identified all conditions that could possibly effect package containment integrity. The conditions of particular interest, however, were those involving the primary containment vessel.

Based on the information identified in the fault trees, questionnaires were prepared for use in the survey of the nuclear industry. These questionnaires are shown in Appendix B.

\subsubsection{Packages Included in Survey}

The risk assessment in this report compares $\mathrm{Pu}\left(\mathrm{NO}_{3}\right)_{4}$ solution transport in L-10 packages and $\mathrm{PuO}_{2}$ powder transport in $6 \mathrm{M}$ packages. Since most of the packages used in plutonium transport have similar components, the survey was extended to also include L-3 and LLD type packages. By doing so, a broader data bank was obtained.

The L-3 model is used for $\mathrm{Pu}\left(\mathrm{NO}_{3}\right)_{4}$ solution shipment and is basically the same design as the $L-10$. The main difference between the two is that the L-3 is a 55-gal drum with a 3-1iter capacity inner bottle, whereas the L- 10 consists of two end-connected 55-gal drums with a 10-1iter capacity inner bottle.

The LLD model represents a basic type used for $\mathrm{PuO}_{2}$ powder and plutonium metal shipments. It has the same type of $2 R$ containment vessel as the $6 \mathrm{M}$. 


\section{TABLE 7.1. Fault Tree Symbolism}

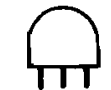

output

inputs

output

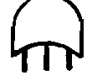

inputs
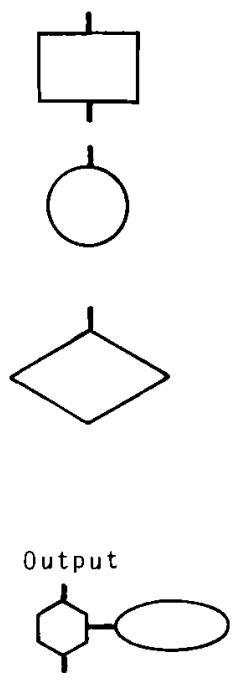

Input
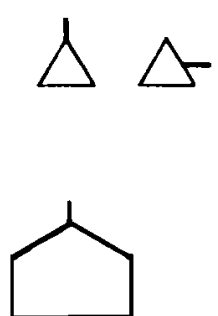

"AND" logic gate. The simultaneous occurrence of inputs is required to cause an output.

"OR" logic gate. The occurrence of any one of the inputs will result in an output.

Fault event that results from the logical operation of two or more fault events. It is always the output from a $\operatorname{logic}$ gate.

Basic fault event. It requires no further development. Data regarding frequency and mode of failure can be derived empirically.

Inferred fault event. Any failure except a primary failure which is not developed further due to lack of information, time or money or due to the low probability of occurrence. It can also be used where other analyses give sufficient information to indicate that further analys is would be redundant.

"Inhibit" gate. The condition specified in the oyal is required for an input fault event to result in an output event. This condition is frequently a design limit which will not transmit a failure until the design limits have been exceeded.

Transfer symbol denoting that failure also impacts on other branches of fault tree. A line at the apex of the triangle represents a "transfer in." A line in the side represents a "transfer out." A number is placed in the triangle to identify transfer locations.

"House" defines an event that must occur, or is expected to occur, due to design and normal operating conditions. 


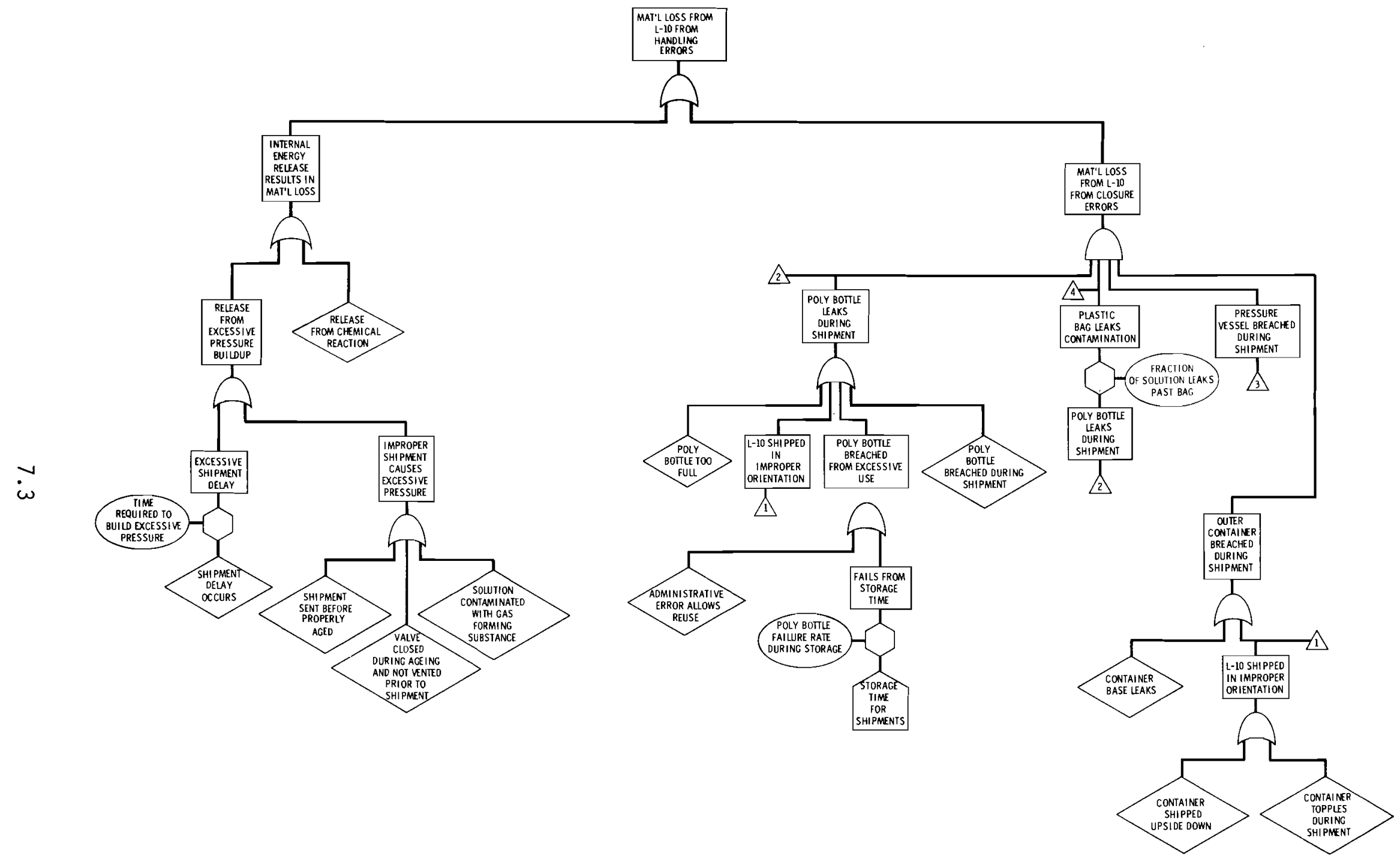

FIGURE 7.1A. Fault Tree For L-10 Plutonium Nitrate Solution Package Closure Analys is 


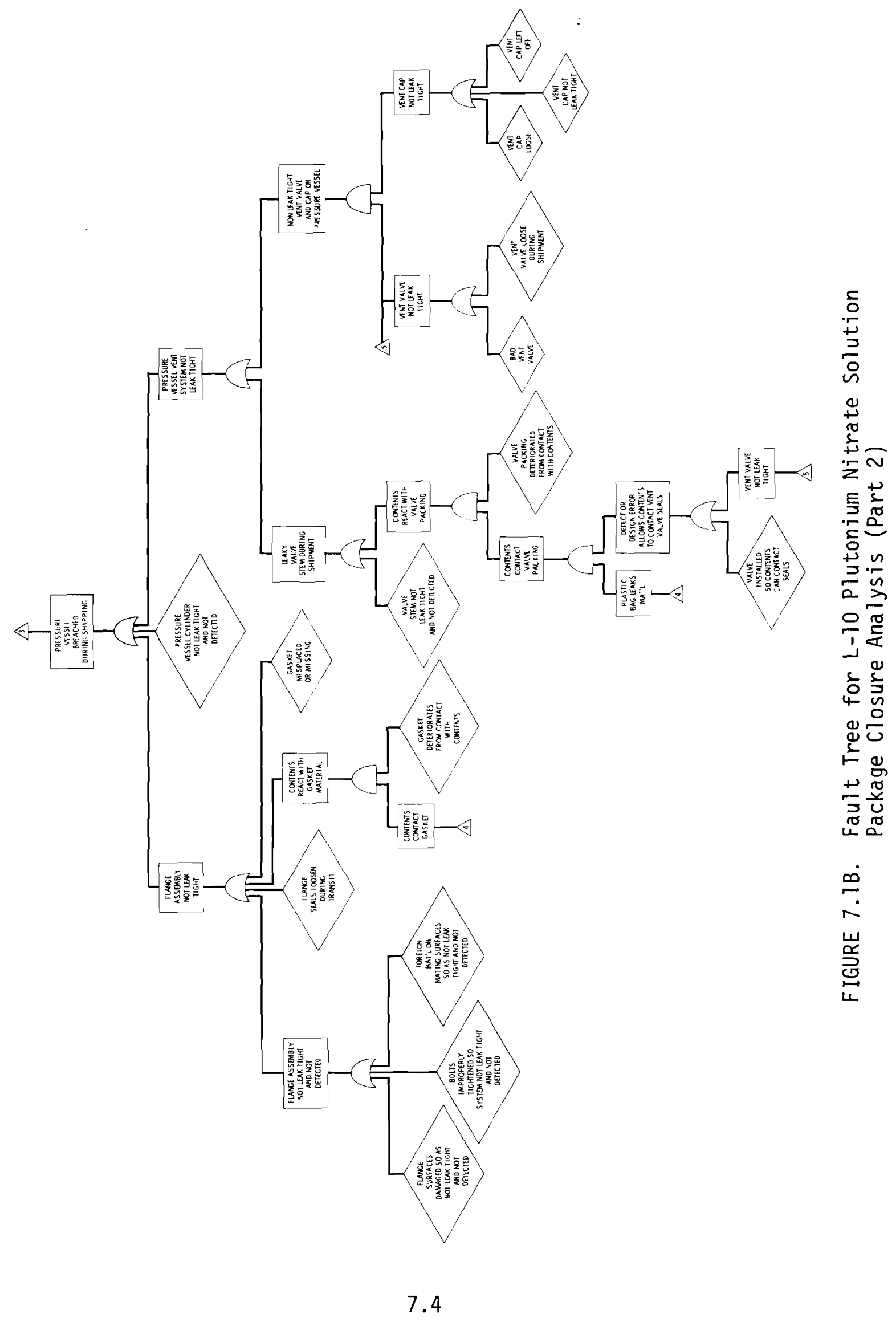




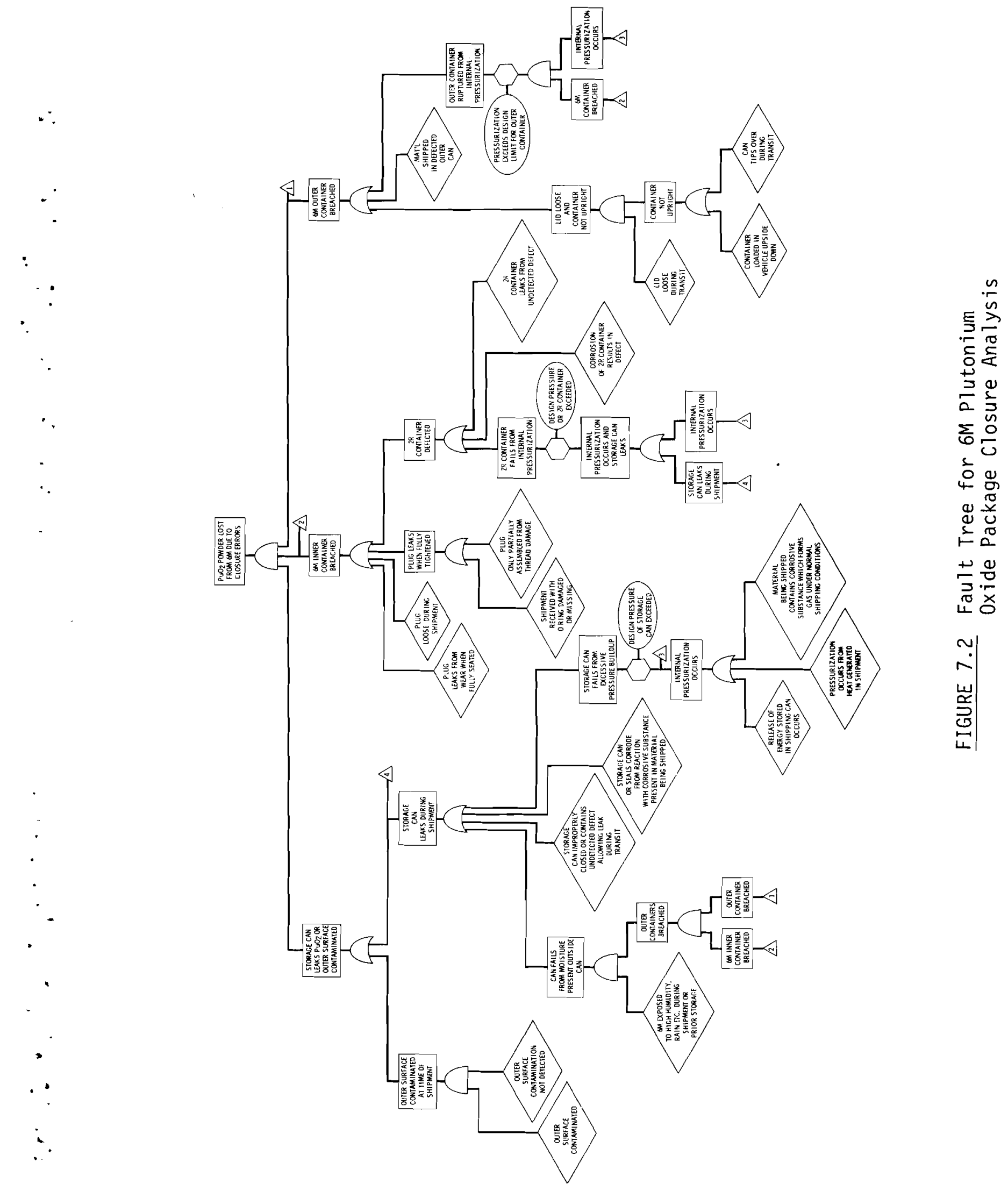


Further, inasmuch as the package conditions during transport are not significantly affected by content, the survey also included experience with ${ }^{233} \mathrm{UO}_{2}\left(\mathrm{NO}_{3}\right)_{2}$ solution shipments in $\mathrm{L}-3$ and $\mathrm{L}-10$ packages and the shipment of various plutonium compounds and meta 1 in LLD-1 and 6M packages.

A description of the $L-10,6 \mathrm{M}$ and LLD-1 package models is given in Appendix A.

\subsubsection{Sites Included in Survey}

The companies and laboratories visited are listed below.

$\begin{array}{ll}\text { Argonne National Laboratory } & \text { Rocky Flats Plant } \\ \text { Argonne, Illinois } & \text { The Dow Chemical Company } \\ \text { E. I. duPont deNemours } & \text { Golden, Colorado } \\ \text { Savannah River Plant } & \text { New York State Atomic and } \\ \text { Aiken, South Carolina } & \text { Space Development Authority } \\ \text { Union Carbide Corporation } & \text { New York, New York } \\ \text { Holifield National Laboratory } & \text { NUMEC } \\ \text { Oak Ridge, Tennessee } & \text { Babcock and Wilcox Company } \\ \text { Kerr-McGee Nuclear Corporation } & \text { Apollo, Pennsylvania } \\ \text { Oklahoma City, Oklahoma } & \text { Atlantic Richfield Hanford } \\ \text { Los Alamos Scientific Laboratory } & \text { Company } \\ \text { Los Alamos, New Mexico } & \text { Richland, Washington } \\ & \end{array}$

\subsubsection{Time Period Covered by Survey}

The survey set out to cover the time period 1970-1974. Due to the limited time for the survey and the format of records kept by the plutonium users, this period was considered flexible. Some experience prior to 1970 was included, and not all experience in the 1970-1974 period could be included.

\subsection{RESULTS OF SURVEY}

\subsubsection{Number of Shipments and Packages}

A summary of the number of packages covered by the survey is given in Table 7.2 The total is about 775 shipments, which includes $2130 \mathrm{~L}-3$ and L-10 type packages and about 4100 LLD and 6M type packages. As previously indicated, several shipments of ${ }^{233} U$ in $L-10$ packages are included with the results for 1iquid $\mathrm{Pu}\left(\mathrm{NO}_{3}\right)_{4}$, and several shipments of plutonium metal in LLD and $6 \mathrm{M}$ packages are 
TABLE 7.2 Estimated Number of Shipments and Packages Included in Survey

(Period covered: $1970-1974$ )

Number

\section{SHIPMENTS}

(A11 package types)

775

PACKAGES SHIPPED

\author{
$\mathrm{Pu}\left(\mathrm{NO}_{3}\right)_{4}$ Solution Packages \\ $(\mathrm{L}-3$ and $\mathrm{L}-10)$ \\ $\mathrm{PuO}_{2}$ Packages \\ LLD- 1 \\ $6 \%$
}

Total Packages $2130^{a}$

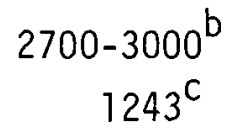

$\sim 6200$

\footnotetext{
a. Includes several $233 \mathrm{U}$ packages that were shipped in $L-3$ 's and L-10's in the same manner as liquid plutonium nitrate.

b. Includes several plutonium metal packages which were shipped in the same manner as plutonium oxide.

c. There are 806 packages in storage not included in this survey which will be unpacked by July 1975 .
} 
included with the $\mathrm{PuO}_{2}$ results. These additions were felt to be justified since the prinary objective of this study was to obtain information on package closure which generally is no dependent on content.

\subsubsection{Fina1 Data Compiled for Use in Risk Assessment l'odel}

A summary of observations made by those contacted in the survey is presented in Table 7.3. It should be emphasized that, in the extensive experience sampled by the survey, a complete loss of packaging integrity has never been observed.

\subsubsection{Limitations of Survey}

Even though the information obtained in the survey (Table 7.3) provides a reasonably good base for the risk assessment model, certain limitations should be recognized. First, for the most part, observations were made by personnel recollections. Consequently, the time periods in which particular abnormal conditions occurred and the number of occurrences were not certain.

Second, nearly all of the sites visited indicated that they now use a check-off sheet to help assure that packages are properly and securely closed. Some of these sheets have been in use for as 1 ong as 10 years while other have been implemented more recently. The implementation of quality assurance $(A Q)$ requirements by the USAEC and quality control (QC) procedures by shippers during 1972 and 1973 would have a significant effect on any package closure information obtained. Most packaging faults occurred prior to 1972. Al1 those interviewed pointed out that very few package closure deficiencies have been observed since about 1972.

Because of these factors, the results reported in Table 7.3 are considered to be conservative and not necessarily representative of current package conditions during transport. 


\section{TABLE 7.3. Data Bank - Package Closure Experience Obtained by Survey \\ (For period 1970-1974)}

\begin{abstract}
Estimated Estimated Number of Occurrence

Occurrence

Frequency

(per container received)

Part 1 - PLUTONIUM NITRATE SOLUTION SHIPMENTS ( $L-3$ and $L-10$ Packages)
\end{abstract}
1. Bolt ring on outer drum
47
0.022 turned upward
2. Vermiculite level low
200
0.094
3. Vermiculite contaminated
4
$1.9 \times 10^{-3}$

।

13

5. No cap on vent line

6. Vent cap loose

7. Valve on vent line not closed

8. Flange bolts too tight (over 80-ft lb torque)

9. Gasket missing

Inside Primary Containment Vessel

1. Plastic bag pressurized

2. Plastic bottle cap loose

3. Plutonium solution in plastic bag

4. Contamination outside plastic bag

5. Plutonium solution outside plastic bag

6. Plastic bottle gasket in "figure eight"

7. Plastic bag broken
2
$5 \times 10^{-4}$

$6.1 \times 10^{-3}$

$1.4 \times 10^{-3}$

$7.5 \times 10^{-3}$

0.024

$9.4 \times 10^{-4}$

$2.4 \times 10^{-3}$

$4.7 \times 10^{-4}$

0.070

$1.2 \times 10^{-2}$

$5.2 \times 10^{-3}$

$1.9 \times 10^{-3}$

$9.4 \times 10^{-4}$
Remarks
The bolt ring closure is designed to be attached so that the bolt is down against the drum rather than upward, al though not a requirement.

Vermiculite is normally 6 in. above top of conta inment vessel lid. If too low, fire protection mav not be adequate. In two instances the vermiculite bags around top were missing.

In each instance contamination is believed to have resulted at the time of closure by the shioper, not by leakage from the vessel. The amount of plutonium involved in contamination was considered neqligible from viewpoints of criticality hazard.

Source of water not certain. Could have entered as rain through vent holes in older desian.

In no instance was the valve open and the vent line cap missing or loose at the same time.

Contrary to expectations before the survey, relativelv few plastic bags were found to be pressurized by receivers of $\mathrm{Pu}\left(\mathrm{NO}_{3}\right)_{4}$

Gasket twisted when tiohtening 
TABLE 7.3. (Contd)

\begin{tabular}{lll} 
& $\begin{array}{l}\text { Estimated } \\
\text { Number of } \\
\text { Occurrences }\end{array}$ & $\begin{array}{l}\text { Estimated } \\
\text { Occurrence } \\
\text { Frequency } \\
\text { (per container received) }\end{array}$ \\
\hline
\end{tabular}

Remarks

Part II - PLUTONIUM OXIDE SHIPMENTS IN 8M PACKAGES

Qutside Primary Containment Vessel

1. Hole in outer drum

$21.6 \times 10^{-3}$

2. Bolt rings turned upward

66

$5.3 \times 10^{-2}$

3. Bolt ring bolt loose

150

0.12

(finger tight)

4. Bolt ring bolt broke off while tightening

6 of 300

$2 \times 10^{-2}$

Inside Primary Containment Vessel

1. Can bulged due to internal pressure

$5 \times 10^{-4}$

2. Contamination outside

13 of can

3. Contamination of plastic bag

\section{Part III - PLUTONIUM OXIDE SHIPMENTS IN (LLD-I PACKAGES)}

Outside Primary Containment Vessel

1. Locking cover loose

2. Plug in $2 R$ containment vesse? not tight
$4 \times 10^{-4}$

0.22

0.18
3. Threads damaged

4. Plug extremely tight

5. 0 ring rissing

\section{1}

1

11

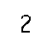

3
$2.4 \times 10^{-4}$

$2.4 \times 10^{-4}$

$3.9 \times 10^{-3}$

Inside Primary Containment Vessel

1. Can bulged due to internal pressure

2. Can breached or not completely sealed upon arriva?

3. Contamination outside can but not outside containment vessel

$4.9 \times 10^{-4}$

$1.1 \times 10^{-3}$

$1.1 \times 10^{-3}$
These estimates are based on the recollection of those interviewed in terms of percentage of total packages received. The estimate could be conservatively high. What apparently happens is that the plug loosens due to vibration during transport. In one instance the plug had worked its way completely out of the containment vessel by the time the package reached $i$ ts destination.

Long handled wrench required to remove plug 


\section{RELEASE SEQUENCE IDENTIFICATION}

No plutonium release has occurred during any truck shipment in the United States. Thus possible ways that releases could occur (release sequences) must be identified by a reasoning process. The information given in Sections 5, 6 and 7 provides a basis for identifying events or combinations of events which could result in a release of plutonium.

This section describes a formalized procedure for identifying combinations of conditions which could result in a release. The first step in the procedure is to develop fault trees using the techniques described in section 8.1. Section 8.2 presents the fault trees developed for the shipment of plutonium oxide powder in $6 \mathrm{M}$ containers and plutonium nitrate solution in L-10 containers. The second step in the procedure is to develop a 1 ist of release sequences from the fault tree. In section 8.3, the release sequences will be identified for the two plutonium shipping forms using the concept of Barrier Release Sequences.

\subsection{FAULT TREE CONSTRUCTION}

The fault tree analysis technique was developed in the 1960's in the aerospace industry to identify design deficiencies before actual space flight of the equipment. Basically the procedure is to assume a failure and work backwards to identify component failures which could cause or contribute to the failure. The fault tree should be related to individual components for which failure data are available. For instance, in an electronic circuit the basic failure might occur in a resistor. In practice, fault trees seldom are developed to that degree. What occurs instead is development of fault trees in terms of basic system modules. Using the electronic example, one would carry the possible failure back through the fault tree only to the amplifier which contained the resistor. Such a fault tree is called a Top Level Fault Tree since it usually identifies only large systems which could result in a failure.

The methodology applied to transportation of plutonium involves postulation of a release of plutonium during transport and then examination of 
the series of events which must have occurred to cause the release. This form of reasoning is thought to be much more inclusive than beginning with an initiating event and working toward a release, (i.e., constructing accident scenarios or decision trees). At the same time, quantification of the release requires specifications of an ordered sequence of events or accident scenarios. From this analysis, the tree constructed using the fault tree methodology is used as the basis for estimating the total release probability. Then the tree is broken down into all the possible release sequences. In effect, all the accident scenarios will be obtained from the fault tree. When properly applied, the accident scenarios obtained from using the fault tree methodology should be more complete than the alternative method of trying to 1 ist all the accident scenarios without the aid of any formalized reasoning process.

\subsection{FAULT TPEES FOR SHIPMENT OF PUO 2 IN THE 6M AND \\ LIQUID NITRATE IN THE L-10}

The fault trees for the plutonium oxide shipments in the $6 \mathrm{M}$ and 1 iquid nitrate shipments in the $L-10$ are developed for normal truck transport on primary roads in the United States. The analysis considers the combined effects of the truck accident environment and packaging condition. The effects of sabotage or diversion are not considered. Based on these criteria, fault trees shown in Figures 3.1 and 8.2 were developed to determine applicable failure sequences for the $6 M$ and $L-10$ shipping containers, respectively. The list of identified events or failure elements which could contribute to a release are shown in Tables 8.1 and 8.2 for the $6 M$ and $L-10$, respectively.

For both the oxide and the nitrate shipments four barriers between the plutonium and man's environment were considered. For the oxide these were: the sample can (the primary container for the plutonium), the $2 R$ container, the $6 \mathrm{M}$ drum, and the van. For the liquid nitrate the barriers were: the polyethylene bottle, the pressure vessel, the L-10 drum, and the van. Generally, in analyses, no credit is taken for the first and fourth barriers (can or bottle and the van). However, they can act to reduce both the probability of a release occurring and the quantity of material dispersed should a release occur. Therefore, they are included in the present analysis. 


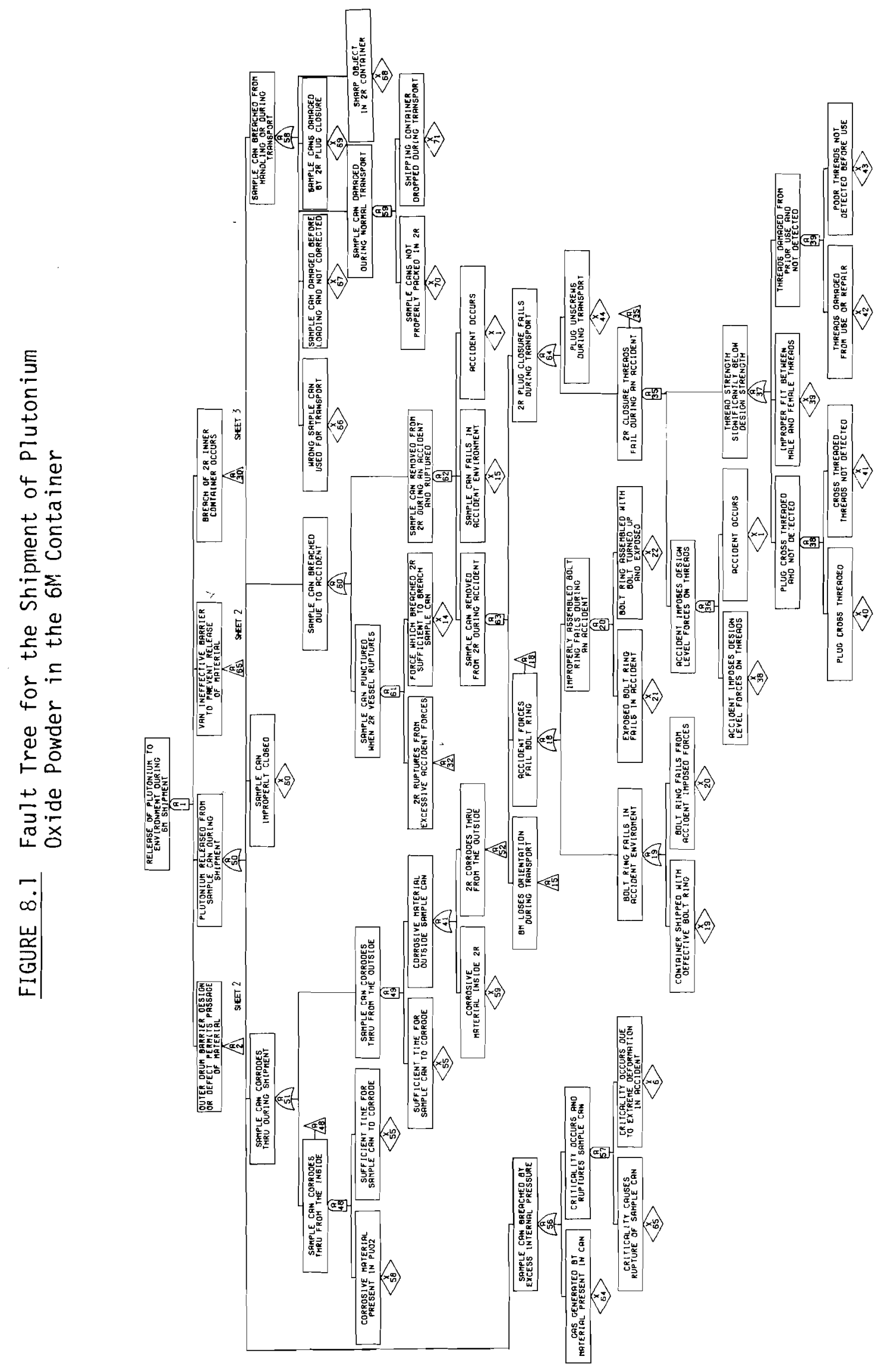


FIGURE 8.1 (Continued)

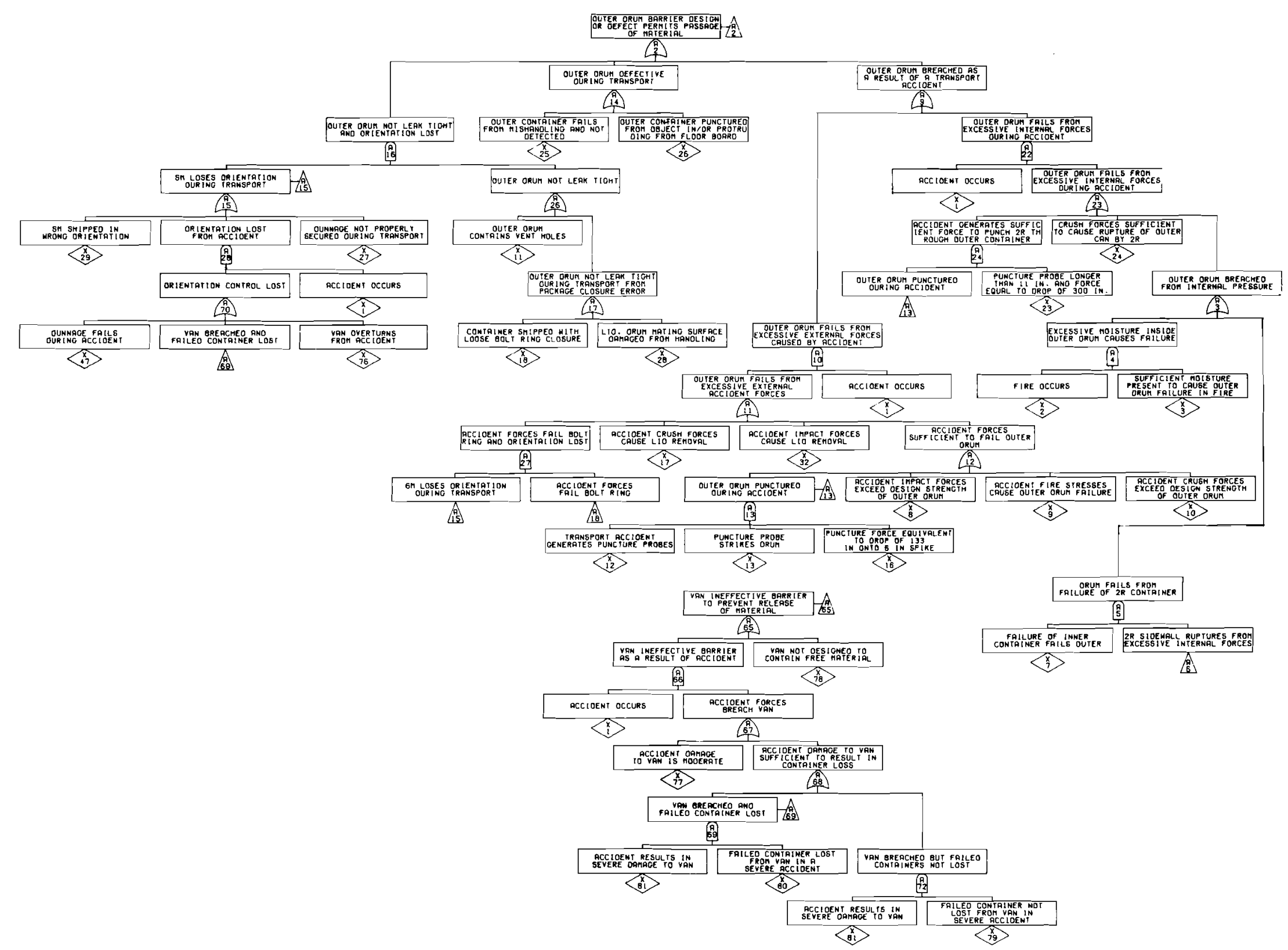


FIGURE 8.1 (Continued)

ir

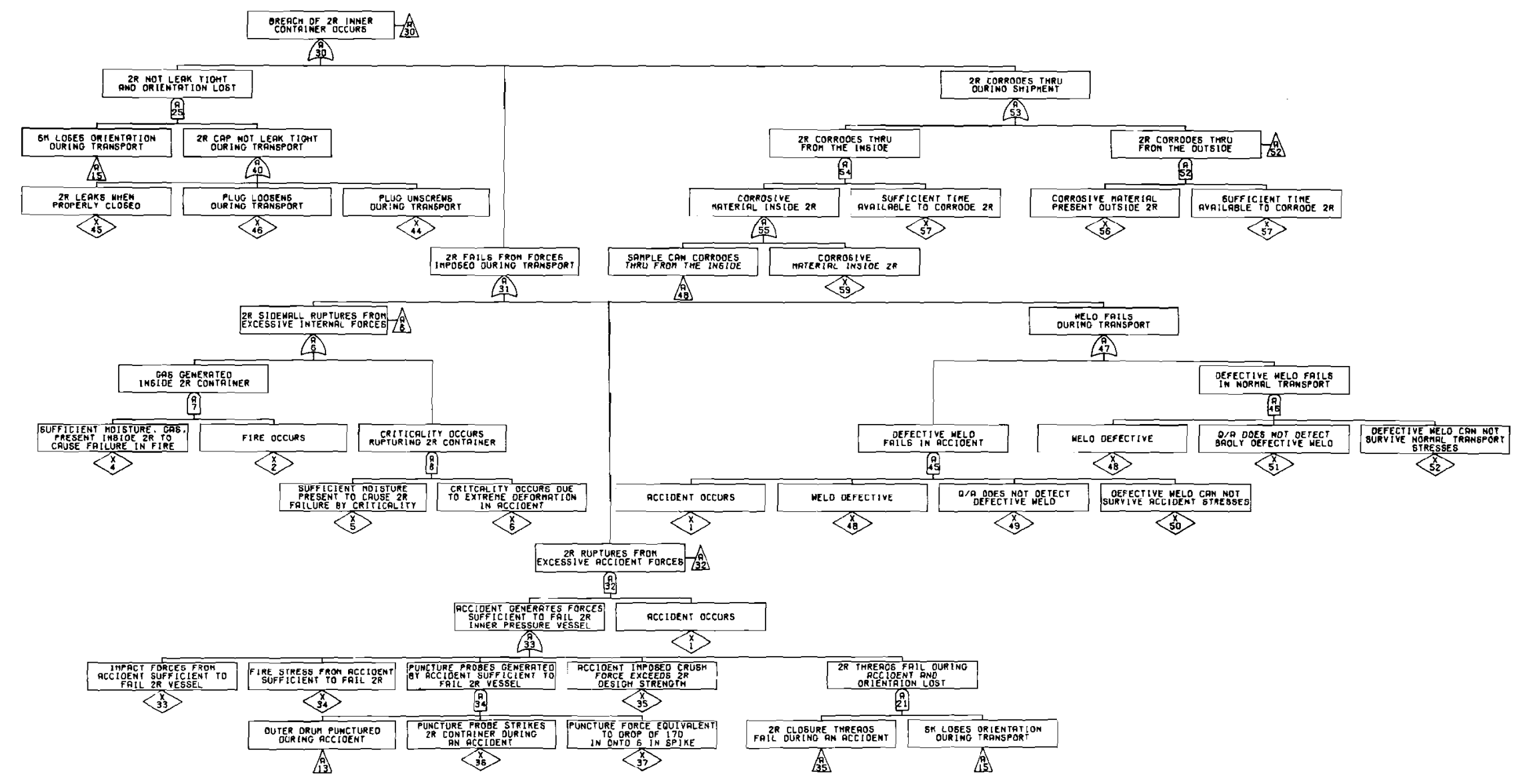




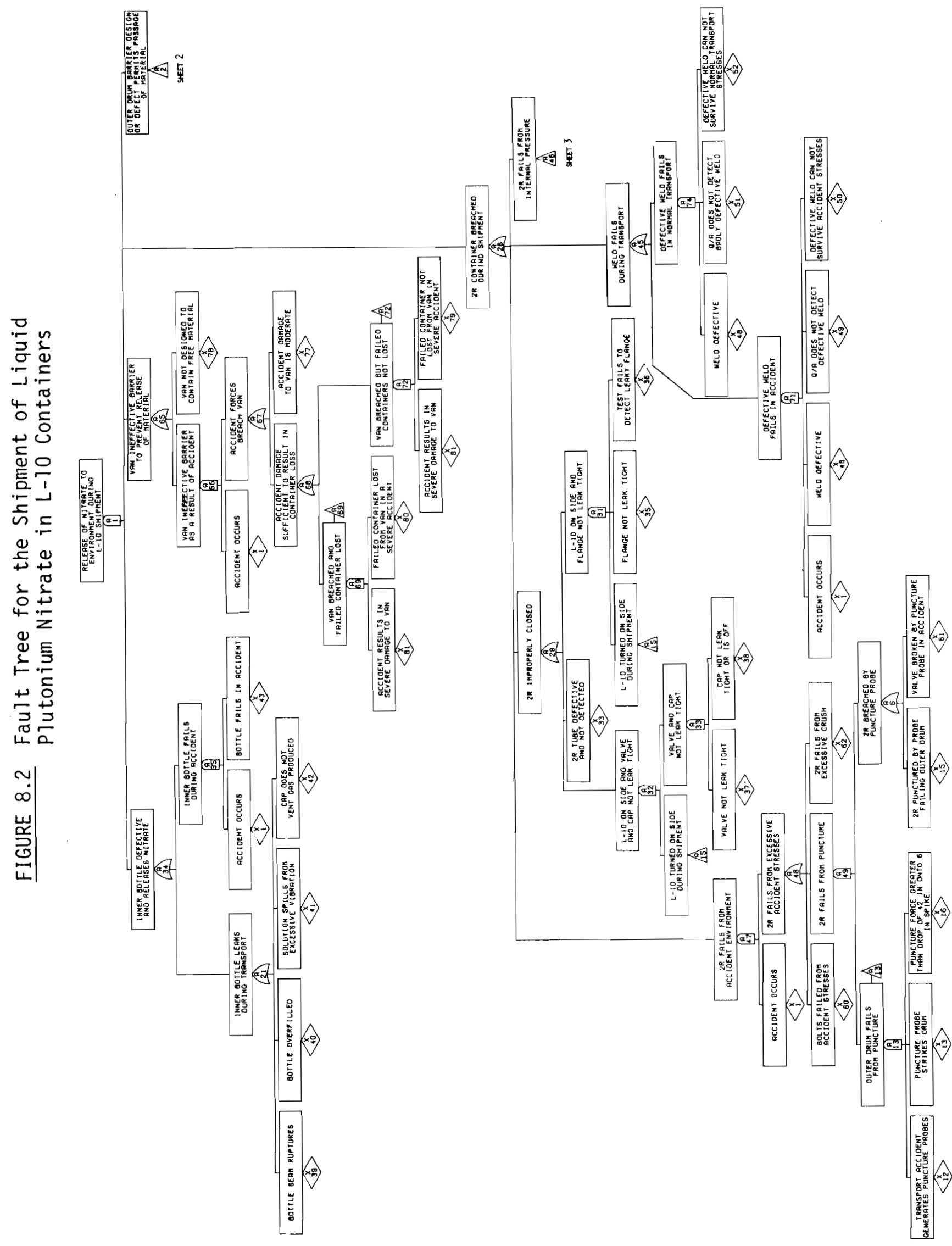


FIGURE 8.2 (Continued)

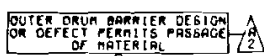

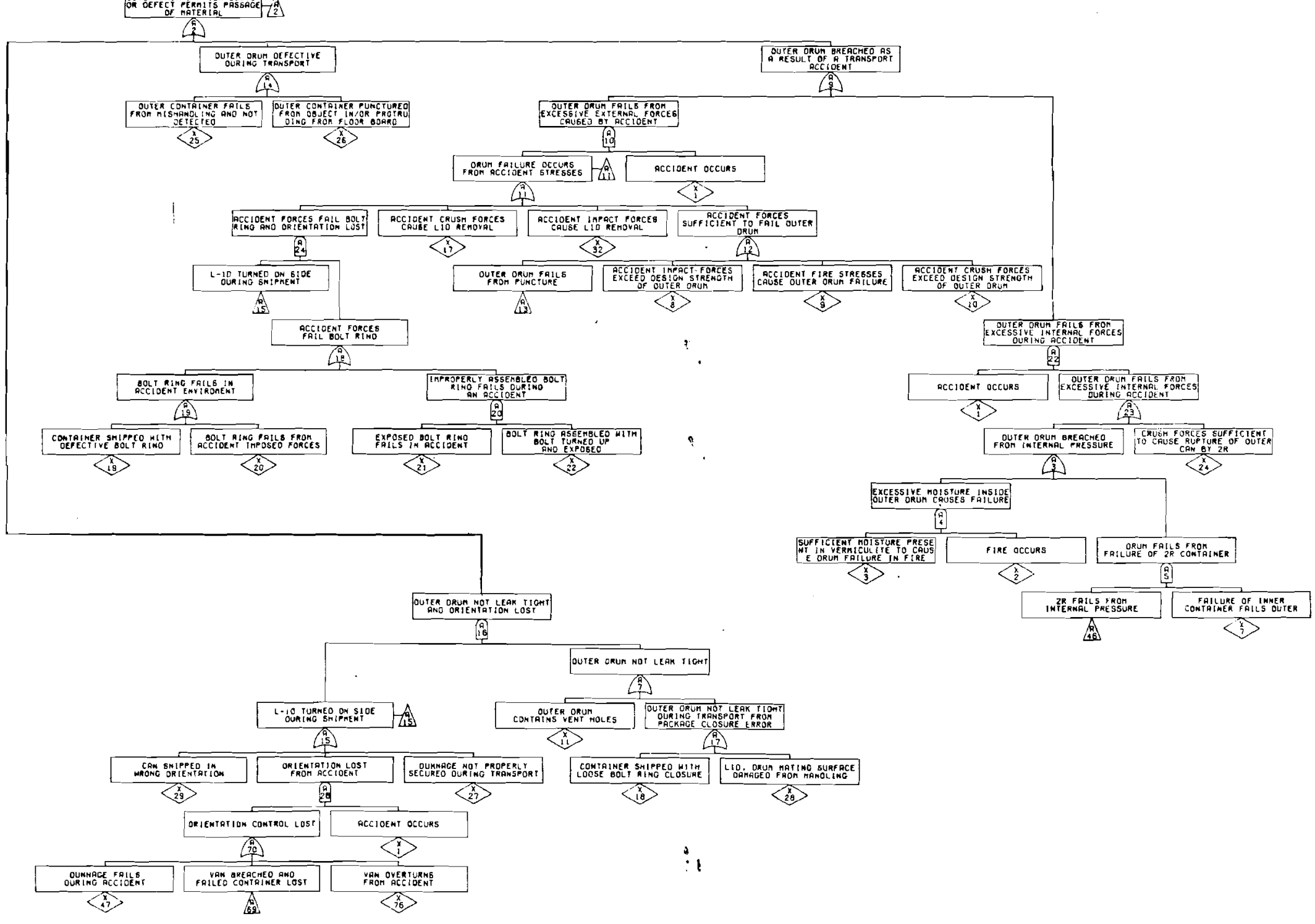




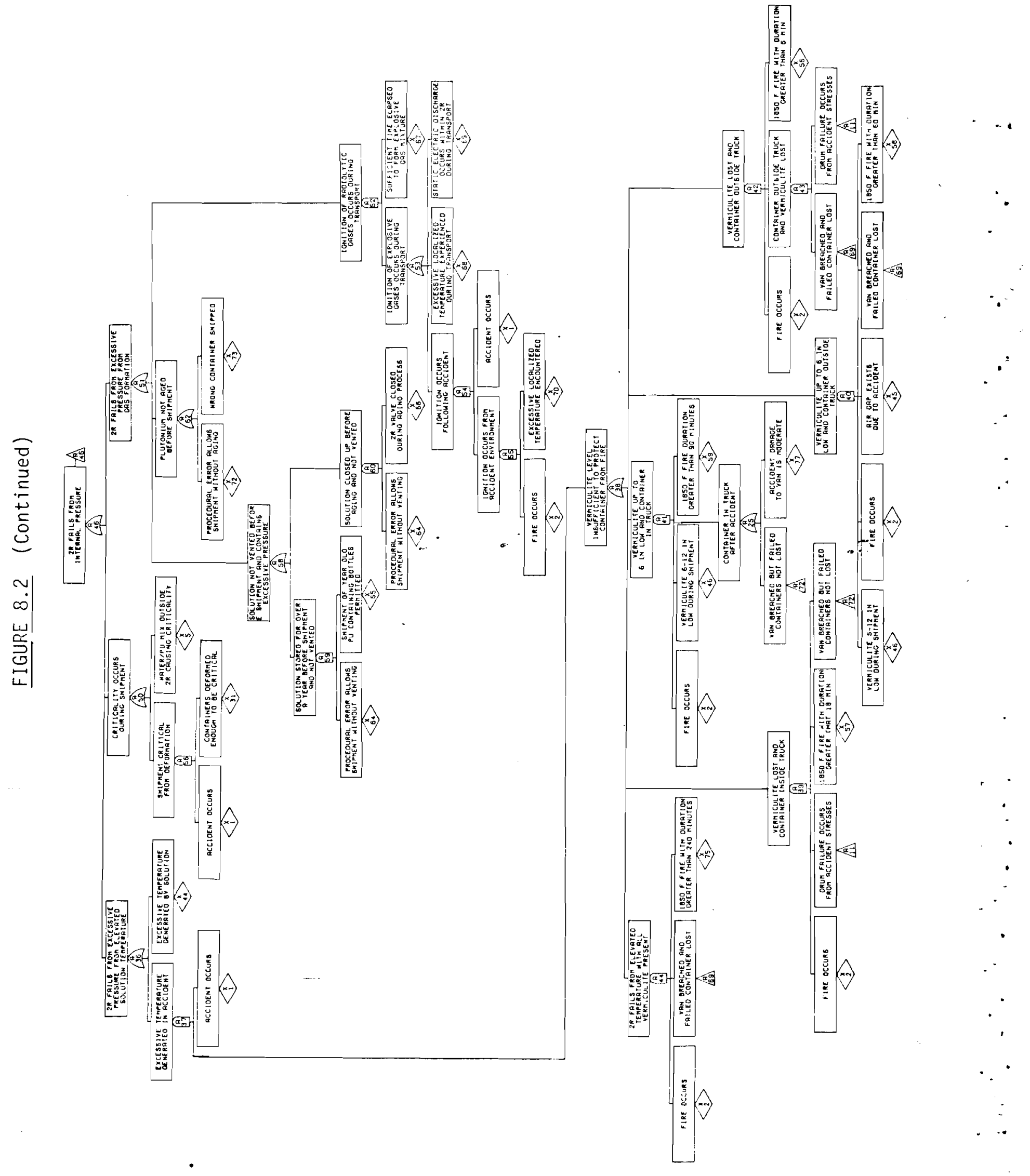




\section{TABLE 8.1 Listing of Basic Events for 6M Analysis}

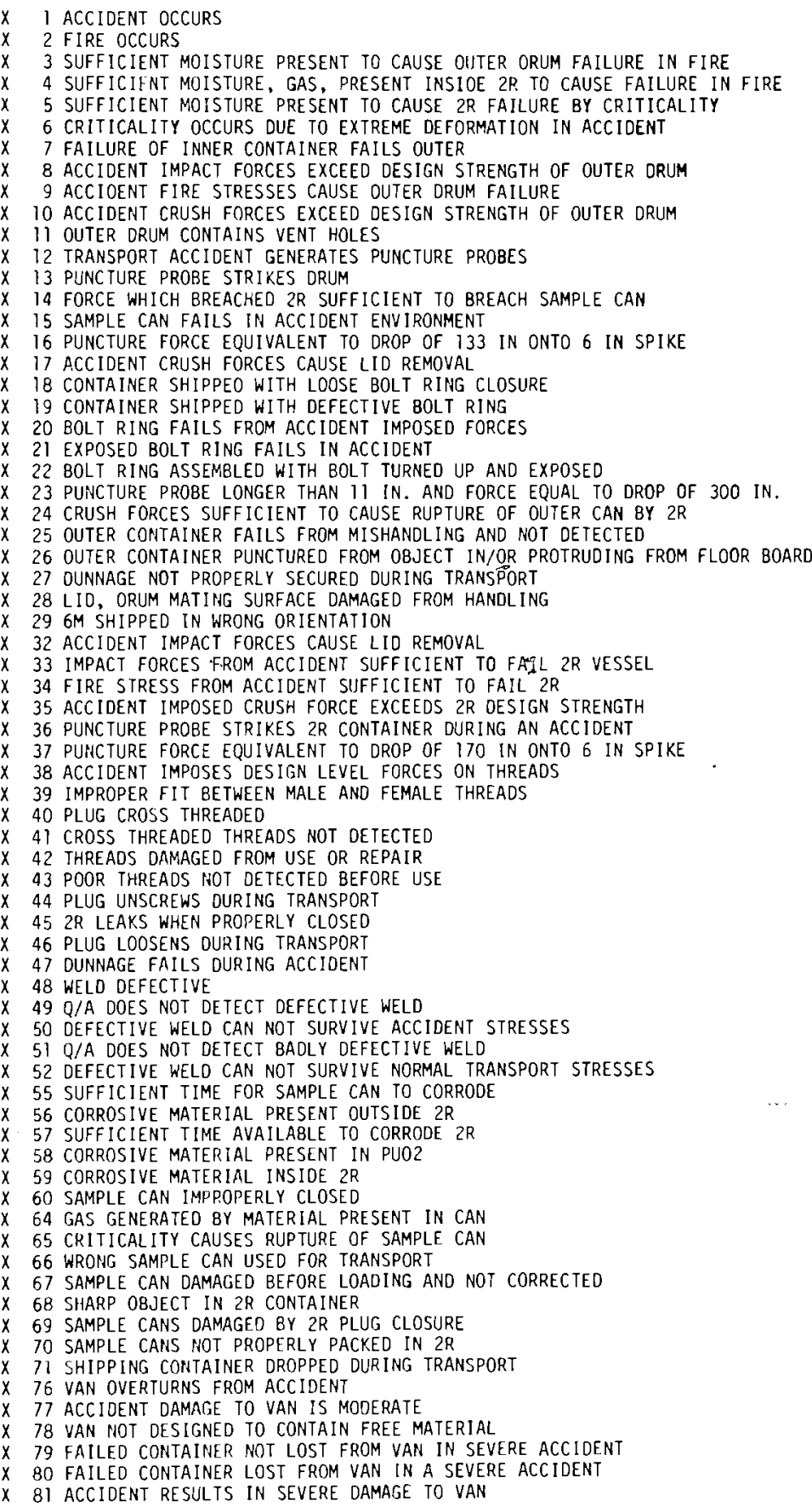




\section{TABLE 8.2 Listing of Basic Events in L-10 Analysis}

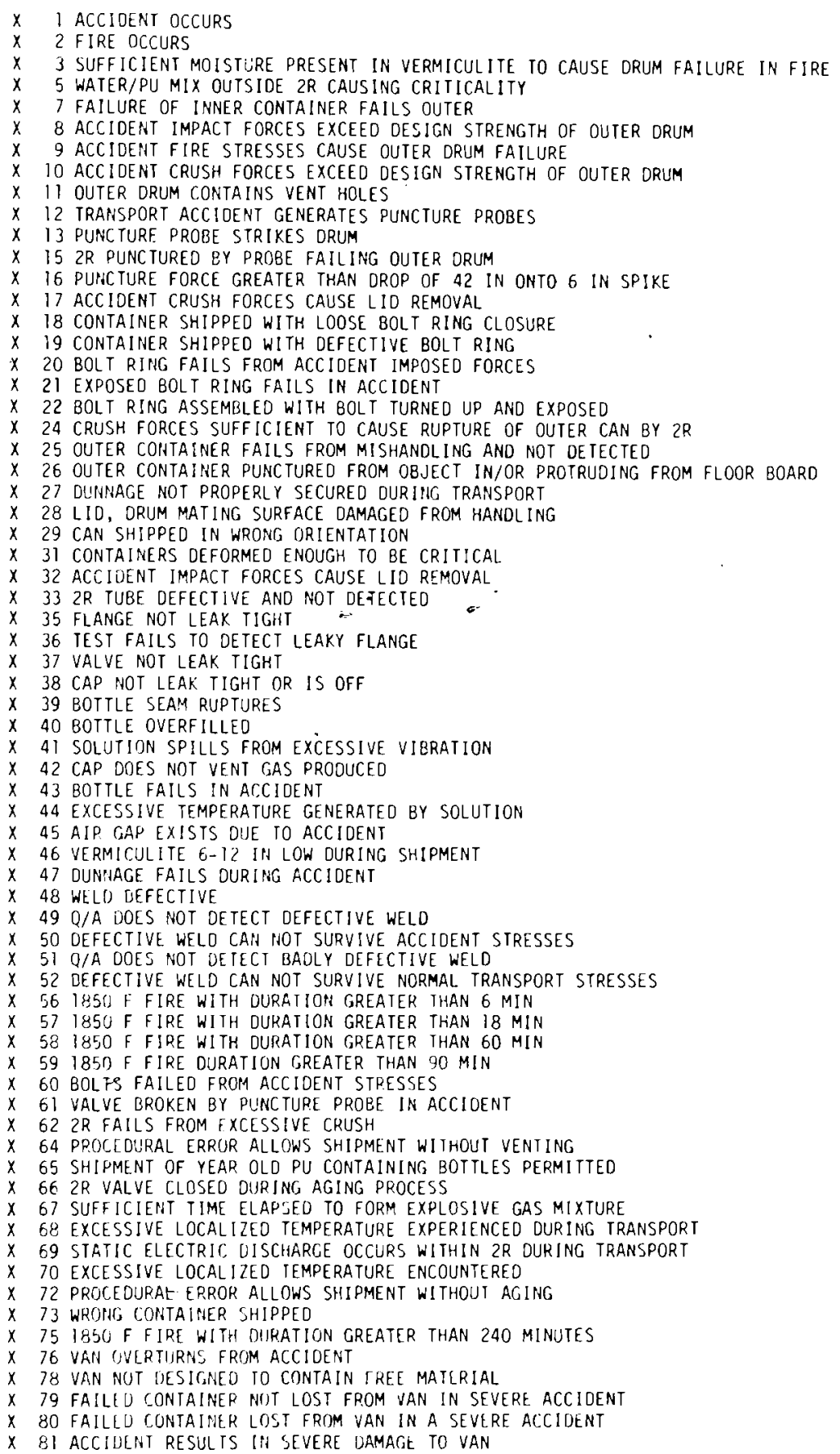




\section{3 BARRIER RELEASE SEQUENCES}

The fault tree can be thought of as a compact notation for identifying and displaying thousands of release sequences. There are several programs that can then develop lists of the release sequences.

These lists are frequently very long and very difficult to summarize for evaluaton. To overcome these difficulties a concept of barrier release sequences has been developed. The fault trees, shown in section 8.2, considered four barriers; the van, the outer drum of the package, the contain- . ment vessel, and the inner can or bottle. For a release of plutonium to the atmosphere to occur requires the concurrent failure of all four barriers. Thus combining a release sequence for one barrier with a release sequence for each of the other three barriers identifies a possible sequence of events which breach all the barriers. All release sequences can be obtained by permuting lists of barrier release sequences.

This procedure is quite powerful for understanding and analyzing the fault tree. For example, if there are four barriers and 25 release sequences for each barrier, then the more than 390,000 release sequences which would be obtained by permuting the list can be summarized in a list of 100 elements.

The barrier release sequence lists developed for the oxide shipment are shown in Table 8.3. In the table the items under heading "Sample Can" are the sample can barrier release sequences; those under the heading "2R" are the $2 R$ containment vessel barrier release sequences, etc. In the 1 ists elements are denoted by "A"S and "X"S with associated numerical designations. Elements which have further development in the fault tree are denoted with "A"s. The "X"s are basic conditions or events which are not developed further in the trees. The descriptive titles for the " $X$ " elements were given in Table 8.2; those for the "A" elements are given in Table 8.4. Corresponding information for the liquid nitrate shipment is given in Table 8.5 and 8.6 .

Some explanation of the evaluation method is required. In the oxide shipment barrier release sequence iists, Table 8.3, the first element under "Sample Can" is A051 which has the title "Sample Can Corrodes Thru During 


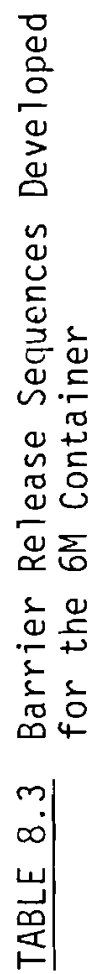

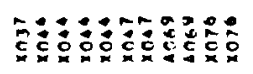

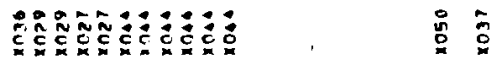

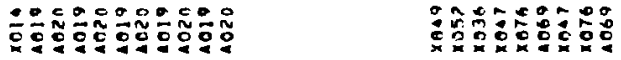

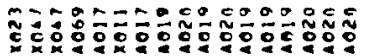

z)

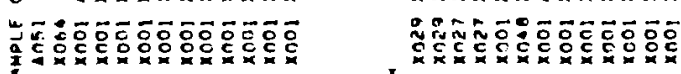

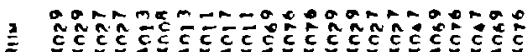

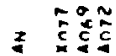

$\cong$

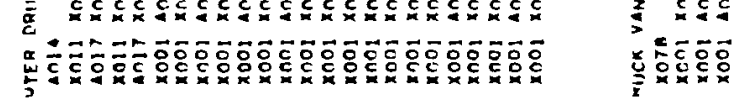




\section{TABLE 8.4 Listing of Input Labels for Rectangles for $6 M$ Container Analysis}

$\therefore$

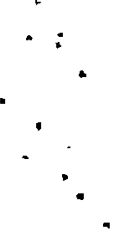

$\therefore$

$\therefore$

1 RELEASE OF PLUTONIUM TO ENVIRONMENT DURING 6M SHIPMENT

2 OUTER DRUM BARRIER DESIGN OR DEFECT PERMITS PASSAGE OF MATERIAL

3 OUTER DRUM BREACHED FROM INTERNAL PRESSURE

4 EXCESSIVE MOISTURE INSIDE OUTER DRUM CAUSES FAILURE

5 DRUM FAILS FROM FAILURE OF 2R CONTAINER

6 2R SIDEWALL RUPTURES FROM EXCESSIVE INTERNAL FORCES

7 GAS GENERATED INSIDE 2R CONTAINER

8 CRITICALITY OCCURS RUPTURING 2R CONTAINER

9 OUTER DRUM BREACHED AS A RESULT OF A TRANSPORT ACCIDENT

A 10 OUTER DRUM FAILS FROM EXCESSIVE EXTERNAL FORCES CAUSED BY ACCIDENT

A 11 OUTER DRUM FAILS FROM EXCESSIVE EXTERNAL ACCIDENT FORCES

A 12 ACCIDENT FORCES SUFFICIENT TO FAIL OUTER DRUM

A 13 OUTER DRUM PUNCTURED DURING ACCIDENT

A 14 OUTER ORUM DEFECTIVE DURING TRANSPORT

A 15 GM LOSES ORIENTATION DURING TRANSPORT

A 16 OUTER DRUM NOT LEAK TIGHT AND ORIENTATION LOST

A 17 OUTER DRUM NOT LEAK TIGHT DURING TRANSPORT FROM PACKAGE CLOSURE ERROR

A 18 ACCIDENT FORCES FAIL BOLT RING

A 19 BOLT RING FAILS IN ACCIDENT ENVIRONMENT

A 20 IMPROPERLY ASSEMBLED BOLT RING FAILS DURING AN ACCIDENT

A 21 2R THREADS FAIL DURING ACCIDENT AND ORIENTATION LOST

A 22 OUTER DRUM FAILS FROM EXCESSIVE INTERNAL FORCES DURING ACCIDENT

A 23 OUTER DRUM FAILS FROM EXCESSIVE INTERNAL FORCES DURING ACCIDENT

A 24 ACCIDENT GENERATES SUFFICIENT FORCE TO PUNCH $2 R$ THROUGH OUTER CONTAINER

A 25 2R NOT LEAK TIGHT ANO ORIENTATION LOST

A 26 OUTER DRUM NOT LEAK'TIGHT

\section{$:$}

A 27 ACCIDENT FORCES FAIL BOLT RING AND ORIENTATION LOST

A 28 ORIENTATION LOST FROM ACCIDENT

A 30 BREACH OF $2 R$ INNER CONTAINER OCCURS

A 31 2R FAILS FROM FORCES IMPOSED DURING TRANSPORT

A 32 2R RUPTURES FROM EXCESSIVE ACCIOENT FORCES

A 33 ACCIDENT GENERATES FORCES SUFFICIENT TO FAIL $2 R$ INNER PRESSURE YESSEL

A 34 PUNCTURE PROBES GENERATED BY ACCIDENT SUFFICIENT TO FAIL $2 R$ VESSEL

A 35 2R CLOSURE THREADS FAIL DURING AN ACCIOENT

A 36 ACCIDENT IMPOSES DESIGN LEVEL FORCES ON. THREADS

A 37 THREAD STRENGTH SIGNIFICANTLY BELOW DESIGN STRENGTH

A 38 PLUG CROSS THREADED AND NOT DETECTED

A 39 THREADS DAMAGED FROM PRIOR USE AND NOT DETECTED

A 40 2R CAP NOT LEAK TIGHT DURING TRANSPORT

A 41 CORROSIVE MATERIAL OUTSIDE SAMPLE CAN

A 45 DEFECTIVE WELD FAILS IN ACCIDENT

A 46 DEFECTIVE WELD FAILS IN NORMAL TRANSPORT

A 47 WELD FAILS DURING TRANSPORT

A 48 SAMPLE CAN CORRODES THRU FROM THE INSIDE

A 49 SAMPLE CAN CORRODES THRU FROM THE OUTSIDE

A 50 PLUTONIUM RELEASED FROM SAMPLE CAN DURING SHIPMENT

A 51 SAMPLE CAN CORRODES THRU DURING SHIPMENT

A 52 2R CORRODES THRU FROM THE OUTSIOE

A 53 2R CORRODES THRU DURING, SHIPMENT

A 54 2R CORRODES THRU FROM THE INSIDE

A 55 CORROSIVE MATERIAL INSIDE 2R

A 56 SAMPLE CAN BREACHEO BY EXCESS INTERNAL PRESSURE

A 57 CRITICALITY OCCURS AND RUPTURES SAMPLE CAN

A 58 SAMPLE CAN BREACHED FROM HANDL ING OR DURING TRANSPORT

A 59 SAMPLE CAI DAMAGLD DURING NORMAL TRANSPORT

A 60 SAMPLE CAN BREACHED DUE TO ACCIDENT

A 61 SAMPLE CAN PUNCTUREO WHEN $2 R$ VESSEL RUPTURES

A 62 SAMPLE CAN REMOVED FROM $2 R$ DURING AN ACCIDENT AND RUPTURED

A 63 SAMPLE CAII REMOVED FROM 2R DURING ACCIOENT

A 64 2R PLUG CLOSURE FAILS DURING TRANSPORT

A 65 VAN INEFFECTIVE BARRIER TO PREVENT RELEASE OF MATERIAL

A 66 VAN INEFFECTIVE BAPRIER AS A RESULT OF ACCIDENT

A 67 ACCIDENT FORCES BREACH VAN

A 68 ACCIDENT DAMACE TO VAN SUFFICIENT TO RESULT IN CONTAINER LOSS

A 69 VAN BREACHED ANID FAILED CONTAINER LOST

A 70 ORIENTATIOII CONTROL LOST

A 72 VAN BREACHED BUT FAILED CONTAINERS NOT LOST. 
TABLE 8.5 Barrier Release Sequences

Developed for the $L-10$

Container
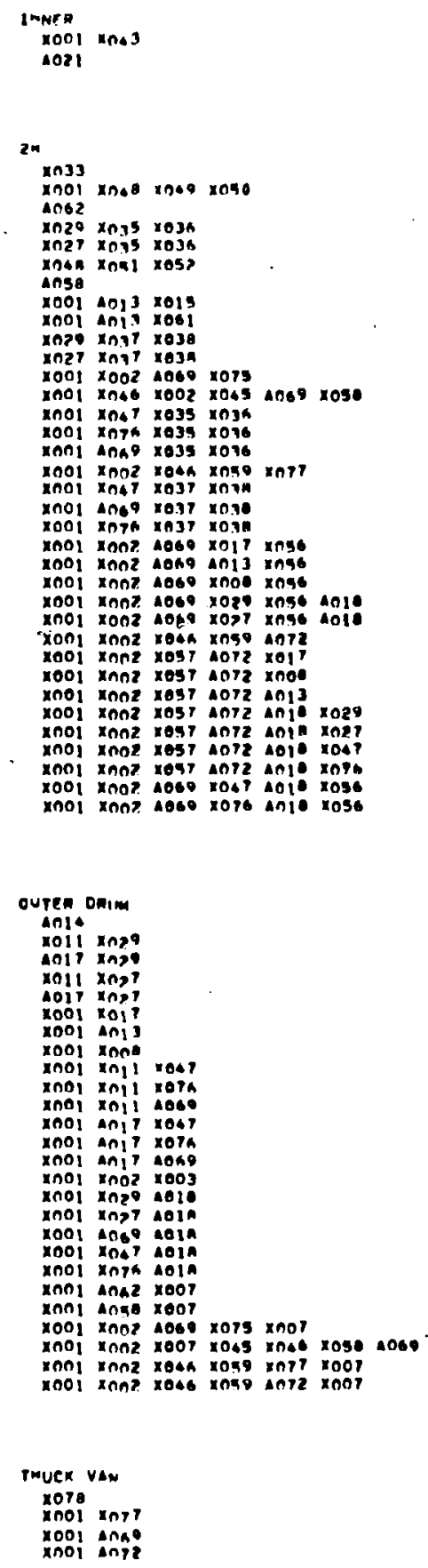


\section{TABLE 8.6 Listing of Input Labels for Rectangles for L-10 Container Analys is}

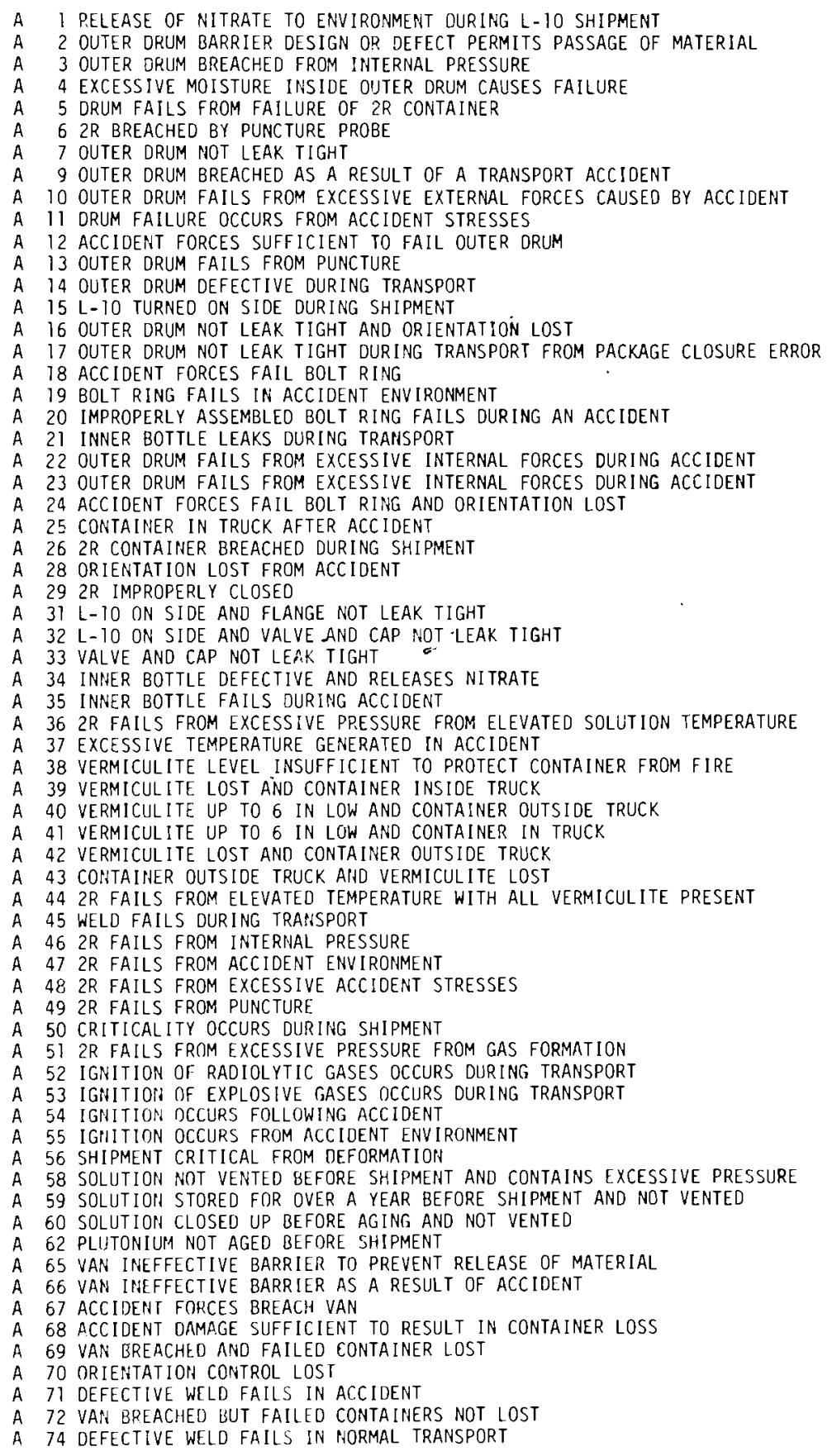


Shipment." In the fault tree, Figure 8.1, it can be seen that A051 is further developed into several basic elements. To shorten the barrier release sequence 1 ist, barrier release probabilities and fractions (see section 9) were evaluated for A051 rather than for the basic elements under A051. This procedure limits the detail available from the risk assessment but in no way affects the value of the risk.

Also in the barrier release sequence lists are many sequences which require multiple events or conditions to occur concurrently before a barrier release can occur. In one sequence in the "Outer Drum" 1ist, x001 entitled "Accident 0ccurs", is combined with X008 entitled "Accident Impact Forces Exceed Design Strength of Outer Drum". Both must occur concurrently for the outer drum to be breached by this barrier release sequence.

A release sequence is constructed by combining elements from each of the four barrier release sequence lists. Thus, as seen in Table 8.3, $A .051$, X029, X046, A014, and X073 comprise a release:-sequence for a plutonium oxide shipment.

If an element occurs more than once in a release sequence, it is not duplicated in the evaluation. For example, for the release sequence (A051) (X001, X046, X047) (X001, X008) (X001, A.069) it would be incorrect for X001 to enter more than once in the evaluation. If it entered more than once, this would be equivalent to saying that an accident could not simultaneously affect the three barriers. Thus the release sequence obtained from these four barrier release sequences is reduced to: X001, A051, X046, X047, X008, and A069 for analysis.

Although the procedure for generating release sequences from the lists of barrier release sequences is relatively straightforward, some care must be taken to ensure that sequences which are physically impossible cannot occur. For example, a container cannot be both inside and outside the van. These are quite easily sorted out through logic statements which do not allow conflicting basic failure events in a release sequence. This situation arises in the analysis of the $L-10$ shipment. The van condition enters 
into some of the evaluations for the integrity of inner barriers. Since a container cannot be both inside and outside the van, the element in the tree designated by A069 cannot coexist in the same release sequence with A072, $\times 077$, or $\times 078$. In the permuting of the barrier release sequence 1 ists to obtain release sequences, those which contain more than one van condition are eliminated from the list of allowable release sequences. 


\section{RELEASE SEQUENICE EVALUATION}

The previous chapter presented the fault trees for the truck shipment of plutonium as either the oxide in the $6 \mathrm{M}$ or the liquid nitrate in the L-10. From the fault trees, a long list of release sequences can be identified. For example, in the tree for liquid nitrate the occurrence of the following eight events is one release sequence which will result in a loss of liquid nitrate from the $L-10$ :

$\begin{array}{ll}\text { X1 } & \text { Accident Occurs } \\ \text { X81 } & \text { Accident Results in Severe Damage to Van } \\ \text { X17 } & \text { Accident Crush Forces Cause Lid Removal } \\ \text { X35 } & \text { Flange Not Leak Tight } \\ \text { X36 } & \text { Tests Fail to Detect Leaky Flange } \\ \text { X43 } & \text { Bottle Fails in Accident } \\ \text { X47 } & \text { Dunnage Fails During Accident } \\ \text { X80 } & \text { Failed Container's Lost from Van in a Severe Accidént }\end{array}$

The fault tree can be thought of as a compact notation for summarizing several thousand release sequences. These release sequences are the common element in the risk assessment. As shown in Figure 9.1, based on the release sequences, both the frequency and the release fraction must be determined for each release sequence. This section presents the basic data required to evaluate all release sequences.

Either of two approaches may be taken to evaluate the probability and consequences of a release during transport. The most direct and detailed evaluation would be obtained from a Monte Carlo computer simulation of the transport system. Shipments would travel along shipment routes until an accident occurs; then each container in the shipment would be evaluated for failure. This is a very efficient way to analyze events which occur frequently. However, as events occur less frequently, much longer running times on the computer are required to obtain the same degree of accuracy. The second approach analyzes a multi-container shipment essentially as if only one container is in the shipment. The analysis permits only one container failure in an accident but at an accident frequency multiplied by the number 


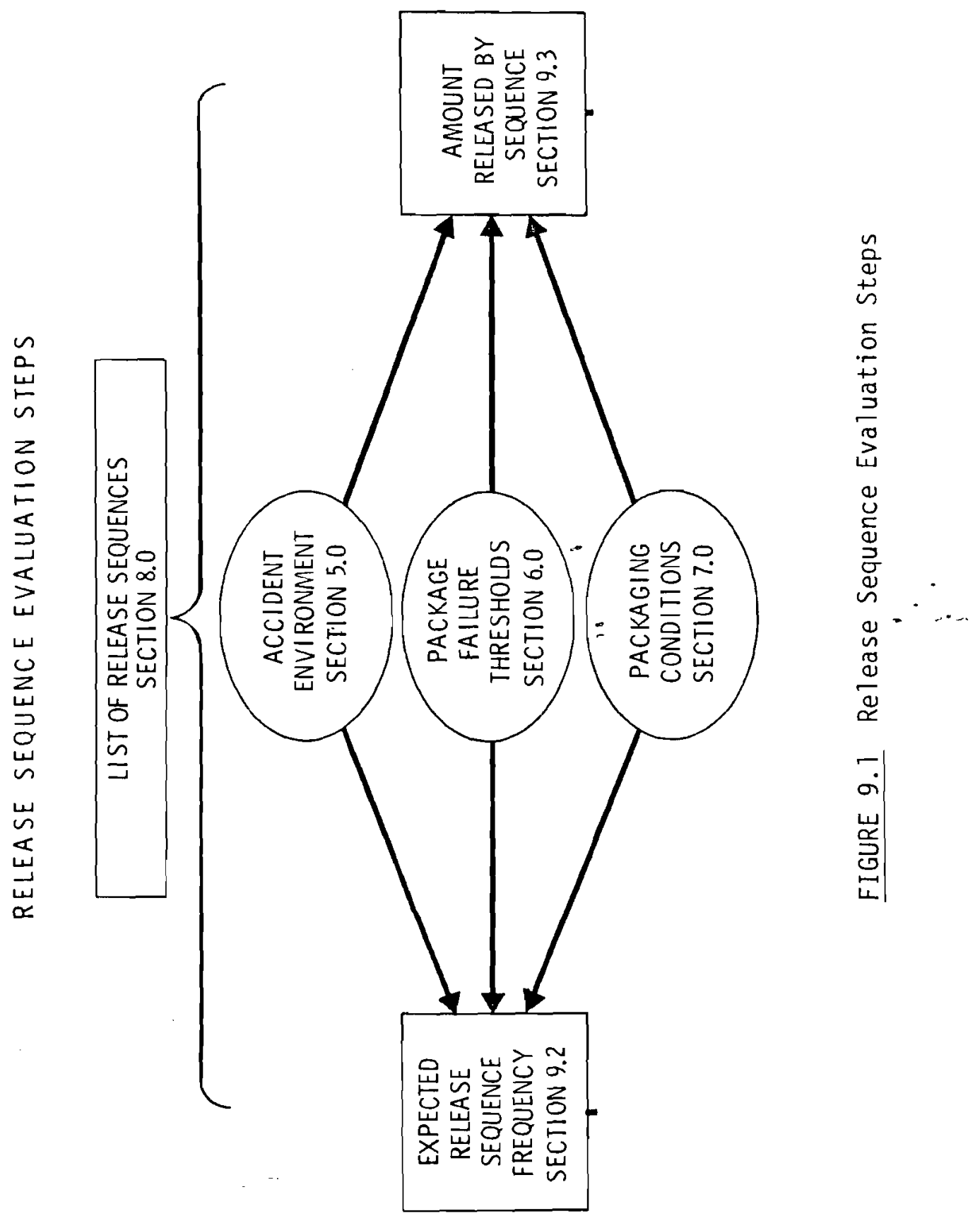


of containers in the shipment. This is a good assumption only when the failure rate is low. In this section, the release fractions and the occurrence frequency for events will be determined using the second method. The validity of the method is demonstrated in section 11 and Appendix $\mathrm{J}$.

The fundamental elemerits in the analysis are the basic event probabilities. The fault trees in section 8 were developed down to a point where data on basic events could be obtained either through analysis or survey. The basic event probabilities are presented in section 9.1 .

The probability data in section 9.1 is then used to develop the information on Barrier Release Sequence Probabilities summarized in section 9.2. Barrier Release Fractions are evaluated in 9.3, and section 9.4 summarizes the results of the chapter by showing how release sequences are evaluated from the barrier failure release fractions and probabilities.

\subsection{BASIC EVENT PROBABILITIES}

The following paragraphs provide two sequential lists of failure probability estimates. The first series is for oxide shipments in the $6 \mathrm{M}$ container. The second series is for the liquid nitrate shipment in the $L-10$. The numbering sequence corresponds to the numbering sequence shown in the fault trees. For ease of comparison, whenever possible, identical numerical designations were given to similar events in the two trees. This necessitated leaving some unused numbers in both lists. The justification for probability estimates which appear in both lists will be presented once and only referenced in the second list of failure probabilities.

\subsubsection{Shipment of $\mathrm{PuO}_{2}$ Powder in the $6 \mathrm{M}$ Container}

Events numbered from 1 to 81 were identified in the fault tree shown in Figure 8.2 of section 8 . Table 8.1 listed the events as they are titled and keyed in the fault tree. Occurrence frequencies for each event are presented in the following paragraphs:

Accident 0ccurs (X1). The accident frequency for truck transport of hazardous material is one accident every 400,000 miles, i.e., a rate of $2.5 \times 10^{-6}$ truck accidents per mile. (1) For shipping distance of 1500 
miles, the expected accident frequency is $3.8 \times 10^{-3}$ per shipment. This value is used in the analysis.

Fire 0ccurs $(x 2)$. Based on data from Sandia ${ }^{(2)}$ on the fire environment during truck accidents, the occurrence rate of fire is estimated to be 0.016 fires per truck accident.

Sufficient Moisture Present to Cause Outer Drum Failure in Fire (X3).

The plutonium receivers survey indicated no instances where water was present in the 6M containers. Even if water were present, the outer drum would not fail in a fire due to the limited free volume and the presence of vent holes. Therefore, the value of $x 3$ was set to zero for the $6 M$ evaluation.

Sufficient Moisture, Gas Present Inside 2R to Cause Failure in Fire (X4). Moisture present inside the $2 R$ could cause the $2 R$ to fail in a fire from excessive pressure buildup. However, there would have to be the equivalent of several hundred grams of water present for creation of sufficient pressure to fail the $2 R$ should it be involved in a fire. Since safeguard procedures require weighings and accountability during the loading operation, the accidental addition of several hundred grams of water could not go undetected. Thus, $X 4$ was set at zero.

Sufficient Moisture Present to Cause 2R Failure by Criticality (X5). The results presented in Appendix $G$ show that no amount of water inside or outside the $2 R$ will make the shipping array critical. Therefore, the value for this element was set at zero.

Criticality Occurs Due to Extreme Deformation in Accident (x6). The conservative analys is reported in Appendix $G$ shows that the array of containers is not critical even when deformed so that the $2 R$ inner vessels of the containers in successive rows are in contact. The data in Appendix $H$ shows that the forces required to deform a container to this extent are equivalent to a 260-ft drop onto an unyielding surface. Based on Equation 1 in section 6, a 260-ft drop is equivalent to a one million pound crush force. As shown under element $\times 10$, the crush forces produced under the most severe decelerations do not exceed 12,800 $1 \mathrm{~b}$ in any row of containers. Since the force decreases toward zero in rows behind the row experiencing the 
highest crush forces, the average crush force experienced by the shipment is approximately 8,000. Since the accident forces are not sufficient to produce the deformations required for a shipment to become critical, this element was set at zero.

Failure of Inner Container Fails Outer (X7). This element was conservatively set at 1.0 .

Accident Impact Forces Exceed Design Strength of Outer Drum $(x 8)$. Based on data from Sandia on the impact forces expected in an accident (2) and the threshold failure value for impact, the probability that a container will experience impact forces exceeding its design strength is estimated to be less than $10^{-5}$ per truck accident. A value of $10^{-5}$ per truck accident was used for $x 8$.

Accident Fire Stresses Cause Outer Drum Failure $(X 9)$. Fire stresses, acting alone, cannot fail the outer drum. No conditions which could cause failure, such as moisture in the Celotex ${ }^{R}$, were found in the plutonium receivers survey. Therefore, this element was set at zero.

Accident Crush Forces Exceed Design Strength of Outer Drum $(x 10)$. Based on the Sandia data on crush forces during an accident, summarized in section 5, a loading on the cargo of 20 times the acceleration of gravity is close to the expected upper limit imposed by accident crush forces. Assuming that an oxide shipment in $6 \mathrm{M}^{\prime}$ 's consists of four rows of containers five across and two high with alternate rows offset to form a hexagonal pitch, then the maximum force on any surface of any container is less than the weight of a container times the rate of deceleration times the number of containers behind $i t$. Using a weight of 160 1b for the container results in a crush force of about $12,800 \mathrm{1b}$. The container is designed to keep its integrity following a 30-ft drop onto an unyielding surface. The force on the side of the container during impact is over 50,000 1b. Since the failure threshold is about a factor of four greater than the expected maximum crush forces imposed by the accident environment, this element was set at zero. 
Outer Drum Contains Vent Holes (X11). All outer drums contain vent holes to permit heat dissipation. Therefore this element was set at 1.0.

Transport Accident Generates Puncture Probes (X12). Not all accidents generate puncture probes. Based on data from Sandia, ${ }^{(2)}$ the occurrence rate of shipping containers experiencing a puncture environment during an accident is estimated to be 0.2 per accident.

Puncture Probe Strikes Drum $(x 13)$. Based on data from Sandia on the puncture environment during an accident, ${ }^{(2)}$ the probability that a puncture probe will strike a drum is estimated to be 0.068 per accident involving a puncture environment. This value is derived from Sandia "soft" cargo puncture probability.

Force Which Breached $2 R$ Sufficient to Breach Sample Can (X14). Very high forces are required to breach the 0.25 inch thick $2 R$ container. The additional force required to rupture a sample can is very small in com-. parison. Thus a value of 1.0 was used for this element.

Sample Can Fails in Accident Environment (X15). Based on data from Sandia, (2) the probability that a sample can will fail if it is not protected from the accident environment by the $2 R$ is estimated to be 0.02 per container.

Puncture Probe Equivalent to Drop of $\geq 133$ in. onto a 6 -in. Spike $(x 16)$. In Appendix $H$, it is shown that a drop from at least $133 \mathrm{in.}$ onto a 6-in. spike is required to breach the outer drum of the 6M. The drop height is equivalent to a $V / R$ of $106 \mathrm{sec}^{-1}$. Based on the Sandia results, of the puncture probes which strike a container, those with a $V / R \geq 106$ $\mathrm{sec}^{-1}$ can be expected with a frequency of $2.2 \times 10^{-2}$ per container strike.

Accident Crush Forces Cause Lid Removal (X17). Based on the model for lid removal explained in section 6 , lid removal requires a minimum crush force of 54,000 lbs. At that point the drum deformation would permit the bolt ring to slip off. As shown for $\times 10$, the crush force generated in the most severe accident does not exceed 12,800 lbs. Thus $x 17$ was set at zero in this analysis. 
Container Shipped with Loose Bolt Ring Closure $(X 18)$. Based on the survey data presented in section $7,12 \%$ of all containers had bolt rings which were finger tight upon receipt. A tenth of an inch slack in the bolt ring is enough to make it loose. When this is compared with the 0.23-in. expansion required to remove the bolt ring, the loose ring is not a significant failure mechanism which is likely to remove the lid. However, it would provide an additional pathway for release if the material were free inside the drum. Thus, the value used for $X 18$ was $0.12 /$ container.

Container Shipped with Defective Bolt Ring (X19). Survey results indicate that $2 \%$ of the bolt rings fail when they are being tightened. This indicates that some bolt rings will be close to their failure point during a shipment. In this analysis $X 19$ was set at 0.02 failures/container involved in an accident.

Bolt Ring Fails from Accident Imposed Forces (X20). This element was included in X19. Therefore, it was set at zero, here.

Exposed Bolt Ring Failed in Accident (x21). The value of this element was estimated to be $4 \times 10^{-3}$ bolt ring failures per container invelved in an accident. It was estimated on the basis of the solid angle in which a probe must strike a protruding bolt to cause failure.

Bolt Ring Assembled with Bolt Turned Up and Exposed (X22). Based on the plutonium receivers survey, the occurrence rate of the bolt ring turned up during transport is estimated to be 0.05 per container.

Puncture Probe Longer than $11 \mathrm{in}$. and Force Equal to Drop of $300 \mathrm{in.}$ $(X 23)$. Calculations indicate that a drop of greater than 300 inches onto a 6 in. diameter spike is required to punch the $2 R$ container through the outer drum. This drop is equivalent to a $V / R$ of $160 \mathrm{sec}^{-1}$. In addition, the probe must be at least 11 inches long and it must strike the outer drum in an area where penetration will result in striking the bottom or top of the $2 R$ vessel. Based on the data presented in Figure 5.2, of the probes with $V / R$ greater than $106 \mathrm{sec}^{-1}, 0.64$ can be expected to have a $V / R$ greater than $160 \mathrm{sec}^{-1}$. Use of this factor for $X 23$ would be very conservative because the probes must have both the energy and the length 
needed to punch the $2 \mathrm{R}$ out through the outer drum. Based on the theory of barrier penetration described in the Sandia report ${ }^{(2)}$ two probes with the same $V / R$ striking the container at the same angle of attack but having different lengths do not have the same puncture capability. The longer probe is more likely to strike the container and ricochet off, converting much of the energy associated with the strike into angular momentum. The theory developed by Sandia states that the acceptance angle of the probe (the angle, between the probe and the normal vector of the surface, below which penetration occurs) is inversely proportional to the length of the probe. The data presented in Figure 5.2 was obtained using a probe with a mean length of $4-i n$. Since the probe needed to push the $2 R$ through the drum must be at least $11 \mathrm{in.}$ long, the expected frequency of such probes is $4 / 11$ of the frequency of probes used in generating Figure 5.2. Thus the 0.64 value for meeting the $V / R$ criterion must be reduced by $4 / 11$. The fraction of probes striking the bottom or top of the drum and then striking the $2 R$ is proportional to their rêlative cross sections $=0.11$. Thus the expected frequency for punching the $2 \mathrm{R}$ through the outer drum was set at $0.64 \times 4 / 11 \times 0.11$, which equals 0.026 per puncture of the outer drum.

Crush Forces Sufficient to Cause Rupture of Outer Can by $2 R(X 24)$. Crush forces in the accident environment are not severe ennugh to fail the outer container. Even larger forces are required to force $2 \mathrm{R}$ through the outer can. Therefore this element was set at zero.

Outer Container Fails from Mishandling and Not Detected (X25). Based on the plutonium receivers survey, the probability that a container will have an undetected breach during transport is estimated to be $2 \times 10^{-3}$ per container.

Outer Container Punctured from Object in/or Protruding from Floor Board ( $x 26)$. No distinction could be made between $\times 25$ and $\times 26$ from the survey results. Therefore both events were included under $\times 25$ and this element was set at zero.

Dunnage Not Properly Secured During Transport (X27). Of the 775 shipments covered in the plutonium receivers survey, none had improperly 
secured dunnage. However, because of the limited number of shipments, no failures does not necessarily mean that the probability of failure in future shipments is zero. Assuming a constant probability of failure, no failures in 775 shipments indicates a failure rate of less than $9 \times 10^{-4}$ per shipment at the $50 \%$ confidence level. A value of $9 \times 10^{-4}$ per shipment was used for $\times 27$.

Lid, Drum Mating Surface Damaged from Handling (X28). The plutonium receivers survey indicated that although some containers showed visible surface damage, no defects in the lid, drum mating surface of approximately 3400 drum-type containers were noted. Assuming. a constant probability of damage, no defects in 3400 containers indicates a damage rate of less than $2 \times 10^{-4}$ per container at the $50 \%$ confidence level. A value of $2 \times 10^{-4}$ per container was used for $\times 28$.

6M Shipped in Wrong Orientation (X29). The plutonium receivers survey indicated that of approximately 6200.packages received, none had been.shipped in the wrong orientation. Assuming a constant probability of misorientation, no wrong orientations of 6200 containers indicates a misorientation rate of less than $10^{-4}$ per container at the $50 \%$ confidence level. A value of $10^{-4}$ per container was used for $\times 29$.

$(\times 30)$ and $(\times 31)$. Not used.

Accident Impact Forces Cause Lid Removal (X32). This element was included in $\times 19$. Therefore it was set at zero here.

Impact Forces From Accident Sufficient to Fail 2R Vessel (X33). As indicated in $X 8$ the probability of failure of the $6 M$ outer drum by impact in an accident is less than $10^{-5}$ per accident. A significantly greater force level would be required to also fail the $2 R$ vessel by impact. Thus, the probability of $2 R$ vessel failure from impact is essentially zero. This element was set at zero.

Fire Stress from Accident Sufficient to Fail 2R (X34). The material being shipped is stable at high temperatures. Thus there is insufficient stress generated in a fire to cause failure. For this reason X34 was set at zero. 
Accident Imposed Crush Force Exceeds 2R Design Strength (X35). As shown in $\times 10$ and $\times 17$, crush forces are insufficient to cause substantial damage to the outer drum. Thus the $2 R$ is protected from the crush environment, and $\times 35$ was set at zero.

Puncture Probe Strikes 2R Container During an Accident (X36). The evaluation of $X 36$ and $X 37$ parallels the evaluation performed in $X 23$. Only non-bending probes at least 8-in. long can strike the 2R container. Furthermore, the $2 R$ container does not extend the full height of the outer drum of the $6 \mathrm{M}$ container. The fraction of the centerline of the outer drum occupied by the $2 \mathrm{R}$ is $14 \mathrm{in.} / 21.5 \mathrm{in} .=0.65$. Since the acceptance angle of the probe decreases linearly with probe length and the puncture data presented in Section 5 is based on a mean probe length of 4 in., half the probes used in generating the data presented in Section 5 cannot be included in an evaluation of $2 R$ puncture. Thus, of the probes failing the outer drum, the expected frequency of strikes at the proper angle for penetration.. of the $2 R \times 36$ was set at $0.65 \times 0.5=0.33$ per puncture of the outer drum.

Puncture Force Equivalent to Drop of $\geq 170$ In. onto a 6 -In. Spike $(\times 37)$. Based on the data shown in Figure 5.2, of the probes capable of piercing the outer drum ( $\geq 133 \mathrm{in}$. drop onto a $6 \mathrm{in}$. spike, which is equivalent to a $\left.V / R=106 \mathrm{sec}^{-1}\right) 0.9$ will have sufficient additional energy to breach the $2 R$ ( $>170 \mathrm{in}$. drop onto a $6 \mathrm{in}$. spike, which is equivalent to a $V / R=121$ $\sec ^{-T}$ ). Thus the expected frequency for $X 37$ was set at $0.92 R$ failures per strike of the $2 R$ by a puncture probe.

Accident Imposes Design Level Forces on Threads (X38). Forces on threads are expected to be inward acting and would tend to jam the plug on more tightly rather than remove it. Therefore, this element was set at zero.

Improper Fit Between Male and Female Threads (X39). This element was set at zero. It is included in $\times 42$.

Plug Cross Threaded (X40). This element is one possible cause of thread damage. Statisitics from the survey are included in $\mathbf{4} 42$. This element was set at zero. 
Cross Threaded Threads Not Detected $(X 41)$. This element was set at zero. It is included in $\mathrm{X} 42$.

Threads Damaged from Use or Repair (X42). Based on the plutonium receivers survey and LLD statistics, the occurrence rate of the container having damaged threads during shipment is estimated to be $2 \times 10^{-4}$ per container.

Poor Threads Not Detected Before Use (X43). The value of this element was set at 1.0 since the value for $X 42$ is based on use of $2 R$ vessels with damaged threads.

Plug Unscrews During Transport $(X 44)$. Based on the plutonium receivers survey including LLD statistics, the occurrence rate of the $2 R$ plug unscrewing during transport is estimated to be $4 \times 10^{-4}$ per container.

$2 R$ Leaks when Properly Closed (X45). This event is included in the $X 46$ value. Therefore, its value was set at zero here.

Plug Loosens During Transport $(X 46)$. Based on the plutonium receivers survey, the occurrence rate of $2 R$ plugs being loose during transport is 0.2 per container.

Dunnage Fails During Accident (X47). According to the Sandia data (2) less than ten percent of all accidents result in decelerations greater than five times normal gravity. Since the dunnage is designed only to secure the cargo during normal transport, these decelerations are assumed to caluse the dunnage to fail. Thus the value of $0.1 /$ accident is assigned to this failure element.

Weld Defective $(X 48)$. Experience at Battelle-Northwest indicates that about 2 feet of every 100 feet of weld requires repair to meet the quality standards for this type of equipment. Since close to 2 feet of weld is required to attach the bottom to the $2 \mathrm{R}$ pipe, a value of 0.02 per container was used for this element.

Q/A Does Not Detect Defective Weld (X49). Inspection, testing and record keeping requirements should make the likelihood of missing a defective weld in quality assurance procedures essentially zero. However, because 
of 1 imited experience a value of $10^{-3}$ per container with defective weld was used for this element.

Defective Weld Cannot Survive Accident Stresses $(X 50)$. The $2 \mathrm{R}$ vesse 1 is protected from all but the very severe accident stresses by the outer drum and the Celotex ${ }^{R}$ insulation. Therefore, the weld should survive accidents less severe than, e.g., puncture of the outer drum llikelihood of less than $10^{-3}$ per accident). A value of $10^{-3}$ per defective weld-accident was used for $\times 50$.

$Q / A$ Does Not Detect Badly Defective Weld $\left(x_{51}\right)$. This element is used in the analysis in combination with element $\mathrm{x} 52$, Defective Weld Can Not Survive Normal Transport Stresses. The only normal transport stresses that might affect the weld are minor jostling and vibration. Any weld so defective that it would not be able to withstand normal transport stresses would shown obvious defects and could not escape detection by quality assurance procedures. In addition; 10 CFR Part 71 , Subpart $D$ requires .. shippers to determine, prior to initial use and each subsequent use, that the packaging has no significant defects. Based on these considerations a value of zero was used for $\times 51$.

Defective Weld Cannot Survive Normal Transport Stresses (X52). It was conservatively assumed that the probability of a badly defective weld failing under normal transport stresses was 1.0 per badly defective weld.

$(\times 53)$ and $(\times 54)$. Not used.

Sufficient Time for Sample Can to Corrode (X55). The sample can is thin walled. Therefore, it was conservatively assumed that if corrosive material were present there would be sufficient time during transport for it to corrode through the sample can. A value of 1.0 was used for $\times 55$.

Corrosive Material Present Outside $2 \mathrm{R}(X 56)$. The plutonium receivers survey indicated that of approximately 6200 packages received, none had any significant corrosive material present outside the $2 R$ vessel. Assuming a constant probability for the presence of corrosive material, no occurrences in the shipment of 6200 containers indicates an occurrence rate of less 
than $10^{-4}$ per container at the $50 \%$ confidence level. A value of $10^{-4}$ per container was used for $\times 56$.

Sufficient Time Available to Corrode 2R (X57). Although there has been some failure of sample cans, possibly due to corrosion, time in transit and material are inadequate to fail the $2 R$. Therefore, this element was set at zero.

Corrosive Material Present in $\mathrm{PuO}_{2}\left(\mathrm{X}_{58)}\right.$. The plutonium receivers survey did not specifically indicate any instances where corrosive material was present in the $\mathrm{PuO}_{2}$. However, it did reveal three instances in the receipt of about $40006 M$ and LLD-1 packages where the sample can was breached or not completely sealed. The cause of the breaches was not determined. Although improper closure is considered the most likely cause of breach, the breaches could have been caused by corrosion. Since, in time, corrosion could potentially lead to greater consequences (failure of the $2 R$ container) than improper closure of the sample can, for this analysis the breaches were all assumed to be due to corrosion. Therefore a probability of $8 \times 10^{-4}$ was used for $\times 58$.

Corrosive Material Inside $2 R(X 59)$. In the analysis, it is assumed that there is sufficient time during transport for the thin-walled sample can to corrode through if corrosive material is present. Thus, it makes essentially no difference whether the corrosive material is initially in the $\mathrm{PuO}_{2}$ or inside the $2 \mathrm{R}$ container. The sample can breaches referred to in $\times 58$ could have resulted from either internal or external corrosive action. The occurrence probability for this element is included in $\times 58$. Therefore, it was set at zero here.

Sample Can Improperly Closed (X60). The sample can failures indicated in the plutonium receivers survey could have been caused by improper closure or corrosion. The occurrence probability for this element is included in x58. Therefore, it was set at zero here.

(X61) through $(\times 63)$. Not used. 
Gas Generated by Material Present in Can (X64). Based on the plutonium receivers survey using both $6 M$ and LLD statistics, the occurrence rate of gas generation in the sample can during transport is estimated to be $5 \times 10^{-4}$ per container.

Criticality Causes Rupture of Sample Can (X65). If criticality occurs, the sample can will rupture. Therefore this element was set at 1.0.

Wrong Sample Can Used for Transport (X66). Cans which are too large or too smal1 could be more susceptible to damage during transport. In the survey results, the cause of the sample can damage included under $X 58$ in this evaluation was not ascertained. One reason could have been use of the wrong cans. In this evaluation the failure data was included under $\times 58$ and set at zero here.

Sample Can Damaged Before Loading and Not Corrected (X67). The survey results could not determine the cause of sample can failure. Therefore the element was included in $\times 58$ statistics.

Sharp object in 2R Container (X68). This event is included in the X58 value. Therefore $i$ ts value was set at zero here.

Sample Cans Damaged by 2R Plug Closure (X69). This event is included in the $X 58$ value. Therefore its value was set at zero here.

Sample Cans Not Properly Packed in $2 R(X 70)$. This event is included in the $X 58$ value. Therefore its value was set at zero here.

Shipping Container Dropped Dropped During Transport $(x 71)$. This event is included in the $x 25$ value. Therefore its value was set at zero here.

(X72) through (X75). Not Used.

Van Overturns from Accident (X76). Of the truck accidents, $8 \%$ are caused by overturn. Other accidents can aiso end in overturn. This secondary factor is not normally compiled in accident summaries. One possible source of information is the annual "Summary of Accident Investigations" prepared by the Bureau of Motor Carrier Safety. This report summarizes the investigations of a few hundred of the hundreds of thousands 
of truck accidents occurring annually. Although the accidents investigated appear to represent spectacular incidents, it would probably take these types of accidents to release material from a container. Based on the 512 accidents investigated in 1970 and 1971 , 9\% of a11 collisions with cars ended with truck overturn, $16 \%$ of all collisions with trucks ended with overturn, and $40 \%$ of a 11 collisions with fixed objects ended in overturn. of all the truck accidents, $55 \%$ are with cars, $17 \%$ involve other trucks, $20 \%$ are with fixed objects, and $8 \%$ are overturns. These percentages are based on Sandia data. ${ }^{(2)}$ Adding the overturn contribution for each category, one obtains a frequency of 0.2 overturns per accident. This value was used in the analysis.

Accident Damage to Van Is Moderate (X77). The criterion used to judge when an accident has occurred is mainly based on economics. If damage from the incident is likely to exceed $\$ 250$ then it is reported. Using this criterion, Sandia estimated that 0.11 accidents result in no van damage. On the other end of the spectrum, 0.068 accidents $\ddot{\hat{r}}$ esulted in loss of containers from the van. The spectrum of accidents excluding these two extemes are included under this failure element. Thus, the expected frequency of occurrence of moderate van damage is estimated to be 0.83 per truck accident.

Van Not Designed to Contain Free Material (X78). At present this event is always applicable. Thus a value of 1.0 was used as the fraction of the vans not designed to contain free material (loose plutonium oxide).

Failed Containers Not Lost from Van in a Severe Accident (X79). In this analysis, a severe accident is defined as one in which some of the cargo is lost from the van. Sandia estimates that the likelihood that a container will remain in the van following a severe accident is 0.67 per severe accident as defined in (X81). There is no information to suggest that a failed container is more likely to be lost from the van. than is an intact container. Thus the value of 0.67 for the frequency of containers remaining in the van following a severe accident is applied to all containers in a shipment. 
Failed Containers Lost from Van in a Severe Accident (X80). This failure element is the reverse of $X 73$. A value of 0.33 per severe acc $i$. dent is used for the likelihood that a failed container will be lost from the van.

Accident Results in Severe Damage to Van (X81). Any accident in which containers are lost from the van is considered to be a severe accident. Sandia estimates that in $6.8 \%$ of all accidents, some cargo is lost from the van. Thus the expected frequency of occurrence of this failure element is 0.068 per accident.

\subsubsection{Shipment of Liquid Pu(NO${ }_{3} L_{4}$ in L-10 Containers}

The analysis of the L-10 parallels the $6 \mathrm{M}$ evaluation summarized in section 9.1.1. The 1ist of basic events were shown in Table 8.2. Wherever possible the events have been numbered and titled to be the same as the identical elements in the 6M. Rather than repeat the justification for the use of an identical event probability, the reader will be referred to the $6 M$ evaluation.

Accicient 0ccurs $(X 1)$. A value of $3.8 \times 10^{-3} /$ shipment was used. This corresponds to value used in $6 M$ analysis.

Fire Occurs (X2). A value of $0.016 /$ accident was used. This corresponds to value used in $6 M$ analysis.

Sufficient Moisture Present in Vermicul ite to Cause Drum Failure in Fire (X3). Vaporization of water in the L-10 outer drum resulting from a fire could cause overpressurization and failure of the drum. The plutonium receivers survey results indicate that the probability of the presence of water is $5 \times 10^{-4}$ per container. This value was used for $\times 3$.

(X4). Not Used.

Water/Pu Mix Outside 2R Causing Criticality (X5). Criticality is not possible in a dry L-10 container in which the solution inside the $2 R$ leaks into the outer drum. Criticality is not possible by adding water to the outer drum of the $L-10$ container so long as plutonium remains in the $2 R$ vessel. There does exist however, a narrow envelope of conditions wherein 
criticality is possible. The conditions require both the addition of some water to the outer drum and the leakage or the presence of plutonium solution out of the $2 R$ vessel. The survey of packaging conditions during transport indicates that the probability of water in the outer drum is $5 \times 10^{-4}$ per container. Instances have been reported where there was plutonium contamination in the vermiculite but these involved only trace levels of material. In the receipt of 2130 plutonium nitrate solution packages there have been no instances where any critically significant quantity of plutonium was present in the outer drum. Assuming a constant probability of pressure vessel leakage, no occurrences in 2130 containers received indicates an occurrence rate of less than $3 \times 10^{-4}$ per container at the $50 \%$ confidence level. Therefore the probability of plutonium and water mixing in the outer drum is less than $2 \times 10^{-7}$. Even if it did occur, the probability of such a mixture being in the right proportions to cause criticality is also extremely sma11. Hence the probability that plutonium and water will mix in the outer drum in the right proportions to cause criticality is essäentially zero. For this analysis $x 5$ was set to zero.

(X6). Not Used.

Failure of Inner Container Fails Outer (X7). A value of 1.0 was conservatively used for this element.

Accident Impact Forces Exceed Design Strength of Outer Drum (X8). Based on data from Sandia on the impact forces expected in an accident ${ }^{(2)}$ and the threshold failure value for impact, the probability that a container will experience impact forces exceeding its design strength is estimated to be $10^{-5}$ per truck accident. A value of $10^{-5}$ per truck accident was used for $x 8$.

Accident Fire Stresses Cause Outer Drum Failure (X9). Fire stresses, acting alone, cannot fail the outer drum. Thus this element was set at zero.

Accident Crush Forces Exceed Design Strength of Outer Drum (X10). As was the case in the $6 M$ analyses, the design strength of the outer drum wall is not exceeded during an accident. Thus this element was set at zero. 
Outer Drum Contains Vent Holes (X11). Vent holes are provided in a11 containers to aid in heat removal. Thus this element was set at 1.0.

Transport Accident Generates Puncture Probes (X12). As in the 6M analysis, the expected frequency of accidents where puncture probes are present is $0.2 /$ accident.

Puncture Probe Strikes Drum (X13). As in the 6M analysis, the expected frequency with which a puncture probe will strike a container is $0.068 /$ accident involving a puncture environment.

(X14). Not Used.

2R Punctured by Probe Failing Outer Drum (X15). Based on the results presented in Appendix $H$, a drop of 100 in. onto a 6-in. diam spike could potentially fail the $2 R$ container in the $L-10$. This corresponds to a $V / R$ of $92 \mathrm{sec}^{-1}$. Based on the results shown in Figure 5.2, of the probes breaching the outer $\operatorname{drum}\left(V / R=60 \mathrm{sec}^{-1}\right)$ the expected frequency of probes .... with a $V / R \geq 92 \mathrm{sec}^{-1}$ is 0.76 . If this value were used for $\times 15$, a very conservative result would be obtained because two additional factors must be included in the analysis. First, the probe must be long enough to breach the outer drum and strike the $2 R$ container. Second, the probe must pierce that fraction of the centerline of the outer drum cylinder which is occupied by the $2 R$.

Based on the penetration theory developed by Sandia, (2) two probes with the same $V / R$ striking the container at the same angle of incidence but having different lengths do not have the same puncture capability. The longer probe is much more likely to strike the container and ricochet off, converting much of the energy associated with the strike into angular momentum. The Sandia theory states that the acceptance angle of a probe (the angle, between the probe and the normal vector to the surface, below which penetration occurs) is inversely proportional to the length of the probe. The data presented in Figure 5.2 was obtained using a probe with a mean length of 4 in. To strike the centerline it must be $12 \mathrm{in.}$ long. The $12 \mathrm{in.}$ long probe with a $V / R$ in excess of $60 \mathrm{sec}^{-1}$, striking the outer drum, will penetrate with a 
frequency $1 / 3$ that of the probes used in generating Figure 5.2. Thus the 0.76 value for meeting the $V / R$ criterion must be reduced by $1 / 3$. The fraction of probes piercing the centerline of the drum in the region occupied by the $2 R$ pressure vessel is proportional to their relative heights, $i . e$. , $52 \mathrm{in.} / 69 \mathrm{in}$. When this factor is included, the expected frequency of $2 \mathrm{R}$ failure by puncture is 0.19 per puncture of the outer drum.

Puncture Force Equivalent to Drop of $\geq 42$ in. onto 6 in. Spike $(x 16)$. Based on the analysis in Appendix $H$, the outer drum of the $L-10$ will be punctured by a drop of $42 \mathrm{in.}$ onto a $6-\mathrm{in}$. spike. This corresponds to a $V / R$ of $60 \mathrm{sec}^{-1}$. Based on puncture probe data shown in Figure 5.2, failure of the outer drum will occur with an expected frequency of 0.032 per container struck with a puncture probe.

Accident Crush Forces Cause Lid Removal (X17). Lid removal is calculated to occur whenever the crush force exceeds $111,0001 \mathrm{~b}$. For the normal cargo arrangement, three across and one high, the first row in the shipment of 50 containers will fail in accidents with cärgo decelerations greater than 13 times gravity. Based on Figure 5.1, greater cargo decelerations can be expected in $0.7 \%$ of a 11 accidents. However, not a 11 the containers in the shipment will fail. By integrating the effect of all accidents with decelerations greater than 13 times gravity, an average of $10.6 \%$ of the containers will experience lid removal (see Appendix $J$ ). Thus the expected frequency that any one container will experience 1 id removal as a result of excessive crush forces generated during an accident is $0.007 x$ 0.106 or $7.4 \times 10^{-4}$ per accident.

Container Shipped with Loose Bolt Ring Closure (X18). The plutonium receivers survey indicated no instances in the receipt of $2130 \mathrm{~L}-3$ and $L-10$ containers where the bolt ring closure was loose. Assuming a constant probability of occurrence, no loose bolt ring closures in the shipment of 2130 containers indicates an occurrence rate of less than $3 \times 10^{-4}$ per container at the $50 \%$ confidence level. A value of $3 \times 10^{-4}$ per container was used for $\times 18$. 
Container Shipped with Defective Bolt Ring (X19). Based on the plutonium receivers survey including the 611 statistics, the occurrence rate for a container with a defective bolt ring was estimated to be $0.02 /$ container.

Bolt Ring Fails from Accident Imposed Stresses (X20). Included in X19 for the reasons given in the 6M evaluation.

Exposed Bolt Ring Failed in Accident (X21). This value was estimated to be $3 \times 10^{-3}$ bolt ring failures per container involved in an accident. It was estimated on the basis of the solid angle in which a probe must strike a protruding bolt to cause failure.

Bolt Ring Assembled with Bolt Turned Up and Exposed (X22). Based on the plutonium receivers survey, the occurrence rate for a container being assembled with an exposed bolt ring is estimated to be $2 \times 10^{-2}$ per container.

$(\times 23)$. Not Used.

Crush Force Sufficient to Cause Rupture of Outer Can by $2 R(X 24)$. Other failure modes, such as 1 id removal (X17), occur at a lower threshold than this element. Therefore this element does not affect the analysis, and its value was set at zero.

Outer Container Fails from Mishandling and Not Detected (X25). Based on thie plutonium receivers survey including the 6l: statistics, the occurrence rate of shipping an L-10 container with a failed drum is estimated to be $2 \times 10^{-3}$ per container.

Outer Container Punctured from Object in/or Protruding from Floor Board (X26). Included in X25 because the survey did not determine actual cause of failures reported under $\times 25$. Therefore this element was set at zero.

Dunnage Not Properly Secured During Transport (X27). As in the 6M evaluation, a value of $9 \times 10^{-4}$ per shipment was used for $\times 27$.

Lid, Drum Mating Surfaces Damaged from Handling (x28). Based on the survey of plutonium receivers, although some containers showed visible surface damage, no defects in the 1 id, drum mating surfaces were noted. As 
in the 6M evaluation, because of the limited number of containers surveyed, a value of $2 \times 10^{-4}$ per container was used for $\times 28$.

Can Shipped in Wrong Orientation (X29). As in the $6 M$ evaluation, a value of $10^{-4}$ per container was used for $\times 29$.

(X30). Not Used.

Containers Deformed Enough to be Critical (X31). The conservative analysis presented in Appendix $G$ shows that the array of containers in the shipments is not critical even when deformed to an 8-in. center-to-center spacing between successive rows of containers. In a normal 92-in.-wide trailer, the normal center-to-center distance between rows is 19.18 in. In order to reduce the distance to 8 in., each contact point must be deformed $3.85 \mathrm{in}$. Based on the data presented in Figure $H_{.1}$ in Appendix $H$, a drop from $126 \mathrm{ft}$ would be required to obtain this deformation. This value was obtained by considering the effect of the vermiculite and the bird cage. Using Equation 1 in section 6 , it is found that this drop.height is equivalent to a crush force of 200,000 1b. The maximum crush force in any accident, caused by a $20 \mathrm{~g}$ deceleration, is $173,4001 \mathrm{~b}$. Thus the crush forces are not sufficient to deform even the first row into a critical configuration. Therefore, the value of $\times 31$ used in this analysis was set at zero.

Accident Impact Forces Cause Lid Removal (X32). This element was included in $\times 19$. Therefore, it was set at zero here.

2R Tube Defective and Not Detected (X33). Shippers are required to make certain $Q A$ determinations on the packages prior to each use. These include determination that the containment ability of the $2 R$ pressure vessel under the normal maximum operating pressure is adequate and determination that the package has not been significantly damaged. These checks will detect any pressure vessel so defective that it would release its contents under normal transport conditions. Therefore a value of zero was used for $\times 33$.

(X34). Not Used. 
Flange Not Leak Tight (X35). Based on the plutonium receivers survey, the occurrence rate of gaskets being left out or otherwise not leak tight is estimated to be $10^{-3}$ per container.

Test Fails to Detect Leaky Flange (X36). This element was set at 1.0 since data in $\times 35$ is based on tested containers.

Valve Not Leak Tight (X37). Based on the plutonium receivers survey, the occurrence rate of an open vent valve during shipment is estimated to be $8 \times 10^{-3}$ per container.

Cap Not Leak Tight or Is off $(\times 38)$. Based on the plutonium receivers survey, the occurrence rate of the cap being left off or being loose upon receipt is estimated to be $8 \times 10^{-3}$ per container.

Bottle Seam Ruptures (X39). In the experience of the plutonium receivers there were a few instances where the bottle had apparently failed during transport. These are included in the Plutonium Solution Outside Plastic Bag category in Table 7.3. However, मno information was obtained on how the plutonium got outside the bottle. Therefore this element was set at zero and all failures included in $\times 41$.

Bottle Overfilled (X40). For the reasons given under $\times 39$, this element was set at zero and all failures included in $\times 41$.

Solution Spills from Excessive Vibration (X41). Based on the survey results, the expected frequency of plutonium solution outside the plastic bag is $0.005 /$ container. This value was used for the combination of $\times 39$ through $\times 42$.

Cap Does Not Vent Gas Produced (X42). Included in the X41 occurrence rate. Therefore the value was set at zero here.

Bottle Fails in Accident (X43). The value for this element was conservatively assumed to be 1.0 .

Excessive Temperature Generated by Solution (X44). Temperatures inside the container are nominal so long as no external heat source is added. Therefore this element was set at zero. 
Air Gap Exists Due to Accident (X45). Based on the plutonium receivers survey, the occurrence rate of an air gap existing above the $2 R$ during shipment as a result of the vermiculite bags being left out is estimated to be $10^{-3}$ per container. This void space is enough to uncover the $2 \mathrm{R}$ after an accident has changed the orientation of the drum.

Vermiculite 6-12 in. Low During Shipment (X46). Based on the plutonium receivers survey, the occurrence rate of containers being transported with vermiculite low in the drum is estimated to be 0.09 per container. Dunnage Fails During Accident (X47). As in the $6 \mathrm{M}$ evaluation, a value of $0.1 /$ container was used.

Weld Defective (X48). A value of 0.02 per container was used for this element for the reasons given in the $6 \mathrm{M}$ evaluation.

Q/A Does Not Detect Defective Weld (X49). A value of $10^{-3}$ per container with defective weld was used for this element for the reasons given in the $6 \mathrm{M}$ evaluation.

Defective Weld Can Not Survive Accident Stresses (X50). Due to the protection of the pressure vessel by the outer drum and the low probability of a severe accident environment a value of $10^{-3}$ per defective weld accident can be used for $X 50$ as was done in the 6M evaluation.

Q/A Does Not Detect Badly Defective Weld (X51). A value of zero was used for this element for the reasons given in the $6 \mathrm{M}$ evaluation.

Defective Weld Can Not Survive Normal Transport Stresses (X52). A value of 1.0 was used for this element for the reasons given in the $6 \mathrm{M}$ evaluation.

(X53) through (X55). Not Used.

$1850^{\circ} \mathrm{F}$ Fire with Duration Greater than 6 Minutes (X56). The therma 1 analys is presented in Appendix I shows that a $1475^{\circ} \mathrm{F}$ fire, imposed directly on the $2 R$ pressure vessel container could be expected to cause failure in 6 minutes. The $2 R$ is attached to a bird cage inside the outer drum. Thus even in an accident in which all the vermiculite is lost 
the $2 \mathrm{R}$ sees the fire through an intermediate surface. The radiant heat flux on the $2 R$ is reduced to about half its normal value when there is one radiative surface between the fire and the $2 R$. Thus failure would be expected in about 12 minutes when the $L-10$ is exposed to a $1475^{\circ} \mathrm{F}$ fire and credit is taken for the presence of the outer drum. However, Sandia found that the fire environment could be better represented by a $1850^{\circ} \mathrm{F}$ average fire temperature. The raciant heat flux from a $1850^{\circ} \mathrm{F}$ fire is double that from a $1475^{\circ} \mathrm{F}$ fire, therefore the factor of two gained by taking credit for the intervening surface is lost due to the higher fire temperature. Thus $2 R$ failure in a $1850^{\circ} \mathrm{F}$ fire can be expected in 6 minutes. Based on the fire duration curve described in section 5 , the frequency of occurrence of fires lasting longer than 6 minutes is 0.75 per accident involving fire.

$1850^{\circ} \mathrm{F}$ Fire with Duration Greater than 18 Minutes (X57). Using X56 as a base point, if the container is in the van, then there is yet another intervening surface between the $2 R$ and the fire. If two intervening surfaces are placed between the $2 R$ and the fire, the heat flux is reduced by about a factor of three. Since the container is in the truck, some of the vermiculite is likely to remain in the failed outer drum. When only half the vermiculite is lost, then only half the $2 R$ sees the thermal flux, thus in a $1475^{\circ} \mathrm{F}$ fire, failure would be expected in 36 minutes. In the $1850^{\circ} \mathrm{F}$ fire environment, failure would be expected in 18 minutes. The Sandia curve presented in section 5 shows that the frequency of occurrence of fires lasting longer than 18 minutes is 0.2 per accident involving fire.

$1850^{\circ} \mathrm{F}$ Fire with Duration Greater than 60 Minutes (X58). This element considers an $1850^{\circ} \mathrm{F}$ fire on a container where the loose vermiculite is 6-12 in. low and the vermiculite bags have been left out of the container. When this occurs, approximately $10 \%$ of the surface area of the $2 R$ container could see thermal radiation even when the outer drum has not been breached. Since only $10 \%$ of the $2 \mathrm{R}$ sees the thermal radiation, the time to failure is 10 times longer than $X 506$. Based on the Sandia fire environment data, presented in section 5 , the likelihood of a fire lasting longer than 60 minutes is 0.01 per accident involving fire. 
$1850^{\circ} \mathrm{F}$ Fire with Duration Greater than 90 Minutes (X59). This element paralle1s $\times 58$ but considers the case where a container with low vermiculite remains in the van for the duration of the fire. In this case the $2 R$ sees the fire through two reradiating surfaces. For $(X 58)$ the outer surface was the only reradiating surface between the fire and the $2 R$. Since one intervening surface reduces the radiant heat flux by a factor of about two and two intervening surfaces reduce the radiant heat flux by a factor of about three, the time to failure for containers inside the truck is $3 / 2$ the value for containers outside. Thus the time to failure for containers with low vermiculite, remaining in the van is estimated to be about 90 minutes. Based on the Sandia fire environment data presented in section 5 , the frequency of occurrence of fires lasting longer than 90 minutes is estimated to be $3 \times 10^{-3}$ per accident involving fire.

Bolts Failed from Accident Stresses (X60). Accident stresses to which the $2 R$ container may be exposed are not severe enough to cause bolt failure. Therefore, this element was set at zero.

Valve Broken by Puncture Probe in Accident (X61). The valve can be broken by a puncture probe. The analysis parallels that used to obtain a value for $x 15$. The only difference is that the valve area occupies about $3 \mathrm{in.}$. of the total container height of $69 \mathrm{in.}$ Valve failure by puncture can be expected to occur with a frequency of 0.011 breaks per puncture probe failing outer container.

2R Fails from Excessive Crush (X62). This element was set at zero since crush forces are insufficient to deform drum enough to contact $2 R$.

(X63). Not Used.

Procedural Error Allows Shipment Without Venting (X64). This element and elements $X 65, X 66, X 72$ and $X 73$ are causative events which could contribute to, or result in, failure of the pressure vessel from overpressurization. Although the plutoniun receivers survey indicated that no vessels have failed from overpressurization, the survey gave essentially no information on the occurrence frequency of these causative events. The packaging condition and quality verifications that are required prior to 
each use of an L-10 shipping container, would appear to make the possibility of occurrence of failure by overpressurization due to these events negligible. Accordingly, a zero value was used in the analysis for element $X 64$ and for each of the elements X65, X66, X72 and X73. However, since the above reasoning is not demonstrative of the impossibility of nonzero values, sensitivity cases were run to determine the effect on the risk of non-zero values for these elements. The results of the sensitivity studies are given in section 11.4.

Shipment of Year-01d Pu Containing Bottles Permitted (X65). This element was set at zero for the analysis. See discussion for element $x 64$.

$2 \mathrm{R}$ Valve Closed During Aging Process (X66). This element was set at zero for the analysis. See discussion for element $x 64$.

Sufficient Time Elapsed to Form Explosive Gas Mixture (X67). This element was conservatively set at 1.0 .

Excessive Localized Temperature Experienced During Transport (X68). There are no excessive localized temperature sources encountered during normal transport. Therefore this element was set at zero.

Static Electric Discharge 0ccurs Within 2R During Transport $(X 69)$. No credible means of generating the potential difference required for a static electric discharge inside the $2 R$ exists in transport. Therefore this element was set at zero.

Excessive Localized Temperature Encountered (x70). The container fails from pressure buildup in fire before temperature is high enough to ignite gases inside $2 R$. Therefore this element was set at zero.

(X71). Not Used.

Procedural Error Allows Shipment Without Aging $(x 72)$. This element was set at zero for the analysis. See discussion for element $\times 64$.

Wrong Container Shipped $(X 73)$. This element was set at zero for the analysis. See discussion for element $\times 64$.

(X74). Not Used. 
$1850^{\circ} \mathrm{F}$ Fire with Duration Greater than 240 Minutes $(X 75)$. The therma 1 analysis results presented in Append $i x$ I shows that a moderately deformed container could protect the $2 R$ from a $1475^{\circ} \mathrm{F}$ fire for 240 minutes. This value was also used for the more severe $1850^{\circ} \mathrm{F}$ fire on the unbreached $L-10$ since containers which have retained their drum 7 ids are expected to be less deformed. Based on the Sandia accident data presented in section 5, the expected frequency of fires that will exceed 240 minutes is less than 0.001 per accident involving fire.

(X76) Through (X81). These values for the L-10 are identical to the values used for the $6 \mathrm{M}$ since the van is assumed to be essentially identical.

\subsection{BARRIER RELEASE SEQUENCE PROBABILITIES}

The Basic Event Probabilities in section 9.1 provide the data necessary to calculate the frequency of any event sequence. Only event sequences which lead to a release are of interest. In this section, attention is directed at the identification of Barrier Release Sequence Probabilities which will ultimately be used to obtain (system) release sequence probabbilities. For plutonium shipping, a release can occur only after four barriers are breached. These are the van, the outer container, the $2 R$ containment vessel and the bottle or sample can. The lists of basic events which breach individual barriers are formulated as discussed in section 8 . Tables 9.1 and 9.2 show the 1 ists of barrier release sequences and associated occurrence frequencies developed for the $6 \mathrm{M}$ and L-10 shipments. The occurrence frequencies were obtained from section 9.1.

The probability data shown in Tables 9.1 and 9.2 have not been multiplied together to obtain barrier failure probabilities. This is not a useful intermediate number because there are common elements which act on all the barriers simultaneously and must not be multiply counted. (see section 8.3). Since the final goal is to evaluate release sequences, which are obtained by permuting the barrier release sequerce lists, the probabilities will be calculated after the elements in a release sequence have been identified and duplicates eliminated. 
TABLE 9.1 Summary of Barrier Release

Sequences and Basic Element

Occurrence Frequencies Used in

the Evaluation of Plutonium Oxide

Shipments in the $6 M$ Container

Barrier

Release Sequences

Basic Element Frequencies

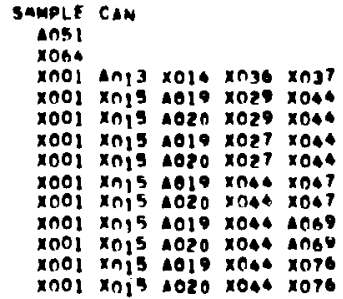

$\times 029 \times 0.6$

$x+29 \times n x^{2}$

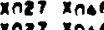

$\times 001 \times 048049 \times 050$

$\times 040 \times 1 \times 51 \times 058$

xoo1 anj $\times 036 \times 037$

$1001 \times 0.6 \times 047$

001 xace xer6

$\times 001 \times 046.069$

$x 001 \times 004 \times 097$

xool xnot xor6

$x 001 \times 04$
$x 001 \times 0.40$

OUTER OHIN

xoli $x n_{2}$ ?

$1017 \times 029$

xoli $x$ xn?

xool anis

xooi anis nes

001 nnil $x 047$

$x 001$ Anj 7047

$x 001$ xn1! 1069

xool Angs 101 ?

xol $x$ ny $x$ xis

xo01 1096 nol

xat

xom

$001 \times 047.010$

10014069019

nol $x$ nit 1 191

$\times 001 \times 047.620$

no) $\times 076$ sese

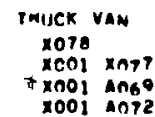

$0.000 \mathrm{~F}=040$.

$.000 E-040.0030$

$3.0008-03 \quad 2.000 E-02 \quad 3.000 E-002$

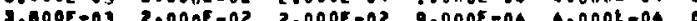

3.400E-01 2.000E-02 2.0008-00 $9.000 \mathrm{E}-04 \quad 0.000 \mathrm{k}-04$

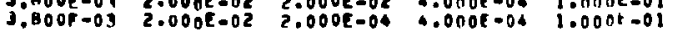

$3.600 E-03 \quad 2.00 A E-02 \quad 2.000 E-02 \quad 4.000 F-04 \quad 2.2402-02$

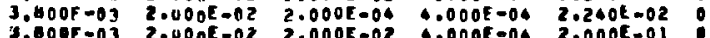

$\begin{array}{lllll}3.000 E-03 & 2.000 E-02 & 2.000 E-02 & 4.000 E-04 & 2.000 E-01 \\ 3.000 E-03 & 2.01 O A E-02 & 2.000 E-04 & 0.0 H O E-00 & 2.000 E-01\end{array}$

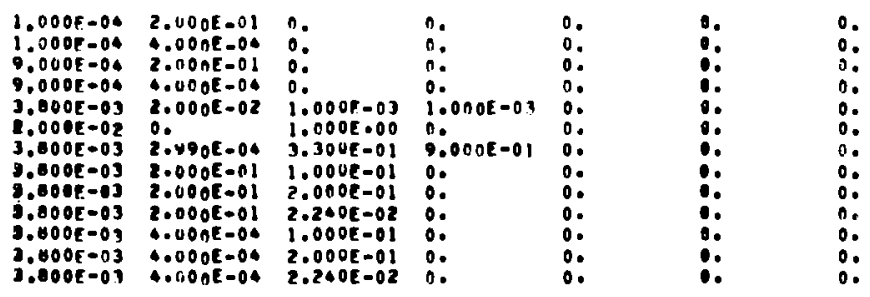

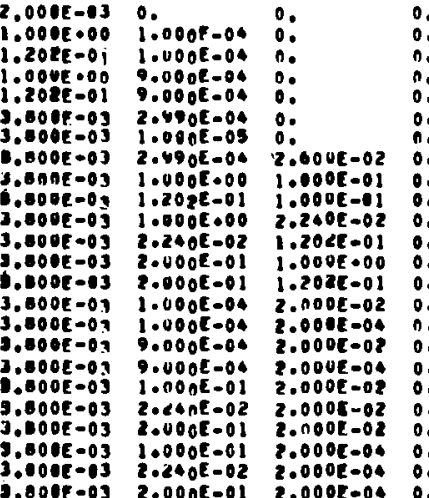

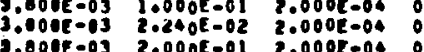

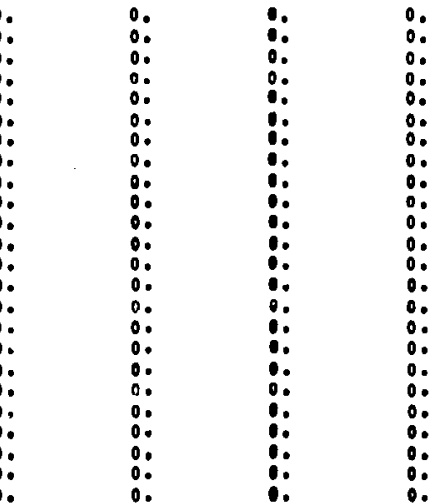

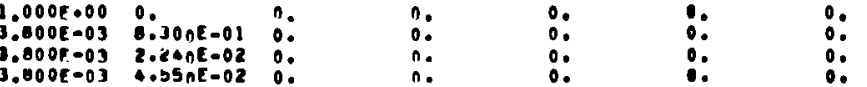


TABLE 9.2 Summary of Barrier Release Sequences and Basic Element Occurrence Frequencies Used in Evaluation of Liquid Plutonium Nitrate Shipments in the L-10 Container

Barrier

$\underline{\text { Release Sequences }}$

I WNFR
XONI

$x \cos x \times a^{2}$

An? 1

$2 \times$

$\begin{aligned} & x+3.3 \\ & x n 01\end{aligned} \times 040 \times 300 \times 050$

$\operatorname{lng} 2$

$x \rightarrow 29 \times 0,35 \times 03 \mathrm{k}$

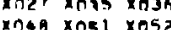

insa

xnol $10,3 \times 015$

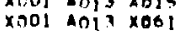

$x \cap>0, x \in 7, x 038$

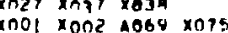

$\times 001 \times 046 \times 002 \times 0454008 \times 05$

$x n 01 \times n a ? \times 035 \times n 36$

xo01 AnTh Yo35 $\times 1036$

$x$ xn1 AnA9 $\times 035 \times 016$

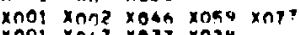

$\times 001 \times \cap 47 \times 037 \times 034$

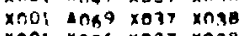

$\times \cap 01 \times n+6 \times n=37 \times n \rightarrow 4$

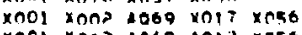

$x \cap 01$ xnn? 1049 AnI3 xn56

$\times 001 \times n n 28069 \times 008 \times 046$

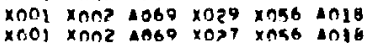

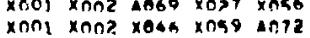

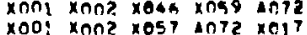

$x 001 \times n n 2$ xos $10 \div 2$ xnos

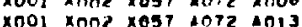

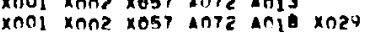

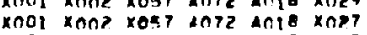

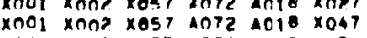

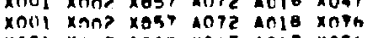

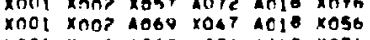

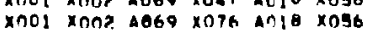

\section{Basic Element Frequencies}

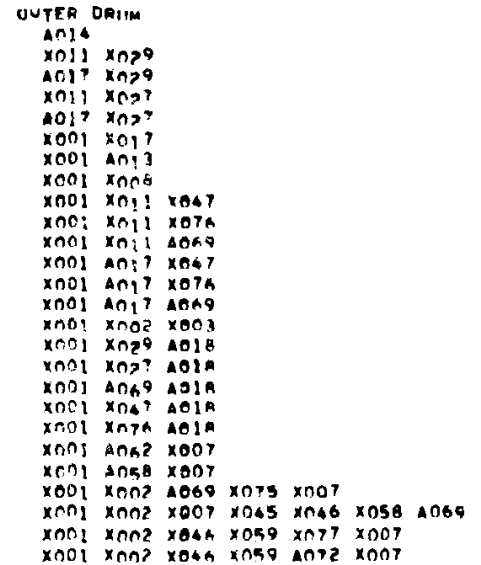

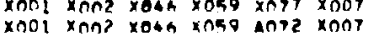

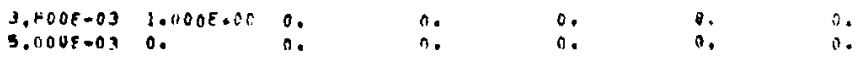

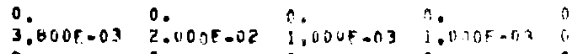

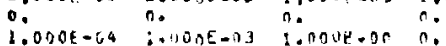

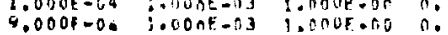

$2,0000-02$ o. $1.000 E=00 \mathrm{n}$.

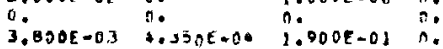

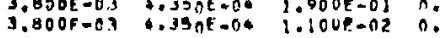

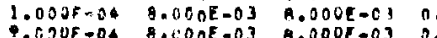

3 BOOE-03

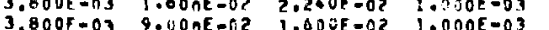

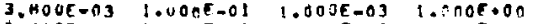

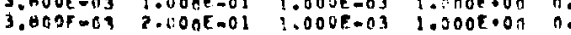

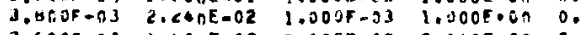

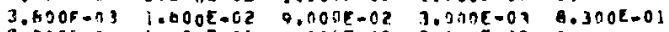

$3 . B 00 E=0.3 \quad 1.00 n F=01$ A.BOUE-03 A.AOOF=03 $n$.

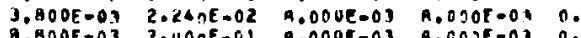

Q.800F-03 Z.UOAE-01 A.nOOE-03 A.0OJE-0.3

$3.000 E-03 \quad 1.000 E-n 2$ T.260E-02 7.070F-04 7.500t-01

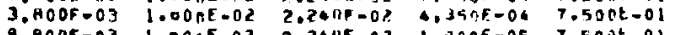

9.800F-03 1.00AE-02 2.240E-0? 1.7nof-05 7.500t-0!

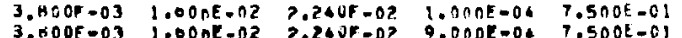

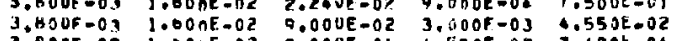

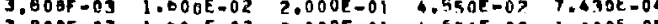

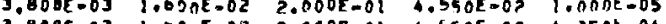

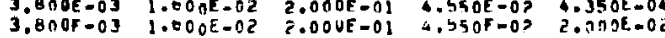

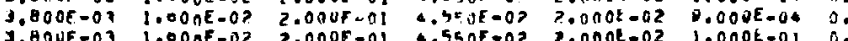

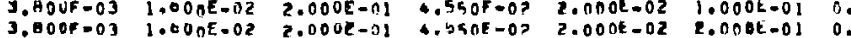

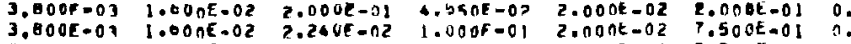

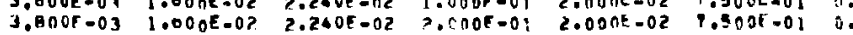

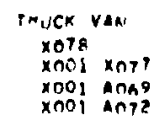

$\begin{array}{lll}2.000 E-03 & 0.00 \\ 1.000 F-00 & 1.000 E-04 & 0 .\end{array}$

0,000 -OOB 1.00OE-OA 0 .

1.0005 .00 9.0ONE-04 0 .

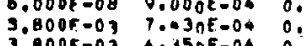

3.AOOF-O3 $\triangle 1350 E-04$ O.

$3.600 E=03$ l.0OnE-05 0 .

3.800E-03 1.010AE.00 1.00UE-01 O.

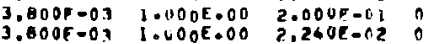

3.800E-0. 6.00AE-0B i.0OOE-OL 0

.800F-03 6.000E-0B 2.000E-0I 0

,AOOF-03 $0.00 \mathrm{OE}-0 \mathrm{~B}$ 2.240E-02 0 .

$3.800 F-7.3 \quad 1.600 E-025.000 F-0$

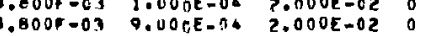

3.

$\begin{array}{llll}3 . A 0 O F-03 & 2.040 E-02 & 2.000 F-02 & 0 .\end{array}$

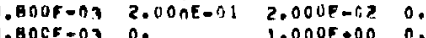

$\begin{array}{llll}3.80 C 5-03 & 0 . & 1.000 E .00 & 0 . \\ 3.8006-03 & 0 . & 1.000 E .000 & 0 .\end{array}$

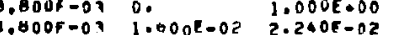

$\begin{array}{lll}.800 F-03 & 1.600 E-02 & 2.2406-02 \\ 3000 F-03 & 1.000 E-03\end{array}$

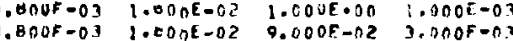

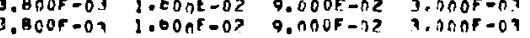

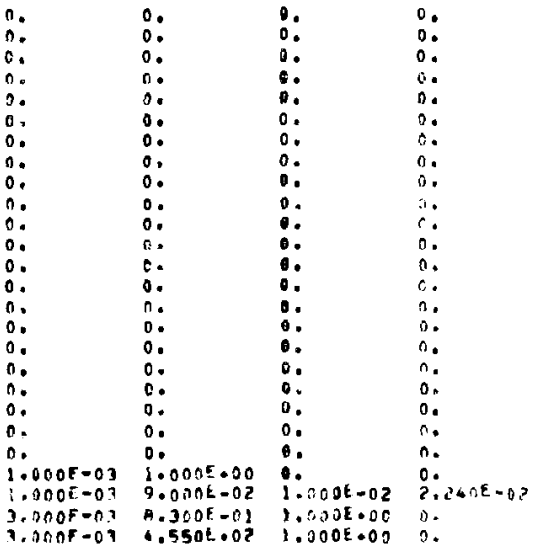




\subsection{RELEASE FRACTIONS}

The barrier release sequence concept also provides a convenient way to evaluate release fractions. In this subsection, release fractions will be selected for each event sequence capable of breaching a barrier (i.e., each barrier release sequence). The release fraction given for a barrier is developed on the basis that it is the only barrier which contains the plutonium. The (system) release fraction is then obtained as the product of barrier release fractions (see section 8.3). In selecting barrier release fractions for use in the analysis, conservatism was a major consideration.

The following paragraphs present the release fraction used in the analysis when a given barrier is breached. A brief rationale for the estimate is also given. Release fractions for $\mathrm{PuO}_{2}$ powder shipments are given first, followed by those for $\mathrm{Pu}\left(\mathrm{NO}_{3}\right)_{4}$ solution shipments.

\subsubsection{Barrier Release Fractions for the 6M Containing Pu0 2 Powder}

The four barriers for this shipping system are the steel sample cans, the $2 R$ inner vessel, the outer drum, and the van.

\section{Sample Cans}

The steel can containing the oxide powder is not considered an effect tive barrier. If the can is defective, all the material in the can is potentially available for release. Since there are two cans in the $6 \mathrm{M}$ container, the release fraction for all can failures from closure errors or defects is conservatively assumed to be 0.5 . The fraction released for failures from accident forces is assumed to be 1.0 .

\section{$\underline{2 R \text { Vessel }}$}

Two types of failures of the $2 R$ vessel can be postulated. One is the loose cap. Assuming that all material is free inside the $2 R$ and the cap is loose, it is still necessary for the material to work its way past the cap 
threads. With the plug half unscrewed, there are assumed to be 5 full turns remaining threaded.* For this condition, a fractional release from the barrier of $10^{-6}$ of the total $2 \mathrm{R}$ contents was used in the analysis.

The second failure mode of the $2 R$ is a failure either because the cap is completely unscrewed or because the $2 R$ is breached in an accident. If the $2 R$ is open and the container is on its side, or if the bottom weld fails in an accident, then the fraction released is assumed to be 1.0. Otherwise the fraction released is assumed to be 0.5 .

\section{Outer Drum}

The outer drum represents a less effective barrier than the $2 R$. If the drum is breached by lid removal and the drum is on its side, or is breached by impact all material is assumed to be released from the drum. If it is punctured, the fraction released is 0.5 . If the outer drum is not extensively damaged, then the powder must work its way past the Celotex ${ }^{R}$ and out a vent hole or some other small opening in the drum. No more than a few grams of material should be released in this matter. Thus a release fraction of $10^{-3}$ has been selected.

$\underline{\operatorname{Van}}$

The van or trailer can be a reasonably effective containment barrier for internally released plutonium provided that it is not extensively damaged in the accident environment. Assuming that material is released into the air inside the van, approximately $0.1 \mathrm{~g} / \mathrm{M}^{3}$ can remain in the air for several hours. (4) Thus a van containins $4011^{3}$ of free space could contain up to $4 \mathrm{~g}$ of plutonium. Assuming that the trailer is only slightly

* Requirements for specification $2 \mathrm{R}$ containers are that only 5 threads have to be engaged when the plug is fully tightened. However, containers examined in this study had at least 10 threads engaged when the plug was fully seated. 
damaged, the air in the trailer will very gradually exchange with the outside air. The plutonium will diffuse out with the exchanging air. Thus the presence of the van reduces the total fraction available for release to that in the van atmosphere, which is approximately $10^{-3}$ of the total amount in any container. In releases not involving an accident, this release fraction is further reduced by a factor of 100 because of the absence of any strong mechanism for making the material airborne in the van's atmosphere.

If the container is lost from the van, the release fraction is 1.0 . A value of 1.0 is also used when the van is breached and the container is not lost.

\subsubsection{Barrier Release Fractions for the L-10 Containing Liquid Pu ( $\left.\mathrm{NO}_{3}\right)_{4}$}

The four barriers for this shipping system are the polyethylene sample bott]e, the $2 R$ inner vessel, the outer drum, and the van.

\section{Sample Bottle}

In the accident environment the sample bottle is not considered to be an effective barrier, a release fraction of 1.0 is used for these cases. If the sample bottle is defective, or overfilled, a release fraction of 0.1 is used. This is considered to be conservative since most sample bottle leakages are through or around the cap and are much smaller than $10 \%$.

\section{R Pressure Vesse1}

The $2 R$ pressure vessel is considered to be the main barrier controlling the release of plutonium nitrate. The release fraction for the $2 R$ vesse 1 is a function of the vessel orientation relative to the location of the breach and the duration of the release. The release fraction estimates have been subdivided into fire and no fire release categories.

Nearly a 11 releases in the no fire category, are dependent on orientation. For sequences where the closure assembly leaks and the container is shipped upside down, a release fraction of 1.0 is used. If the bottom weld on the $2 R$ is defective and the container is upright, a release fraction of 1.0 is also used. Internal pressurization will cause leakage through the 
closure which will stop when the pressure is sufficiently relieved. Whether the leakage is in the gas phase or in the liquid phase depends on the orientation of the container. A 0.1 release fraction is conservatively used for this release mechanism for any orientation. When the vessel is on its side, the release fraction is very dependent on the relationship of the leak path to the level of the liquid. The amount released varies randomly from 0 to 1.0 with a mean of 0.5 . For a 11 the remainder of the postulated no fire breaches of the $2 R$ vessel, a release fraction of 0.5 is used. This includes the $2 \mathrm{R}$ punctured sequence.

The release fractions for the fire cases are a function of orientation and fire duration. For release sequences where the container remains upright and the solution is boiled off, the release fraction is estimated to be $2.0 \times 10^{-3}$. This value was derived from experiments summarized in Appendix $C$. For the cases where orientation is lost, liquid is present in the flange region, the material released in a fire would be expected to be a flashing two phase liquid. For fires that last long enough to evaporate the entire contents of the $2 R$, the release fraction would be 1.0. However, if the fire is put out before the solution can be completely evaporated then the release fraction would be reduced accordingly.

Based on an enthalpy balance, heating the solution to $610^{\circ} \mathrm{F}$ represents about $45 \%$ of the energy required to cause complete vaporization. Assuming the rate of energy input to the container is approximately constant for the entire accident results in the conclusion that a container which begins releasing material after 6 minutes will have released a11 the material in approximately 13 minutes. Based on the fire duration curve presented in section $5,35 \%$ of al1 fires last longer than 13 minutes. These fires represent $0.35 / 0.80$ or $45 \%$ of the fires which last long enough to cause a release. Thus $45 \%$ of all fires which 1 ast 6 minutes will release all the material. Since fires with a duration between 6 and 13 minutes are postulated to release orly part of the solution, $55 \%$ of all the fires which release some material release only part. When the partial releases are included in the release fraction estimate, the mean release fraction from 
a fire lasting longer than 6 minutes is 0.6 . Following the same procedure results in release fractions of about 0.33 for any releases which are initiated from fires lasting longer than 18 minutes.

\section{Outer Drum}

The effectiveness of the outer drum is mainly a function of the degree of damage incurred by this barrier. Since orientation effects were included in the $2 \mathrm{R}$ release fraction estimates, they are not considered again for this barrier. Two cases are considered: 1) the material does not have to pass through vermiculite in order to be released, and 2) the release path is through vermiculite. For the first case, if the drum has a major breach (e.g., lid removed) a release fraction of 1.0 is used. If the drum has a smaller breach (e.g., puncture) a release fraction of 0.5 is used.

In the second case some credit is taken for deposition on the vermiculite in the drum. Based on experiments with vermiculite as an air filter media, (5) approximately $50 \%$ of any respirable dust particles are removed by an 8 in. vermiculite filter bed. In releases where the liquid is jetted out of the $2 \mathrm{R}$ as a result of a fire, at least $90 \%$ of the particles are larger than $10 \mu$ and would quickly deposit out on any contacted surface. Thus it is conservative to assume that the fraction of the material released from the outer drum is less than 0.05 . For nonfire-driven releases the release fraction can be expected to be even smaller. A value of 0.005 was used as a release fraction for a nonfire release through vermiculite.

$\underline{\text { Van }}$

The van was not assumed to be as effective a barrier for liquid nitrate spills as it was for oxide. Nitric acid solution could eat through the metal side walls of the trailer or could drain through small cracks in the side wall and floor construction. The requirement that a significant area must be wetted before the solution drains from the van appears to be a controlling factor. Thus, a release fraction of 0.01 , similar to that used for the outer drum will be used for cases where the van has not been significantly damaged in an accident. For cases where the van was postulated to be failed from puncture or other accident forces, a barrier release fraction of 1.0 is used. 


\subsection{SUMMARY OF RELEASE SEQUENCE EVALUATIONS}

The release sequence evaluations for the $6 \mathrm{M}$ containing $\mathrm{PuO}_{2}$ powder and the L-10 containing liquid $\mathrm{Pu}\left(\mathrm{NO}_{3}\right)_{4}$ are summarized in Tables 9.3 and 9.4, respectively. Under the first heading are the event numbers which result in failure of one of the four barriers. These events were obtained from the fault tree. Under the second heading are the basic event probabilities associated with the events given in the first column. The third column summarizes the Barrier Release Fractions presented in 9.2.

Since a release sequence is made up of a single member from each of the four barrier release sequences, the fraction released for a release sequence is obtained by multiplying the barrier release fractions for each selected barrier release sequence. Release sequence probabilities must be obtained by forming a list of basic failure elements and by eliminating any duplicates before the probability multiplication is performed. Following both of these calculations, a release fraction can be paired with a release probability for all the release sequences. The release fraction is the $A F R_{\mathbf{j}}$ term and the release probability is the $P_{R_{j}}$ term in section 3 , Equation 2:

$$
R_{i}=\left(A F_{R_{j}} \times P R_{j}\right) \underset{q}{\sum}\left(C E_{i, q} \times P E_{q}\right)
$$

The environmental terms $\left(C_{E_{i, q}} \times P_{E_{q}}\right)$ are developed in section 10. 
TABLE 9.3 Summary of Barrier Release Sequences, Basic Element Frequencies and

Barrier Release Fractions for Shipping Plutonium 0xide Powder a Distance of 1500 Miles in the $6 \mathrm{M}$ Container

Barrier

Release Sequence

Basic Element Frequencies

Release

Fractions
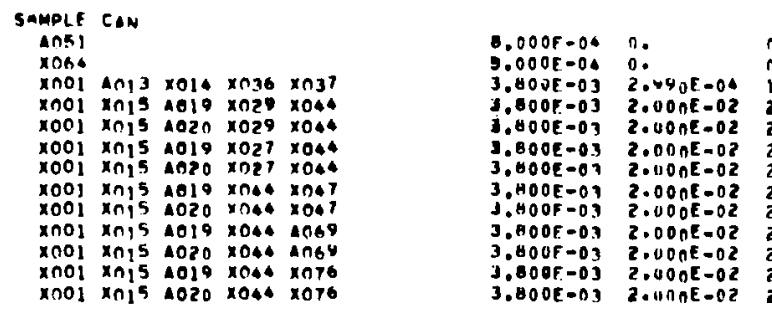

n.

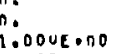

$\stackrel{n}{n} \quad \vdots:$

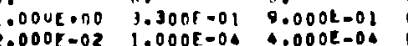

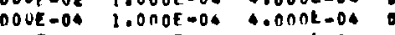

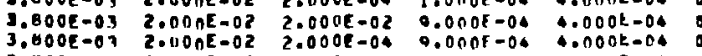

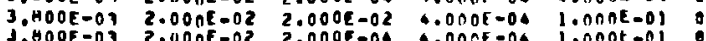

$3, A 00 E-0) 2.000 E-02,0.00 E-02 \div .000 E-042.240 E-02$

$3.800 F-03 \quad 2.000 E-02 \quad 2.000 R-04 \quad 4.0001-06 \quad 2.200 E-02 \quad 0$

$\times 001 \times 15$
$\times 001 \times 015$
$\times 0020 \times 040 \times 076$

$2 n$

$\times 029 \times 0.6$

$\times 029 \times 0.4$

$x \in 27$
$x \in 27$$x \in \rightarrow$

$\times 001 \times n \times 8 \times 049 \times 050$

$\times 046 \times n a 1$ xos

$\times 001 A_{13} \times 036 \times 037$

$\times 001 \times n 46 \times 047$

$\times n x^{2} \times n_{40} \times 074$

$\times n 01 \times n+6 \quad 1069$

$\times 001 \times 044 \times 047$

$\times 001 \times 044 \times 076$

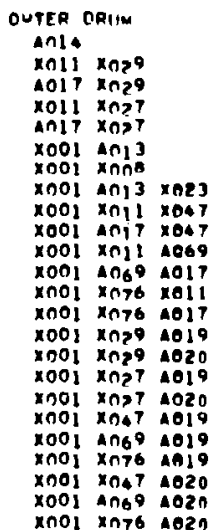

$1,0005-042.1008-010$.

$1.0008-04 \quad 9.000 E-040$

$1.000 E-04$
$2.0 O O E-01$

$.000 E-04$
$3.000 E-03 \quad 2.000 E-04$
$0.000 E-002$

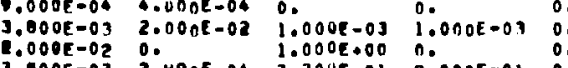

$3.000 E-03$ 2.490E-04 $3.300 E-01000$.

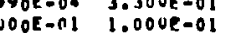

$3.800 E-03$ Z.00OE-OI Z,000E-01 O.

$3.800 E-03 \quad 2.00 n E-01$ 2.240E-02 0 .

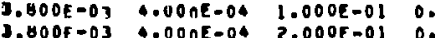

$3.800 E-03 \quad 0.000 E-04 \quad 2.000 E-01 \quad 0$

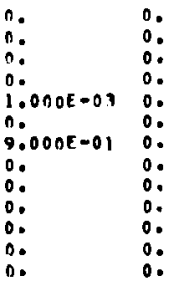

$\begin{array}{ll}0: & \because: \\ 0: & \because: \\ 0: & \because: \\ 0: & \because: \\ 0: & \end{array}$

$1.000 E-06$

$1.300 E-06$

1.0006 .00

1.000 . 060

S.DOOE-O:

$3.000 E-61$

$1.000 E=06$
$1.000 E=06$

$1.000 E=06$

1.0006 .00

$1.000 E \cdot 00$
1,000600

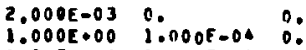

l.202E-0i l.UONE-04 $\mathrm{n}$.

$1.000 E+0090000 E-04 \quad 0$.

$\begin{array}{lll}3.0005-03 & 2.490 E-04 & 0 . \\ 3.000 E-03 & 1.000 E-05 & 0 .\end{array}$

$9, B 00 E-03$ 2.49OE-n4 2.600E-02

$3.8 \cap n E-01 \quad 1.0006000$ 1.000E-OL

$3.000 E-03 \quad 1.202 E-01$ 1.000E-01

$3.000 E-03 \quad 1.000 E+00$ 2.240E-02 0.

$3.8005-03 \quad 2.240 E-02 \quad 1.202 E-02$

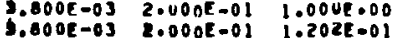

$1.600 E-03 \quad 2.000 E-0) \quad 1.202 E-01$
$1.000 E-01$

J.8COE-0.1 $1.000 E-042.000 E-02 \quad 0$.

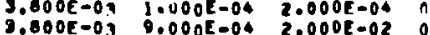

$3.800 E-0,9.000 E-042.000 E-02$ a.

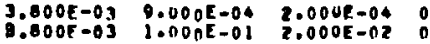

$\begin{array}{llll}9.800 E-63 & 1.00 H E-01 & 2.000 E-02 & 0 \\ 9.800 E-03 & 2.240 E-02 & 2.000 K-02 & 0 \\ 3.800 E-03 & 2.000 E-01 & 2.000 E-02 & 0\end{array}$

$3.800 E-03$ 2.0.

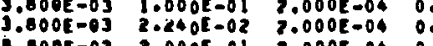

0.
$0:$
$0:$
$0:$
$0:$
$0:$
$0:$
$0:$
$0:$
$0:$
$0:$
$0:$
0.
$0:$
$0:$
$0:$
$0:$
0.0

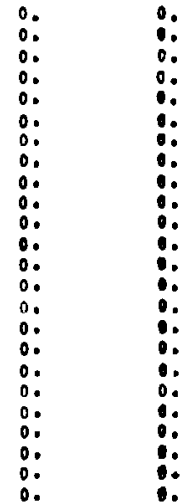

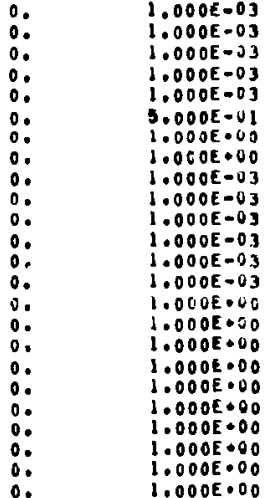

THUEK VAN

rote

xan $x$ ant

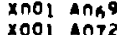

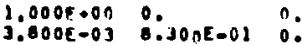

1.800E-01 2.24nE-02 $\because: \quad 0:$

$\because: \quad \because: 0$
$1.000 E \times 05$ $1.000 E-23$ $1.000 E+00$
$1.000 t+00$ 
TABLE 9.4 Summary of Barrier Release Sequences, Basic Element Frequencies and Darrier Release Fractions for Shipping Liquid Plutonium Nitrate a Distance of 1500 Miles in the L-10 Container

Barrier

Release Sequences

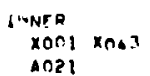

24

$\times 033$
$\times 001 \times 0,8 \times 8 \times 009 \times 020$

$\cos 2$

mo2 $\times n .35 \times 03 \mathrm{f}$

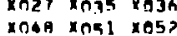

ins

$x 0010013 \times 019$

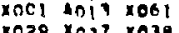

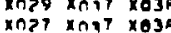

100] $\times 002$ 4060 $\times 075$

$\times n 09 \times 1 \times 4 \times 002 \times 0454069 \times 058$

$\times n 01 \times n+7 \times 035 \times n 34$

$\times 001 \times n>4 \times 035 \times 076$

$\times 001 \times 002 \times 04 \times \times 090 \times 077$

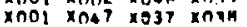

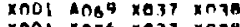

xno1 xorh xn37 xח3A

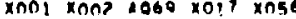

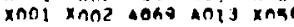

$\times n 01 \times n n ? \times 069 \times 006 \times n=6$

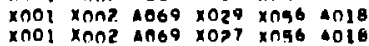

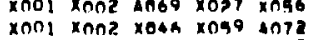

$x 001$ xnn2 $\times 057$ a 072 xo1

$\times 001 \times n n 2 \times 0571072 \times 00$

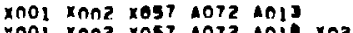

xoo1 xnn? xos? anyz anis xop?

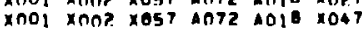

xnoi xnn? xear aniz anis xnin

$\times 001 \times 007.060 \times 0474018 \times 05$
Basic Element Frequencies

Release

Fractions

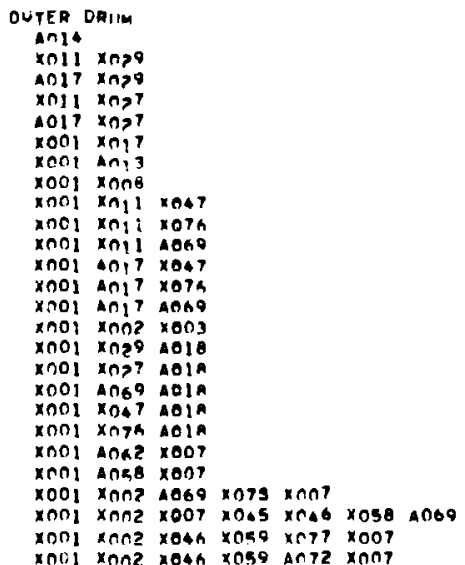

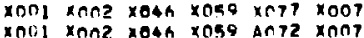

$2.000 E-03$
$1.000 F+00$
$0.000 E-00$

$1.000 F+00$
$6,000 F-00$
$1.0000-06$

$1.0005=00 \quad 1.000 E-040$.

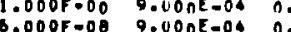

$3,0007-03$ T.43nE-O4 0 :

3., AO OF $=03$ ?. $350 E-040$.

3,000E-03 1.01ONE-05 $n$ :

1.00neton 1.000E-01 0.

.80 of-03 1. 1100E+nC $2.000 E-010$

$3.800 F-0 ? \quad 1.000 E+00$ ?.240E-0? 0

$3.0008-036.000 E-00$ 1.000F-01 0

D.BODE-0. G.0OOE-OB ?.0OOE-OI O

$3.800 F-03$ G.UODE-08 2.240E-02 O

$3.800 E-03$
$3.0005-03$
3

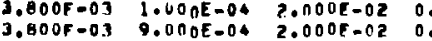

$\begin{array}{llll}3.800 F-03 & 9.00 O E-04 & 2.000 E-02 & 0 . \\ 3.800 F-03 & 2.040 E-02 & 3.000 F-02 & 0.0\end{array}$

$3.800 F-03$ 1.00OE-0I $3.000 E-02$ O.

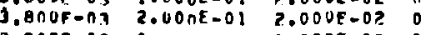

$3.800 F-0300 \quad 1.000 \%+000$

3.000F-03 $0.000-02 \quad 1.000 E+00$

$3.000 F-03 \quad 1.000 E-02 \quad 2.240 E-02$

$\begin{array}{lllll}3.400 F-03 & 1.00 n E-02 & 1.00 J E+O N & 3.0 n O E-03 & 9.0 n O E-02 \\ 3.800 F-03 & 1.000 E-02 & 9.000 E-02 & 3.000 F-0.3 & 9.300 E-01\end{array}$

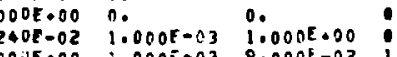

$4.3006-0$
$+.5506+0$ $\begin{array}{lll}9 . & 0.000 E+00 \\ 0 . & 0.000-01\end{array}$

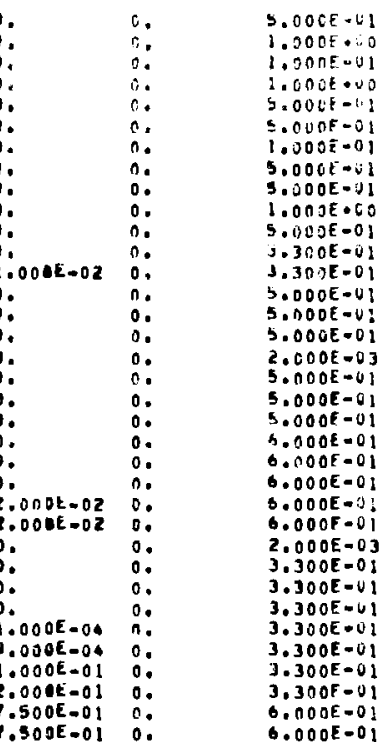

PMUCK VAR

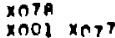

$\begin{array}{ll}x 001 & \text { Anko } \\ \text { xnot ant? }\end{array}$
3,000E=00 0.000

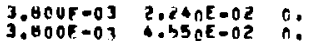

$\begin{array}{ll}0 . & 0: \\ n: & 0:\end{array}$

$\begin{array}{lll}\because: & 0: & 1.050 E=62 \\ \because: 000 E=02 \\ 0 & 0: & 1.090 E=00 \\ & 0.000000\end{array}$ 


\section{REFERENCES}

1. R. K. Clark, J. T. Foley, W. F. Hartman and D. W. Larson, Severities of Transport Accidents, Volume III - Motor Carriers, SLA-7 $\overline{4}-001$, Sandia Laboratories, Albuquerque, New Mexico, (to be published).

2. Summary of Accident Investigations 1971, U. S. Department of Transportation, Federal Highway Administration, Bureau of Motor Carrier Safety, Washington, D.C., December 29, 1972.

3. W. F. Hartman, Fire Duration Dat for Trucks Carrying Non-Combustible Cargo, personal communication to T. I. McSweeney, June 1974.

4. J. M. Selby, et. a1., Considerations in the Assessment of the Consequences of Effluents from Mixed Oxide Fuel Fabrication Plants, BNWL-1697, Battelle, Pacific Northwest Laboratories, Richland, WA, June 1973.

5. W. Washington, R. Chi, R. Regan, The Use of Vermiculite to Control Dust and Radon Daughters in Underground Uranium Mine Air. Proc. of the 12th AEC Air Cleaning Conference, CONF-720823, Oak Ridge, Tennessee, August 1972 , p. 355. 


\section{EVALUATION OF ENVIRONMENTAL CONSEQUENCES}

In section 9, release sequences were identified and evaluated by determining their expected frequency of occurrence and the associated amount of material released. A risk number could be obtained by forming the product of the expected frequency of occurrence and the amount of material released and summing over all release sequences. This number does not fit a certain criterion for a risk assessment as specified in the introduction. Namely, the results of the assessment must be expressed in a form that permits comparison to other societal risks.

This section develops the data required to compare the plutonium transportation risk assessment to other societal risks. Factors in developing this information are: Quantity Airborne, Meteorology, Demography, Individual and Population Dose, Population Health Effects and Expected Exposure Frequency.

Analyses of these factors are summarized sequentially in separate parts of this section. These factors and their relationships to other steps in the risk assessment are shown in Figure 10.1.

Results given in this section can be thought of as conversion factors required to obtain risk values which can be compared to other societal risks.

\subsection{QUANTITY AIRBORNE}

Part 9.4 showed the method used to get release sequence data and summarized the data in terms of Barrier Release Sequences. The released material considered in section 9 is in the environment but it is not dispersed. Based on the plutonium pathway analysis calculations presented in Appendix $E$, the airborne pathway dominates all other pathways through the environment by about four orders of magnitude. Thus, only the airborne pathway was considered in this analysis.

This part of section 10 will summarize the results of experiments which provide a basis for airborne dispersal estimates. The basic experimental 


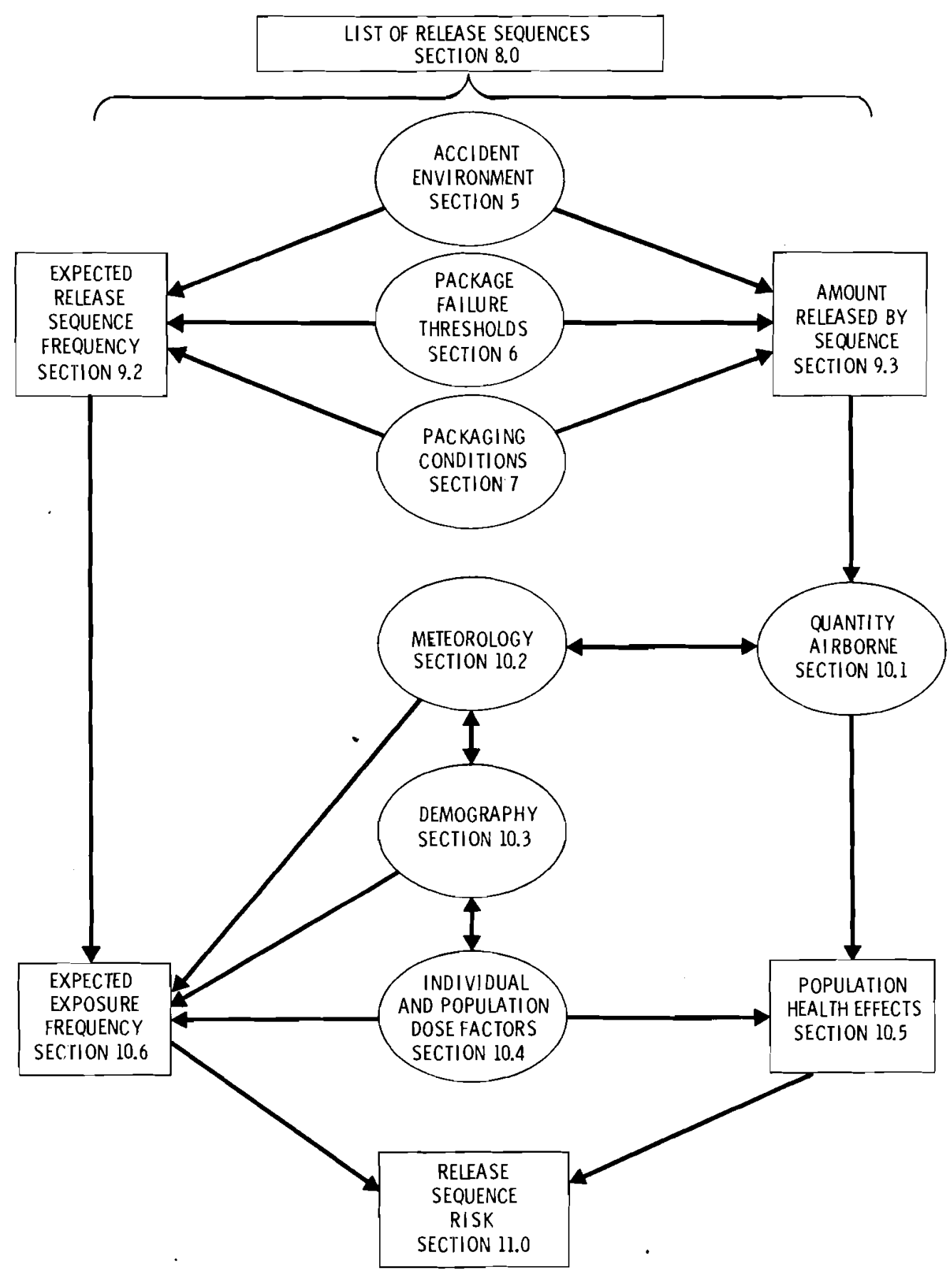

FIGURE 10.1 Release Sequence Evaluation Steps 
data is shown in Appendix C. The dispersal evaluation reported here considers two components of the release: Quantity of Material Immediately Dispersed and Quantity Dispersed During Time Intervals Following the Initial Release.

\subsubsection{Quantity of Material Immediately Dispersed}

There have been no experiments performed which exactly simulate the breach of a container in an accident and the subsequent puff of material which becomes airborne and is dispersed downwind.

A relevant simulation was reported by $S$. Hagsgard et al. (1) They determined the quantity of material released when a Type A package* filled with a fine sand was breached by a puncture probe. Releases of sand from both plastic bottles and tin cans were studied.

The fraction of material released upon failure was found to have a mean of $0.76 \times 10^{-3}$ and a standard deviation of $0.46 \times 10^{-3}$. These fractions include all the material released which could be greater than the amount airborne. However, since the $\mathrm{Pu}_{2}$ power is a very fine, easily entrained powder, it is conservatively assumed that when the container is breached all the material immediately released will be airborne. In this analysis a value of $10^{-3}$ was used for the fraction immediately airborne when a $6 M$ container is failed in an accident.

The failure analysis of the sand-filled Type A containers gives little direct guidance in determining the airborne release fraction for liquidfilled L-10 containers. There are two basic classes of releases which are immediately airborne when an L-10 fails. The first class of releases considers the puff-dispersible material which becomes airborne when the container is initially breached. The second type of release occurs when the nitrate solution is exposed to a fire and the containment vessel is breached by the resultant pressure increase.

In the first case, the fraction instantaneously released upon failure can be expected to be nearly the same as occurred for the oxide case.

\footnotetext{
* As defined in 10 CFR Part 71.
} 
However, whereas the oxide is a very fine, highly dispersible powder, the liquid will be dispersed in droplet form. The size of the droplets can be expected to be similar to droplets formed by slow-speed jet atomizers. They produce droplets with a mean size of approximately 280 microns. (2) The particle size distribution is log normal with only $0.1 \%$ less than 160 microns. Particles must be an order of magnitude smaller before they can be entrained for long periods of time in even rapidly moving air currents. Thus, the fraction of the plutonium solution immediately dispersed upon rupture of the L-10 is very much less than $0.1 \%$ of the $0.1 \%$ immediately released to the air when the barriers are failed. As a result, the amount immediately airborne upon spillage from the L-10 will not be included in the source term. This source term is used for accidents where no fire occurs following the accident.

Releases which result from excessive heating of the nitrate solution have characteristics which differ markedly from the previous release. First the release occurs at high temperature and at high pressure. Secondly the material released will be dried by the high temperature gases, which exist in the fire environment. Both these factors make the final particle size much smaller and much more dispersible.

The mechanical evaluations, presented in Appendix $\mathrm{H}$, indicate that the $2 R$ pressure vessel will relieve the excessive internal pressure by jetting either gas or a flashing liquid past the flange gasket. Two accident conditions must be considered. If the $L-10$ is upright, then a release fraction of $2 \times 10^{-3}$ is used in the analysis. This release fraction is inferred from the "rolling" boil results reported by Mishima. (3) If the container is on its side, then liquid is normally present in the flange region. As the pressure is relieved it is impossible to guarantee separation of phases. It is therefore assumed that the escaping material is in the form of a flashing liquid jet. Based on analyses reported by Brown and York ${ }^{(4)}$ and 0strowski, (5) most of the liquid escaping is expected to be in drops less than 60 microns in diameter. Although these drops are too large to be easily carried by air currents, they are ejected into a high temperature gas stream. The arrangement parallels the conditions which exist in a spray drying operation. The 
Chemical Engineering Symposium Series Monograph on atomization and spray drying (6) states that: "Spray drying produces a product consisting of approximately spherical particles which are more or less hollow, depending on the material and on certain operating variables." The article goes on to state that: "it is not a simple matter to produce solid spherical particles by spray drying. Hollow particles are the rule, solid particles the exception." Thus, the most likely product from the release of material in the fire environment is hollow spherical particles with an average diameter less than 60 microns. Many of these hollow spheres may be ruptured. In any case, the dried material can be expected to be as extremely buoyant and as entrainable as a very fine powder. Since conversion of the nitrate solution to the oxide is rapid above $250^{\circ} \mathrm{F}$, (7) the solid is expected to be a fine oxide powder. For this reason, the material released as a result of the fire environment was assumed to be immediately airborne and be $100 \%$ dispersed downwind.

\subsubsection{Quantity Dispersed During Time Intervals Following Initial Release}

The total amount of material which is made airborne is the sum of the fraction immediately airborne and any subsequent releases. For the plutonium oxide powder there are two types of delayed releases. One occurs as a result of airborne entrainment of oxide powder spilled on the ground. The other occurs as a result of the release to the atmosphere of plutonium powder which has been made airborne in an enclosure. For plutonium nitrate solutions, the only delayed release is by entrainment from ground spills.

\subsubsection{Aerodynamic Entrainment of Plutonium Dioxide Powder Following Spillage on the Ground}

The basic data on resuspension of oxide powder spilled on the ground is shown in Appendix $C$. Resuspension factors ranging over 10 orders of magnitude have been generated over the lifetime of the atomic energy industry. (8) Some attempts have been made to generate resuspension rates, (9-13) but none appeared to be directly applicable to model this case. Thus, an empirical fit was made to data on the time-dependent removal of bal1-milled uranium dioxide powder from smooth, sandy soil. (14) Plutonium dioxide is expected to act aerodynamically similar to uranium dioxide. 
Based on the release fraction data in Appendix C for ball-milled uranium dioxide powder from smooth, sandy soil, the fraction airborne over a 24-hr period can be correlated by the expression:

$$
f=4.6 \times 10^{-4} u^{1.78} \text {. }
$$

In this expression, $U$ is the windspeed normally measured at the $50-\mathrm{ft}$ level. In deriving this equation, the data in Appendix $C$ which expressed windspeeds in mph at the $1-\mathrm{ft}$ level had to be corrected to an equivalent windspeed expressed in $\mathrm{m} / \mathrm{sec}$ and measured at an elevation of $15-\mathrm{m}$. When a l-mph wind is encountered at $1-\mathrm{ft}$, the windspeed measured at the 15-m elevation can be expected to be $1 \mathrm{~m} / \mathrm{sec}$; thus the data in Appendix $C$ can be used as if $U$ had been expressed in $\mathrm{m} / \mathrm{sec}$ measured at $15-\mathrm{m}$.

The release fractions for times less than 24-hr are shown in Figures 10.2 and 10.3. These data were taken from Reference 14. It shows that for times longer than 24-hr, essentially all the material that is going to be dispersed will have been dispersed. Since shipment of plutonium is escorted for safeguard reasons, prompt notification of emergency personnel is possible. As a result, it should be possible to fix any released material within a half hour after the accident. A half hour release duration was used in the analysis. The effect of 2-hr release durations on the risk magnitude is considered in Section 11.4 .

An empirical time-dependent term which fits the fractional release values for times under $24-\mathrm{hr}$ is:

$$
f=\left(1-e^{-0.15 U t}\right) \text {. }
$$

Where $U$ is the windspeed $1 \mathrm{ft}$ above ground in miles/hr and $t$ is in hours. Converting the $U$ to $\mathrm{m} / \mathrm{sec}$ at $15 \mathrm{~m}$ and correcting for difference in heights results in the same expression. Equation 1 and 2 can be combined with the $10^{-3}$ fraction immediately airborne to obtain the following source term for airborne dispersal of plutonium dioxide powder. 


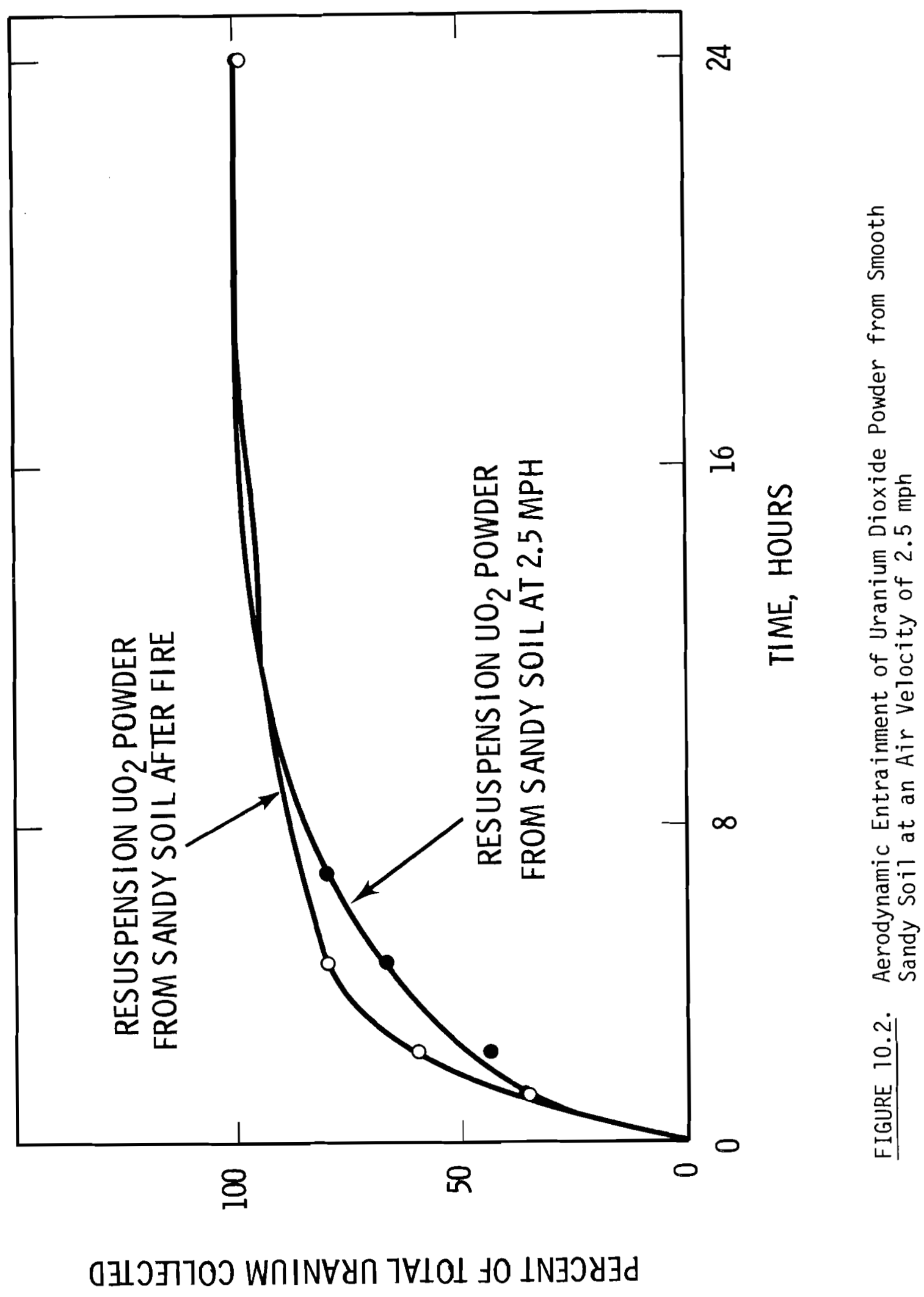




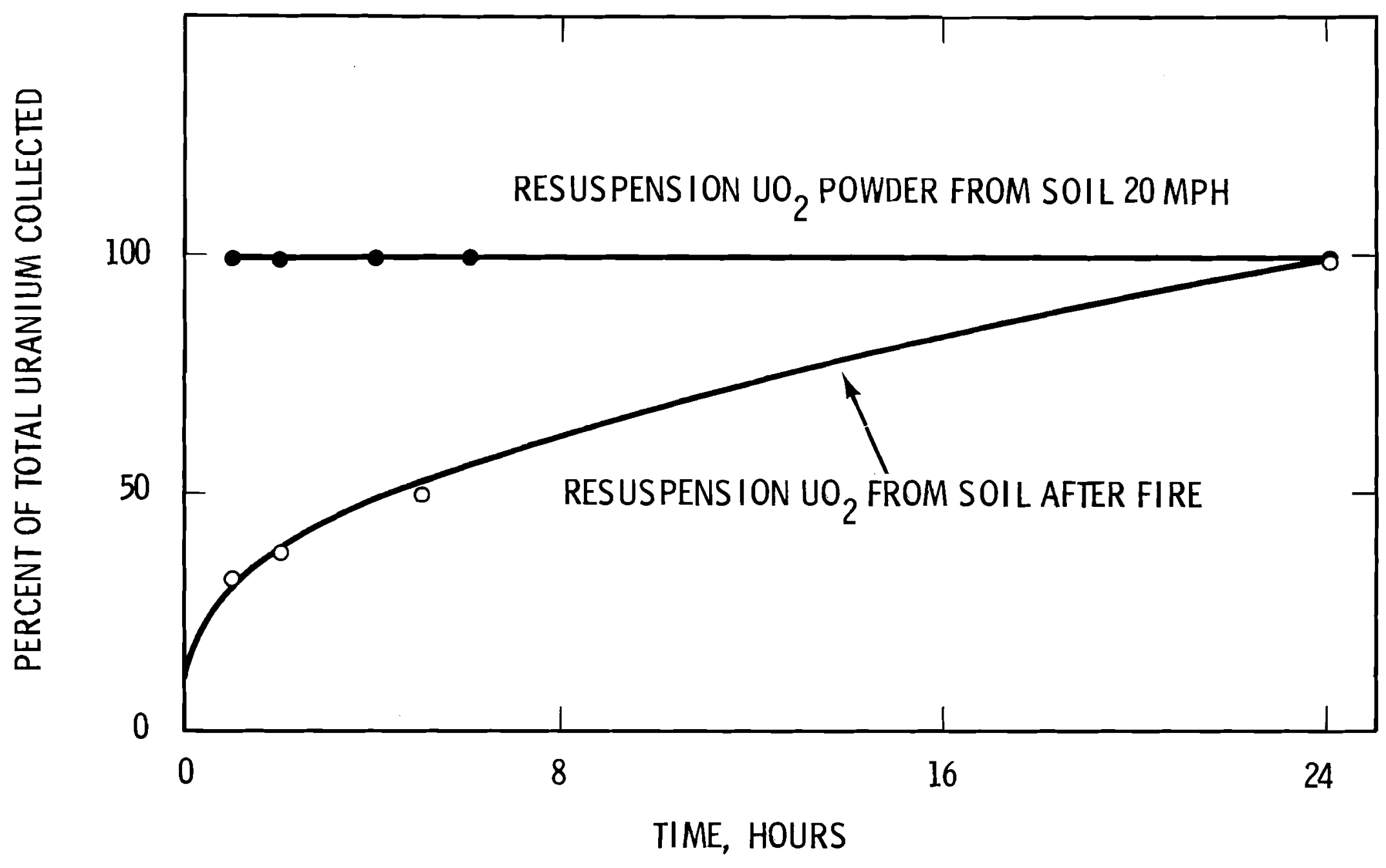

FIGURE 10.3. Aerodynamic Entrainment of Uranium Dioxide Powder from Smooth, Sandy Soil at an Air Velocity of $20 \mathrm{mph}$ 


$$
S=k\left[0.001+4.6 \times 10^{-4}\left(1-e^{-0.15 U t}\right) u^{1.78}\right] .
$$

$K$ is the quantity of material available for dispersal (i.e., the quantity assumed to have penetrated the barriers which contain the plutonium)

$U$ is the windspeed at $50 \mathrm{ft}$, expressed in $\mathrm{m} / \mathrm{sec}$

$t$ is the duration of the release, hours.

The expression used in the risk evaluation for a $0.5 \mathrm{hr}$ release duration was:

$$
A=k\left[0.001+4.6 \times 10^{-4}\left(1-e^{-0.075 U}\right) U^{1.78}\right] .
$$

10.1.2.2 Release of Plutonium Dioxide Aerosols from an Enclosure

The other type of release mechanism for plutonium dioxide powder is the case where the container fails in the van and the van is the controlling barrier. The evaluation in section 9.3 showed that a $10^{-3}$ fraction of the container inventory could be entrained in the air inside the van and gradually leak out following the accident.

The leak rate from the enclosure is very dependent on the extent of the damage to the van. In a very tight van, a leak rate of a few percent per day would be reasonable. However, accident forces sufficient to fail a container in all likelihood will fail the van. In the evaluation it was assumed that any release inside the van had to pass through one orifice $1 \mathrm{~cm}$ wide and $1 \mathrm{~m}$ long and the velocity through the orifice was equal to the windspeed at the $15-\mathrm{m}$ level. In a well mixed volume, the release rate is then:

$$
S=K\left(1-e^{-0.015 U t}\right)
$$

where the symbols are the same as those in Equation 3 . In the 30-min postulated release time, the source term is:

$$
S=k\left(1-e^{-0.0075 U}\right) \text {. }
$$




\subsubsection{Aerodynamic Entrainment of Plutonium Nitrate Solution Spilled on the Ground}

As in Equation 3, an empirical fit was made to existing experimenta1 data on the release of uranium nitrate on smooth, sandy soil at windspeeds of 2.5 and $20 \mathrm{mph}$ measured $1 \mathrm{ft}$ above the surface in a $2-\mathrm{ft}$ square wind tunne1. (14) The equation used to model this case was:

$$
S=K\left(10^{-4} U^{1.41}\right)
$$

where the symbols are defined the same as in Equation 3. Time-dependent release values were not available, and thus data for a 24-hr sampling period were used. Inasmuch as the time span assumed for the accidental releases is $30 \mathrm{~min}$, the value is expected to be conservative.

\subsection{METEOROLOGY}

The diffusion climatology along the transport route must be incorporated into any risk analysis where the atmosphere is an important pathway for dosage to man. The important atmospheric variables are (1) wind direction - indicates the initial direction of trave1, (2) wind speed indicates the rate of transport, and (3) atmospheric stability - indicates the rate of dilution and plume rise potential. Certain characteristics of the release (e.g., height and temperature) are also important in the evaluation of the atmospheric pathway.

Assuming a postulated accident with a surface release and little or no release-related plume rise, the immediate and greatest impact will be in the region surrounding the location of the event. Transport and diffusion are often determined by local influences. Wind speeds and directions show considerable variation that cannot be always summarized by large geographic regions. Local influences include topography (surface roughness, channeling), heat island effects, and proximity to large bodies of water. The inclusion of such influences in the present analysis is not possible, principally because the information is not available either from a data base or from current modeling capabilities. 
For estimates of long-term diffusion averages, the average persistence of winds by sectors are used. Considering wind direction persistences alone, the actual sector annual-average air concentrations can be considerably higher or lower than an average. Based on reported values from 129 weather bureau surface stations in continental U.S., the concentrations range on the order of from half to 5 times the average. The air concentrations near a particular population center can be expected to vary by the same factor depending on the direction of the population center from the selected route. Such a factor could be quite important in determining the effects of releases near large population centers. Over a sufficiently long route the effect of different wind direction persistences may tend to cancel if there is a random relationship between the prevailing wind directions and population centers. The alternative of picking a route based on known diffusion climatologies to minimize risk could be beneficial; however, at the present time it is not included in the model.

The meteorological data used in this analysis are shown in Table 10.1. The values were developed from micrometeorological data collected for diffusion calculations for reactor sites. Seven sets of micrometeorological data were selected from about 26 compilations from reactor sites to account for the range of conditions that could reasonably occur along the route. The use of a single averaged distribution allows for the typical range of windspeeds without undue weighting to any particular site. Although this result cannot be expected to necessarily represent any particular portion of the route, it does represent the type of conditions that may be encountered on the average.

\subsection{DEMOGRAPHY}

The objective of this section is to characterize the population distribution along the plutonium shipping routes. As shown in Figure 10.1, this information is needed to determine both the exceeded frequency at which a given population distribution will be exposed to a release and the 
TABLE 10.1. Average Windspeed/Stability Characteristics

\begin{tabular}{|c|c|c|}
\hline \multicolumn{3}{|c|}{ Wind Speed } \\
\hline $\begin{array}{c}U_{k} \\
m / s e c\end{array}$ & $\underline{k}$ & $P_{k}$ \\
\hline 1 & 1 & 0.255 \\
\hline 3.5 & 2 & 0.508 \\
\hline 7 & 3 & 0.161 \\
\hline 10 & 4 & 0.052 \\
\hline 18 & 5 & 0.024 \\
\hline
\end{tabular}

\begin{tabular}{|c|c|c|c|}
\hline$B(j=1)$ & $D(j=2)$ & $E(j=3)$ & $F(j=4)$ \\
\hline 0.136 & 0.202 & 0.299 & 0.363 \\
\hline 0.243 & 0.274 & 0.272 & 0.211 \\
\hline 0.190 & 0.290 & 0.339 & 0.181 \\
\hline 0.240 & 0.312 & 0.358 & 0.090 \\
\hline 0.276 & 0.348 & 0.356 & 0.020 \\
\hline
\end{tabular}

distribution of the resultant exposure. This data can be developed only after the shipping routes are well defined and realistic population projections have been made.

The population distribution along shipping routes was characterized by dividing the continental U.S. into four zones based roughly on population density and degree of urbanization. The zones are shown in Figure 10.4. A representative state was chosen for each of the zones. Then for the purpose of the study, the population data of the selected states were used in forecasting population characteristics of their respective zones.

The population densities were grouped into three classes: Urban for densely populated urban areas, Suburban for areas of moderate population density, and Rural for the nonurbanized areas. The Suburban area data were obtained by taking the Standard Metropolitan Statistical Area (SMSA) data, which include Urban, and subtracting out the population and land area of the cities. In this way no elements of the population are included twice.

The initial approach was to establish a set of population data for the representative states. Census data for 1960 was used as a data base. This data was extended to 1970 with information available from the 1970 census. Population projections were also made to the year 2000, and, using the compound interest formula to model population growth, estimates were made for 1980 and 1990. 


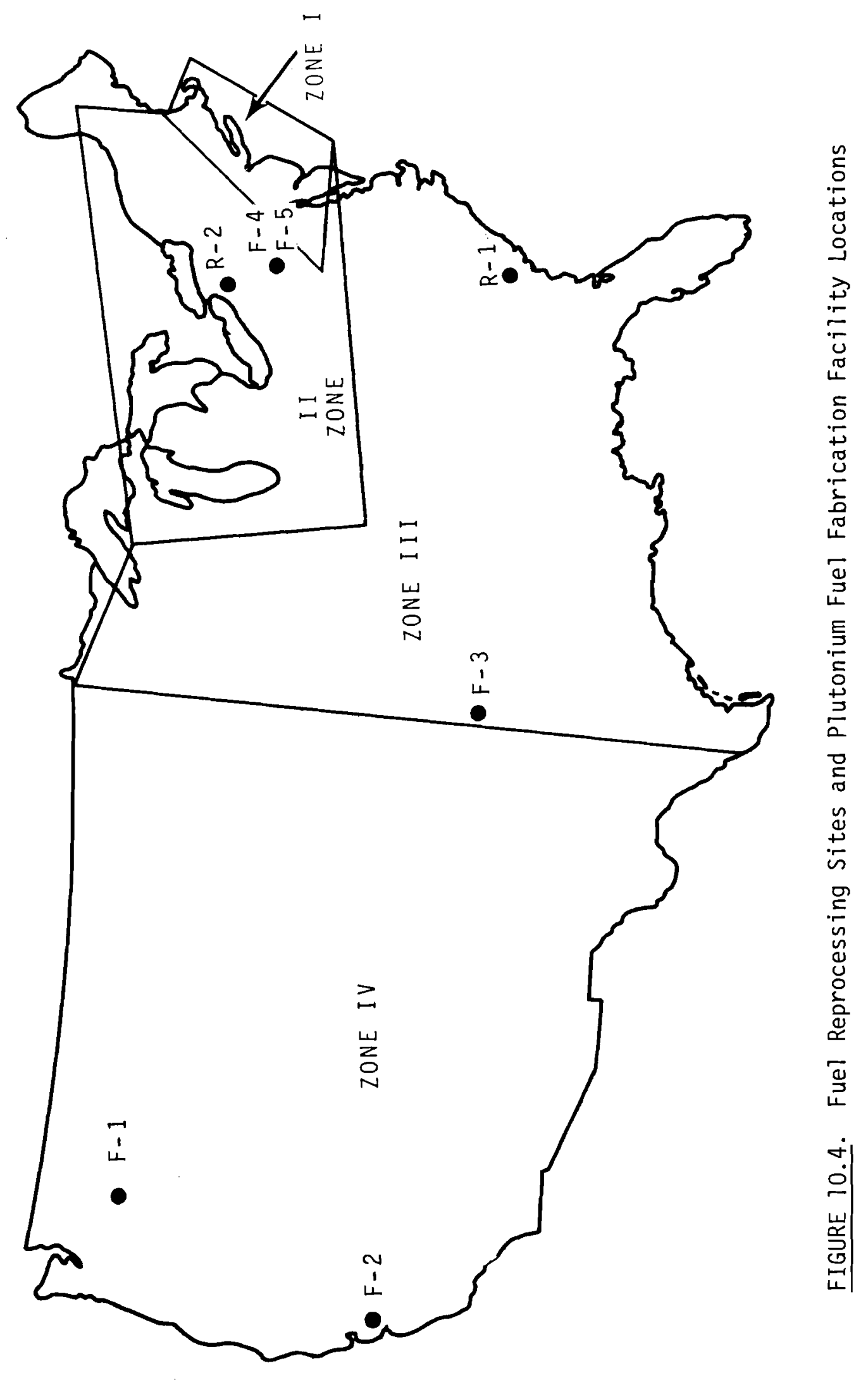

10.13 
The fraction of each fuel reprocessor to plutonium fuel fabricator route in each of the population zones was identified. Using this, a route population density was calculated for each route for each of the time periods considered: 1980, 1990, 2000.

The techniques employed in each step of the analysis are described in more detail below.

\subsubsection{Population Zones Data}

The continental U.S. was divided into four population zones (see Figure 10.4). A representative state for each zone was chosen and data for the state taken to be representative of the entire zone. The states chosen by zone are shown below:

$\begin{array}{cc}\text { Zone } & \text { Representative State } \\ \text { I - High urbanization } & \text { New Jersey } \\ \text { II - Densely populated } & \text { Massachusetts } \\ \text { II - Moderately populated } & \text { Missouri } \\ \text { IV - Low population } & \text { Washington }\end{array}$

The population characteristics for each of the representative states based on 1960 census figures $(15)$ is shown in Tables 10.2 through 10.5 respectively.

TABLE 10.2. New Jersey Population Characteristics-1960

\begin{tabular}{|c|c|c|c|c|}
\hline & Population & Land Area, $\mathrm{mi}^{2}$ & $\begin{array}{r}\text { Density } \\
\text { People/mi } \\
\end{array}$ & Land Area, \% \\
\hline State & $6,066,782$ & 7,532 & 806 & 100 \\
\hline Cities & $2,440,602$ & $226^{(a)}$ & 10,800 & 3 \\
\hline SMSA ${ }^{(b)}$ & $4,821,032$ & 4,227 & 1,147 & 56.1 \\
\hline Rural & $1,245,750$ & 3,305 & 377 & 43.9 \\
\hline
\end{tabular}

a. City of Vineland, $\mathrm{NJ}$ showed an area of $67 \mathrm{mi}^{2}$. This was corrected to $10 \mathrm{mi}^{2}$, which is larger than most cities of comparable population in New Jersey.

b. Includes cities. 
TABLE 10.3. Massachusetts Population Characteristics-1960

\begin{tabular}{|c|c|c|c|c|}
\hline & Population & Land Area, $\mathrm{mi}^{2}$ & $\begin{array}{r}\text { Density } \\
\text { People/mi } 2\end{array}$ & Land Area, \% \\
\hline State & $5,148,578$ & 7,828 & 657 & 100 \\
\hline Cịties & $2,876,806$ & 713 & 4,035 & 9.1 \\
\hline SMSA & $4,379,477$ & 2,924 & 1,498 & 37.3 \\
\hline Rural & 769,101 & 4,904 & 157 & 62.7 \\
\hline
\end{tabular}

TABLE 10.4. Missouri Population Characteristics-1960

\begin{tabular}{|c|c|c|c|c|}
\hline & Population & Land Area, $\mathrm{mi}^{2}$ & $\begin{array}{r}\text { Density } \\
\text { People/mi } \\
\end{array}$ & Land Area, $\%$ \\
\hline State & $4,319,813$ & 69,046 & 63 & 100 \\
\hline Cities & $1,715,093$ & 336 & 5,104 & 0.5 \\
\hline SMSA & $3,414,071$ & 7,967 & 429 & 11.5 \\
\hline Rural & 905,742 & 61,079 & 15 & 88.5 \\
\hline
\end{tabular}

TABLE 10.5. Washington Population Characteristics-1960

\begin{tabular}{|c|c|c|c|c|}
\hline & Population & Land Area, $\mathrm{mi}^{2}$ & $\begin{array}{r}\text { Density } \\
\text { People/mi } 2 \\
\end{array}$ & Land Area, \% \\
\hline State & $2,853,214$ & 66,663 & 43 & 100 \\
\hline Cities & $1,066,336$ & 226 & 4,718 & 0.3 \\
\hline SMSA & $1,707,136$ & 7,663 & 223 & 11.5 \\
\hline Rural & $1,146,078$ & 59,000 & 19 & 88.5 \\
\hline
\end{tabular}

In Tables 10.2 through 10.5 the city data is based on cities of 25,000 population or greater and the SMSA are a 11 the standard metropolitan statistical areas in the state. The rural population and area values are those of the total state minus those of the SMSA. It should be recognized that since the SMSA includes many major cities, the cities are in effect counted twice. This shows up in both the land area and total population counts which result in the numbers adding to greater than $100 \%$. For this reason, the Suburban class has been used to illustrate the projected population densities in subsequent tables. 
The next step was to obtain the same data for 1970 and then determine the population and land area change for major cities (100,000 population) from 1960 to 1970. The 1970 census data was obtained from the Statistical Abstracts of the U.S. (16)

The extrapolation to 2000 was then made based on information presented in an article by J. P. Pickard. (17) Pickard stated that by the year 2000 the urban land area will double. He also states that $85 \%$ of the total population growth will occur in major urban areas. Using this, the total population increase is the urban increase divided by 0.85 . This leaves the rural increase at $15 \%$ of the total growth.

Based on Pickard's projections the land areas and rural populations were calculated for the year 2000. The data for 1980 and 1990 were filled in using the compound interest formula. The resultant population characteristics for each of the four zones in the years 1980, 1990 and 2000 are presented in Table 10.6. The composite population densities for the four zones are shoun in Table 10.7 .

\subsubsection{Average Size of an Urban Area}

The data in Table 10.6 show that urban areas occupy a small fraction of the land area. If a release occurs in a city, it would be incorrect to assume that the release plume is confined completely to an urban area. For that reason, it is important to determine the size of a representative urban area and thereby limit the urban area included in any dose calculation. Using the representative states for each of the four zones, the average urban land area was determined. Only urban areas having a population greater than 25,000 in the year 1960 were used in the analysis. The results of this analysis are summarized in Table 10.8 for the years of interest.

\subsubsection{Shipping Route Mileage by Population Zones}

The second factor in the characterization of the demography is to relate the shipping routes to the population zones. Plutonium shipment routes were previously determined in section 4 . Previous parts of 
잉

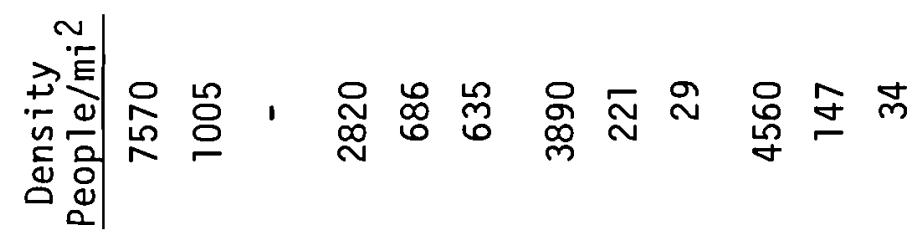

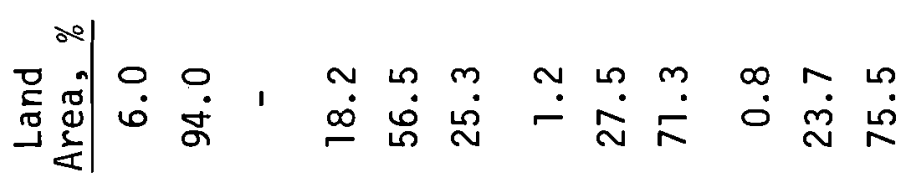

荌

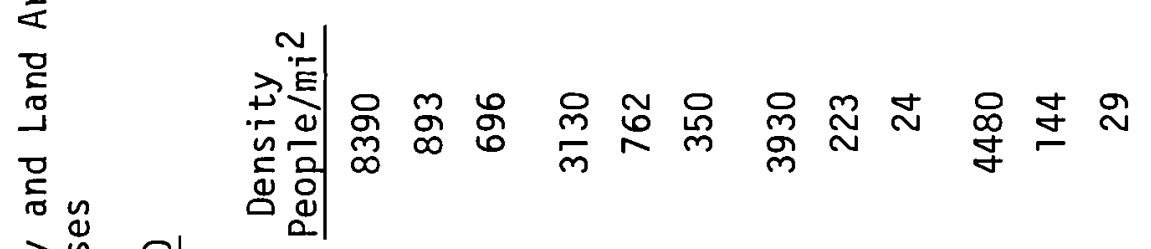

임

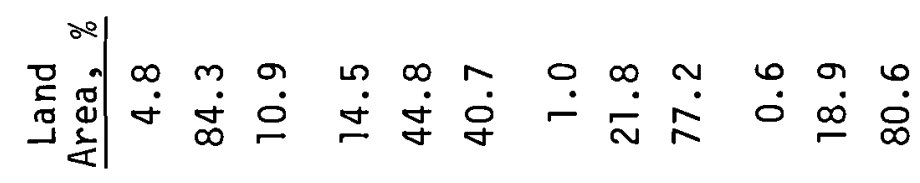

음

흠

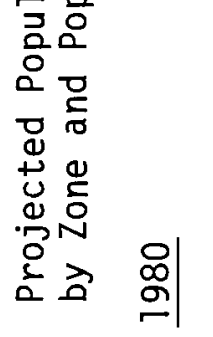

\begin{tabular}{l}
$\dot{0}$ \\
$\dot{0}$ \\
$\dot{w}$ \\
\hline \\
\hline \\
\hline
\end{tabular}

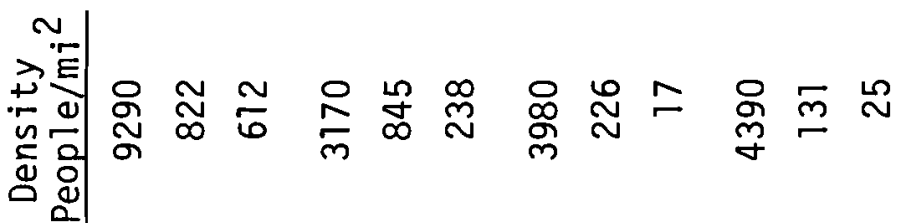

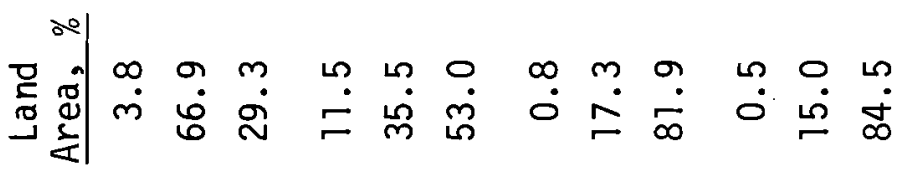

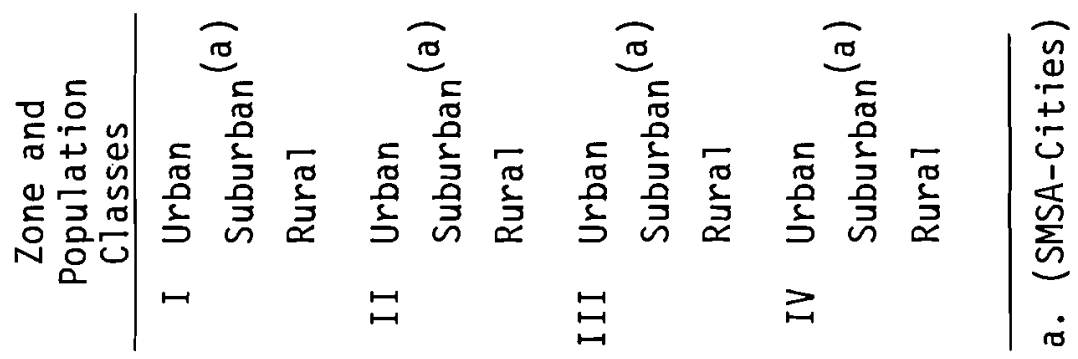


TABLE 10.7. Average Population Densities by Zone (People/mi ${ }^{2}$ )

\begin{tabular}{|c|c|c|c|}
\hline Zone & 1980 & 1990 & 2000 \\
\hline I & 1082 & 1231 & 1399 \\
\hline I I & 824 & 936 & 1061 \\
\hline II I & 84 & 104 & 129 \\
\hline IV & 62 & 76 & 93 \\
\hline
\end{tabular}

TABLE 10.8. Projected Land Area of Urban Areas

in the Four Zones of the U. S.

\begin{tabular}{|c|c|c|c|c|}
\hline \multirow[b]{2}{*}{ Zone } & \multirow{2}{*}{$\begin{array}{c}\text { Number of } \\
\text { Urban Areas (a) } \\
(\text { Pop }>25,000) \\
1960 \\
\end{array}$} & \multicolumn{3}{|c|}{$\begin{array}{l}\text { Average Urban } \\
\text { Land Area, } \mathrm{mi}^{2}\end{array}$} \\
\hline & & 1980 & 1990 & 2000 \\
\hline I & 36 & 7.92 & 9.97 & 12.56 \\
\hline I I & 35 & 25.66 & 32.34 & 41.77 \\
\hline I I I & 12 & 43.92 & 55.33 & 69.67 \\
\hline IV & 8 & 37.80 & 47.63 & 60.00 \\
\hline
\end{tabular}

a. Only includes urban areas in representative state.

10.3 have characterized the population distribution for the various zones of the country for the same years. This section will develop the information on the route mileage in each zone that is needed to obtain the population density along each shipping, route.

A map with the population zones and the location of the fabrication and reprocessing plants is shown in Figure 10.4 The designations F- 1 through F-5 refer to the fuel fabrication facilities listed in Table 4.2. The designations $R-1$ and $R-2$ refer to the fuel reprocessing facilities identified in section 4.2. The distance between each reprocessor and fabricator was obtained from Rand McNally road maps. (18) For each route the fraction of the route in each of the four zones was determined by drawing arcs of a great circle between each fuel fabricator and reprocessor and determining 
the fraction of the arc in each zone. This data is summarized in Table 10.9. The four columns under each reprocessor contain the fractioned route mileage in each zone to each fuel fabricator.

TABLE 10.9. Fractional Shipping Route liileage by Population Zones

(values in percent)

$\begin{array}{lll}\text { 2, NFS, } & \text { 1, A-G, } \\ \text { Reprocessor Number, Name, Location } & \text { Barnwe11, SC } & \text { West Valley, NY } \\ \text { Population Zone Numbers } & \text { I II III IV I II III IV }\end{array}$

Fabricator Number, Name, Location

Percent of Transport Poute in Zone liumber

1 Exxon, Richland, Wash.

2 GE, Pleasanton, Calif.

3 Kerr-McGee, Cresent, Okla.

4 NUMEC, Apollo, Penn.

5 Westinghouse, Cheswick, Penn.

$\begin{array}{rrrrrrrr}- & - & 42 & 58 & - & 28 & 16 & 56 \\ - & - & 40 & 60 & - & 25 & 17 & 58 \\ - & - & 100 & - & - & 42 & 57 & - \\ 4 & 26 & 70 & - & -100 & - & - \\ 2 & 26 & 72 & - & -100 & - & -\end{array}$

- Denotes zero contribution.

Contributions less than 0.05 are neglected, i.e., added to or averaged between other zones.

Example: Route 1-1 Barnwel1, SC to Richland, Wash. $42 \%$ of Mileage in Zone III

$58 \%$ of Mileage in Zone IV

The shipping routes are now completely characterized. The mileage between any reprocessor and fabricator can be determined from Table 4.3. $f$ The fraction of the route in each zone is shown in Table 10.9, and the population distribution in each zone along the route for a particular year can be determined from the data presented in Table 10.6.

\subsection{INDIVIDUAL AND POPULATION DOSE FACTORS}

As shown in Figure 10.1, factors from the meteorological and demographic characteristics of the shipping route are combined with the dose 
conversion factors developed here to determine the population doses resulting from an accidental release of plutonium. There are two parts to the calculation, discussed in the following subsections. First, Dose Conversion Factors must be developed to characterize the effect of inhaled plutonium on an individual's health. Second, using the meteorological data, an Atmospheric Dispersion Model must be developed to characterize the plutonium aerosol concentration downwind from the release point.

\subsubsection{Dose Conversion Factors}

The dose to an individual from inhalation of a plutonium aerosol is a function of the duration of the release, the concentration during the release period, the particle size, the isotopics of the released plutonium, the individual's ventilation rate, the solubility of the inhaled material in body fluids and the retention time of plutonium in body organs.

The dose resulting from plutonium inhalation is calculated using either of two lung models reconmended by the International Commission on Radiological Protection (ICRP). The Initial Lung Model (ILM) recommended by ICRP differentiates soluble and insoluble inhaled material. $(19,20)$ When the inhaled material is soluble, the uptake by other organs is assumed to be essentially instantaneous. A more sophisticated lung model (TGLM), recently suggested by ICRP, characterizes more completely the metabolic pathways of the inhaled material. (21) The derived equations for estimating the dose to organs other than the lung are considerably more complex than those for the ILM. A computer program has been developed for calculating the dose to lung and other organs using the TGLM. ${ }^{(22)}$

A detailed discussion of the two lung models is presented in Appendix $F$. Only results from the TGLM calculations were used in the dose conversion for the present analysis.

For both lung models, the inhalation dose to an individual exposed to a passing cloud can be expressed by:

$$
D_{j}=51.1\left[\frac{f_{a} \varepsilon T(\lambda e, t)}{\lambda_{e}^{m}}\right]_{j} P
$$


where:

$D_{j}$ is dose to organ of interest, $j$, delivered over time $t$, rem $f_{a}$ is fractional uptake, via inhalation by organ of interest

$\varepsilon$ is effective absorbed energy for organ of interest, Mev•rem/dis·rad

$P$ is quantity inhaled, $\mu \mathrm{C} \mathbf{i}$

$\lambda_{e}$ is effective elimination rate constant for organ $j, d^{-1}$

$t$ is time following initial intake, $d$

$m$ is mass of organ $j, g$

$T\left(\lambda_{e}, t\right)$ is function of $\lambda_{e}$ and $t$ and its exact form is dependent upon lung model used to describe inhalation uptake.

The quantity of material inhaled is dependent upon the time-integrated air concentration as expressed by:

$$
P=b c_{a} \tau=b E
$$

where:

b is human ventilation rate, $\mathrm{cm}^{3} / \mathrm{sec}$

$c_{a}$ is air concentration, $\mu \mathrm{Ci} / \mathrm{cm}^{3}$

$\tau$ is duration of inhalation exposure, sec

$E$ is time-integrated air concentration, $\mu C i \cdot \sec / \mathrm{cm}^{3}$.

The time-integrated air concentration, $E$ is obtained from the Atmospheric Dispersion Model discussed in section 10.4.2.

Combining Equation 8 with Equation 9 and normalizing the result to the quantity released yields:

$$
\left(\frac{D_{j}}{Q}\right)=51.1\left[\frac{f_{a} \varepsilon T\left(\lambda_{e}, t\right)}{\lambda_{e}^{m}}\right]_{j} b\left(\frac{E}{Q}\right)
$$

where $Q$ is the quantity released in curies. 
or

$$
\left(\frac{D_{j}}{Q}\right)=k\left(\frac{E}{Q}\right)
$$

where $k$ is the inhalation dose conversion factor for an accidental atmospheric release. Dose conversion factors for 50-year dose commitments for several plutonium isotopes and for ${ }^{241}$ Am based on both the ILM and TGLM are tabulated in Table 10.10.

The conversion factors presented in Table 10.10 are values of $K$ in Equation 10 for the individual isotopes. In the case of the TGLM calculations the particle size is based on an equivalent aerodynamic median diameter (AMAD) of 1 micron. Using this table, one set of conversion factors for any specified isotopic mixture can be obtained.

Table 10.11 lists the plutonium isotopic mixture, assumed to be representative of that which will be shipped in the early 1980's, which was used for the dose calculations reported in this document. Using this isotopic mixture, the conversion factors for the mixture have been calculated and summarized in Table 10.12 using the TGLM conversion factors. The set of $K$ values shown in Table 10.12 convert the amount of material inhaled, expressed in total curies of the mixture, into 50-year dose commitments to the lung and bone for both soluble and insoluble particles. The Task Group Lung Model was used in this analysis with $\mathrm{PuO}_{2}$ metabolized as translocation class $\mathrm{Y}$ and a11 nitrate compounds as class $W$.

The release fractions developed in section 10.1 are presented as fractions of the total weight of plutonium in a container based on the isotopic mixture shown in Table 10.11 .

$$
Q=11.4 \times A \times F_{r}
$$

where:

11.4 is the number of curies per gram in the plutonium isotopic mixture being shipped. (See Table 10.11)

$Q$ is the curies released 
TABLE 10.10. Dose Conversion Factors for Inhalation of Plutonium and Americium-241 Isotopes (Standard Man) ${ }^{(a)}$

\begin{tabular}{|c|c|c|c|c|}
\hline \multirow[b]{2}{*}{ Isotope } & \multirow{2}{*}{ 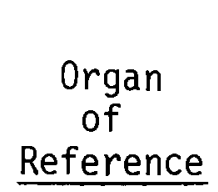 } & \multirow{2}{*}{$\begin{array}{c}\text { Solubility } \\
\text { in } \\
\text { Body Fluids (e) }\end{array}$} & \multicolumn{2}{|c|}{ 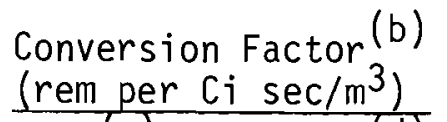 } \\
\hline & & & $\operatorname{ILM}(\mathrm{C})$ & $\operatorname{TGLM}^{(\mathrm{d})}$ \\
\hline${ }^{238} \mathrm{Pu}$ & Lung & $\begin{array}{l}\text { Insol (Y) } \\
\text { Sol }(W)\end{array}$ & $4.4 E+4$ & $\begin{array}{l}1.2 E+5 \\
1.2 E+4\end{array}$ \\
\hline \multirow[b]{2}{*}{${ }^{239} \mathrm{Pu}$} & Bone & $\begin{array}{l}\text { Insol }(Y) \\
\text { Sol }(W)\end{array}$ & $\begin{array}{l}6.0 \mathrm{E}+5 \\
1.2 \mathrm{E}+6\end{array}$ & $\begin{array}{l}1.2 E+5 \\
3.2 E+5\end{array}$ \\
\hline & Lung & $\begin{array}{l}\text { Insol }(Y) \\
\text { Sol }(W)\end{array}$ & $\begin{array}{c}4.0 E+4 \\
----\end{array}$ & $\begin{array}{l}1.1 E+5 \\
1.1 E+4\end{array}$ \\
\hline \multirow[b]{2}{*}{${ }^{240} \mathrm{Pu}$} & Bone & $\begin{array}{l}\text { Insol }(Y) \\
\text { Sol }(W)\end{array}$ & $\begin{array}{l}7.0 E+5 \\
1.4 E+6\end{array}$ & $\begin{array}{l}1.4 \mathrm{E}+5 \\
3.7 \mathrm{E}+5\end{array}$ \\
\hline & Lung & $\begin{array}{l}\text { Insol }(Y) \\
\text { Sol }(W)\end{array}$ & $\begin{array}{c}4.0 E+4 \\
----\end{array}$ & $\begin{array}{l}1.1 E+5 \\
1.1 E+4\end{array}$ \\
\hline \multirow[b]{2}{*}{${ }^{241} \mathrm{Pu}$} & Bone & $\begin{array}{l}\text { Insol (Y) } \\
\text { Sol (W) }\end{array}$ & $\begin{array}{l}7.0 \mathrm{E}+5 \\
1.4 \mathrm{E}+6\end{array}$ & $\begin{array}{l}1.4 E+5 \\
3.7 E+5\end{array}$ \\
\hline & Lung & $\begin{array}{l}\text { Insol }(Y) \\
\text { Sol }(W)\end{array}$ & $4.0 E+1$ & $\begin{array}{l}2.0 \mathrm{E}+2 \\
3.7 \mathrm{E}+0\end{array}$ \\
\hline \multirow[b]{2}{*}{${ }^{242} \mathrm{Pu}$} & Bone & $\begin{array}{l}\text { Insol (Y) } \\
\text { Sol (W) }\end{array}$ & $\begin{array}{l}1.4 \mathrm{E}+4 \\
2.7 \mathrm{E}+4\end{array}$ & $\begin{array}{l}2.1 E+3 \\
6.7 E+3\end{array}$ \\
\hline & Lung & $\begin{array}{l}\text { Insol }(Y) \\
\text { Sol }(W)\end{array}$ & $3.9 E+4$ & $\begin{array}{l}1.0 E+5 \\
1.1 E+4\end{array}$ \\
\hline \multirow[b]{2}{*}{${ }^{241} \mathrm{Am}$} & Bone & $\begin{array}{l}\text { Insol (Y) } \\
\text { Sol (W) }\end{array}$ & $\begin{array}{l}6.4 E+5 \\
1.3 E+6\end{array}$ & $\begin{array}{l}1.3 E+5 \\
3.4 E+5\end{array}$ \\
\hline & Lung & $\begin{array}{l}\text { Insol }(Y) \\
\text { Sol }(W)\end{array}$ & $\begin{array}{l}1.4 E+4 \\
----\end{array}$ & $\begin{array}{l}5.2 \mathrm{E}+4 \\
1.2 \mathrm{E}+4\end{array}$ \\
\hline \multirow{3}{*}{$\begin{array}{l}\text { Reference } \\
\text { Mixture }\end{array}$} & Bone & $\begin{array}{l}\text { Insol (Y) } \\
\text { Sol (W) }\end{array}$ & $\begin{array}{l}7.0 \mathrm{E}+5 \\
1.4 \mathrm{E}+6\end{array}$ & $\begin{array}{l}7.6 E+4 \\
2.0 E+5\end{array}$ \\
\hline & Lung & $\begin{array}{l}\text { Insol (Y) } \\
\text { Sol (W) }\end{array}$ & $1.4 E+3$ & $\begin{array}{l}5.4 \mathrm{E}+3 \\
4.0 \mathrm{E}+2\end{array}$ \\
\hline & Bone & $\begin{array}{l}\text { Insol }(Y) \\
\text { Sol }(W)\end{array}$ & $\begin{array}{l}3.5 E+4 \\
6.9 E+4\end{array}$ & $\begin{array}{l}6.1 E+3 \\
1.7 E+4\end{array}$ \\
\hline
\end{tabular}

\footnotetext{
a. Biological parameters recommended by ICRP. (20)

b. Calculated as a 50-year dose commitment per $\mathrm{Ci} \mathrm{sec} / \mathrm{m}^{3}$ inhaled. Ventilation rate assumed to be $230 \mathrm{~cm}^{3} / \mathrm{sec}$.

c. Initial Lung Mode1, ICRP (19)

d. Task Group Lung Model.(2i) Particle Size: 1 micron (AMAD).

e. Material treated as insoluble or soluble for ILM and as translocation Class $Y$ or 1. for the TGLI?.

f. See Table 10.11 for composition of Reference Mixture.
} 
$A$ is the amount of plutonium in a container in grams

$F_{r}$ is the release fraction of plutonium dispersed during a release.

TABLE 10.11. Reference Mixture of Plutonium and Americium

$\begin{array}{lcc} & \begin{array}{c}\text { Composition (a) } \\ \text { by Weight }(\%)\end{array} & \begin{array}{c}\text { Activity (b) } \\ \text { (Ci/g of Mix) }\end{array} \\ { }^{238} \mathrm{Pu} & 1.5 & 0.26 \\ { }^{239} \mathrm{Pu} & 58 & 0.036 \\ { }^{240} \mathrm{Pu} & 24 & 0.054 \\ { }^{241} \mathrm{Pu} & 11 & 11 \\ { }^{242} \mathrm{Pu} & 4.9 & 1.9 \times 10^{-4} \\ { }^{241} \mathrm{Am} & -\cdots & 0.034\end{array}$

a. Initial composition, after separation from $U$ and FP. Note: Sum does not equal 100 because only two significant figures are used.

b. Activity of isotope in mixture 2 years after separation.

TABLE 10.12. Dose Conversion Factors for Inhalation of Reference Plutonium Mixture (Standard Man)

\begin{tabular}{|c|c|c|}
\hline $\begin{array}{c}\begin{array}{c}\text { Organ } \\
\text { of }\end{array} \\
\text { Reference } \\
\end{array}$ & $\begin{array}{c}\text { Solubility } \\
\text { in } \\
\text { Body Fluids } \\
\end{array}$ & $\begin{array}{l}K \\
(\text { rem per } \\
\left.C i \mathrm{sec} / \mathrm{m}^{3}\right)\end{array}$ \\
\hline Lung & $\begin{array}{l}\text { Insol (Y) } \\
\text { Sol }(W)\end{array}$ & $\begin{array}{l}5.4 \times 10^{3} \\
4.0 \times 10^{2}\end{array}$ \\
\hline Bone & $\begin{array}{l}\text { Insol }(Y) \\
\text { Sol }(W)\end{array}$ & $\begin{array}{l}6.1 \times 10^{3} \\
1.7 \times 10^{4}\end{array}$ \\
\hline
\end{tabular}

\subsubsection{Atmospheric Dispersion Model}

The atmospheric dispersion model calculates the ground level, time integrated air concentration at any downwind distance $x$ and crosswind distance $y$. Based on the coefficients derived in the previous section, the dose to an individual standing at point $(x, y)$ can be calculated. By integrating over the contaminated area, a population dose can then be determined. 


\subsubsection{Time-Integrated, Ground Level Air Concentration}

For releases of short duration, less than a day, the time-integrated air concentration at ground level is evaluated by the bivariate normal diffusion model using Pasquill diffusion parameters. ${ }^{(23)}$ In equation form:

$$
E=\frac{Q}{\pi \sigma_{y} \sigma_{z} \bar{J}_{h}} \exp \left[\left(-y^{2} / 2 \sigma_{y}^{2}\right)-\left(h^{2} / 2 \sigma_{z}^{2}\right)\right]
$$

where:

$E$ is ground leve 1 time-integrated air concentration at point $x, y, C i \cdot s e c / m^{3}$

$x$ is downwind distance measured from point of release, $m$

$y$ is crosswind distance measured horizontally from centerline of cloud, $m$

$Q$ is total release from source, curies

$\sigma_{y}$ is crosswind lateral standard deviation of cloud concentration, $m$

$\sigma_{z}$ is crosswind vertical standard deviation of cloud concentration, $m$ $\bar{U}_{h}$ is average windspeed at the height of release in direction of
travel, $\mathrm{m} / \mathrm{sec}$

$h$ is height of release, $m$.

The values of $\sigma_{y}$ and $\sigma_{z}$ are a function of the downwind distance $x$ and the Pasquill Stability Category existing at the time of the accident. These values are shown in Tables 10.13 and 10.14 , respectively.

The dose to an individual at point $(x, y)$ can now be obtained by specifying the windspeed, height of release and the Pasquill Stability Category. For these conditions, values of $\sigma_{y}$ and $\sigma_{z}$ at the downwind distance, $x$, can be obtained from Tables 10.13 and 10.14 by interpolation. Then E/Q can be calculated at $x, y$ using Equation 12 and $D / Q$ obtained using Equation 10 and Table 10.12.

The population dose could, in theory, be calculated by locating every individual or groups of individuals and going through the above procedure until all individuals receiving a dose have been included in the calculation. 
TABLE 10.13. Values of $\sigma_{y}$ for Pasquill Stability Categories

\begin{tabular}{|c|c|c|c|c|c|c|}
\hline \multirow{2}{*}{$\begin{array}{l}\text { Downwind } \\
\text { Distance } \\
\text { (meters) }\end{array}$} & \multicolumn{6}{|c|}{$\sigma_{y}$ for Pasquill Type } \\
\hline & $\mathrm{A}$ & $\mathrm{B}$ & $\mathrm{C}$ & $D$ & $E$ & $F$ \\
\hline 100 & 21 & 16 & 12 & 8.0 & 6.0 & 3.9 \\
\hline 250 & 54 & 40 & 28 & 20 & 14 & 9.8 \\
\hline 500 & 100 & 76 & 55 & 37 & 28 & 18 \\
\hline 1,000 & 200 & 150 & 110 & 72 & 52 & 36 \\
\hline 2,500 & 450 & 340 & 240 & 160 & 120 & 81 \\
\hline 5,000 & 830 & 630 & 450 & 310 & 220 & 150 \\
\hline 10,000 & 1,600 & 1,200 & 850 & 570 & 410 & 280 \\
\hline 25,000 & 3,400 & 2,600 & 1,800 & 1,200 & 880 & 610 \\
\hline 50,000 & 6,200 & 4,700 & 3,400 & 2,300 & 1,600 & 1,100 \\
\hline 100,000 & 11,000 & 8,500 & 6,300 & 4,100 & 2,800 & 2,000 \\
\hline
\end{tabular}

TABLE 10.14. Values of $\sigma_{z}$ for Pasquill Stability Categories

\begin{tabular}{|c|c|c|c|c|c|c|}
\hline \multirow{2}{*}{$\begin{array}{l}\text { Downwind } \\
\text { Distance } \\
\text { (meters) }\end{array}$} & \multicolumn{6}{|c|}{$\sigma_{z}$ for Pasquill Type } \\
\hline & A & $B$ & C & $D$ & $E$ & $F$ \\
\hline 100 & 15 & 10 & 7.8 & 4.7 & 3.0 & 1.4 \\
\hline 250 & 43 & 26 & 18 & 10 & 7.1 & 4.0 \\
\hline 500 & 140 & 57 & 34 & 19 & 13 & 7.6 \\
\hline 1,000 & 670 & 140 & 64 & 33 & 22 & 14 \\
\hline 2,500 & 2,000 & 580 & 140 & 62 & 41 & 25 \\
\hline 5,000 & 2,000 & 2,000 & 260 & 95 & 61 & 35 \\
\hline 10,000 & 2,000 & 2,000 & 440 & 140 & 84 & 47 \\
\hline 25,000 & 2,000 & 2,000 & 880 & 220 & 120 & 64 \\
\hline 50,000 & 2,000 & 2,000 & 1,400 & 320 & 140 & 79 \\
\hline 100,000 & 2,000 & 2,000 & 2,000 & 450 & 170 & 94 \\
\hline
\end{tabular}

In practice, however, Equations 10 and 12 are used mainly to obtain the maximum individual dose. The population dose is more easily estimated by calculating isopleths of constant dose or time-integrated air concentration. Then the differential area between isopleths and the mean dose received by individuals residing between the two isopleths is calculated. 
The isopleth areas outside $100 \mathrm{~m}$ from the release are obtained using Equation 12. Rather than evaluate $E$ in Equation 12 for every $Q$ and every windspeed $U$, it is more convenient to move $Q$ and $U$ to the other side of the equation and determine isopleths of constant (UE/Q). The isopleths are determined by first selecting a value of $U E / Q$, obtaining values of $\sigma_{y}$ and $\sigma_{z}$ for each $x$ beginning at 100, and then solving Equation 12 using the $k^{\text {th }}$ average wind speed (see Table 10.1) to obtain the value of $y$ for each $x$. The $x, y$ coordinates for an entire isopleth of constant UE/Q can be obtained in the same way. Then by integration, the area enclosed by any isopleth can be determined. The area between two isopleths receives a dose which is intermediate between the two boundary isopleths.

Table 10.15 presents a summary of the isopleth calculations for a $1 \mathrm{~m} / \mathrm{sec}$ wind speed $\left(U_{k}=U_{1}\right)$, similar tables could be constructed for other wind speeds. Isopleths were calculated for $U E / Q$ values at order of magnitude intervals from $10^{-2}$ to $10^{-10}$. Areas between adjacent isopleths were calculated and are shown as the area values for each Pasquill Stability Class. The mean value of $\overline{U E / Q}$ is set at 2.5 times the value of UE/Q at the outer isopleth. The $n$ subscript refers to the isopleth number and the $j$ subscript denotes the stability class. A value of $j=1$ refers to $B$ stability and $j=2$ refers to $D$ stability, etc. The wind speed index, $k$, is one in the table. In Table 10.15 some of the values of $A_{n, j, 1}$ are zero. These zeros are present because the calculations indicate that for those stabilities the isopleth areas lie entirely within the $100 \mathrm{~m}$ evacuation distance.

It is assumed that the people residing within $100 \mathrm{~m}$ of the accident can be evacuated by the escort personnel. Based on the description of the dynamite truck explosion just outside Waco, Georgia, (24) escort personnel should be capable of controlling entry into the $100 \mathrm{~m}$ radius circle. Outside that radius many more individuals are needed to control people who may happen onto the accident scene. The model evacuates the individuals residing within the $100 \mathrm{~m}$ radius circle, which would be in the release plume, to a point where they receive the centerline dose at $100 \mathrm{~m}$. This is conservative since 
TABLE 10.15. Land Areas Within Isopleths of a Release Plume and More Than $100 \mathrm{~m}$ from the Release Point

$\left(U_{k}=U_{1}=1 \mathrm{~m} / \mathrm{sec}\right)$

\begin{tabular}{|c|c|c|c|c|c|}
\hline & \multirow{2}{*}{$(\overline{U E / Q})_{n, j, 1}$} & \multicolumn{4}{|c|}{ Pasquill Stability Classification } \\
\hline & & B & $D$ & $E$ & $F$ \\
\hline & $m^{-2}$ & & $j, 1^{\text {(Area }}$ & & \\
\hline & $2.5 \times 10^{-2}$ & 0 & 0 & 0 & $4.4 \times 10^{3}$ \\
\hline & $2.5 \times 10^{-3}$ & 0 & $1.6 \times 10^{4}$ & $2.2 \times 10^{4}$ & $2.6 \times 10^{4}$ \\
\hline & $2.5 \times 10^{-4}$ & $4.1 \times 10^{4}$ & $1.4 \times 10^{5}$ & $3.8 \times 10^{5}$ & $8.0 \times 10^{5}$ \\
\hline & $2.5 \times 10^{-5}$ & $1.8 \times 10^{5}$ & $3.0 \times 10^{6}$ & $3.8 \times 10^{6}$ & $2.2 \times 10^{7}$ \\
\hline & $2.5 \times 10^{-6}$ & $1.4 \times 10^{6}$ & $7.1 \times 10^{7}$ & $1.9 \times 10^{8}$ & $2.3 \times 10^{8}$ \\
\hline & $2.5 \times 10^{-7}$ & $3.3 \times 10^{6}$ & $4.8 \times 10^{8}$ & $3.1 \times 10^{8}$ & $1.5 \times 10^{8}$ \\
\hline & $2.5 \times 10^{-8}$ & $2.8 \times 10^{6}$ & $2.9 \times 10^{8}$ & $1.7 \times 10^{8}$ & $1.1 \times 10^{8}$ \\
\hline & $2.5 \times 10^{-9}$ & $1.3 \times 10^{7}$ & $2.1 \times 10^{8}$ & $1.3 \times 10^{8}$ & $8.8 \times 10^{7}$ \\
\hline & $2.5 \times 10^{-10}$ & $6.0 \times 10^{6}$ & $1.8 \times 10^{8}$ & $1.1 \times 10^{8}$ & $7.7 \times 10^{7}$ \\
\hline
\end{tabular}

it is hoped that they could be moved out of the release plume entirely. However, onlookers who happen onto the accident scene also have to be considered. It is felt that giving the centerline dose at $100 \mathrm{~m}$ to all evacuated individuals will more than compensate for the dose received by any onlookers. Based on this model, Table 10.16 shows the area within $100 \mathrm{~m}$ which would be in an isopleth for the various stability conditions. Also shown are the values of UE/Q at the centerline $100 \mathrm{~m}$ downwind from the release point.

TABLE 10.16. Land Area Contaminated Within $100 \mathrm{~m}$ of Accident Scene and Centerline Value of UE/Q at 100 m Versus Pasquill Stability Classification

Pasquill Stability

Classification

B

D

E

$\mathrm{F}$

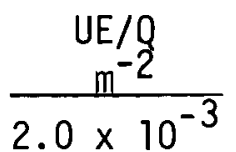

$8.6 \times 10^{-3}$

$1.9 \times 10^{-2}$

$5.7 \times 10^{-2}$ $\frac{\mathrm{m}^{2}}{5.9 \times 10^{3}}$

$3.3 \times 10^{3}$

$2.5 \times 10^{3}$

$1.9 \times 10^{3}$ 


\subsection{POPULATION HEALTH EFFECTS}

The health effects of plutonium are discussed in several survey articles. Bair and Thompson ${ }^{(25)}$ and Bair, Richmond and Wachholz ${ }^{(26)}$ summarize the major findings of over 30 years of research with plutonium. These findings indicate that exposure of humans to large quantities of plutonium ( $\mu \mathrm{C} i$ range) may ultimately result in undesirable health effects; however, none have been observed to date. The few individuals who have been so exposed consist of occupational workers at nuclear facilities, and after more than 25 years of these exposures there have been no observable deleterious effects. Such findings give little guidance in estimating the health effects which may result from the exposure of large populations to small quantities of plutonium. The effects of ionizing radiation on large populations are the only applicable data source available. The number of deaths in the U.S. population which might result from continual exposure to ionizing radiation at a rate of $0.1 \mathrm{rem} / \mathrm{yr}$ has been estimated by an advisory committee of the National Academy of Science. (27) Two risk models were used to estimate the number of excess deaths due to radiation-induced cancer. The results for each model are reported here as Tables 10.17 and 10.18. Details of the models can be found in the NAS-BEIR committee report. (27)

A range of risk estimators for the present study was determined as follows. The excess deaths due to "all other cancers" for all ages were assumed to range from the lower subtotal value of the "Absolute Risk Model" to the upper subtotal value of the "Relative Risk Model." As shown in Table 10.17, the resulting range is from 1210 to 8340 excess deaths per year due to all cancers other than leukemia. Based on a U.S. population of $200 \mathrm{million}$ people and a dose rate of $0.1 \mathrm{rem} / \mathrm{yr}$ the range can be expressed as $6 \times 10^{-5}$ to $4 \times 10^{-4}$ in units of deaths per man-rem.

The frequency of cancer death by type of cancer was estimated from Table 10.18 to be: 


\begin{tabular}{lc} 
Type of Cancer & Frequency \\
\cline { 1 - 2 } Breast & 0.30 \\
Lung & 0.26 \\
GI including stomach & 0.20 \\
Bone & 0.04 \\
A11 other cancer & $\underline{0.20}$ \\
$\quad$ Total & 1.00
\end{tabular}

TABLE 10.17. Estimated Numbers of Deaths per Year in the U.S. Population Attributable to Continual Exposure at a Rate of $0.1 \mathrm{rem} / \mathrm{yr}$, Based on Mortality from Leukemia and from all Other Malignancies Combined(27)

Irradiation

During Period

In Utero

$0-9$ years

$10+$ years

Subtotal

TOTAL

\begin{tabular}{|c|c|}
\hline $\begin{array}{r}\text { Excess } \\
\text { Leukemia }\end{array}$ & $\begin{array}{l}\text { Deaths Due t } \\
\text { All Other }\end{array}$ \\
\hline 75 & 75 \\
\hline 164 & $\begin{array}{r}73(b) \\
122(c)\end{array}$ \\
\hline 277 & $\begin{array}{l}1,062(b) \\
1,288(c)\end{array}$ \\
\hline 516 & 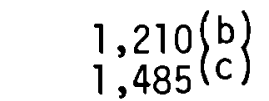 \\
\hline
\end{tabular}

$1,726=0.6 \%$ incr. $2,001=0.6 \%$ incr.

Relative Risk Mode ${ }^{(a)}$
Excess Deaths Due to:
Leukemia All Other Cancer

56 56

93 $715(b)$
$869(c)$

589 $5,869(\mathrm{c})$ 1,665 (b)
$2,415(c)$ 738

a. The figures shown are based on the following assumptions:

- 1967 U.S. vital statistics can be used for age specific death rates from leukemia and all other cancer and for total U.S. population.

- Values for the duration ( $b$ or $c$ ) of the latent period (the length of time after irradiation before any excess of cancer deaths occur), duration of risk ("plateau region"), and magnitude of average increase in annual mortality for each group are as shown in Table 10.18.

b. Thirty year duration of plateau (see Table 10.18).

c. Lifetime duration of plateau (see Table 10.18). 

TABLE 10.18. Assumed Values Used in Calculatjing Estimates
of Risk Shown in Table 10.17 27$)$

\begin{tabular}{|c|c|c|c|c|c|}
\hline \multirow[b]{2}{*}{$\begin{array}{c}\text { Age at } \\
\text { Irradiation }\end{array}$} & \multirow[b]{2}{*}{$\begin{array}{l}\text { Type of } \\
\text { Cancer }\end{array}$} & \multirow[b]{2}{*}{$\begin{array}{l}\text { Duration } \\
\text { of Latent } \\
\text { Period } \\
\text { (years) } \\
\end{array}$} & \multirow[b]{2}{*}{$\begin{array}{c}\text { Duration } \\
\text { of Plateau } \\
\text { Region (a) } \\
\text { (years) } \\
\end{array}$} & \multicolumn{2}{|c|}{ Risk Estimate } \\
\hline & & & & $\begin{array}{c}\text { Absolute } \\
\text { Risk(b) } \\
\text { (deaths/106/ } \\
\text { yr/rem) } \\
\end{array}$ & $\begin{array}{l}\text { Relative } \\
\text { Risk } \\
\text { (\% incr. in } \\
\text { deaths/rem) } \\
\end{array}$ \\
\hline \multirow[t]{2}{*}{ In Utero } & \multirow{2}{*}{$\begin{array}{l}\text { Leukemia } \\
\text { A11 0ther } \\
\text { Cancer }\end{array}$} & 0 & 10 & 25 & 50 \\
\hline & & 0 & 10 & 25 & 50 \\
\hline \multirow[t]{2}{*}{ 0-9 years } & \multirow{2}{*}{$\begin{array}{l}\text { Leukemia } \\
\text { All Other } \\
\text { Cancer }\end{array}$} & 2 & $\begin{array}{l}25 \\
30\end{array}$ & 2.0 & 5.0 \\
\hline & & 15 & Life & 1.0 & 2.0 \\
\hline \multirow[t]{2}{*}{$10+$ years } & \multirow{2}{*}{$\begin{array}{l}\text { Leukemia } \\
\text { All Other } \\
\text { Cancer }\end{array}$} & 2 & $\begin{array}{l}25 \\
30\end{array}$ & 1.0 & 2.0 \\
\hline & & 15 & Life & 5.0 & 0.2 \\
\hline
\end{tabular}

a. Plateau region is the interval following latent period during which risk remains elevated.

b. The absolute risk for those aged 10 or more at the time of irradiation for all cancer excluding leukemia can be broken down into the respective sites as follows:

\begin{tabular}{lc} 
Type of Cancer & Deaths $/ 10^{6} / \mathrm{yr} / \mathrm{rem}$ \\
\cline { 2 - 2 } Breast & 1.5 \\
Lung & 1.3 \\
GI incl. Stomach & 1.0 \\
Bone & 0.2 \\
A11 Other Cancer & $\underline{1.0}$ \\
$\quad$ Total & 5.0
\end{tabular}

These frequencies of occurrence were then applied to the range of excess deaths previously derived to estimate the range of excess deaths which might occur from plutonium releases postulated in this study. The resulting risk estimators are shown in Table 10.19.

It is noted that the risk estimators 1 isted in Table 10.19 are based on observed health effects produced at high dose levels, primarily by low linear energy transfer (LET) radiations and a hypothosis of linearity between effect and dose. It is probable that these estimators are 
TABLE 10.19. Cancer Risk Estimates for Plutonium in Man

Organ of

Reference

Lung

Bone
Estimated Excess Cancer Deaths

Per $10^{6}$ man-rem(a)
Range of Values Value Used (b)

$16-110$

2-17
40

6

a. Derived from the BEIR Report

b. Geometric Mean

significantly dependent on the energy transfer (LET) of the ionizing radiation and upon the dose levels actually encountered. ${ }^{(28)}$ Determination of these probable dependencies is not within the scope of this study and the dependencies have not yet been determined by others. Therefore they have been ignored in this analysis.

Conversion of population doses in man-rem to estimated possible excess cancer deaths was based on the factors presented in Table 10.19. These conversion factors enable a comparison to be made of plutonium shipment risk estimates with other societal risks.

\subsection{ESTIMATED EXPOSURE FREQUENCY}

As shown in Figure 10.1, the risk calculation proceeds along two parallel and interrelated paths. One path characterizes the consequences of an accidental release, and the other path determines the frequency of occurrence for each event in the consequence analysis.

As briefly discussed in section 3 , risk is expressed by the equation:

$$
R_{j}=\left(A F_{R_{j}} \times P_{R_{i}}\right) \times \sum_{q}\left(C_{E_{i, q}} \times P_{E_{q}}\right)
$$

where $q$ represents a number of indices as indicated below.

The terms inside the first set of parentheses represent the product of the amount of material present in a shipment times the fraction of that material 
which is lost to the environment in the $i^{\text {th }}$ release sequence times the expected frequency of occurrence of the release sequence. This part of the analysis is shown as the top half of Figure 10.1 and all the information needed to evaluate these terms was developed in section 9 . The last 2 terms represent the consequences of a unit release and the expected frequency of encountering a given set of environmental conditions. These parts of the analysis are shown in the bottom part of Figure 10.1. The primary purpose of previous parts of this section has been to determine the factors required to evaluate the consequences of a release. Simultaneously, the information required to determine the expected frequency that a given environmental consequence will be encountered has been presented. This part of section 10 will show the development of the frequency of occurrence term.

The analysis presented in this section treated the windspeed, weather stability class and population class as distributed variables. The expected frequency of encountering a given set of environmental conditions can be expressed as:

$$
P_{E_{j, k, l, m}}=P_{j / k} P_{k} P_{l / m} P_{m}
$$

where:

$j$ is the atmospheric stability classification index

$k$ is the windspeed index

$\ell$ is the population density index in zone $m$ of the U.S.

$m$ is the zone index for the shipping routes.

The notation $j / k$ indicates that the expected frequency of encountering the $j^{\text {th }}$ stability class is a function of the windspeed existing at the time of release. In like manner the expected frequency of encountering the $e^{\text {th }}$ population density is dependent on the expected frequency that a shipment will pass through zone $\mathrm{m}$.

The values for the "P" in Equation 14 are obtained from the following tables in this section: 


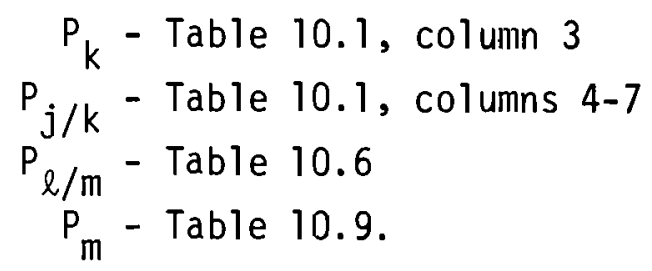

By specifying a value for $\mathrm{j}, \mathrm{k}, l$, and $\mathrm{m}$, one can obtain the expected frequency that an environmental condition will be experienced during a shipment. Associated with that frequency is a corresponding value for the environmental consequences. The relationship is best summarized by the following equation for the environmental term in the risk equation:

$$
\sum_{q}\left(C_{E_{i, q}} \times P_{E_{q}}\right)=\sum_{j, k, \ell, m, n} 11.4 K_{1, i} K_{2} A_{n, j, k}(\overline{E / Q})_{n, j, k} N_{\ell / m} P_{j / k} P_{k} P_{l / m} P_{m}
$$

where:

11.4 is the factor to convert grams released to curies (Table 10.11)

$K_{1, i}$ converts curies received to organ dose (Table 10.12)

$K_{2}$ converts organ dose to heal th effects (Table 10.19)

$A_{n, j, k}$ is the area between two isopleths $n$ and $n-1$ (Tables 10.15 and 10.16)

$(\overline{E / Q})_{n, j, k} \begin{aligned} & \text { is the time integrated air concentration received in } A_{n, j, k} \\ & \text { curie released }\end{aligned}$

$\overline{E / Q}=\overline{U E / Q}$ (Tables 10.15 and 10.16) divided by $\bar{U}$ (Table 10.6).

$\mathrm{N}_{\ell / \mathrm{m}}$ is the population density in the release plume (Table 10.6).

The subscripts and the values for $P$ in Equation 15 have been defined following Equation 14. The product $\left(C_{E_{i, q}} \times P_{E_{q}}\right)$ has units of population health effects per gram of material released. If several organs receive a dose as a result of a release, then the product $\mathrm{K}_{1, i} \mathrm{~K}_{2}$ for each organ receiving a dose must be summed to get the overall effect to the human body.

Equation 15 summarizes the information presented in this section. In section 11, these results will be used in conjunction with the release sequences developed in section 9 to obtain the risk of shipping plutonium oxide in the 6li and liquid nitrate in the L-10 by truck in the United States. 


\section{REFERENCES}

1. S. Hagsgard, S. F. Johnson, G. Jonasson, and S. Henriksson, "The Release of Radioactive Material in the Event of the Destruction of a Ful1 Type A Package," Proc. Second International Symposium on Packaging and Transportation of Radioactive Materials, Gatlinburg, TN, October 1968.

2. W. R. Marsha11, Jr., "Atomization and Spray Drying," Chemical Engineering Progress Monograph Series, no. 2, vol. 50, Amer. Inst. Chem. Engineers, p. 6, 1954.

3. J. Mishima, L. C. Schwendiman, and C. A. Radasch, Plutonium Release Studies, IV. Fractional Release from Heating Plutonium Nitrate Solutions in a Flowing Airstream, BNWL-931, Battelle, Pacific Northwest Laboratories, Richland, WA, November 1968.

4. R. Brown and J. L. York, "Sprays Formed by Flashing Liquid Jets," J. Amer. Inst. Chem. Engineers, vol. 8, no. 2, pp. 149-153, May 1962.

5. H. S. Ostrowski, Evaporation and Induced Airflows in Sprays Produced by Superheated Water Jets, Ph.D. Thesis, The University of Michigan, 1966.

6. W. R. Marsha11, Jr., "Atomization and Spray Drying," Chemical Engineering Progress Monograph Series, no. 2, vol. 50, Amer. Inst. Chem. Engineers, p. 105, 1954.

7. 0. J. Wick, Ed., Plutonium Handbook, Gordon and Beach Science PubIishers, New York, 1967.

8. J. Mishima, A Review of Research on Plutonium Release During Overheating and Fires, HW-83668, General Electric Co., Richland, WA, August 1964.

9. A. M. Amato, A Mathematical Analysis of the Effects of Wind on Redistribution of Surface Contamination, WASH-1187, USAEC, Division of Biology and Medicine, Washington, D.C., September 1971.

10. D. E. Michels, Diagnos is of Plutonium Re-Entrainment in Air, RFP-1927, Dow Chemical Co., Rocky Flats Division, Golden, CO, Apri1 1973.

11. G. A. Sehme1, Particle Resuspension from Asphalt Roads Caused by Car and Truck Traffic, BNWL-SA-4175, Battelle Northwest, Richland, WA, January 1972. 
12. W. G. N. Slinn, "Initial Resuspension Model, " in Pacific Northwest Laboratory Annual Report for 1972 to the USAEC Division of Biomedical and Environmental Research, Volume II: Physical Sciences, Part I, Atmospheric Sciences, BNWL-1715 Pt. 1, Battelle-Northwest, Richland, WA, Apri1 1973.

13. G. A. Sehmel, "Resuspension by Wind at Rocky Flats," in Pacific Northwest Laboratory Annual Report for 1972 to the USAEC Division of Biomedical and Environmental Research, Volume II: Physical Sciences, Part I, Atmospheric Sciences, BNWL-1715 Pt. 1, Battelle, Pacific Northwest Laboratories, Richland, WA, April 1973.

14. J. Mishima and L. C. Schwendiman, Some Experimental Measurements of Airborne Uranium (Representing Plutonium) in Transportation Accidents, BNWL-1732, Battelle-Northwest, Richland, WA, March 1973.

15. County and City Data Book 1967, U.S. Dept. of Commerce, 1968.

16. Statistical Abstracts of the U.S. 1970, Census Division, U.S. Dept. of Commerce, Washington, D.C., 1971.

17. J. P. Pickard, Urban Land and New Trends in Land Development, Dept. of Housing and Urban Development, January 1970.

18. Rand McNally Standard Highway Mileage Guide no. 10, Household Goods Carrier's Bureau, Arlington, VA, 1973.

19. Report of Committee II on Permissible Dose for Internal Radiation, ICRP Publication 2, Pergamon Press, 1959.

20. Recommendations of the International Commission on Radiological Protection, ICRP Publication 6, Pergamon Press, 1962.

21. The Metabolism of Compounds of Plutonium and Other Actinides, A Report prepared by a Task Group of Committee 2 of the International Commission on Radiological Protection, ICRP Publication 19, Pergamon Press, May 1972.

22. J. Houston, D. L. Strenge, and E. C. Watson, DACRIN Computer Program for Calculations of Organ Dose from Acute or Chronic Radionuclide Inhalation, BNWL-B-389, Battelle, Pacific Northwest Laboratories, Richland, WA, December 1974.

23. David H. Slade, Ed., Meteorology and Atomic Energy, 1968, TID 24190, Office of Information Services, U.S. Atomic Energy Commission, Washington, D.C., 1968. 
24. Highway Accident Report - Automobile-Truck Collision Followed by Fire and Explosion of Dynamite Cargo on U.S. Highway 78, near Waco, Georgia, on June 4, 1971, NTSB-HAR-72-5, National Transportation Safety Board, Washington, D.C., September 21, 1972.

25. W. J. Bair and R. C. Thompson, "Plutonium: Biomedical Research," Science, vol. 183, p. 715, February 22, 1974.

26. W. J. Bair, C. R. Richmond, and B. W. Wachholz, A Radiobiological Assessment of the Spatial Distribution of Radiation Dose from Inhaled Plutonium, WASH-1320, U.S. Atomic Energy Commission, Washington, D.C., September 1974.

27. The Effects on Populations of Exposure to Low Levels of Ionizing Radiation, Report of the Advisory Committee on the Biological Effects of Ionizing Radiations, National Academy of Science, November 1972.

28. National Council on Radiation Protection and Measurements, Review of the Current State of Radiation Protection Philosophy, NCRP Report No. 43, Washington, D.C., January 15, 1975. 
11 THE RISK OF SHIPPING PLUTONIUM OXIDE AND LIQUID NITRATE BY TRUCK

In this section the risk of shipping plutonium by truck is calculated using the model described in section 3 and the data developed in sections 9 and 10 . As stated in section 3 , the first step in making the risk assessment is to develup a system description to define the extent and conditions of the assessment. Two risk assessments for plutonium nitrate and oxide shipments were made in this study. System descriptions for the two cases are given in section 11.1. The risk evaluations are presented in section 11.2. Section 11.3 contains a discussion of uncertainties in the results. Major contributors to the risk and the sensitivity of the assessment to pertinent parameters are indicated in section 11.4 .

\subsection{SYSTEM DESCRIPTION}

Two cases were analyzed. The first case compares the risk of shipping plutonium oxide powder in $6 M$ containers with the risk of shipping plutonium nitrate solution in L-10 containers. The second case evaluates the annual U.S. risk from plutonium transport at a shipping level projected to occur in the early 1980's.

\subsubsection{System Description for the Plutonium Oxide and Liquid Nitrate Comparison}

For the comparison it is assumed that there is a requirement to ship 1 metric ton of plutonium a distance of 1500 miles in either the form of oxide or liquid nitrate; the oxide being shipped in $6 \mathrm{M}$ containers and the nitrate solution in L-10 containers. It is further assumed that shipments would be made in 1980 on primary roads, by escorted exclusive use truck, across a region designated as Zone III (S.E. and N. Central United States). Vans are assumed to be of standard trailer design approved for transport of radioactive materials.

The number of shipments, quantity shipped and the shipping distance must be defined for each form of plutonium before the risk can be assessed. The number of shipments required to transport 1 metric ton of plutonium in both the form of oxide and the form of nitrate has been based on shipping regulations, container capacities, transport indices for criticality safety, weight 
limitations and the physical dimensions of the trailers. These results and the expected accident frequency per metric ton shipped are shown in Table 11.1.

TABLE 11.1. Shipping Characteristics for L-10 and 6M Assumed for Analysis (Based on the Shipment of 1 Metric Ton of Pu)

Amount Pu/Container, kg

Containers/MT of Pu

Containers/Shipment

Shipments/MT of Pu

Distance/Shipment, mi.

Shipment Distance, mi.

Accident Probability, \#/mile

Accident Frequency, \#/MT of Pu

\section{$\mathrm{Pu} 02$ Form \\ in $6 M$ Container}

2.55
390
$39(b)$
10
$1500^{(d)}$
15,000
$2.5 \times 10^{-6(e)}$
$3.8 \times 10^{-2}$

$\mathrm{Pu}(\mathrm{NO} 3) 4$ Form

(a) 8.0 liters of $250 \mathrm{~g} \mathrm{Pu} / 1$ solution.

(b) Based on $2.9 \mathrm{~kg}$ of $\mathrm{PuO}_{2}$ per container of projected $\mathrm{Pu}$ isotopics in the early 1980's. (Assumed to comply with 30 watts heat generation, $10 \mathrm{mrem} / \mathrm{hr}$ at $6 \mathrm{ft}$, and total truck weight limits; limited by the dose rate external to the truck. Additional neutron shielding could increase the number of containers per shipment.)

(c) Limited by dose rate.

(d) Assumed average distance between reprocessing plant and fuel fabrication plant.

(e) Reference 1 .

The isotopic composition of the plutonium used in this study is given in Table 10.11. The composition represents the average expected from LWR fuel in the early 1980's. Based on 30 watt per container heat generation 1 imit, the mass of $\mathrm{PuO}_{2}$ permitted in a $6 \mathrm{M}$ is $2.9 \mathrm{~kg}\left(11.4\right.$ watts $/ \mathrm{kg}$ of $\mathrm{PuO}_{2}$ for these isotopics). With this limit, 390 containers are required to hold 
1 metric ton of plutonium. Based on dose rate calculations by Brackenbush, Brown and Faust, ${ }^{(2)}$ and assuming that some neutron shielding could be placed around the array of containers, 39 containers can be transported in one shipment. This means that each shipment would contain $100 \mathrm{~kg}$ of plutonium and 10 shipments would be required to transport 1 metric ton of plutonium.

For the liquid nitrate it has been assumed that the dose rate per equal mass of plutonium would be similar to that of the oxide and that the shipment would be dose rate 1 imited. Using these assumptions, a shipment of liquid nitrate with $100 \mathrm{~kg}$ of plutonium could be made. Since an L-10 normally contains $2 \mathrm{~kg}$ of plutonium in approximately 81 iters of nitrate solution (250 g Pu/l) 50 containers would be required for each shipment. A total of 500 containers would be needed to transport 1 metric ton of plutonium.

\subsubsection{System Description for Evaluating the Risk of Plutonium Transport in the United States in the Early 1980's}

A major portion of the description for the comparison case can be used in the system description for the U.S. annual risk evaluation for the early 1980's. Two additional pieces of information are required. First, the total quantity shipped annually must be specified. Second, a composite shipping route, representative of plutonium transportation throughout the contiguous United States, must be constructed.

As stated in section 4.1, it is assumed that in the early 1980's the nuclear power industry will have grown to include 100 operating power reactors. It is further assumed that an industry this size will ship 18 metric tons of plutoni um annually.

The composite route can be obtained from information developed in section 4. In 1980 the reprocessing load is assumed to be met by the Barnwe 11 and West Valley Plants, with Barnwell handling $67 \%$ of the load. Using this factor and the distribution of plutonium fuel fabricators listed in section 4.4, the relative region mileage of a composite shipment route in the United States can be developed. The composite route is shown in Table 11.2. 
TABLE 11.2 Characteristics of a Composite U.S. Route for Plutonium Transport in the Early 1980's.

\begin{tabular}{|c|c|c|c|}
\hline $\begin{array}{c}\text { Zone } \\
\text { Number }\end{array}$ & $\begin{array}{r}\text { Geographical } \\
\text { Description }\end{array}$ & $\begin{array}{c}\text { Average Route } \\
\text { Length in Zone } \\
\text { (weighted by all routes) } \\
\text { Miles } \\
\end{array}$ & $\begin{array}{l}\text { Fraction of } \\
\text { Total Mileage } \\
\text { Transversing } \\
\text { the Zone } \\
\end{array}$ \\
\hline I & North Atlantic Seaboard & 3 & 0.002 \\
\hline II & Great Lake States & 262 & 0.178 \\
\hline II I & $\begin{array}{l}\text { North Central and } \\
\text { Southeast }\end{array}$ & 590 & 0.400 \\
\hline IV & West & 619 & 0.420 \\
\hline Total & Entire U.S. & 1474 & 1.000 \\
\hline 11.2 & \multicolumn{3}{|c|}{ RISK EVALUATIONS FOR PLUTONIUM OXIDE AND LIQUID PLUTONIUM NITRATE } \\
\hline
\end{tabular}

The risk calculated for plutonium shipment is presented in this section. Section 11.2.1 presents a detailed development of the risk equation and a discussion of measures of risk. A comparison of the risk in truck shipment of plutonium oxide powder in 6M containers and of plutonium nitrate solution in L-10 containers is given in section 11.2.2. The annual risk in the early 1980 's from these two types of shipments is given in section 11.2.3.

\subsubsection{The Risk Equation}

As described in section 3 , the total risk is defined as:

$$
R=\sum_{i} R_{i}
$$

where

$$
R_{i}=\left(A F_{R_{i}} \times P_{R_{i}}\right) \times \sum_{q}\left(C_{E_{i, q}} \times P_{E_{q}}\right)
$$


The subscript " $i$ " refers to the $i^{\text {th }}$ release sequence. In section 10 , a general equation was developed for the terms in the second set of parenthesis in Equation (2). Substituting this expression into Equation (2) results in the following equation.

$R_{i}=\left(A F_{R_{i}} \times P_{R_{j}}\right) \sum_{j, k, \ell, m, n} 11.4 K_{1, j} K_{2} A_{n, j, k}(\overline{E / Q})_{n, j, k} N_{\ell / m} P_{j / k} P_{k} P_{\ell / m} P_{m}$

The total risk of shipping one container then becomes

$$
\begin{aligned}
R= & \sum_{i, j, k, \ell, m, n}\left[11.4 k_{1, i} K_{2} A F_{R_{i}} A_{n, j, k}(\overline{E / Q})_{n, j, k} N_{\ell / m}\right] x \\
& {\left[P_{R_{j}} P_{j / k} P_{k} P_{\ell / m} P_{m}\right] . }
\end{aligned}
$$

Equation (4) has been arranged so that the frequency of occurrence terms are separated from the consequence terms. As described in section 10, each container is analyzed individually. Thus the risk of shipping $\mathrm{N}_{\mathrm{C}}$ containers is given by the following equation:

$$
\begin{aligned}
R_{T}= & \sum_{i, j, k, \ell, m, n}\left[11.4 K_{1, i} K_{2} A F_{R_{i}} A_{n, j, k}(\overline{E / Q})_{n, j, k} N_{\ell / m}\right] x \\
& {\left[N_{c} P_{R_{j}} P_{j / k} P_{k} P_{\ell / m} P_{m}\right] . }
\end{aligned}
$$

The $\mathrm{N}_{\mathrm{C}}$ term is included in the frequency of occurrence term. By putting $N_{C}$ in this part of Equation (4) the consequences of an accident are made proportional to the amount of material in one container and the frequency of release increases with the number of containers shipped in any year. This agrees with the risk model.

In Equation (5) the frequencies of occurrence and the consequences of all accidents are summed to obtain a single annual risk number. This number can be thought of as the expected frequency of occurrence of a fatality attributable to plutonium transport. As discussed in section 1, 
the risk spectrum must also be considered because it differentiates between an event which occurs once a year and results in one fatality and an event which occurs once in a thousand years but results in 1000 fatalities. In order to distinguish between these two events which have the same risk but different severities, curves are constructed which plot accident severity versus the expected frequency of accidents with greater severity. The two events described above have discrete contributions to the graph. Thus for the risk of two operations to be truly comparable, they must have both the same risk and the same risk spectrum.

Both the risk and the risk spectrum can be obtained from the terms in Equation (5). The number of fatalities from an accident release sequence is expressed by the term inside the first set of brackets in Equation (5). The frequency of the consequence (i.e., number of fatalities) is obtained by calculating the terms within the second set of brackets. These two terms can be thought of as pairs of numbers. The risk spectrum curves can be obtained choosing a value for $N$, the number of fatalities, and then scanning the paired sets of numbers for any first terms which exceeds $N$. The summation of all second terms which have a first term greater than or equal to $N$ is the expected frequency of occurrence of accidents which result in $\mathrm{N}$ or more fatalities. This is one point on the risk spectrum curve. This operation is continued until points on the risk spectrum curve are calculated for selected values of $N$ down to one fatality.

\subsubsection{Risk Comparison of Plutonium Oxide and Liquid Plutonium Nitrate Shipments by Truck}

Based on the data shown in Table 11.1, accidents are expected to occur at a rate of $2.5 \times 10^{-6} /$ shipment mile, i.e. once in 400,000 shipment miles. For a shipping distance of 1500 miles, the expected frequency at which plutonium shipments will be involved in an accident is 1 in 267 shipments. Most accidents will not result in a release of plutonium.

The frequency of a release has been estimated using the data presented in section 9. For the liquid nitrate shipment, the analys is shows that 
one out of $5.3 \times 10^{5}$ containers shipped is estimated to release some material as a result of an accident. For the oxide shipment in the $6 \mathrm{M}$ container, one release can be expected for every $2.3 \times 10^{6}$ containers shipped. Since fifty $L-10$ containers are transported per shipment and accidents are expected at a rate of once per 267 shipments, then one accident in 40 can be expected to release some nitrate solution. The comparable number for the oxide shipments is one accident involving a release for every 220 accidents during transport.

The risk spectrum curves for shipping 1 metric ton of plutonium across the north central and southeastern United States for the two plutonium forms are shown in Figure 11.1. Also shown in the figure are the risk spectra for meteorites, chlorine shipments, the total of all natural disasters and the total of all man-caused disasters. These later curves were taken from the draft version of WASH 1400. (3) It can be seen from the figure that the nitrate solution represents a risk of an individual fatality which is more than an order of magnitude above the oxide. In addition, the spectrum curves show that the expected number of fatalities is more than 2 orders of magnitude above the oxide at the comparable expected rates of occurrence. One in 120 accidents where an L-10 containing nitrate solution fails will result in one or more fatalities attributable to the release. For the oxide, one release in about 600 will result in one or more fatalities.

Combining the above occurrence frequencies, the likelihood of one or more fatalities from plutonium release during a 1500 mile shipment of plutonium nitrate solution in L-10 containers is about 1 in 1 million. The corresponding likelihood for plutonium oxide powder shipment in $6 \mathrm{M}$ containers is 1 in 35 million.

Al though not shown in the spectrum curves, the calculations show that the highest number of fatalities occurred under very stable atmospheric conditions (Pasquill F Stability) and at 1 meter per second wind speeds. The curves shown in Figure 11.1 do not consider evacuation of people from the release plume. However, it should be noted that at low wind speeds, there is some time available to evacuate people before the release plume reaches their location. For example if the average wind speed is $1 \mathrm{~m} / \mathrm{sec}$, 


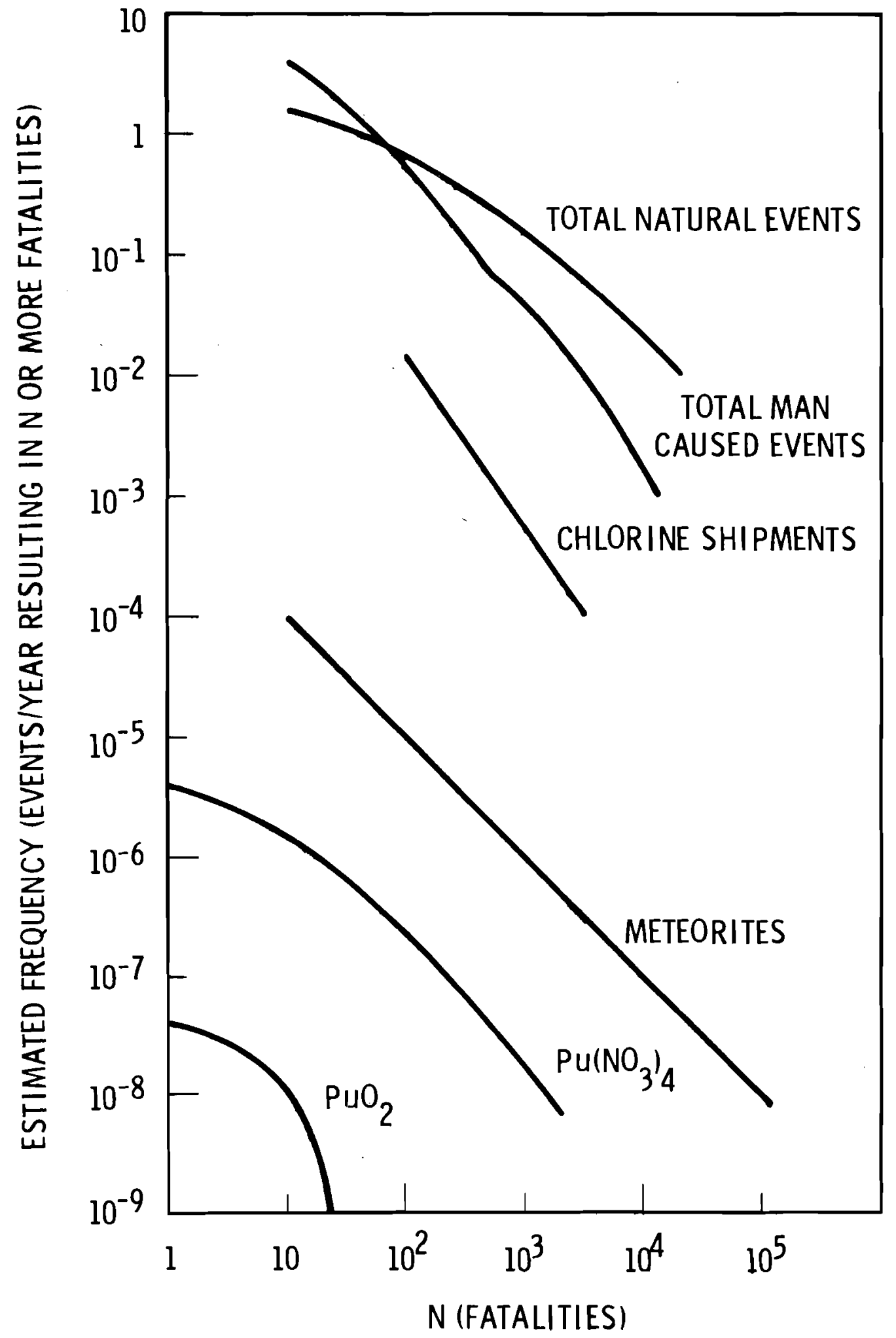

FIGURE 11.1 Risk Spectrum for Shipping One Metric Ton of Plutonium 1500 Miles Across the North Central and Southeastern U.S. 
approximately 16 minutes is available before the release plume travels $1 \mathrm{~km}$. Over 2.5 hours is available $10 \mathrm{~km}$ downwind. Although 16 minutes does not allow time to evacuate individuals, two and a half hours would appear to represent a time interval during which some evacuation might be possible. In this respect, the results presented here represent a conservative upper limit.

Sensitivity analyses presented in section 11.4 will further analyze the risk spectrum curves and identify the more important contributors to the risk.

\subsubsection{The Risk of Shipping Plutonium Oxide or Liquid Plutonium Nitrate in the Early 1980's}

The annual risk to the U.S. from plutonium oxide powder shipment in $6 \mathrm{M}$ containers and plutonium nitrate solution shipment in L-10 containers in the early 1980's is reported in this section. Figure 11.2 shows the risk spectrum for both the oxide and nitrate shipments. The liquid nitrate fatality spectrum remains more than 2 orders of magnitude more severe than the oxide case at comparable rates of occurrence. Also shown in Figure 11.2 are the risk spectra for meteorites, chlorine shipments, the total of all natural disasters and the total of all man-caused events. It can be seen that the liquid nitrate shipment risk spectrum is comparable to the risk spectrum for meteorites. Since the risks from chlorine shipments and other man-caused events pose a significantly greater hazard, the conclusion would be that many commonly accepted risks pose a hazard which is greater than that from plutonium shipments.

Figure 11.3 shows the nitrate shipment risk spectrum curve for the U.S. and also the contribution from four zones in the U.S. For the nitrate shipments, Zones III and IV have essentially the same risk spectrum. Zone III represents the Southeastern and North Central states and Zone IV represents the Western states. These two zones contribute most significantly to the left hand portion of the risk spectrum curve, i.e., accidents resulting in from 1 to 10 fatalities. To the right of that portion the curve for the total U.S. is controlled by Zone II. This zone consists of the lower Great 


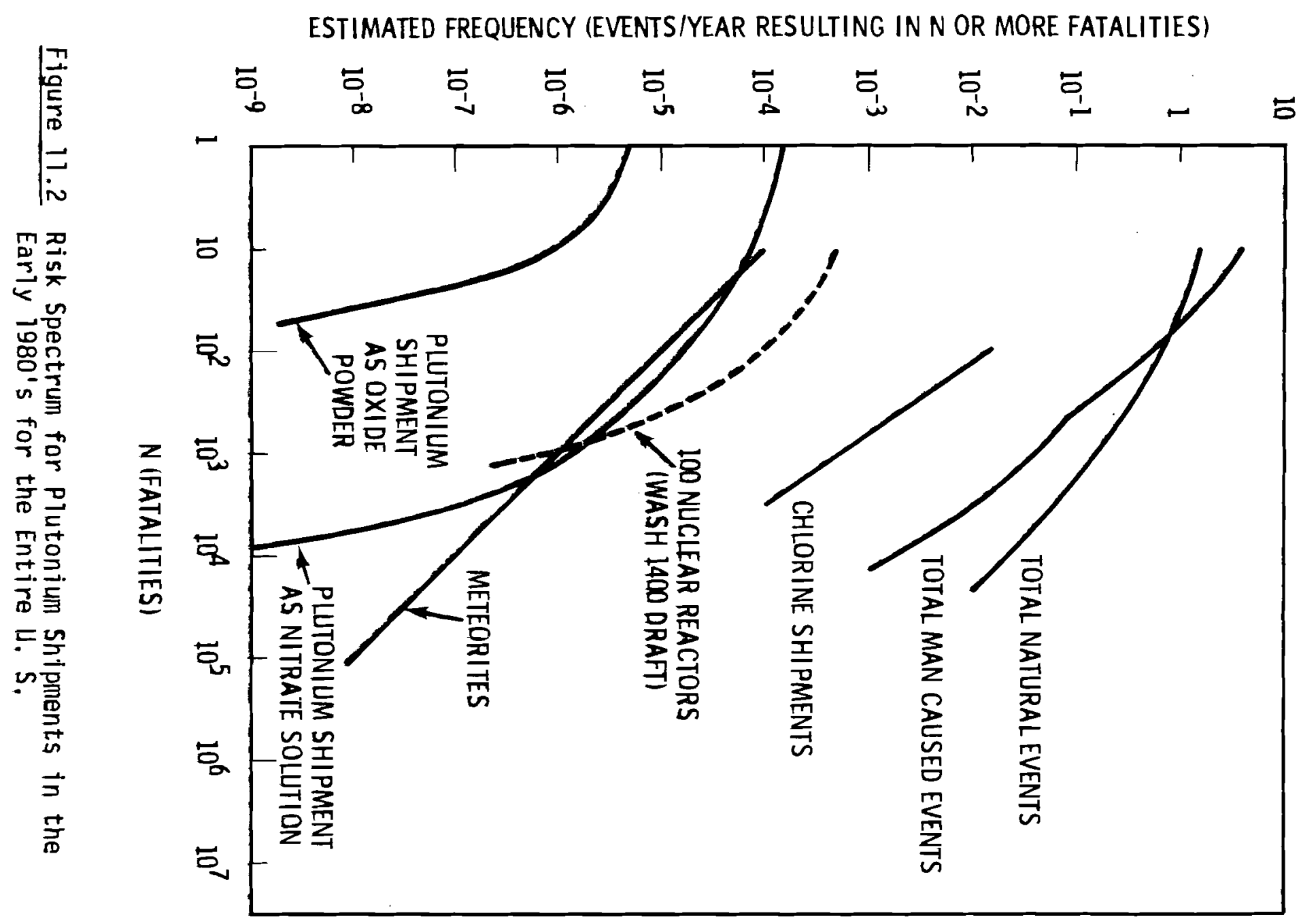




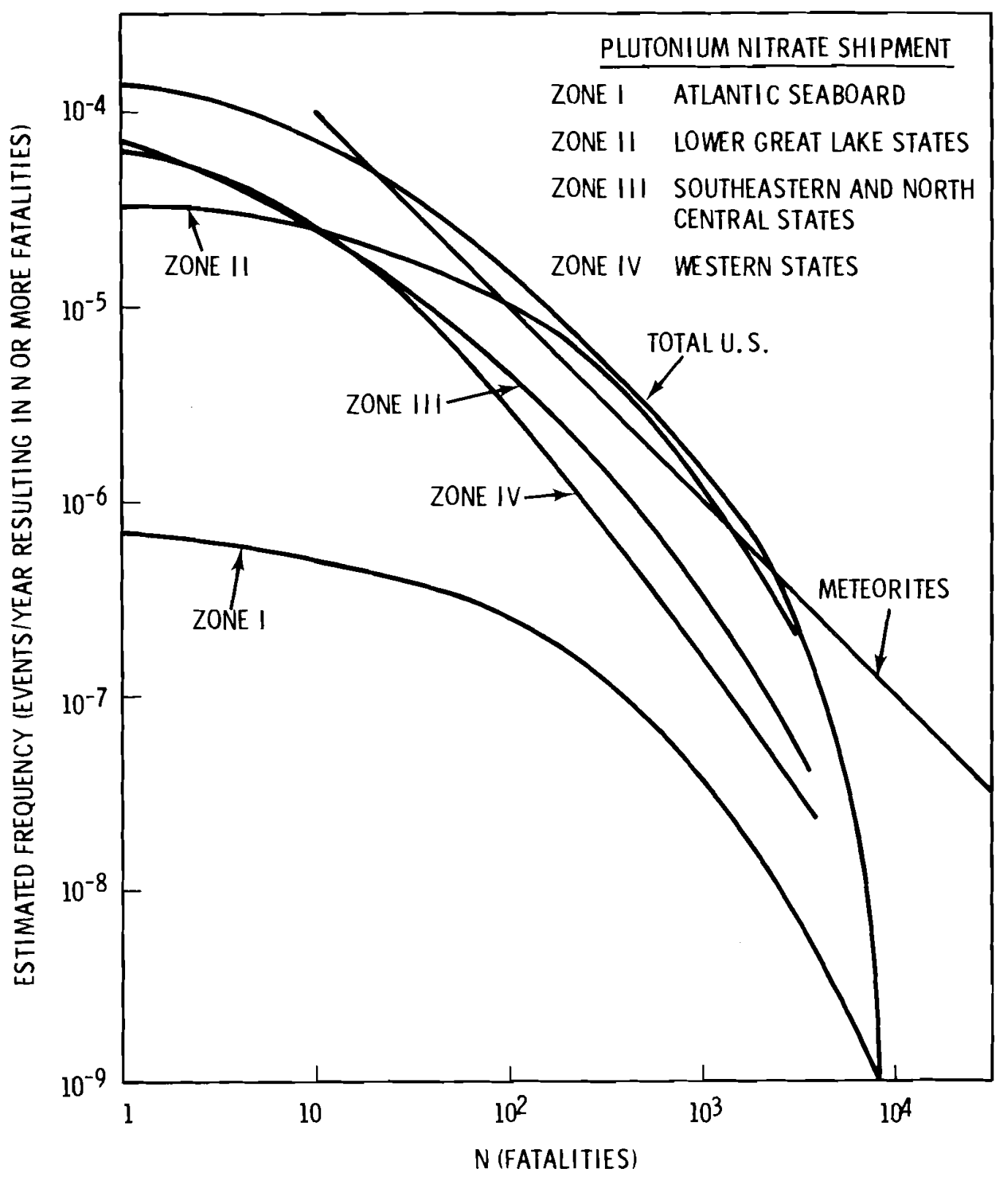

FIGURE 11.3 Risk Spectra for Liquid Plutonium Nitrate Shipments in the Early 1980's for Four Zones in U. S. 
Lake States. Zone I, which represents the Northeastern states bordering on the Atlantic 0cean becomes controlling only at the high consequence end of the risk spectrum curve.

Figure 11.4 shows the risk by zone for the plutonium oxide shipments. Zone 1 controls the right end of the spectrum with Zone II dominating at lower severity levels. Zones III and IV, although contributing to the risk at the lower end of the spectrum, never dominate the U.S. risk spectrum as was the case with the nitrate.

Discussions of the uncertainties in the results presented in this section and their sensitivity to pertinent parameters in the analysis are presented in sections 11.3 and 11.4 .

\subsection{RISK CALCULATIONAL UNCERTAINTIES}

In this section, two types of calculational uncertainties will be discussed. The first concerns the propagation of uncertainty in the basic risk equation. The second concerns the assumption that multiple container failures are unlikely to occur from the same accident.

\subsubsection{Analyses of Variance in Risk Value}

The risk value obtained in the evaluation is the linear product of several parameters, each of which has a mean and a distribution of values about the mean. The basic risk equation for the $i^{\text {th }}$ release sequence is:

$$
R_{i}=\left(\begin{array}{ll}
A F_{R_{i}} & P_{R_{i}}
\end{array}\right)\left(\begin{array}{lll}
\sum_{q} & C_{E_{i, q}} & P_{E_{q}}
\end{array}\right)
$$

The terms were defined in section 3 . The first three terms specify the release fraction and the remainder the environmental consequences. In generating the figures shown in this section, the environmental terms were included in the analysis as distributed variables. However, the mean values were used for the release terms. This section will consider the uncertainties resulting from the use of the mean values. 


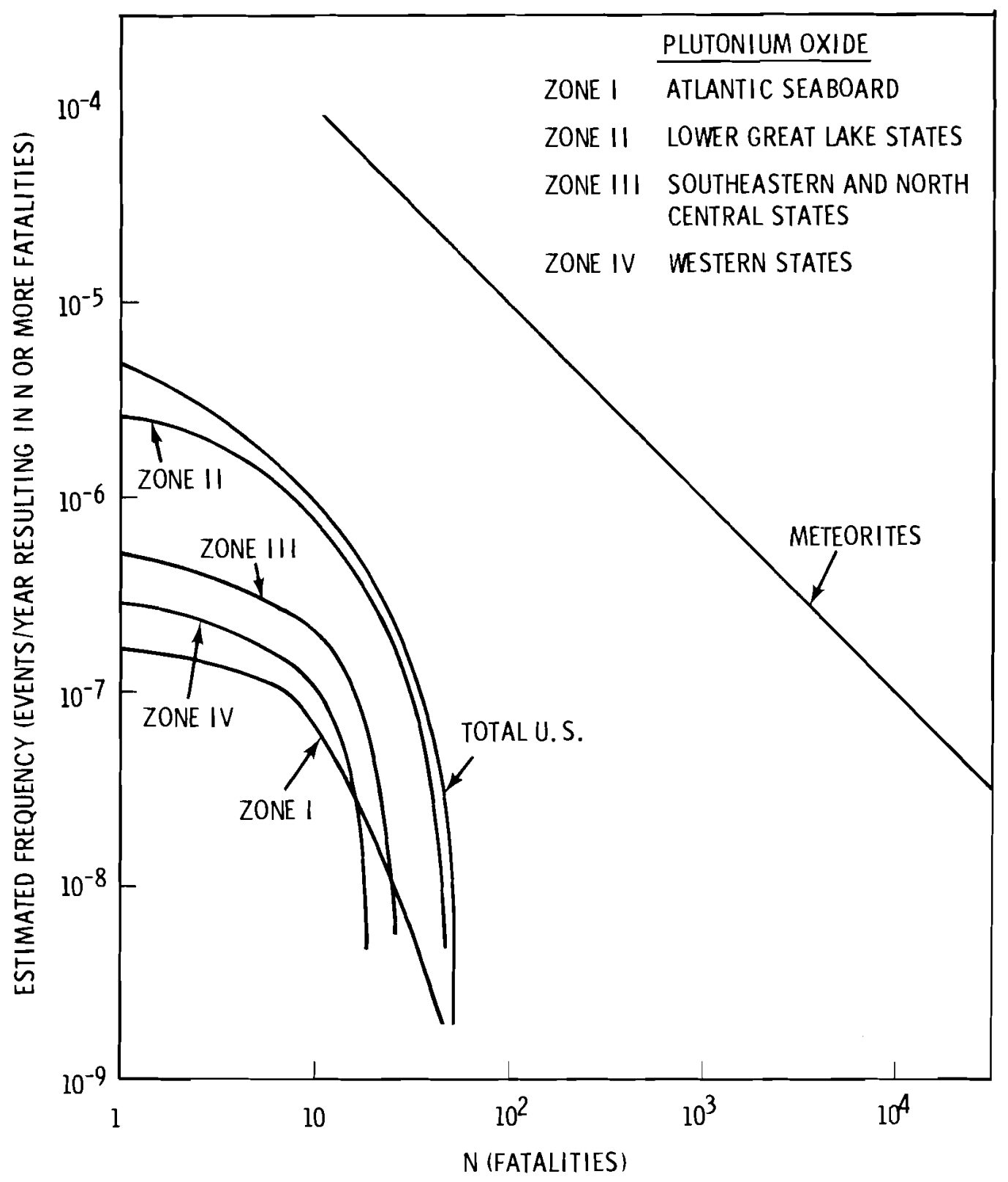

FIGURE 11.4 Risk Spectra for Plutonium 0xide Shipments in the Early 1980's for Four Zones in U. S. 
$F_{R_{j}}$ and $P_{R_{j}}$ can be represented by equations of the form:

$$
\begin{aligned}
& F_{R_{i}}=f_{1_{i}} f_{2}{ }^{f} 3_{i}{ }^{f} 4_{i} \\
& P_{R_{i}}=\prod_{n=1}^{N} P_{i_{n}} .
\end{aligned}
$$

In these equations the $f^{\prime} s$ are barrier release fractions and the $P^{\prime} s$ represent the expected frequency of occurrence for the $\mathrm{N}$ elements in release sequence $i$. Since some of the terms are poorly known it is important to quantify to some extent, the effect of the uncertainties on the final result. This section will look primarily at several measures of uncertainties derived from a statistical evaluation of Equations (1) and (2).

The statistical evaluation requires the definition of several terms. The first is the expected value of a variable " $x$ " which is defined as:

$$
E(x)=\int_{-\infty}^{\infty} x f(x) d x
$$

where $f(x)$ is the probability density function.

The expected value of $x$ is frequently represented by the symbol " $\mu$ " and represents the mean value.

The second term is the variance, denoted by the symbol " $\sigma^{21}$ and defined as:

$$
\sigma^{2}=E(x-\mu)^{2}=\int_{-\infty}^{\infty}(x-\mu)^{2} f(x) d x=E\left(x^{2}\right)-[E(x)]^{2} .
$$

The standard deviation, denoted by the symbol " $\sigma$ " is obtained by taking the square root of the variance. Finally, the coefficient of variation, denoted by the symbor " $\vee$ ", is defined as:

$$
\nu=\frac{\sigma}{\mu} \text {. }
$$

The behavior of the coefficient of variation is a measure of how uncertainties propagate through various equations like Equations (7) and (8)

Equation (7) is the product of four terms. If they are independent then the variance of the product is related to the variance of the terms by the relationship: 


$$
\sigma_{F_{R}}^{2}=E\left(F_{R}^{2}\right)-\left[E\left(F_{R}\right)\right]^{2}=\underset{r=1}{4} E\left[f_{r_{j}}^{2}\right]-\underset{r=1}{4}\left[E\left(f_{r_{j}}\right)\right]^{2}
$$

The best way to look at the propagation of uncertainties is to look at some examples. Consider the case where the release fractions through each barrier are independent and uniformly distributed between the limits of zero and one. Then:

$$
{ }^{\mu_{f}}=1 / 2 \text { for all values of } r \varepsilon[1,4]
$$

and

$$
\stackrel{2}{\sigma_{f_{r}}}=1 / 12 \text { for a } 11 \text { values of } r \varepsilon[1,4] \text {. }
$$

Then using Equation (12)

$$
\sigma_{F}^{2}=\left(\frac{1}{3}\right)^{4}-\left[\left(\frac{1}{2}\right)^{2}\right]^{4}=\frac{1}{81}-\frac{1}{256}=8.44 \times 10^{-3}
$$

and

$$
v_{F}=\frac{\sqrt{8.44 \times 10^{-3}}}{0.0625}=1.47 \text {. }
$$

The coefficient of variation of the individual terms was

$$
v_{f_{r}}=\frac{\sqrt{1 / 12}}{1 / 2}=0.5774 \text {. }
$$

Thus the coefficient of variation, which is a measure of the width of the distribution relative to the mean has increased by a factor of 2.55 .

It is interesting to note that the fraction immediately released upon failure determined in section 10.1 was found to be $0.76 \times 10^{-3}$ with a standard deviation of $0.46 \times 10^{-3}$. This corresponds to a coefficient of variation of 0.60 which is quite close to the value of $v_{f_{r}}=0.5774$ used in the previous example. If the same relative uncertainty held true for each barrier then the final result would have a coefficient of variation equal to 1.47. Assuming the final distribution is normal, then there is $95 \%$ confidence that the value of the release fraction will not be greater than $1.645 \sigma_{f}+\mu$. Thus it can be said with a confidence level of $95 \%$ that the release fraction will not be more than 3.4 times the value used. 
In order to evaluate the propagation of uncertainties in the expected release frequency it is convenient to consider a specific distribution, the log normal distribution. The density function for this distribution is:

$$
f(x)=\frac{1}{\sigma x \sqrt{2 \pi}} e^{-\frac{(\ln x-\mu)^{2}}{2 \sigma^{2}}} .
$$

This is the probability density for $x$ which occurs when the variable $\ln x$ is normally distributed.

When the expected frequencies are expressed as their logs then the expression for $P_{R}$ shown in Equation (8) becomes

$$
\log P_{R_{i}}=\sum_{n}^{N}\left(\log P_{i_{n}}\right) \text {. }
$$

The variance of a sum of random variables is related to the variance of the individual random variables by the expression:

$$
\sigma^{2}\left(\log P_{R_{i}}\right)=\sum_{n} \sigma^{2}\left(\log P_{i_{n}}\right) .
$$

Typically, the values of $P_{i}$ may be only known to an order of magnitude, i.e., $25 \%$ of the time the value will be more than a half an order of magnitude lower and $25 \%$ of the time it might be more than a half order of magnitude higher. These uncertainty levels correspond to a $\sigma=0.74$. If there are four terms in Equation (8) which have standard deviations approaching this value, then $\sigma\left(\log P_{R_{j}}\right)=1.48$.

Expressed in terms of uncertainties, the resultant frequency of occurrence can be expected to be two orders of magnitude lower than the value of $P_{R_{j}} 25 \%$ of the time and it can be expected to be two orders of magnitude higher $25 \%$ of the time. 
Since there are some variables which are known no more accurately than a $\sigma=0.74$ using the $\log$ normal distribution, $a \sigma=1.48$ on the final result, using the same distribution appears reasonable. Since the one sided $95 \%$ confidence interval corresponds to a $(1.645) \sigma=2.44$, the $95 \%$ confidence limit on the occurrence frequency is estimated to be slightly greater than two orders of magnitude above the values presented in the analysis. A more complete analysis may show that a smaller confidence level is warranted.

Since all the risk plots are constructed on a $\log$ scale, the $95 \%$ confidence level on the release fraction, assuming a normal distribution is about a half an order of magnitude. This could be considered to be the estimated uncertainty level in the number of fatalities resulting from a given release.

\subsubsection{Analysis of Multiple Container Failures}

Based on the information presented in section 11.2, for oxide shipments there is one container failure in 220 accidents. This is one container failure out of 8580 containers which have been involved in accidents. What is the probability that two will fail in the same accident? If it is assumed that failures are independent, i.e., that there are no accident stresses capable of causing many simultaneous failures, then the probability of " $x$ " failures in a shipment of " $n$ " containers given the probability of one defective container is:

$$
P(x)=\left(\begin{array}{l}
n \\
x
\end{array}\right) P^{x}(1-P)^{n-x}
$$

where

$$
\left(\begin{array}{l}
n \\
x
\end{array}\right)=\frac{n !}{x !(n-x) !}
$$

Then the probability of one container out of 39 in the shipment failing in an accident is: 


$$
P(1)=\left(\begin{array}{c}
39 \\
1
\end{array}\right)\left(\frac{1}{8580}\right)\left(1-\frac{1}{8580}\right)^{38}=\left(\frac{39}{1}\right)\left(\frac{0.9956}{8580}\right)=4.5 \times 10^{-3}
$$

The probability of two failing in the same accident is:

$$
P(2)=\left(\begin{array}{c}
39 \\
2
\end{array}\right)\left(\frac{1}{8580}\right)^{2}\left(1-\frac{1}{8580}\right)^{37}=\frac{(39)(38)}{(1)(2)} \frac{(0.9957)}{(8580)^{2}}=1.0 \times 10^{-5}
$$

Thus two container failures in the same accident are expected once in 100,000 accidents. This is greater than two orders of magnitude less frequent than the single container failure statistics and can be neglected in the risk assessment.

The previous analysis assumed that there are no accident stresses capable of causing many simultaneous failures. However, there are two accident stresses which do not meet this criterion. One is criticality and the other is crush.

If criticality occurs, the internal pressures generated within each container could rupture the containers. Based on the results presented in sections 7.0 and 9.0, and Appendix G, criticality would not be an initiating event. However, events and conditions following a severe accident in which plutonium is released could result in criticality. Nevertheless, the necessary events and conditions for criticality to occur are so limited that this stress should not significantly contribute to the risk levels.

The crush environment on the $L-10$ requires more detailed analys is because in accidents involving extreme decelerations multiple containers could fail by drum 1id removal. Since Sandia estimates that about $1 / 3$ of the cargo could be lost in $6.8 \%$ of all accidents, more than one failed container would likely be removed from the truck in this case. Failed containers which lose vermiculite when removed from the truck are then susceptible to releasing plutonium if a fire occurs after the accident.

The detailed evaluation of the crush envirorment is presented in Appendix $\mathrm{J}$. The results of this supplemental evaluation are shown in Figure 11.5. The evaluation presented in section 11.2 assumed that only one container failed in an accident but at an accident frequency 


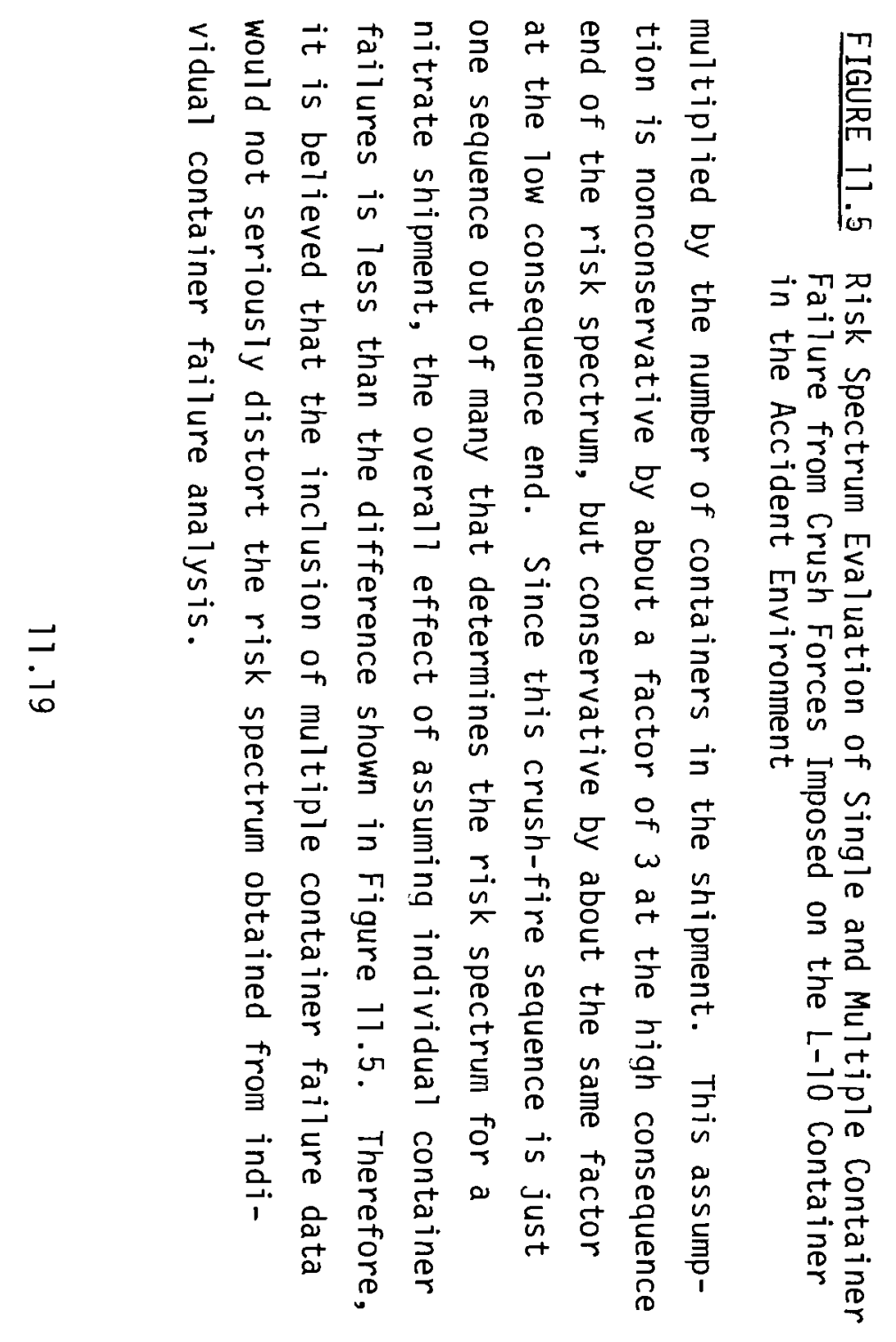

ESTIMATED FREQUENCY

(EVENTS/YEAR RESULTING IN N OR MORE FATALITIES)

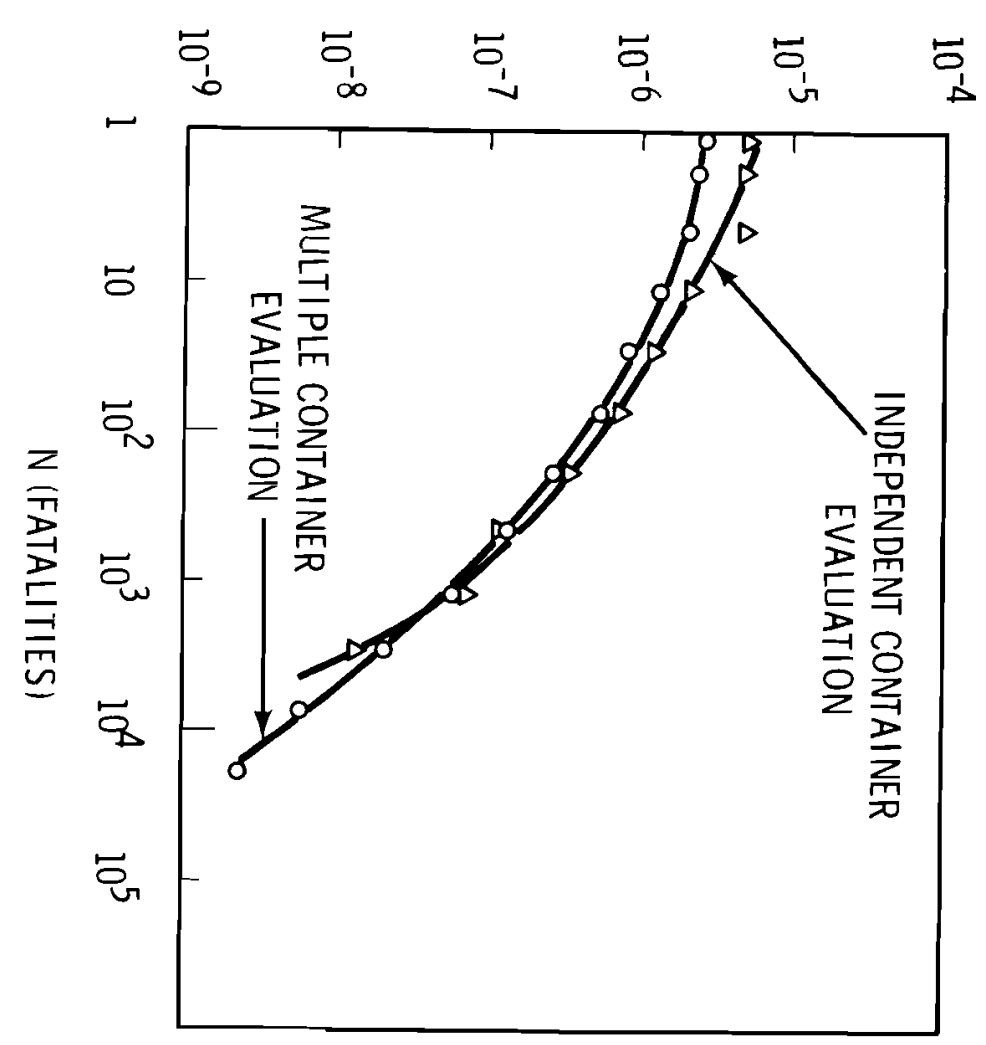




\subsection{RISK SENSITIVITY EVALUATIONS}

Prior to discussion of the sensitivity of the risk evaluation to the values of certain system parameters it is important to point out a fundamental sensitivity of the risk evaluation; i.e., the calculated risk is a function of the shipping assumptions. The present risk assessment is made for the system described in section 11.1. Shorter shipment distances, the use of different shipping containers, safe secure trailers, etc. would result in a different risk. In general, reevaluation would be required to determine the risk under these changed conditions. However, for some simple changes in shipment conditions, determination that the risk would be less than, or greater than, that calculated for the systems considered in this analysis could be made without recalculation.

Risk sensitivity evaluations permit analys is of the importance of the various factors which contribute to the risk. They can be used: 1) to identify and quantify the effects of the major contributors to the risk, and 2) to identify ways to improve the certainty in the risk evaluation.

Most sensitivity studies are performed by repeating the risk calculation with a changed value for the parameter of interest. In general, the dependence of the risk on a particular parameter is complex. In some cases, however, a parameter enters simply and directly into the risk equation and the sensitivity can be determined directly.

The results of the risk sensitivity studies for the L-10 liquid plutonium nitrate shipment analysis are given in Table 11.3. The effects on the risk spectrum of the more important of these are also shown in Figure 11.6. For the liquid nitrate shipment the controlling releases involve a fire acting on a container which has less than the required coverage of vermiculite over the pressure vessel (resulting from either an inadequate vermiculite level in the drum or loss of vermiculite in an accident). To show the effect of the loose vermiculite, a case was run in which the containers had the required vermiculite level and the vermiculite was stabilized so that loss of integrity of the outer drum would not result in loss of vermiculite and subsequent failure of the pressure vessel in a short 
TABLE 11.3 Risk Sensitivity Cases for Liquid Nitrate Shipments for U.S. in the Early 1980's

\begin{tabular}{|c|c|c|}
\hline $\begin{array}{c}\text { Description of } \\
\text { Sensitivity Case } \\
\end{array}$ & $\begin{array}{c}\text { Risk Level } \\
\text { (Estimated Annual Frequency } \\
\text { of Occurrence of One } \\
\text { or More Fatalities) } \\
\end{array}$ & $\begin{array}{l}\text { Risk Level } \\
\text { Relative to } \\
\text { Base Case } \\
\end{array}$ \\
\hline Base Case ${ }^{(a)}$ & $1.41 \times 10^{-4}$ & -- \\
\hline Stabilized Vermiculite & $1.79 \times 10^{-6}$ & 0.01 \\
\hline Zero Low Vermiculite & $1.26 \times 10^{-4}$ & 0.89 \\
\hline $\begin{array}{l}\text { Zero Packaging Condition } \\
\text { Deficiencies }\end{array}$ & $1.23 \times 10^{-4}$ & 0.87 \\
\hline Zero Crush of Outer Drum & $1.32 \times 10^{-4}$ & 0.94 \\
\hline $\begin{array}{l}\text { Zero Puncture of Pressure } \\
\text { Vessel }\end{array}$ & $1.37 \times 10^{-4}$ & 0.97 \\
\hline $2 \mathrm{Hr}$ Release Duration & $1.41 \times 10^{-4}$ & 1.00 \\
\hline Release Fractions $=1.0$ & $4.65 \times 10^{-4}$ & 3.3 \\
\hline $\begin{array}{l}\text { Improper Shipment (Over- } \\
\text { pressurization) }\end{array}$ & $1.71 \times 10^{-4}$ & 1.2 \\
\hline
\end{tabular}

a. Shipment in early 1980's as described in section 11.1.2.

duration fire. The results, shown in Table 11.3 and Figure 11.6 with the designation "Stabilized Vermiculite," indicate a reduction of about 2 orders of magnitude in the risk level.

A sensitivity run was made to further analyze the cause of the risk reduction seen in the previous case. In this run the vermiculite was required to be in place but was not stabilized. The results of this case, designated "Zero Low Vermiculite" in Table 11.3, showed only an $11 \%$ reduction in risk level. This indicates that low vermiculite level during shipment, which is a packaging deficiency, contributes to the risk but is not a controlling factor.

To study the effect of other packaging deficiencies on the risk a case entitled "Zero Packaging Deficiencies" was run. For this case the occurrence frequencies of all packaging deficiency elements (see section 9) were set at zero. It is seen from Table 11.3 that this reduces the risk level 


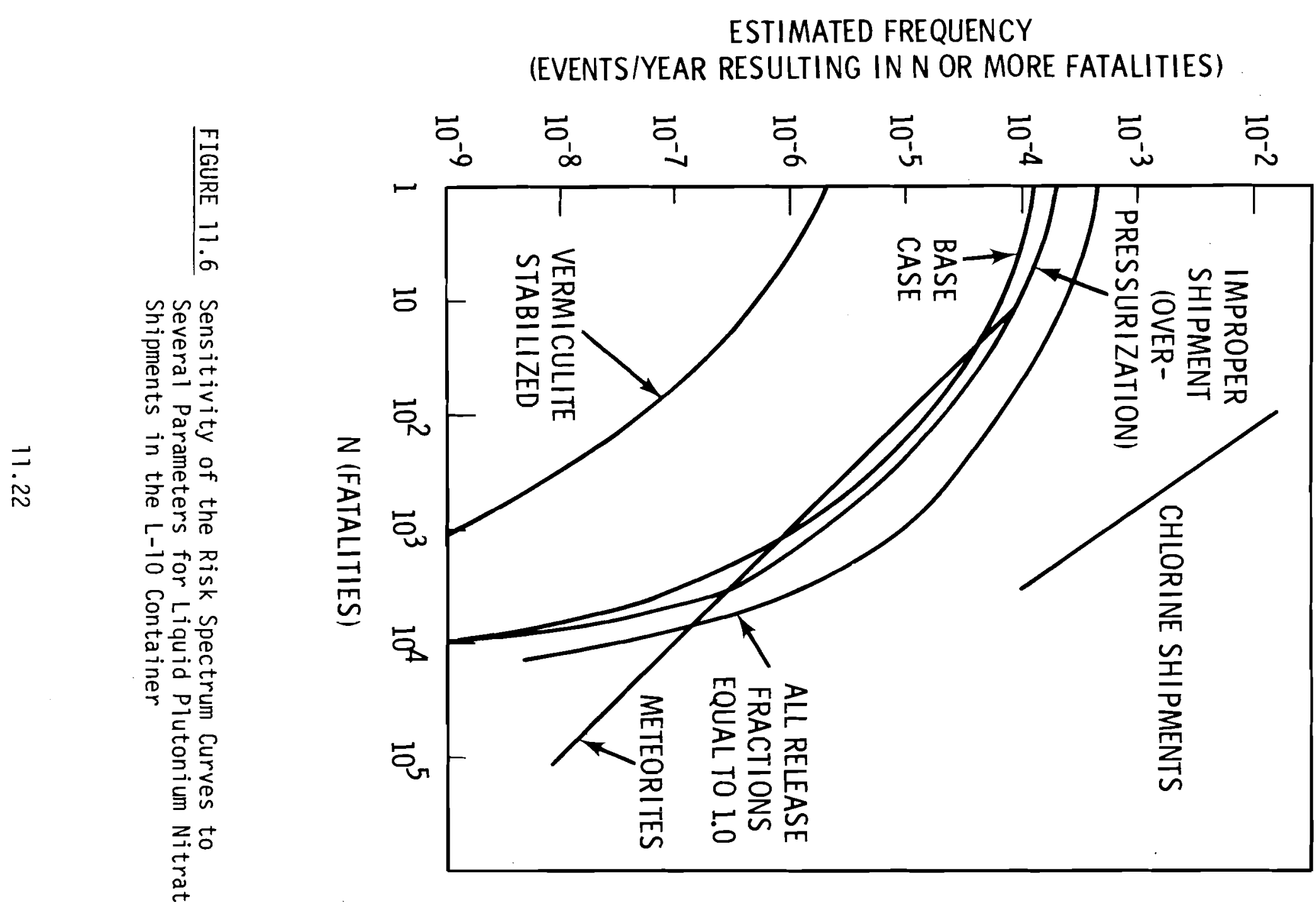


only $2 \%$ more than the previous case, indicating that low vermiculite level is the most important packaging deficiency but that packaging deficiencies are not a controlling factor in the risk.

Two sensitivity cases were run in which the probabilities of crush of the outer drum and puncture of the pressure vessel were set at zero. These resulted in, respectively, 3 and $6 \%$ reduction in the risk level, indicating that these elements do contribute to the risk but that they do not dominate.

In the base case it was assumed that actions by escort and emergency personnel could terminate a nonfire-associated release within a half hour after it starts. To study the effect of this assumption a case was run with a $2 \mathrm{hr}$ release duration. It is seen that, due to the characteristics of the nitrate release mechanisms, this has essentially no effect on the plutonium nitrate shipment risk.

As an upper limit example, a case was run which assumed that any release sequence releases the entire content of a container (i.e., the fraction released $=1)$. It is seen that this increases the risk only about a factor of three.

A possible release mechanism in plutonium nitrate solution shipment is failure of the pressure vessel seal due to extreme pressure resulting from nuclear and chemical actions. Preshipment procedures are designed to preclude the occurrence of this unlikely failure mechanism. It has never occurred in the shipment of plutonium nitrate solution (see discussion for element $\times 64$ in section 9.1.2). However, to study the possible effect of this failure mechanism on the risk an occurrence frequency of $2 \times 10^{-3}$ per container $\left(10^{-3} /\right.$ container for both element $A 58$ and element $\left.A 62\right)$ was used in a sensitivity case. This value is considered to be conservative. The results, indicated in Table 11.3 as "Improper Shipment (Overpressurization)," show only a $20 \%$ increase in the risk level.

The results of risk sensitivity studies for the oxide shipment analysis are given in Table 11.4. The effect on the risk spectrum of the more important cases are also shown in Figure 11.7. It is seen that packaging deficiencies and crush of the outer drum do not contribute significantly to the risk of plutonium oxide powder shipment in 6M containers. 
TABLE 11.4. Risk Sensitivity Cases for 0xide Shipments

in the U.S. in the Early 1980's

Risk Level

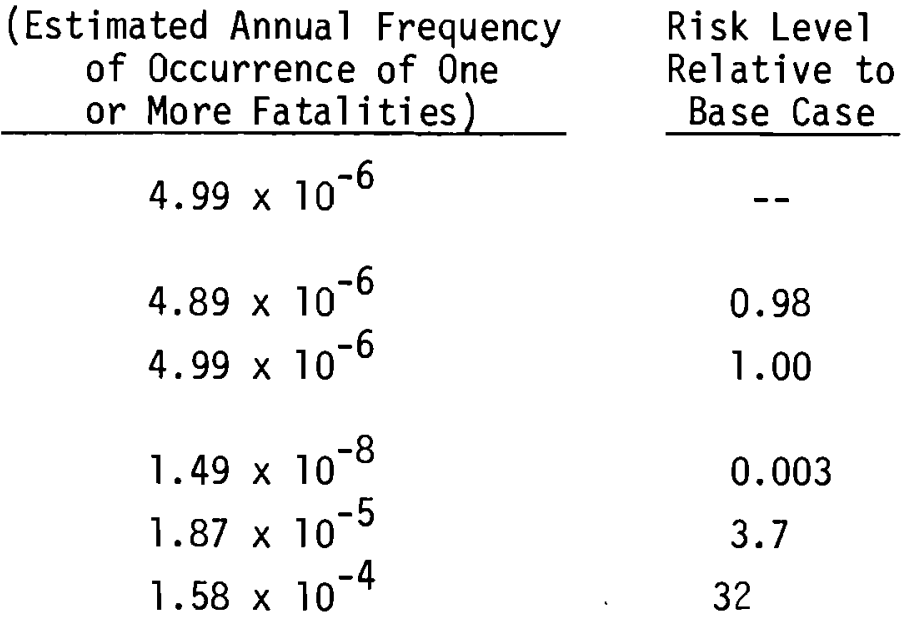

a. Shipment in early 1980's as described in section 11.1.2.

For the oxide shipment puncture of the $2 \mathrm{R}$ vessel contributes to greater than $99 \%$ of the risk. There was no accident environment or test data applicable to evaluating the puncture probability of the inner $2 R$ vessel, thus the probability was developed from analysis. Further analyses or test data could better determine the probability of $2 \mathrm{R}$ vessel puncture.

Unlike the results for the plutonium nitrate shipment, the use of a $2 \mathrm{hr}$ release duration in the plutonium oxide shipment analysis results in an increase of nearly a factor of four in the risk.

As an upper limit example, a run was made which assumed that any release sequence releases the entire content of a container (i.e., the fraction released $=1$ ). The results indicate that this increases the risk about a factor of 30 .

The risks for both the nitrate and oxide shipments are strongly dependent on the amount of material released and dispersed in an accident. Directly applicable data on these processes are sparse. Conservative extensions of existing data were used in the analyses. Additional data on the fraction released and dispersed under simulated extreme accident conditions could increase the certainty of the evaluation. 


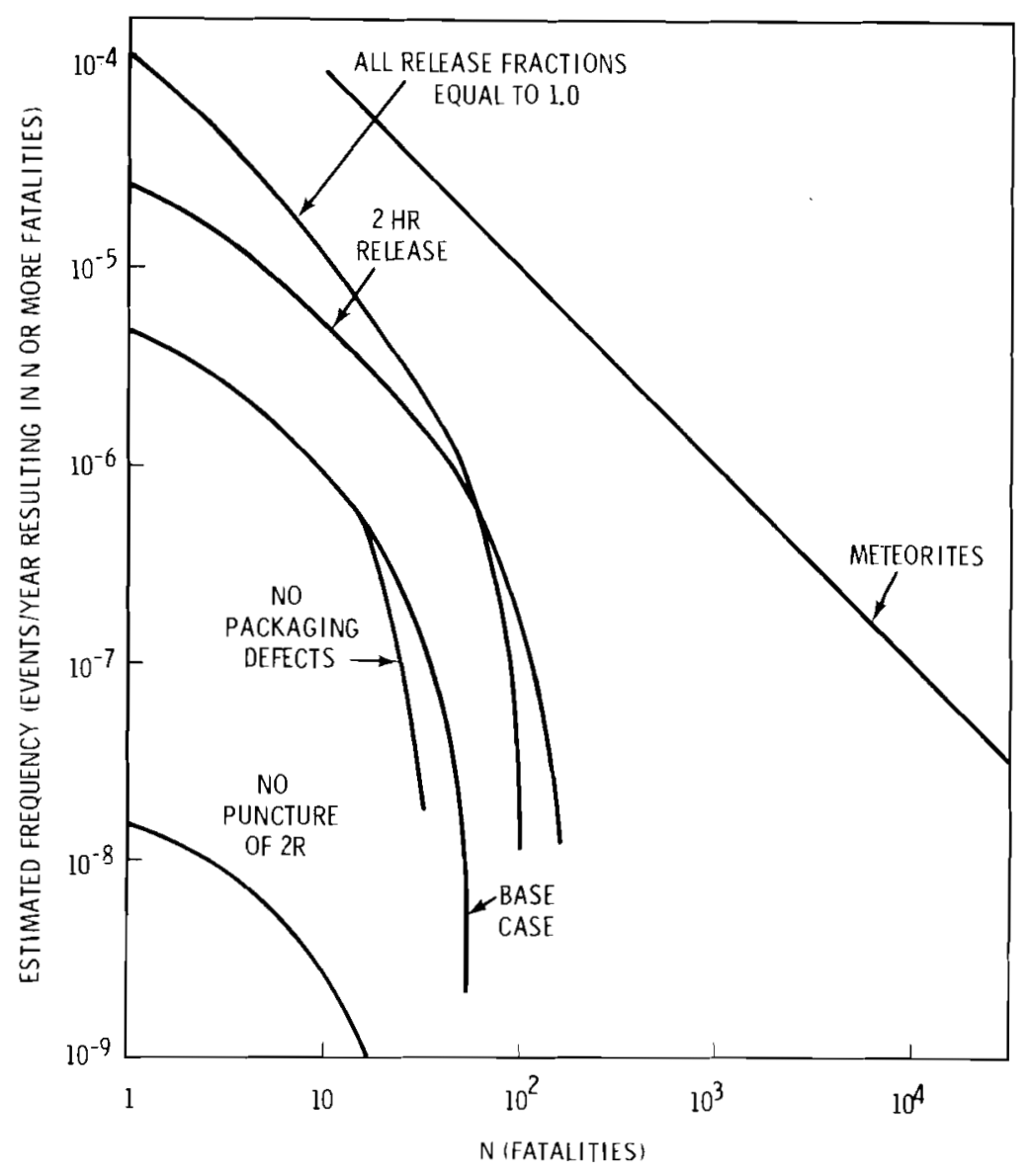

FIGURE 11.7 Sensitivity of the Risk Spectrum Curves to Several Parameters for the Plutonium oxide Shipments in the 6M Container 
These sensitivity studies have identified both the major contributors to the shipment risk and areas in which further studies could result in increased knowledge of events and processes pertinent to the assessment. 


\section{APPENDIX A}

DESCRIPTION OF PACKAGES USED

TO SHIP Pu(NO$\left.{ }_{3}\right)_{4}$ and $\mathrm{PuO}_{2}$

\section{PLUTONIUM NITRATE PACKAGES}

In present fuel reprocessing plants, the initial form of the plutonium produce is plutonium nitrate $\left[\mathrm{Pu}\left(\mathrm{NO}_{3}\right)_{4}\right]$ in $3-6$ Molar Nitric Acid. Plutonium nitrate solution is normally shipped at a concentration of about $250 \mathrm{~g} \mathrm{Pu} / 1$ iter. The most commonly used containers for $\mathrm{Pu}\left(\mathrm{NO}_{3}\right)_{4}$ are the L-C and L-10. These hold 3 liters and 10 liters of solution, respectively. The outer container of the L-3 container is a 55 gal drum and the outer container of the L-10 is two 55 gal drums welded end-to-end.

A single shipment is limited by criticality safety considerations to 68 bottles, or a total of $170 \mathrm{~kg}$ of plutonium. A diagram of the L-10 container is shown in Figure A.1. Further detai1s taken from the "Directory of Packagings for Transportation of Radioactive Materials"(1) are summarized below:

\section{AUTHORIZED CONTENTS:}

Up to 10.5 liters per package UHN solutions having concentration of ${ }^{235} \mathrm{U}$ not exceeding $350 \mathrm{~g} / 1 \mathrm{iter}$, or having a combined concentration of ${ }^{233} \mathrm{U}$ and ${ }^{235} \mathrm{U}$ not exceeding $250 \mathrm{~g} / \mathrm{liter}$; or plutonium nitrate solutions of concentration not exceeding $250 \mathrm{~g}{ }^{239} \mathrm{Pu} / \mathrm{liter}$; or $4.5 \mathrm{~kg}$ dry $\mathrm{Pu}-\mathrm{U}$ compounds and mixtures.

INTERIORS AND EXTERIOR DIMENSIONS:

Pressure vesse $1-4.8 \mathrm{in}$. ID $\times 52.2 \mathrm{in}$. deep inside; Drum - 24 in. diam. $x 66-2 / 3$ in. high outside $x 18$ ga. wall.

DESCRIPTION OF CONTAINER:

Outer container consists of two 55-gal DOT Spec. 17H drums end-to-end. Inner container is a stainless steel pressure vessel (3000 psi at $600^{\circ} \mathrm{F}$ ) supported inside the drum by a tubular steel fram. Annular space is 


\section{L-10 CONTAINER}

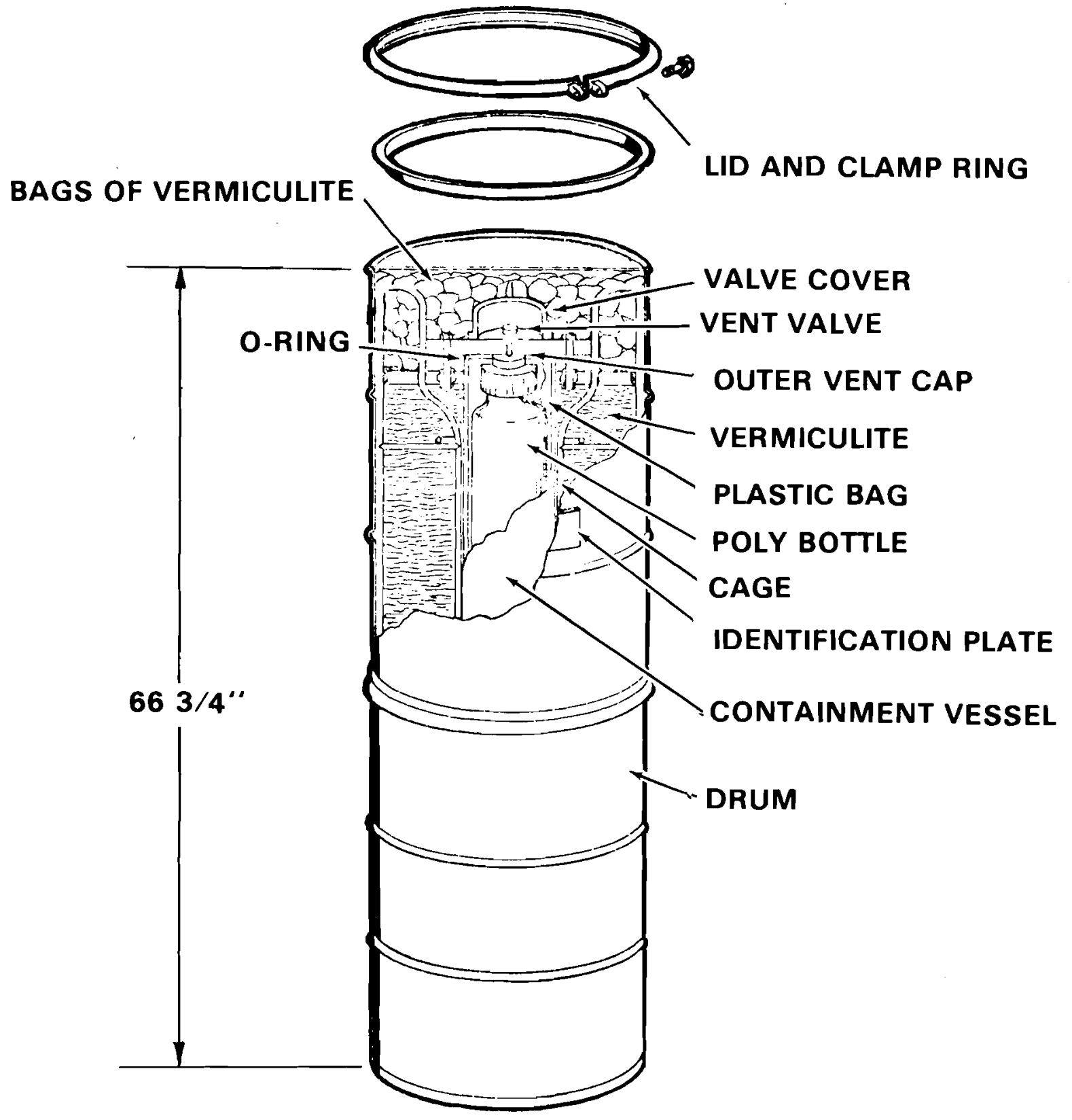

FIGURE A.1 L-10 Container 
filled with vermiculite for thermal insulation. The product solution is contained in a 10-1iter polyethylene bottle sealed in a polyvinylchloride bag and then inserted into the pressure vessel, with a thin neoprene pad to cushion the bottom of the bottle. Weight: $510 \mathrm{1b}$, total; $4551 \mathrm{~b}$ wi thout bottle.

TYPE AND THICKNESS OF SHIELDING:

Nine inch vermiculite insulation.

HEAT REMOVAL CAPACITY:

Not applicable.

AUTHORIZED MODES OF TRANSPORT:

Cargo-only aircraft, motor vehicle, rail and vessel. May be used for fissile Class II or Class III.

\section{PLUTONIUM OXIDE PACKAGES}

Two licensed plutonium oxide containers are described here. These are the $6 M$ and LLD-1 containers.

\section{DOT SPECIFICATION 6M CONTAINERS}

The 6M designation represents a class of containers which have been approved for radioactive material transport. The general set of design criteria are found in 49CFR 178.104. The outer drum must conform to Spec. $6 \mathrm{C}$ and $17 \mathrm{C}$ as defined under paragraph 178.99 and 178.115 , respectively. The inner container design must meet or exceed the $2 \mathrm{R}$ specification presented in paragraph 178.34.

The outer container of the 6M can vary from a 10 to 110 gal capacity. The following description is based on the $15 \mathrm{gal}$ size. This size 6M was used throughout the report and is shown in Figure A.2. Much of the information shown below was taken from Reference 1. Other information has been obtained from actual container measurements. AUTHORIZED CONTENTS:

Up to $4.5 \mathrm{~kg}$ of Plutonium metal, alloy or compound or up to $13.5 \mathrm{~kg}$ of uranium 235 metal or alloy. Additional details and restrictions are provided in 49CFR 173.396. 


\section{M CONTAINER}

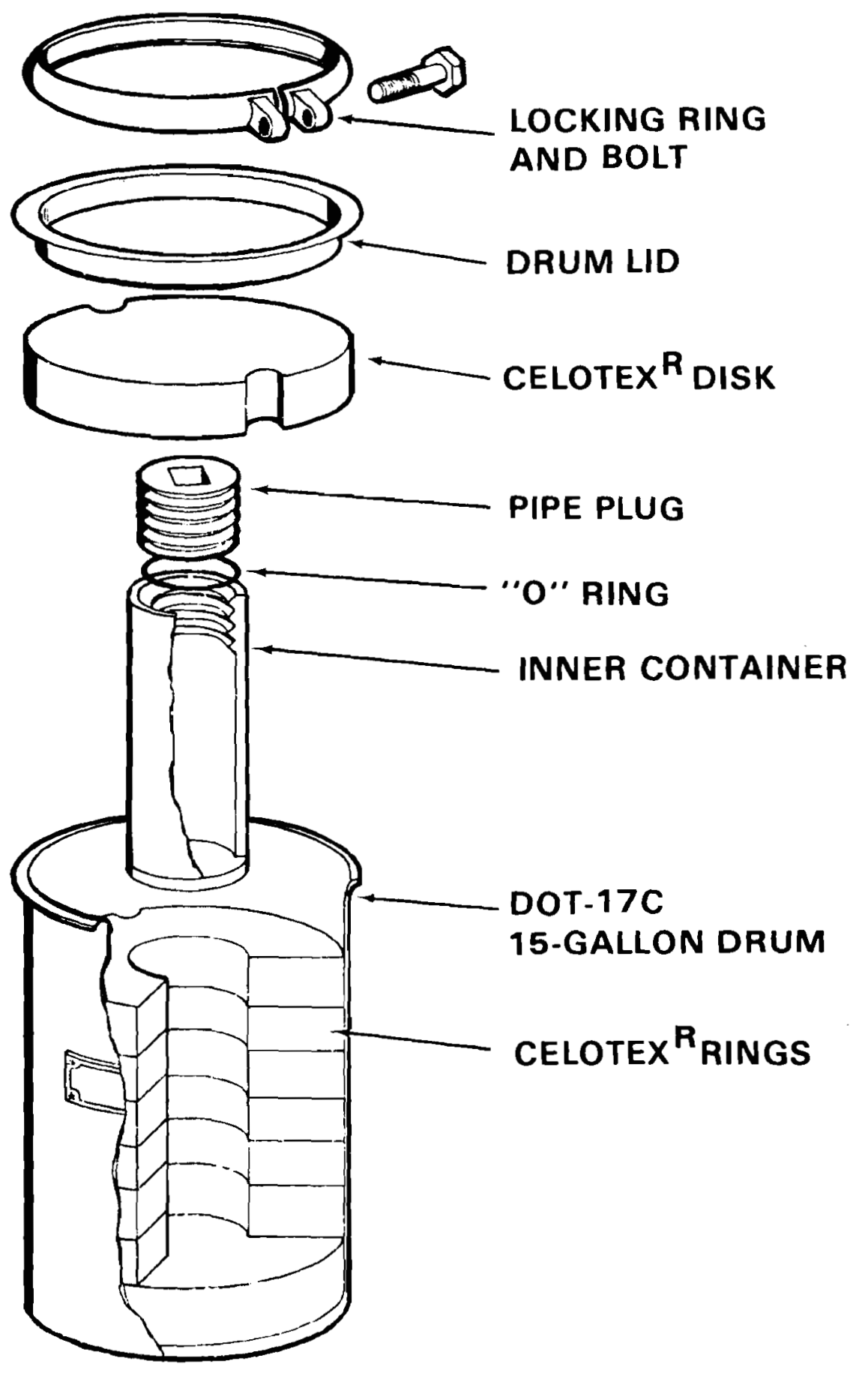

FIGURE A.2 6M Container 
INTERIOR AND EXTERIOR DIMENSIONS:

Interior 5.25 in. ID $\times 10.5$ in. deep inside; Drum - 15.57 in. diam. $x$ $21.25 \mathrm{in}$. high outside with $18 \mathrm{ga}$. wal1.

DESCRIPTION OF CONTAINER:

The outer container is a $15 \mathrm{ga} 1$ DOT Spec. 17C drum. The inner container is a 5 in. Sch. 80 steel pipe with a threaded plug and a gas filled 0 -ring seal. The bottom end is closed by welded $1 / 2$ in. thick steel cap. The oxide powder is contained in two sealed No. 8 steel cans which are placed inside the inner container. The inner container is lined with padding to minimize damage to the steel cans during a shipment.

TYPE AND THICKNESS OF INSULATION:

The inner container is insulated by Celotex ${ }^{R}$ Industrial Board with a minimum thickness of 3 in.

SHIELDING:

None provided, may be added within the containment vessel when required.

HEAT REMOVAL CAPACITY:

Normal licensed limit of 10 watts. Special permits have been issued for designs which allow for up to 50 watts. The 10 watt limit results in a containment vessel temperature limit of $155^{\circ} \mathrm{F}$ for a $70^{\circ} \mathrm{F}$ ambient temperature. Special handling requirements are required when materials that generate more than 10 watts are shipped.

AUTHORIZED MODES OF TRANSPORT:

Vessel, cargo or passenger-carrying aircraft, motor vehicle, rail freight, and rail express.

LLD-1 PACKAGE FOR PuO 2

A diagram of the LLD package is shown in Figure A.3. The following table, taken from Reference 1, summarizes the container design characteristics. 


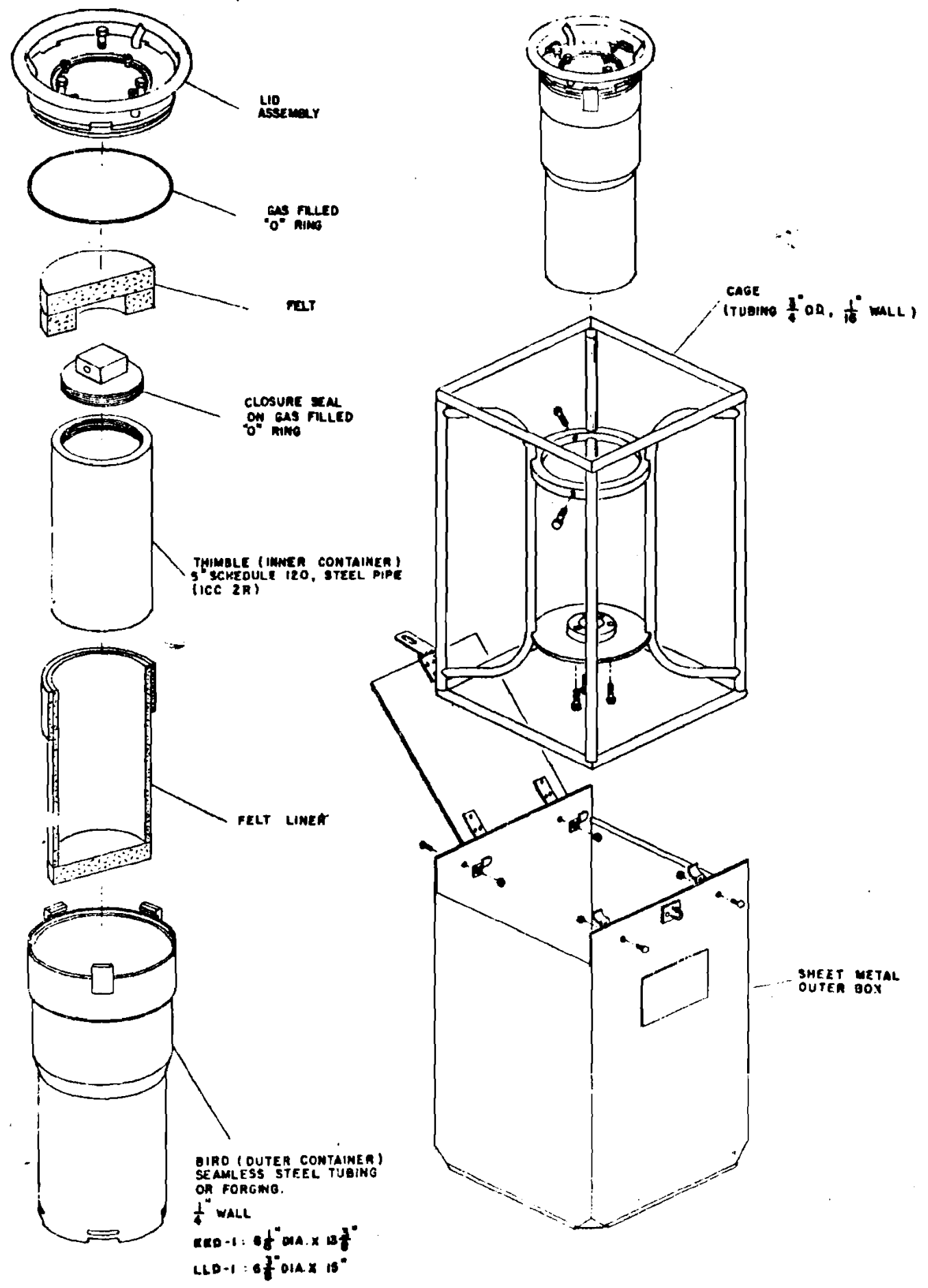

FIGURE A.3 LLD-1 Container 
AUTHORIZED CONTENTS:

Up to $7 \mathrm{~kg}$ of Pu metal, or Pu-U alloy containing $7 \mathrm{~kg}$ of fissile uranium or up to $4.5 \mathrm{~kg}$ of $\mathrm{Pu}$ oxide.

INTERIOR AND EXTERIOR DIMENSIONS:

Interior $-4.5 \mathrm{in.}$ ID $\times 10.25 \mathrm{in.} \mathrm{high.} \mathrm{Exterior}-16.5 \mathrm{in.} \times 16.5 \mathrm{in.}$ $x 26$ in. high.

DESCR.IPTION OF CONTAINER:

A cylindrical outer container is supported in a cage of $3 / 4$ in. OD $x$ $1 / 16$ in. wa 11 seamless steel tubing. This outer container is closed by engaging the closing lugs on the bird. Seal is effected by tightening the lid against a gas-filled 0-ring using the hex head bolts on the lid assembiy. The inner container is a DOT-2R container, fabricated of 5 in. Sch. 80 steel pipe with a threaded plug and a gas-filled 0-ring seal. The oxide powder is contained in two No. 8 steel cans which are placed inside the irner container. The inner container is lined with padding to minimize damage to the steel cans during transport.

TYPE OF SHIELDING:

None.

HEAT REMOVAL CAPACITY:

By convection only. AUTHORIZED MODES OF TRANSPORT:

Air, highway, rail, water. Fissile Class II or III by cargo only aircraft. 


\section{REFERENCES}

1. Division of Waste Management and Transportation "Directory of Packagings for Transportation of Radioactive Materials," WASH 1279. United States Atomic Energy Commission, Washington, D.C. 1973. 
APPENDIX B

QUESTIONS USED IN SURVEY TO DETERMINE PACKAGING CONDITION DURING TRANSPORT

Part I - RECEIVERS OF Pu(NO$\left.{ }_{3}\right)_{4}$

A. Shipments and Packages Received

\begin{tabular}{lll} 
Approximate & Approximate & Approximate \\
No. of & No. of & No of \\
Shipments & L-3 Packages & L- 10 Packages \\
\hline
\end{tabular}

1970

1971

1972

1973

B. Outer Container Integrity

1. Number of packages having visible external damage

Number damaged upon receipi

Number with punctures

2. Number packages received with bolt ring loose

3. Number of packages received with bolt in bolt ring above top of lid

C. Packing

1. Number of packages received with vermiculite bags missing

2. Number of packages received with low vermiculite level

3. Number of packages received with water in vermiculite

4. Number of packages received with vermiculite contaminated

B. 1 
D. Pressure Vessel Integrity

1. Number of packages having a loose vent cap or no cap at all

2. Number of packages having pressure bleed valve opened

3. Number of packages having a bolt in the bolt ring loose or missing

4. Number of packages having bolts tightened too tight (greater than $80 \mathrm{ft}$-1b)

5. Number of packages received with gasket out of place

6. Number of packages received with gasket damaged If yes - what was gasket material

7. Number of packages received with gasket missing

8. Number of packages received with damaged gasket mating surfaces

9. Number of packages received with contamination outs ide plastic liner

10. Have you ever experienced any difficulty while Yes venting the containers

11. Do you have any procedure for testing tightness of pressure vessel for a leak upon receipt

12. If yes for \#11, how many vessels have been tested via this procedure

13. If yes for \#11, how many vessels were received not leak tight

E. Inner Bottle, Cap and Plastic Liner

1. Number of packages received with contamination outside inner bottle

2. Number of packages received with plastic cap loose

3. Number of packages received with vent cap assembly malfunctioning 
4. Number of packages received with leaking inner bottle

5. Number of Packages received with ruptured inner bottle

- Side seam leak

- Bottom leak

- Top leak

6. Number of packages received with pressure buildup inside plastic liner

7. Number of packages received with no plastic liner on inner bottle

8. Number of packages received with any evidence of plastic melting

F. General Condition of Shipment

Number of shipments that have been delayed in transit

- What is the maximum number of days any shipment was delayed in transit for any reason?

- Number of packages received which have tipped over during shipment 


\section{Part II - RECEIVERS OF $\mathrm{PuO}_{2}$}

A. Shipments and Packages Received

$$
\text { No. of Shipments }
$$

Number of Packages

$\underline{L L D-1} \underline{6-M}$

1970

1971

1972

1973

B. Outer Container Integrity

1. Number of packages having visible external damage No. damaged upon receipt No. with punctures

2a) For LLD-1 Shipments: Number of packages received with locking cover loose

b) For 6-M Receivers: Number of packages received with bolt ring loose

3a) For LLD-1 Shipments: Number of packages received with missing and damaged 0 ring

b) For 6-M Shipments: Number of packages received with bolt ring above top of $1 \mathrm{id}$

4. Number of packages received which were shipped up-side down

C. Packing

1. Number of packages received with fiber-board discs missing 


\section{Inner Container Integrity}

1. Number of packages received with plug loose

2. Number of packages received with $2 R$ container threads damaged

3. Number of packages received with 0 -ring missing

4. Number of packages received with 0-ring misaligned or damaged

E. Pu02 Storage Can Integrity

1. Number of packages received with contamination outside of can

2. Number of packages received with damaged can

3. Number of packages received with any evidence of corrosion on can or water inside $2 R$ containers

4. Number of packages received with contamination outside of inner plastic bag.

5. Number of packages received with any evidence of plastic melting

\section{F. General Condition of Shipment}

1. Number of shipments that have been delayed in transit

What is the maximum number of days any shipment has been delayed

Number of shipments received that have had packages tipped over during transit 
APPENDIX C

CONSIDERATIONS IN EVALUATION OF THE

AIRBORNE RELEASE AND DISPERSION OF PLUTONIUM

Factors Influencing Airborne Release

Many factors can influence the airborne release of plutonium under accident conditions. Some, but not necessarily a11, of the areas to be considered are:

- Physical and Chemical Characteristics of the Source Materials and the Conditions under which the Source Material Exists: Chemical compound, size distribution if powder, involvement with other materials, moisture, amount airborne, containment. . .

- Alteration of Source Material and Conditions as a Result of Accident: forces imposed, location of forces, fire, changes in chemical and physical characteristics of radioactive material, size and location of breach of containment, surface. . .

- Alteration of Airborne Material Prior to Release: changes in chemical and physical characteristics due to conditions (drying, stress, fracture, oxidation, dilution, agglomeration, settling, thermophoresis, electrophoresis). . .

- Resuspension of Deposited Material: surfaces involved, windspeed and turbulence "weathering" forces holding deposited material to surface, etc. .

Estimates of the potential airborne release under postulated accident conditions can be obtained in several ways. The best way to estimate releases would be to use values derived from actual accident experience under similar circumstances. Such data are not available. Thus, the data from other than actual accidents must be used. There are two sources of data that can be used--that derived from experimental simulations and that developed from the known chemical and physical responses of the materials 
involved. The former is preferable since it can encompass some of the conditions postulated for the accident. However, since accidents are unique events and cannot be exactly duplicated, engineering judgment is required to arrive at realistic estimates.

An additional consideration in the generation of release values is their ultimate use. Fractional airborne release values are only an intermediate step in the assessment of the potential consequences to man. Other physical processes are influential in the quantity of the airborne material which reaches and enters man. These processes--atmospheric transport and respiration--are sensitive to the size of airborne particles. It is not within the scope of this appendix to discuss either topic, but there are size limitations under various conditions for both. $(1,2,3)$ Considering both processes, the significant size fraction is that which is less than 10um Aerodynamic Equivalent Diameter.*

Fractional Airborne Release of Plutonium Under Various Conditions

This section summarizes the existing fractional airborne release information applicable to two forms of plutonium--dioxide powder and nitrate solution.

Plutonium dioxide is formed when plutonium metal or certain compounds are heated in air. The dioxide is chemically stable and refractory, particularly when prepared at high temperature. Normally green, the color is a function of purity and of particle size, which varies with the method of preparation. (4) The fraction of plutonium dioxide airborne varies greatly with the circumstances. Under most conditions postulated for industrial type accidents, volatilization is not a significant factor. (5) Known experimentally derived release values are listed in Table C. 1. Very little of a coarse plutonium dioxide powder, 15 to 150 $\mu$ m Aerodynamic Equivalent Diameter, $\star \star$ was made airborne during heating to $1000^{\circ} \mathrm{C}$ on a stainless steel surface in upsweeps of air with velocities of 10 and 100 $\mathrm{cm} \operatorname{per} \sec \left(0.2\right.$ to $2.2 \mathrm{mph}$ )--from $5 \times 10^{-8}$ to $2.5 \times 10^{-4}$ (fraction) of the mass during a 1-hr. experiment. The quantity of material airborne was insufficient to determine a size distribution. (6)

* Behaves in air as a sphere of unit density of the stated size. ** Equivalent to spheres of $\mathrm{PuO}_{2}$ of 4.4 to $44 \mu \mathrm{m}$. 
TABLE C.1 Fractional Airborne Release of Plutonium Dioxide-Summary (Fraction of Source Airborne as Particles less than $10 \mu \mathrm{m}$ Aerodynamic Equivalent Diameter)

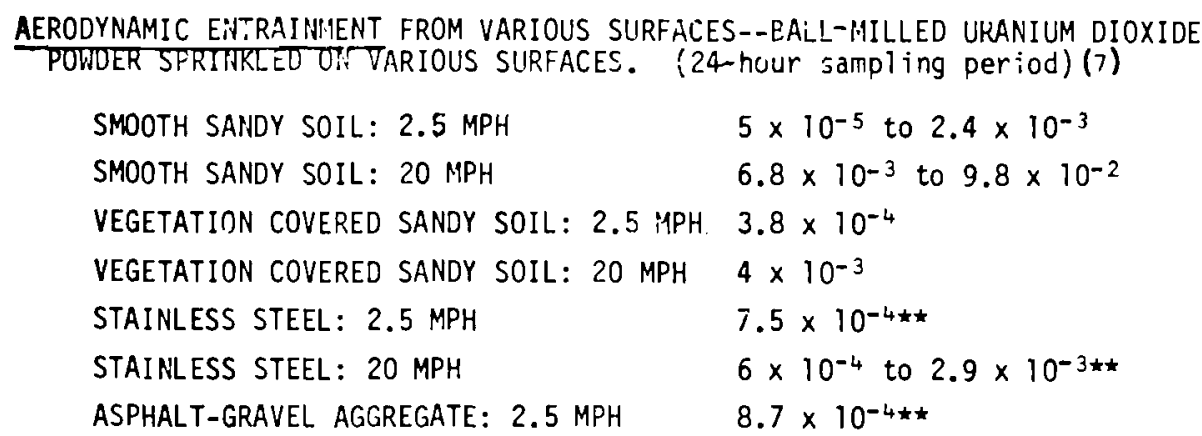

HEATING PLUTONIUM DIOXIDE POWDER, 15 to $150 \mu \mathrm{m}$ AED, IN AN UPSWEEP OF AIR (1-hour sampling period) 6
$1000^{\circ} \mathrm{C} .10 \mathrm{CM}$ PER SEC
$5.3 \times 10^{-9}+$
$1000^{\circ} \mathrm{C}, 100 \mathrm{CM}$ FER SEC
$2.5 \times 10^{-4}$

FIRES, BALL-MILLED URANIUM DIOXIDE POWDER SPRINKLED ON VARIOUS SURFACES ENGULFED IN A GASOLINE FIRE (to self extinguishment of fire, 20 min to 2 hours) (7)
SMOOTH SANDY SOIL: $2.5 \mathrm{MPH}$
3.2 to $3.5 \times 10^{-4}$
SMOOTH SANDY SOIL: $20 \mathrm{MPH}$
$2 \times 10^{-3}$
VEGETATION COVERED SANDY SOIL: $2.5 \mathrm{MPH}$
$1.3 \times 10^{-4}$
VEGETATION COVERED SANDY SOIL: $20 \mathrm{MPH}$
$2.5 \times 10^{-3}$
STAINLESS STEEL: $2.5 \mathrm{MPH}$
$7.9 \times 10^{-4}$
STAINLESS STEEL: $20 \mathrm{MPH}$
$9 \times 10^{-5}$
ASPHALT-GRAVEL AGGREGATE: $2.5 \mathrm{MPH}$
$2.9 \times 10^{-4}$

BALL-MILLED URANIUM DIOXIDE POWDER DISPERSED ON FLAMMABLE MATERIALS (to self extinguishment of fire, 6 minutes to 1 hour)
STATIC
$5.2 \times 10^{-4}$ to $1.5 \times 10^{-3}(10)$
50 TO 100 CPI PER SEC AIR DRAWN THROLIGH BUIRHING MASS
0.016 to $0.38(11)$

*total fraction AIRBORNE

* SOURCE WAS SOLID RESIDUE REMAINING AFTER A GASOL INE FIRE 
The entrainment of a bal1-milled uraniun dioxide powder (Aerodynamic Median Diameter ${ }^{\dagger}$ of approximately $1 \mu \mathrm{m}$ ) freshly sprinkled on various surfaces was evaluated. ${ }^{(7)}$ The fractions of the mass as particles less than $10 \mu \mathrm{m}$ AED from hard, impervious surface and smooth, sandy soil with vegetation covering the surface ranged from $4 \times 10^{-4}$ at $2.5 \mathrm{mph}$ to $4 \times 10^{-3}$ at $20 \mathrm{mph}$ over roughly a $24 \mathrm{hr}$. period. The air was drawn horizontally across the source with velocity measurements taken $1 \mathrm{ft}$. above the surface. Greater than $50 \%$ of the mass airborne from a stainless steel surface at $20 \mathrm{mph}$ was measured in the first hour. The fractional release from smooth, sandy soil shows greater variation and probably reflects the participation of the surface in the entrainment phenomena.

Slinn ${ }^{(8)}$ and Chepel ${ }^{(9)}$ indicate that particles in the size range of $200 \mu \mathrm{m}$ AED are most readily entrained by aerodynamic stresses. Movement of particles of other sizes can be induced by the movement of particles of this size range and by alternation of the surface due to the dislocation of soil particles. At an air speed of $2.5 \mathrm{mph}$, the fractional airborne release of ball-milled uranium dioxide from smooth, sandy soil ranged from $5 \times 10^{-5}$ to $2.4 \times 10^{-3}$ for particles less than $10 \mu \mathrm{m}$ in a $24-\mathrm{hr}$ period. (7) The values for an airspeed of $20 \mathrm{mph}$ ranged from $6.8 \times 10^{-3}$ to $9.8 \times 10^{-2}$ over the same period. ${ }^{(7)}$ Essentially all of the entrainment of uranium dioxide at $20 \mathrm{mph}$ occurred within the first hour while less than $50 \%$ was entrained at $2.5 \mathrm{mph}$ over the same time span. ${ }^{(7)}$

+ The presence of a fire does not appear to have a significant effect on the fractional release of the dioxide from the four surfaces tested. The presence of a fire is significant if the dioxide is on a flammable material which produces a buoyant particle. Under static conditions (no airflow through the system), the fractional release of the ball-milled uranium dioxide powder ranged from $5.2 \times 10^{-4}$ to $1.5 \times 10^{-3}$ for particles less than $10 \mu \mathrm{m}$ AED to self-extinguishment of the fire ( 1 to $2 \mathrm{hrs}$ ). (10) In bench-scaled experiments where air was drawn through the burning mass at 50 and $100 \mathrm{~cm} / \mathrm{sec}(1.1$ and $2.2 \mathrm{mph})$, the fractional release of ballmilled uranium dioxide powder ranged from 0.016 to 0.31 . No size

${ }^{+}$Half the mass of the powder behaves in air as spheres less than the stated size. 
distributions of airborne particles was obtained. (11) Since fires are vapor phase reactions and are heterogenous when the fuel is a liquid or solid, the plutonium on solid surfaces is subjected to temperatures less than measured at the flame front, is generally out of the direct path of the airflow and is not injected into the buoyant plume produced by the fire. In the case of uranium dioxide mixed with flammable solids with the air drawn through the burning mass, the uranium dioxide particles were dropped into the airstream by the decomposition of the surface supporting the particle, and fractional releases were orders of magnitude higher.

Plutonium nitrate pentahydrate $\left(\mathrm{Pu}\left(\mathrm{NO}_{3}\right)_{4} \cdot 5 \mathrm{H}_{2} \mathrm{O}\right)$ is readily soluble in water, producing a brown solution at high concentration. Solutions in concentrated nitric acid are green due to the formation of a plutonium nitrate complex. Dilute solutions of plutonium nitrate, initially brown, turn green as colloidal plutonium forms. Data on the solid is scarce. Solid plutonium nitrate pentahydrate can be prepared by evaporation of the solution at room temperature and is relatively stable in dry or moist air. Decomposition begins around $40^{\circ} \mathrm{C}$, and conversion to the dioxide is rapid and complete above $250^{\circ} \mathrm{C}$. (4) Experimentally derived fractional airborne release values for plutonium and uranium nitrate are compiled in Table C.2.

The fractional release from the liquid nitrate state appears to depend upon rate of heat input and air velocity. Both factors influence film formation and breakup. Thus the fractional release of plutonium to the air is very smal1 $\left(5 \times 10^{-6}\right)$ at low heat inputs and air velocities and increases as the heat input increases to $2 \times 10^{-3}$ at boiling. (12) From shallow layers on hard surface (i.e., steel, asphalt, etc.) fractional releases increase from less than $2 \times 10^{-10}$ at $10 \mathrm{~cm} / \mathrm{sec}(0.2 \mathrm{mph})(12)$ to $2.6 \times 10^{-2}$ at $20 \mathrm{mph}$ during approximately $24-\mathrm{hr}$ sampling periods. The size distribution of the aerosol at $10 \mathrm{~cm} / \mathrm{sec}$ was not determined (insufficient material for classification) while only $30 \%$ of the latter value was

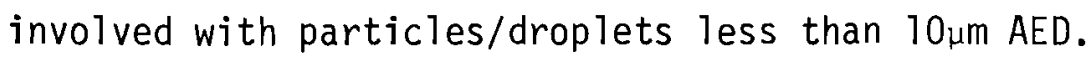


TABLE C.2 Fractional Airborne Release of Plutonium Nitrate under Thermal and Aerodynamic Stress--Summary

EVAPORATION OF SHALLOW POOLS OF LIQUID: 10 to $100 \mathrm{cM} / \mathrm{SEC}$, AMEIENT TO $100^{\circ} \mathrm{C}$ (12) (1.5 to 24 -hour sampling feriod)

$$
<2 \times 10^{-10} \text { to } 5.7 \times 10^{-7}
$$

REDUCTION OF VOLUME OF HEATING (90\% REDUCTION): $5.9 \mathrm{CM} / \mathrm{SEC}{ }^{(12)}(63$ to $151 \cdot \mathrm{min}$. sampling period)

SIMMER

DISTURBED SURFACE

BOILING

$$
\begin{aligned}
& 1.3 \text { to } 4.5 \times 10^{-6} \\
& 8 \times 10^{5} \text { to } 8.4 \times 10^{-4} \\
& 3 \times 10^{-4} \text { to } 1.8 \times 10^{-3}
\end{aligned}
$$

HEATING OF SOLID RESIDUES FROM AIR DRYING OF SOLUTION: ON STAINLESS STEEL (12) (1-hour sanpl ing period)

$$
\begin{array}{ll}
10 \mathrm{TO} 100 \mathrm{CM} / \mathrm{SEC} \text {. AMCIENT TO } 100^{\circ} \mathrm{C} & <2 \times 10^{-10} \text { to } 3 \times 10^{-8} \\
10 \mathrm{to} 100 \mathrm{CM} / \mathrm{SEC}, 400^{\circ} \text { to } 1000^{\circ} \mathrm{C} & 2 \times 10^{-6} \text { to } 1.2 \times 10^{-3} \\
100 \mathrm{cM} / \mathrm{SEC}, 240^{\circ} \text { TO } 1000^{\circ} \mathrm{C} & 2 \times 10^{-6} \text { to } 2.8 \times 10^{-4}
\end{array}
$$

AERODYNAMIC ENTRAINMENT OF FRESHLY DEPOSITED MATERIAL: AT $2.5 \mathrm{MPH}^{(7)}$ (24-hour sampl ing period)

SMOOTH SANDY SOIL

STAINLESS STEEL

ASPHALi - SHATVEL AGGREGATE

SMOOTH SAIDY SOIL

STAINLESS STEEL
$4.2 \times 10^{-5}$ to $3.7 \times 10^{-4 *}$

$1.7 \times 10^{-4 *}$

$3.3 \times 10^{-4 *}$

: AT $20 \mathrm{MPH}$

$2.7 \times 10^{-4}$ to $7 \times 10^{-3}$

$7.8 \times 10^{-3 \star}$

DURING A PETROLEUM FIRE ON VARIOUS SURFACES: AT $2.5 \mathrm{MPH}^{7}$ (to self extinguishment of fire, 20 minutes to 2 hours)

SMOOTH SANDY SOIL

VEGETATION COVER ON SANDY SOIL

STAINLESS STEEL

ASPHALT-GRAVEL AGGREGATE

SMOOTH SANDY SOIL

VEGETATION COVER ON SARIDY SOIL

STAINLESS STEEL
$7.2 \times 10^{-6}$ to $4.8 \times 10^{-5 *}$

$7.5 \times 10^{-4 *}$

$4.4 \times 10^{-3 *}$

$1.6 \times 10^{-3 *}$ : AT $20 \mathrm{MPH}$

$3.8 \times 10^{-4}$ to $2.2 \times 10^{-3 \star}$ *

$1.7 \times 10^{-3 \star}$

$3.9 \times 10^{-2}$

DURING BURNING OF CONTAMINATED FLAMMABLE MATERIALS (to self extinguishment of fire, 6 minutes to 1 hour)

CONTAINED STATIC CONDITIONS

UNCONTAINED $5.9 \mathrm{CM} / \mathrm{SEC}$

$3 \times 10^{-5}$ to $1.5 \times 10^{-4}(10)$

UNCONTAINED 50 to $100 \mathrm{CM} / \mathrm{SEC}$

$<10^{-4}$ to $10^{-2}(11)$

$3.6 \times 10^{-6}$ to $8 \times 10^{-2}(11)$

*FRACTION OF SOURCE AIRBORNE IN AERODYNAMIC FRACTION LESS THAN $10 \mu \mathrm{m}$. 
When conditions are imposed on liquid mixed with other materials, the fractional release of plutonium appears to reflect the response of the substrate rather than the liquid alone. Thus little of the plutonium or uranium nitrate mixed with sand or sandy soil is airborne at low temperatures and air velocities- $-4 \times 10^{-4}$ at $2.5 \mathrm{mph}$ to $8 \times 10^{-3}$ at $20 \mathrm{mph}$ for the uranium associated with particles less than 10um AED during a 24-hr. sampling period. (7) Very little moist soil is eroded by the wind, (13) and thus a significant portion of the fraction of plutonium released may occur after the immediate surface is dried.

The simultaneous occurrence of a petroleum fire over a liquid spilled on sandy soil does not appear to enhance the airborne release of the salt in solution. This appears reasonable inasmuch as the liquid penetrates into the soil and heating of the surface occurs slowly as the fuel in the soil is depleted. As the water in the aqueous solution is evaporated, the salts left in the soil tend to bind large masses together and sinter into quasi-ceramic aggregates upon additional heating. Thus the fractional releases during a petroleum fire are in the same order as those during air blowing over the spilled liquid on the ground. This is primarily due to the difference in sampling period--20 min. to $2 \mathrm{hrs}$ versus $20 \mathrm{hrs}$. The fractional release of plutonium from heating nitrate solution dried on sand in low upsweeps of air were even lower--2 $\times 10^{-6}$ to $2.8 \times 10^{-4}$ during a $1 \mathrm{hr}$ sampling period. (11)

The fraction of plutonium (and uranium) nitrate made airborne during the burning of the flammable material upon which it is absorbed is dependent on several factors. Salts can be used to make fabrics fire resistant by preventing the generation of fuel. Thus if the salts of radioactive materials form a continuous layer over the surface of the flammable material after the removal of water, large masses are formed that are not readily made airborne. In the absence of airflow to carry particles, fractional releases are smal1--1.5 $\times 10^{-4}$ during the course of the fire to self extinguishment. Fractional releases for less concentrated solutions on various flammable material (ranging from plugs of wood to cheesecloth) ranged up to $10^{-2}$. As air was passed through flammable materials impregnated with concentrate solutions or uranium nitrate at velocities 
around $100 \mathrm{~cm} / \mathrm{sec}(2.2 \mathrm{mph})$, fractional releases as high as $8 \times 10^{-2}$ were measured.

General Comparison of the Behavior of Plutonium Dioxide and Nitrate

A comparison of fractional airborne release values of the dioxide powder and nitrate liquid under similar conditions is shown in Table C. 3. In most cases, the release values for both types of material are comparable. The release of the dioxide exceeds that for nitrate solutions under two conditions--aerodynamic entrainment from sandy soil and during fires involving contaminated flammable materials. In both cases, the properties of the nitrate solution (or solid residue) inhibit the reaction's occurring. Under one set of conditions, a petroleum fire over nitrate solution on stainless steel, airborne releases from the nitrate solution were greater. This emphasizes the passive nature of the dioxide powder under most accident conditions and the variety of parameters interacting to produce airborne release.

Application of Existing Data for Estimation of Potential Airborne Release Fractions Under Postulated Shipping Accident Conditions

To demonstrate the application of existing data for estimation of the fractional airborne release from a postulated accident, two release scenarios are analyzed. One involves plutonium nitrate solution; the other, plutonium dioxide powder.

A truck carrying $L-10$ containers is assumed to be involved in an improbable (see Sections 9 and 11 for probabilities) accident which results in loss of some plutonium nitrate solution. This released plutonium nitrate solution forms a shallow layer on the asphalt-gravel aggregate surface of the roadway.

The value for release of a nitrate solution due to aerodynamic entrainment from an asphalt-gravel surface shown in Table C. 2 can be applied-$3.3 \times 10^{-4}$ airborne as particles/drops less than $10 \mu \mathrm{m}$ in a 24-hr. period at a windspeed of $2.5 \mathrm{mph}$ measured $1 \mathrm{ft}$. above the surface. This value 


\section{TABLE C.3 Comparison of Fractional Airborne Release of Dioxide Powder and Nitrate Solution under Simulated Accident Conditions} HEATING IN UPSWEEP OF AIR (0.2 to $2.2 \mathrm{MPH})$ TO $1000^{\circ} \mathrm{C}, 1-\mathrm{hr}$. sampling
period

AEROOYNAMIC ENTRAINMENT FROM FRESHLY DISPERSED MATERIAL ON VARIOUS

SURFACES, 24-hr. sampling period

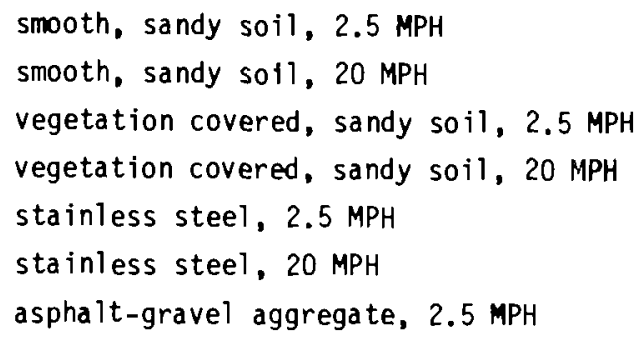

DURING A PETROLEUM FIRE OVER VARIOUS SURFACES (FROM FRESHLY DISPERSED

MATERIAL), to self extinguishment of fire, $20 \mathrm{~min}$. to $2 \mathrm{hr}$.

smooth, sandy soil, $2.5 \mathrm{MPH}$

smooth, sandy soil, $20 \mathrm{MPH}$

vegetation covered sandy soil, 2.5 MPH

vegetation covered sandy soil, $20 \mathrm{MPH}$

stainless steel, 2.5 MPH

stainless steel, $20 \mathrm{MPH}$

asphalt-gravel aggregate, $2.5 \mathrm{MPH}$

DURING FIRE INVOLVING CONTAMINATED MATERIALS, (to self extinguishment of fire)

static, 1 to $2 \mathrm{hr}$.

1.1 to $2.2 \mathrm{MPH}, 6 \mathrm{~min}$. to $20 \mathrm{~min}$.
FRACTION OF MASS

\begin{tabular}{lr}
\hline $\begin{array}{c}\text { dioxide } \\
\text { powder }\end{array}$ & $\begin{array}{c}\text { nitrate } \\
\text { solution }\end{array}$ \\
\hline $\begin{array}{l}5.3 \times 10^{-8} \text { to } \\
2.5 \times 10^{-4}(\mathrm{~d})\end{array}$ & $\begin{array}{r}2 \times 10^{-10} \text { to } \\
1.2 \times 10^{-3}(\mathrm{~b})\end{array}$ \\
$2.4 \times 10^{-3}(\mathrm{c}, \mathrm{d})$ & $3.7 \times 10^{-4}(\mathrm{~d}, \mathrm{e})$ \\
$9.8 \times 10^{-2}(\mathrm{c}, \mathrm{d})$ & $7 \times 10^{-3}(\mathrm{~d}, \mathrm{e})$ \\
$3.8 \times 10^{-4}(\mathrm{c}, \mathrm{d})$ & \\
$4 \times 10^{-3}(\mathrm{c}, \mathrm{d})$ & \\
$7.5 \times 10^{-4}(\mathrm{~d}, \mathrm{f})$ & $1.7 \times 10^{-4}(\mathrm{~d}, \mathrm{e})$ \\
$2.9 \times 10^{-3}(\mathrm{~d}, \mathrm{f})$ & $7.8 \times 10^{-3}(\mathrm{~d}, \mathrm{e})$ \\
$8.7 \times 10^{-4}(\mathrm{~d}, \mathrm{f})$ & $3.3 \times 10^{-3}(\mathrm{~d}, \mathrm{e})$
\end{tabular}

$$
\begin{array}{r}
3.5 \times 10^{-4}(c, d) \\
2 \times 10^{-3}(c, d) \\
1.3 \times 10^{-4}(c, d) \\
2.5 \times 10^{-3}(c, d) \\
7.9 \times 10^{-4}(c, d) \\
9 \times 10^{-5}(c, d) \\
2.9 \times 10^{-4}(c, d)
\end{array}
$$

$4.8 \times 10^{-5}(\mathrm{~d}, \mathrm{e})$

$2.2 \times 10^{-3}(d, e)$

$7.5 \times 10^{-4}(d, e)$

$1.7 \times 10^{-3}(d, e)$

$4.4 \times 10^{-3}(\mathrm{~d}, \mathrm{e})$

$3.9 \times 10^{-2}(d, e)$

$1.6 \times 10^{-3}(\mathrm{~d}, \mathrm{e})$

$1.5 \times 10^{-3}(c)$
0.016 to $0.38^{(c)}$
$1.5 \times 10^{-4}(e)$

$3.6 \times 10^{-6}$ to
$0.08(\mathrm{e})$

(a) Plutonium dioxide particles from oxidation of metal above ignition temperature in the range 15 to $150 \mu m$ AED.

(b) Plutonium nitrate solid from air drying $250 \mathrm{~g}$ Pu per liter solution at ambient temperature.

(c) Ball-milled uranium dioxide powder of AMD approximately 1 um used as source.

(d) Fraction of mass as particles airborne less than $10 \mu \mathrm{m}$ AED.

(e) Uranium nitrate solution in dilute nitric acid (5l0 $\mathrm{g} \mathrm{U}$ per liter) used as a source.

(f) Solid residue from ball-milled uranium dioxide (see c) following a petroleum fire used as a source. 
would be high for lower windspeeds at that height and equivalent to a windspeed 5.7 mph measured at 30 feet.* There is no value given for higher windspeeds. The release values for nitrate solution from asphalt-gravel aggregate and stainless steel under the same conditions (airborne particles/ droplets less than 10um AED during a 24-hr period using a windspeed of 2.5 mph) are similar. Both are:hard, impervious surfaces. The airborne release from the asphalt-gravel surface is a factor of two higher, and thus a value of $1.6 \times 10^{-2}$ particles/droplets less than 10um AED during a 24- hr. period would be used at $20 \mathrm{mph}$ (approximately $46 \mathrm{mph}$ measured at $30 \mathrm{ft}^{\star}$ ). Intermediate values could be chosen for intermediate windspeeds.

For the second demonstration, it is assumed that a truck carrying $6 \mathrm{M}$ containers is involved in an improbable (see Sections 9 and 11 for probabilities) accident which results in loss of some plutonium nitrate powder. The released powder is deposited in a shallow layer on the asphalt-gravel aggregate surface of the roadway.

It is assumed that the size distribution of the powder is as described by Caldwell and Thomas (14)--Mass Median Diameter (MMD) of 1 to $2 \mu \mathrm{m}$. The MMD of the dioxide powder used in all the experiments in Table C.2 except those involving heating of plutonium dioxide in flowing air used a dioxide powder of similar size. The airborne release of particles less than $10 \mu \mathrm{m}$ was $8.7 \times 10^{-4}$ in $24 \mathrm{hrs}$ from an asphalt-gravel surface at $2.5 \mathrm{mph}(5.7 \mathrm{mph}$

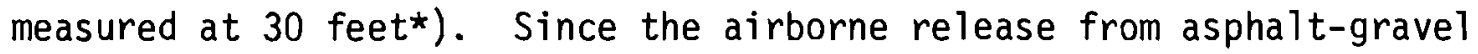
and stainless steel surfaces (see Table C.1) are almost the same under the same conditions, an airborne release of $3 \times 10^{-3}$ is assumed at $20 \mathrm{mph}$ (approximately $46 \mathrm{mph}$ measured at $30 \mathrm{ft}^{\star}$ ).

* The velocity of air in turbulent flow increases with height above the surface. Thus a wind of given speed measured at one height will not have the same speed at a different height. The wind velocity profile is related to $U^{*}$, the friction velocity, defined by $U^{*}=\sqrt{\tau} / \rho$, in which $\tau$ is the shear stress and $\rho$ is the density of the medium. For typical surfaces, when the windspeed is $2.5 \mathrm{mph}$ at $1 \mathrm{ft}$. above the surface (the wind tunnel centerline velocity), the same wind would have a speed of approximately $6 \mathrm{mph}$ at $30 \mathrm{ft}$. above the surface. 
Limitations and Uncertainties in the Estimation of Potential Airborne Release Under Accident Conditions

The estimates calculated are probably reasonable to an order of magnitude or less for the stated conditions and are comparable to the accuracy of the atmospheric diffusion/deposition calculations. Significant difference in airborne release could result from many easily foreseeable conditions. The road condition may be poor and much of the liquid collected in holes and cracks, making it unavailable for entrainment. Release from other surfaces--soil ranging in porosity from clay to sand, water, grass, steel, etc.--is also possible. A fire increases the number of potential conditions.

Since an accident is a unique and unplanned occurrence, the conditions and events in any given accident cannot be precisely predicted. The uncertainties created by the lack of precision varies since the conditions and events inducing airborne release vary. No model to predict airborne release under accident conditions has been formulated. The lack of precision in predicting accident conditions and events is carried into the experimentally derived and calculated values since the postulated conditions are used in experiments and as a basis for calculations.

In conclusion, data are available to provide order of magnitude estimates of the potential airborne release of plutonium under many shipping accident conditions. Many factors are believed to influence the fractional airborne release, but their effects are not fully quantified. Assumptions are made to maximize the calculated release predicted for postulated accidents and thus compensate for the uncertainties inherent in predicting accident conditions and events. 


\section{REFERENCES}

1. "Report of Task Group and Lung Dynamics to ICRP Committee 2. Deposition and Retention Models for Internal Dosimetry to Human Respiratory Tract," Health Physics, Vol. 12, p. 173, 1966.

2. D. H. Slade, Meteorology and Atomic Energy, 1968, USAEC Division of Technical Information, July 1968.

3. E. J. Katz, "Atmospheric Diffusion of Settling Particles with Sluggish Response," Journal of Atmospheric Sciences, Vol. 23, p. 159, 1966.

4. 0. J. Wick, Ed. Plutonium Handbook, Gordon and Breach - Science Publishers, New York, 1967.

5. R. K. Hilliard, Probable Volatilization of Plutonium During a Fire, HW-71743, GeneraT Electric Co. - HAPO, Richland, WA, December 196T.

6. J. Mishima, L. C. Schwendiman and C. A. Radasch, Plutonium Release Studies, III, Release from Heated Plutonium Bearing Powders, BNWL-786, Battel1e, Pacific Northwest Laboratories, Richland, WA, JuTy 1968.

7. J. Mishima and L. C. Schwendiman, Some Experimental Measurements of Airborne Uranium (Representing Plutonium) in Transportation Accidents, BIWL-1732, Batte11e, Pacific Northwest Laboratories, Richland, WA, March 1973.

8. W. G. H. Slinn, "Initial Resuspension Mode1," Pacific Northwest Laboratory Annual Report for 1972 to the USAEC Division of Biomedical and Environmental Research, Volume II: Physical Science, Part 1, Atmospheric Sciences BNWL-1751, Pt. 1, Battel1e, Pacific Northwest Laboratories, Richland, WA, Apri1 1973.

9. W. S. Chepe1, "Relation of Wind Erosion to Water Stable and Dry Clod Structure of Soi1," Soil Science, JJ, pp. 275, 278, 1943.

10. J. Mishima and L. C. Schwendiman, Fractional Airborne Release of Uranium (Representing Plutonium) During the Burning of Contaminated Waste, BIWL-1730, Battelle, Pacific Northwest Laboratories, Richland, WA, Apri1 1973.

11. J. Mishima and L. C. Schwendinan, The Amount and Characteristics of Plutonium Made Airborne Under Thermal Stress, BNWL-SA-3379, Battelle, Pacific Northwest Laboratories, Richland, WA, October 20, 1970.

12. J. Mishima, L. C. Schwendiman and C. A. Radasch, Plutonium Release Studies. IV. Fractional Release from Heating Plutonium Nitrate Solutions in a Flowing Airstream, BNWL-931, Battelle, Pacific Northwest Laboratories, Richland, WA, November 1968. 
13. W. S. Chepe1, "Properties of Soil Which Influence Soil Erosion: I. The Governing Principle of Surface Roughness," Soil Science, Vol. 69, pp. 149, $162,1952$.

14. C. S. Caldwe11 and I. D. Thomas, "Plutonium Uranium Mixed 0xide Preparation and Fabrication Experience," Chemical Engineering Progress Symposium Series, Vol. 63, p. 80, 1967. 


\section{APPENDIX D}

\section{PHYSICAL AND CHEMICAL PROPERTIES OF PLUTONIUM DIOXIDE}

AND PLUTONIUM NITRATE SOLUTION

Plutonium is commonly shipped in two different forms, solid plutonium dioxide and plutonium nitrate solution. The physical and chemical properties of these materials will be briefly described in this appendix.

Properties of Plutonium Dioxide

Plutonium dioxide may be prepared in many ways. It is normally a green powder, but its color and particle size is a function of the method of preparation. Its desirable properties include high melting point, irradiation stability, compatibility with metals, and ease of preparation. (1)

TABLE D.1 Summary of $\mathrm{PuO}_{2}$ Properties (2)

Theoretical Density $\left(\mathrm{gm} / \mathrm{cm}^{3}\right)$

11.45

Melting Point $2400 \pm 30^{\circ} \mathrm{C}$

Crystal System and Parameter FCC (Fluorite) $\alpha_{0}=5.3960 \pm 0.0003$

Coefficjent of Linear Thermal Expansion

$\left({ }^{\circ} \mathrm{C}-1\right.$, Range $25^{\circ}$ to $\left.1000^{\circ} \mathrm{C}\right)$

$10.9 \times 10^{-6}$

Therma 1 Conductivity

(W/cm - ${ }^{\circ} \mathrm{C}$, at $95 \%$ TD )

Electrical Resistivity (ohm-cm)

0.023 at $1000^{\circ} \mathrm{C}$

Resistance to Thermal Shock

$1-3 \times 10^{8}$

Fairly Good

$X$-ray crystallographic data indicate that plutonium dioxide forms a face centered cubic lattice. The reactivity of the substance prepared at higher temperatures is much reduced, apparently due to an increase in purity and a very ordered crystal structure. 0xide prepared at temperatures below $800^{\circ} \mathrm{C}$ has a strongly distorted lattice. (3) The lattice constant increases slightly with time due to damage to the crystal from alpha radiation, but the generally accepted value is $5.3960 \AA$. The theoretical 
density calculated from this value is $11.45 \mathrm{~g} / \mathrm{cm}^{3}$ (1) However, the observed density varies widely as a function of the impurity content of the crystal and the particle size.

The factors which influence density are the type of material from which the dioxide was formed and the degree to which the material was heated in its formation. Bulk densities of the dioxide generally range from 1 to $5 \mathrm{~g} / \mathrm{cm}^{3}$. Density increases with higher temperatures of formation. Grinding and milling of the powder also tends to increase the density. (4)

The plutonium to oxygen ratio of the oxide is also dependent on the method of preparation. The furnace temperature, heating cycle, and decomposition temperature of the parent materials all affect the plutonium content. At lower calcination temperatures (less than $800^{\circ} \mathrm{C}$ ) the crystal may contain extra interstitial oxygen, anionic impurities, and water. Calcination temperatures in excess of $870^{\circ} \mathrm{C}$ are required to remove all anionic impurities, but excess interstitial oxygen is observed until temperatures of over $1200^{\circ} \mathrm{C}$ are reached. The $0 / \mathrm{Pu}$ atom ratio for plutonium

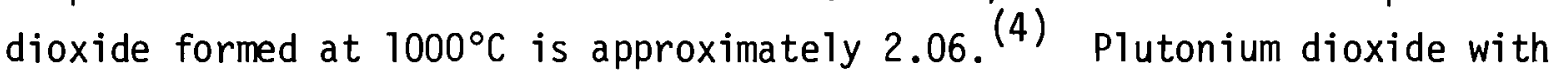
an $0 / \mathrm{Pu}$ ratio of less than 2.00 has been prepared for use in mixed uranium-plutonium fuels. (2)

Plutonium dioxide is practically insoluble in water and dilute acids, but it is difficultly soluble in some concentrated acids. The best solvents are 12 to 16 normal (N) $\mathrm{HNO}_{3}$ with 0.01 to 0.1 (N) HF, 5 to 6 (N) HI, and $9(\mathrm{~N}) \mathrm{HBr}$. Increasing acidity generally increases the rate of dissolution. 4 The dioxide calcined at temperatures below $275^{\circ} \mathrm{C}$ is soluble in hydrochloric acid. Concentrated sulfuric acid will dissolve dioxide calcined at temperatures up to $600^{\circ} \mathrm{C}$. (3) Refluxing is necessary in all cases, and dissolution is very slow, generally requiring at least several hours to dissolve small samples. (4)

If exposed to humid air, calined plutonium dioxide powder will adsorb moisture. The powder eventually saturates at about 1 to 2 wt\% water. 
The surface area and crystallite size of plutonium dioxide particles have also been investigated. Some typical specific surface area values range from about 5 to $60 \mathrm{~m}^{2} / \mathrm{g}$. The surface area of oxide powders was observed to decrease with increasing calcination temperature, possibly due to sintering effects. Similarly the crystallite size increased with increasing temperature. It is suspected that there is a correlation between crystallite size, as well as surface area, and the reactivity of plutonium dioxide, specifically its rate of dissolution. (4)

Study of the size of plutonium dioxide particles reveals that it is an extremely fine powder. Some distributions of particle size are shown in Figure D.1. (5) Many of the particles are small enough to become airborne and be inhaled. ${ }^{(6)}$

\section{Properites of Plutonium Nitrate}

Plutonium nitrate is shipped as a dark brown aqueous solution. It is somewhat more viscous than water but is easily pourabie. The nitrate may be shipped with a concentration of up to $250 \mathrm{~g}$ of plutonium per liter of solution. It is commonly shipped in concentrations of about $200 \mathrm{~g} / \mathrm{liter}$. (7)

\section{TABLE D.2 Specifications for Plutonium Nitrate to be} Purchased by the AEC (8)

Plutonium Concentration ( $g / 1$ iter) $\mathrm{HNO}_{3}$ Concentration

Total Metal1ic Impurities Residues Insoluble in $50 \% \mathrm{HNO}_{3}$ Entrained Organic Material $\mathrm{Cl}^{-}$and $\mathrm{SO}_{4}^{-}$
$50-250$

2-10N "...as required to sustain a stable nitrate solution"

Less than $500 \mathrm{ppm}$

Less than $500 \mathrm{ppm}$

Less than $0.5 \%$ by volume

Minimum consistent with use of technical grade chemicals

The density of plutonium nitrate solutions is given by the formula $d_{25}=1.0012+0.22 \times M_{P u}+0.03096 \times M_{\mathrm{HNO}_{3}}$ 

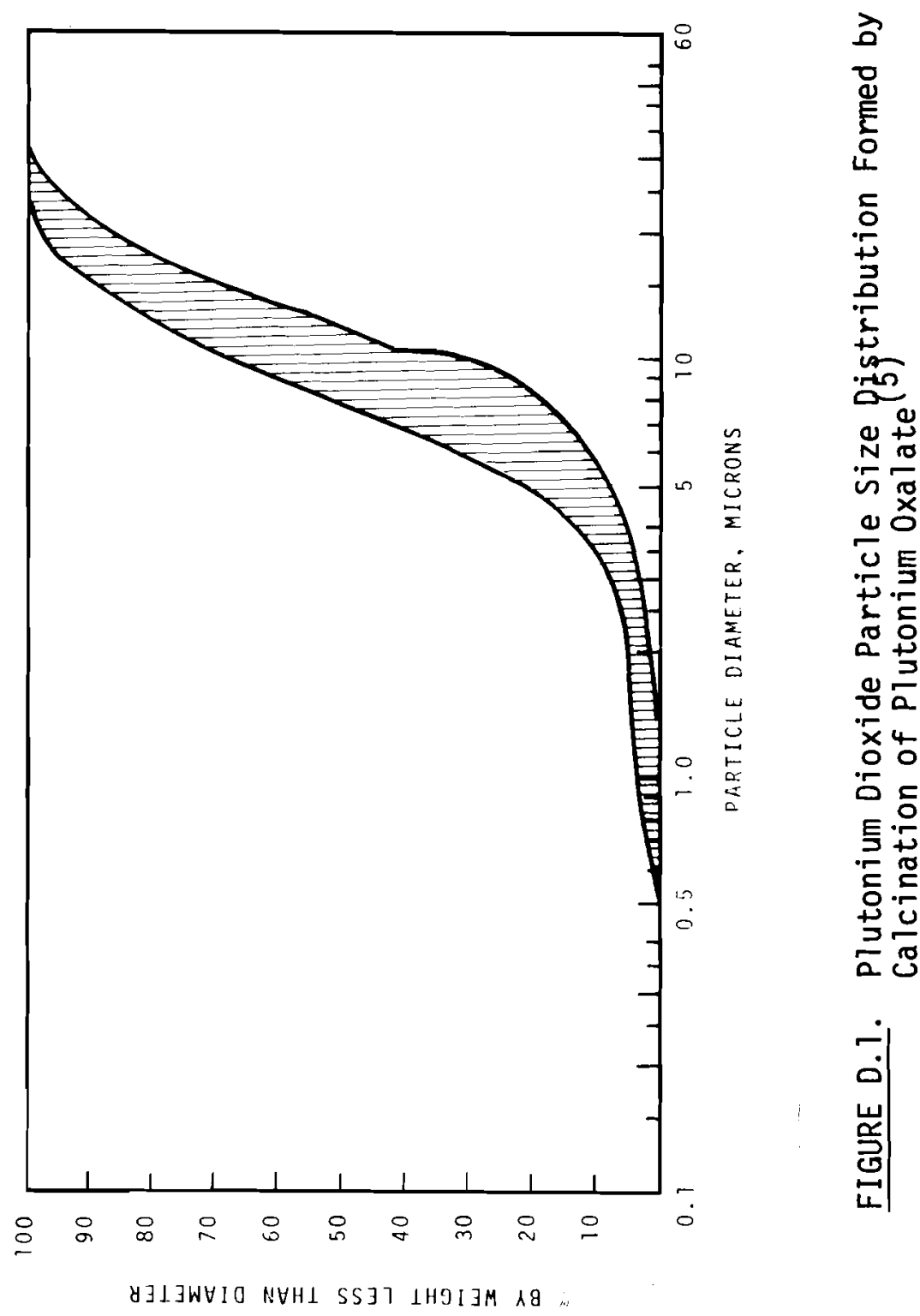
where $d_{25}$ is the density of the solution in grams per cubic centimeter at $25^{\circ} \mathrm{C}, \mathrm{M}_{\mathrm{Pu}}$ is the molarity of plutonium nitrate in moles per liter, and $\mathrm{M}_{\mathrm{HNO}_{3}}$ is the molarity of nitric acid. The maximum solubility of plutonium nitrate is from 2.1 to $2.5 \mathrm{M}$ in $1.8 \mathrm{M}$ nitric acid solution. ${ }^{(9)}$ The viscosity of plutonium nitrate solution may be approximated for low plutonium concentration by a formula for uranyl nitrate solution:

$$
\begin{aligned}
\log _{10}(\mathrm{~m}) & =0.9527+0.246 \mathrm{M}_{\mathrm{u}}+0.010 \mathrm{M}_{\mathrm{u}}^{2} \\
& +\left[0.0089-0.0023 \mathrm{M}_{\mathrm{u}}\right] \times \mathrm{M}_{\mathrm{HNO}_{3}} .
\end{aligned}
$$

1.1 is the viscosity of uranyl nitrate solution in millipoise at an assumed temperature of $25^{\circ} \mathrm{C}, \mathrm{M}_{\mathrm{u}}$ is the molarity of $\mathrm{UO}_{2}\left(\mathrm{NO}_{3}\right)_{2}$, and $\mathrm{M}_{\mathrm{HNO}_{3}}$ is the
molarity of nitric acid.

Plutonium nitrate solution is generally quite dilute in nitric acid. The lower limit is $2 \mathrm{~N}$ in nitric acid to prevent plutonium (IV) polymer formation. The expected composition range for shipping solutions is from 3 to $6 \mathrm{~N}$ nitric acid. Above $50 \mathrm{~g}$ plutonium per liter, polymer forms quickly if the acidity is less than $0.3 \mathrm{~N}$ nitric acid. It is practically impossible to dilute plutonium nitrate solutions with water without the formation of a colloidal solution because of regions of momentary low acid concentration. The polymerization is rapid, but it takes a long time for depolymerization. (8)

Polymer formation is favored by higher temperatures. A nitric acid concentration of $1.5 \mathrm{~N}$ is required to prevent polymer formation in boiling plutonium nitrate solution containing 100 to $200 \mathrm{~g}$ plutonium per liter. ${ }^{(8)}$

The gas pressure in the shipping container is controlled by three phenomena. These are the vapor pressure versus temperature curve for the solution, the radiolytic decomposition of the solution and the radiolytic reduction of the solution if any plutonium (VI) is present. When considering the failure of the $2 R$ containment vessel, the vapor pressure versus temperature curve should normally control. The latter two phenomena 
are of lesser importance so long as the solution is not shipped without adequate aging to allow reduction of any plutonium (VI) to plutonium (IV) and the containment vessel is vented prior to shipment. Although the vapor pressure versus temperature curve for $1 \mathrm{M} \mathrm{Pu}\left(\mathrm{NO}_{3}\right)_{4}$ in 3 to $6 \mathrm{M} \mathrm{HNO}_{3}$ has never been measured, the vapor pressure can be expected to be due almost entirely to the vapor pressure of $\mathrm{HNO}_{3} \cdot(11)$

Using the equation:

$$
\ln P=A-B / T
$$

where $P$ is in psi, $T$ is in ${ }^{\circ} K$, Staples, Procopio and $S u^{(12)}$ present values of $\mathrm{A}$ and $\mathrm{B}$ for various $\mathrm{HNO}_{3}$ concentrations. For the $6 \mathrm{M} \mathrm{HNO}_{3}$ solution, $A=16.6749$ and $B=5399.03$. Using these constants, a pressure of 3000 psi is reached at $350^{\circ} \mathrm{C}$. For pure water a 3000 psi vapor pressure is reached at $370^{\circ} \mathrm{C}$. This shows that the vapor pressure is due primarily to the water with a very small vapor pressure contribution from the $\mathrm{HNO}_{3}$. Equation (1) will be used in the thermal analysis section (Appendix I) to predict times to failure for the $2 R$ containment vessel.

Radiolytic decomposition of the nitrate solution by alpha decay of plutonium results in gas release from nitrate solutions. The principal component of the gas evolved is oxygen with lesser but very significant amounts of nitrogen and hydrogen. The mechanism for the gas formation is not fully understood. (8)

Radiolytic reduction of the higher oxidation state plutonium (VI), which appears in the form $\mathrm{PuO}_{2}{ }^{+2}$, has been observed to be associated with oxygen gas formation. $(8,13)$ Presumably the plutonium (VI) is reduced to plutonium (IV) by the hydrogen radical or hydrogen peroxide formed by the alpha radiolysis of water. The formation of plutonium (VI) by disproportion action reactions is highly sensitive to the acidity. At nitric acid concentrations of less than $1 \mathrm{~N}$ the amount of plutonium (VI) may be very significant, but higher acidity favors the stabilization of plutonium (IV).

0xygen and hydrogen are also formed directly from the radiolysis of water. Other radiolytic reactions in nitric acid generate gaseous oxides 
of nitrogen. Since the gaseous products are the result of a chain of chemical reactions initiated by alpha radiolysis, the amount of gaseous products formed should be directly proportional to the alpha radiation energy absorbed by the system. (13)

Bryan and Ryan ${ }^{(14)}$ reported the following equation for determining the rate of pressurization of a closed container containing plutonium nitrate solution:

$$
\begin{aligned}
& \frac{d p}{d t}=2.01 \times 10^{-4}\left(\frac{K}{V-V_{1}}\right) g_{P_{u}} G_{T}\{(\% P u-239)+ \\
& \left.3.7(\% P u-240)+302(\% P u-238)+60(\% P-241)\left[1-e^{-0.049 Y}\right]\right\}
\end{aligned}
$$

where $K$ is the solution temperature, ${ }^{\circ} \mathrm{K}$

$t$ is the time in days

$V$ is the container volume $\mathrm{cm}^{3}$

$V_{1}$ is the volume of liquid solution in the container, $\mathrm{cm}^{3}$

$Y$ is the time in years since chemical separation of Am from $\mathrm{Pu}$

$g_{\mathrm{Pu}}$ is the total grams plutonium in the container

$p$ is the pressure in psi

$\mathrm{G}_{\mathrm{T}}$ is the total number of gas molecules produced per $100 \mathrm{ev}$ of energy absorbed

The value of $G_{T}$ in equation (2) is obtained experimentally since it is a function of many parameters. Table $D .3$ shows the values of $G_{T}$ obtained at several nitric acid and plutonium solution molarities. These values were reported in Reference 13. Also shown are values of $\mathrm{GO}_{2}, \mathrm{GH}_{2}, \mathrm{GN}_{2}$. These values indicate the number of molecules of $\mathrm{O}_{2}, \mathrm{H}_{2}$ and $\mathrm{N}_{2}$ produced per $100 \mathrm{ev}$ of energy absorbed by the solution. The value of $G_{T}$ is the sum of the "G" values for any gas molecule produced as a result of the activity of the plutonium solution and the subsequent absorption of decay energy by the solution.

It can also be seen from the behavior of $G_{T}$ in Table 0.3 that the rate of gas generation decreases as the nitric acid concentration increases. 
Although the $G_{T}$ values reported were obtained using a plutonium isotopic mixture containing 7.5 to $8.4 \%{ }^{240} \mathrm{Pu}$ and about $0.3 \%{ }^{238} \mathrm{Pu}$, the values of $\mathrm{G}_{\mathrm{T}}$ are not expected to change if different isotopic mixtures had been used.

Based on these values of $G_{T}$ and equation (2) gas generation rates can be calculated for various isotopic mixture of plutonium in nitric acid solutions. Brooksbank ${ }^{(15)}$ has estimated that the rate of gas evolution could increase by a factor of nine when plutonium from LMFBR operations is introduced into the nuclear fuel cycle.

TABLE D. 3 Effect of Nitric Acid and Plutonium Nitrate Concentration on the Value of $G_{T}$

\begin{tabular}{|c|c|c|c|c|c|c|}
\hline Experiment & $\begin{array}{c}\left(\mathrm{HNO}_{3}\right) \\
\text { Molarity }\end{array}$ & $\begin{array}{l}(\mathrm{Pu})_{\text {total }} \\
\text { Molarity }\end{array}$ & $\mathrm{G}_{T}$ & $\mathrm{G}\left(\mathrm{O}_{2}\right)$ & $\mathrm{G}\left(\mathrm{H}_{2}\right)$ & $G\left(N_{2}\right)$ \\
\hline 1 & 1.0 & 0.244 & 0.56 & 0.21 & 0.28 & 0.06 \\
\hline 2 & 2.4 & 0.487 & 0.264 & 0.12 & 0.13 & 0.01 \\
\hline 3 & 4.2 & 0.466 & 0.096 & 0.030 & 0.059 & 0.004 \\
\hline 4 & 4.2 & 0.466 & 0.088 & (a) & - & - \\
\hline 5 & 4.0 & 0.992 & 0.096 & (b) & - & - \\
\hline 6 & 6.6 & 0.470 & 0.073 & 0.017 & 0.057 & - \\
\hline 7 & 6.6 & 0.470 & 0.073 & (a) & - & - \\
\hline 8 & 8.0 & 0.467 & 0.039 & 0.009 & 0.024 & 0.005 \\
\hline 9 & 10.0 & 0.496 & 0.021 & (c) & - & - \\
\hline
\end{tabular}

(a) Experiments 4 and 7 are repeats of 3 and 6 . The duration of each experiment was about 1 month.

(b) Ten times as much plutonium was used in this experiment as in experiment 3.

(c) The rate of pressure buildup was too low to collect a gas sample for analysis.

The above analysis shows that sealed containers must be periodically vented to relieve the pressure buildup from gas formation. The rate of buildup, using equation (2), is only a few psi/day for the isotope mix- 
ture being analyzed in this report (Table 10.11). Thus, the pressure buildup is only a major concern during storage and not while in transit. The gas mixture produced by radiolytic decay is a mixture of $\mathrm{H}_{2}$ and $\mathrm{O}_{2}$ which has the potential for ignition and subsequent explosion.

The major advantage of shipping plutonium in the nitrate form is that it is readily adaptable to processing into sinterable plutonium dioxide at a fuel fabrication facility. The liquid form is easily blended to reach a desired isotopic assay and easily sampled for inventory purposes. There is little danger of suspension of plutonium particles in the air from plutonium nitrate solution. $(15,16)$

If the solution is spilled and allowed to evaporate slowly, plutonium nitrate pentahydrate, $\mathrm{Pu}\left(\mathrm{NO}_{3}\right)_{4} \cdot 5 \mathrm{H}_{2} \mathrm{O}$, crystallizes out. This solid salt is readily soluble in water. When heated to $40^{\circ} \mathrm{C}$, the hydrated plutonium nitrate begins to decompose, and it melts at 95 to $100^{\circ} \mathrm{C}$. An intermediate material thought to be plutonyl nitrate, $\mathrm{PuO}_{2}\left(\mathrm{NO}_{3}\right)_{2}$, is formed at 150 to $200^{\circ} \mathrm{C}$. Decomposition of the nitrate to the dioxide proceeds rapidly at $220^{\circ} \mathrm{C}$ and is essentially complete at $250^{\circ} \mathrm{C}$. Thus, if airdrying occurs at temperatures high enough to produce the dioxide, the danger of human inhalation is increased. If the proper conditions of temperature, atmosphere, and gas velocity are present the plutonium dioxide powder may become airborne. (16) 


\section{REFERENCES}

1. B. R. Fish, G. W. Keilholtz, W. S. Snyder, and S. D. Swisher, Calculation of Doses Due to Accidentally Released Plutonium from an LMFBR, ORNL-NSIC-74, November 1972.

2. B. F. Rubin, Comp., Summary of $(\mathrm{U}, \mathrm{Pu}) \mathrm{O}_{2}$ Properties and Fabrication Methods, GEAP-13582, November 1970.

3. 0. J. Wick, Ed., Plutonium Handbook, A Guide to the Technology, Gordon and Breach, 1967.

4. J. D. Moseley, and R. 0. Wing, Properties of Plutonium Dioxide, RFP-503, August 1965.

5. C. S. Caldwe11, "Relationship Between Process Variables and Final Properties of $\mathrm{UO}_{2}, \mathrm{U}_{2}-\mathrm{Pu} 02$, and $\mathrm{PuO} 2$, "Meeting on Characterization of Uranium Dioxide Held at Oak Ridge National Laboratory, December 12-13, 1961, TID-7637, pp. 249-271.

6. J. Mishima, L. C. Schwendiman, and C. A. Radash, Plutonium Release Studies III. Release from Heated Plutonium Bearing Powders, BNWL-786, Battelle, Pacific Northwest Laboratories, Richland, WA July 1968.

7. L. M. Knights, "Evaluation of Product Form in Safety of Plutonium Transportation (ARH-SA-108)," Proceedings of the Third International Symposium on Packaging and Transportation of Radioactive Materials, Richland, WA, August 16-20, 1971, BNWL-SA-3906, Battel1e, Pacific Northwest Laboratories, Richland, WA, pp. 227-240.

8. J. T. Byrne, R. L. Delnay, W. E. Domning, L. F. Grill, and F. J. Miner, Measurements of Plutonium Nitrate Shipping Solutions, RFP-436. October 1964.

9. Unclassified sections of the Purex Manual, HW3100. March 1955, p. 448.

10. L. L. Berger et al., Properties of Uranyl Nitrate Solutions in Nitric Acid-Hexone Systems, HW- 11276, March 1949.

11. R. D. Scheele, personal communication to T. I. McSweeney, November 21 , 1973.

12. B. G. Staples, J. M. Procopio, Jr., and G. J. Su, "Vapor Pressure Data for Common Acids at High Temperatures," Chem. Eng., vol. 77, no. 25, pp. 113-115, 1970.

13. J. C. Sheppard, Alpha Radiolys is of Plutonium (IV) - Nitric Acid Solutions, BNWL-757, Battel1e, Pacific Northwest Laboratories, Richland, WA, May 1968.

14. G. H. Bryan, and J. L. Ryan, "Solid Plutonium Nitrate Shipping Forms," Proceedings of the 4th International Symposium on Packaging and Transportation of Radioactive Materials, Miami Beach, FL, 1974. 
15. R. E. Brooksbank, Material Forms for Maximum Safety in the Shipping of Alpha Emitting Materials, ORNL-4554. March 1970.

16. J. Mishima, L. C. Schwendiman, and C. A. Radasch, Plutonium Release Studies IV. Fractional Release from Heating Plutonium Nitrate Solutions in a Flowing Air Stream, BNWL-931, Battelle, Pacific Northwest Laboratories, Richland, WA, November 1968. 


\section{BIBL IOGRAPHY}

C. Affortit, Contribution to the Study of the Specific Heat of Actinide Compounds, CEA-R-4266, February 1972, (In French).

Big Rock Nuclear Plant. License No. DPP-6, DOCKET-50155-22, January 1970. C. W. Bjorklund, and E. Staritsky, Some Observations on the Reactivity of Plutonium Dioxide, LA-1869, 1964.

J. T. Byrne, F. E. Adcock, R. L. Delnay, R. D. Gauthier, D. W. Park, and

C. L. Schuske, Plutonium Nitrate Shipping Packages, RFP-437. October 1964.

J. T. Byrne, C. E. Caldwell, R. L. Delnay, J. D. Moseley, and F. L. Oetting, Measurements Involved in Shipping Plutonium Dioxide, RFP-502. August 1965.

C. S. Caldwe11, "Preparation and Characterization of Fuel Materials," Development of Plutonium-Bearing Fuel Materials, Progress Report for Period July-September, 1967, NUMEC p. 80.

C. S. Caldwe11, and 0 . Menis, "Preparation and Characterization of Fuel Materials," Development of Plutonium-Bearing Fuel Materials, Progress Report for Period January-March, 1962, NUMEC p. 100.

T. D. Chikalla, C. E. McNeilly, and R. E. Skavdah1, The Plutonium-0xygen System, HW-74802, September 1962.

J. M. Cleveland, The Chemistry of Plutonium, Gordon and Breach, 1970.

J. L. Drummond, and G. A. We 1ch, "The Preparation and Properties of Some Plutonium Compounds, Part VI. Plutonium Dioxide," Chemical Society Journa 1, Pt 4, pp. 4781-4784, 1957.

Paul A. Haas, Comp., LMFBR Fuel Materials Conversion Development: A Partial Technical Evaluation, ORNL-TM-3071, May 1972.

C. E. Holley, R. N. R. Mulford, E. J. Huber, E. L. Head, F. H. Ellinger, and $C$. W. Bjorklund, "Thermodynamics and Phase Relationships for Plutonium 0xides," Proceedings of the Second United Nations International Conference on the Peaceful Uses of Atomic Energy, Geneva, 1958, p. 215.

J. J. Katz, and G. T. Seaborg, The Chemistry of the Actinide Elements, Methuen and Co., 1957.

R. E. Lerch, and G. F. Schiefelbein, Dissolution of Unirradiated Mechanically Blended Mixed Oxide Fast Breeder Fuel, HEDL-SA-131, Apri1 1971.

F. J. Miner, and J. R. Seed, "Radiation Chemistry of Plutonium Nitrate Solutions," Chem. Rev., vol. 67, p. 299, 1967.

J. Mishima, A Review of Research on Plutonium Release During Overheating and Fires, HW-83668, August 1964.

G. L. O'Nei11, Plutonium Utilization in Boiling Water Reactors. Phase II 1969 Annual Report, NEDC-T2T11, JuTy 1970. 
S. W. Rabideau, "Equilibria and Reaction Rates in the Disproportion of Pu (IV)," J. Amer. Chem. Soc., vol. 75, p. 798, 1953.

G. T. Seaborg, and J. J. Katz, The Actinide Elements, McGraw-Hil1 Book Co., 1954.

A. L. Uriarte, and R. H. Rainey, Dissolution of High Density $\mathrm{U}_{02}, \mathrm{PuO}_{2}$, and U02-Pu02 Pellets in Inorganic Acids, ORNL-3695, Apri1 1965.

A. W. Wenzel, H. N. Simmons, J. L. Duke, and C. E. Pietri, Effect of Humidity on Low-Fired Plutonium Oxide Samples, NBL-262, pp. 43-46.

E. F. Westrum, "The Preparation and Properties of Plutonium Oxides," The Transuranium Elements, NNES, IV-B, Ed. by Seaborg, Katz, and Manning, pp. 936-945, 1949.

West Valley Reprocessing Plant. Safety Evaluation for Transfer and Processing of PTutonium Nitrate-Uranyl Nitrate Solutions, Addendum 2, DOCKET-50201-90, October 1971. 
APPENDIX E*

\section{PLUTONIUM PATHWAYS}

Exposure transport routes to man were developed for plutonium as a means of locating points of expected long-term contaminant accumulations and points of population-contaminant interfaces. (1) The more important plutonium pathways are shown in Figure E.1.

Media appearing inside the diamond shapes on the figure are those commonly sampled in environmental surveillance programs. Individual discrimination factors (IDF), defined as the recipient-to-donor concentration ratio or as the fraction of incident contaminant retained by recipients, are provided for each medium-to-medium transfer link. Identification of the predominant exposure pathways was made by propagating the IDFs into combined discrimination factors (CDF) for each recognized potential transport route from effluent release to human exposure. A CDF is defined as the product of all of the IDFs in an exposure pathway.

Discrimination factors which were not available from the literature were inferred by comparison as shown in Table E.1. Two assumptions were made based on similar transport routes. These are noted in Table E.1. The first assumption was that bottom-feeding aquatic animals exhibit the same IDF toward their sources of nourishment as do plant-feeding aquatic animals. Additionally, the irrigation water-soil-land plant pathway and the sedimentaquatic plant pathway were assumed to have the same IDF. Based on work by Langham, ${ }^{(2)}$ an IDF of $2 \times 10^{-5}$ was assigned to most animal ingestion processes, $10^{-2}$ for surface contamination mechanisms, and $10^{-1}$ for food processing. Other inferences indicated in Table E.1 are based on work by Soldat ${ }^{(3)}$ and Noshkin. ${ }^{(4)}$ Exposure routes with CDFs less than $10^{-15}$ were considered insignificant and are not shown on the diagram. The four transport

* Taken from: J. M. Selby et al., Considerations in the Assessment of the Consequences of Effluents from Mixed Oxide Fuel Fabrication Plants, BNWL-1697, June 1973. 


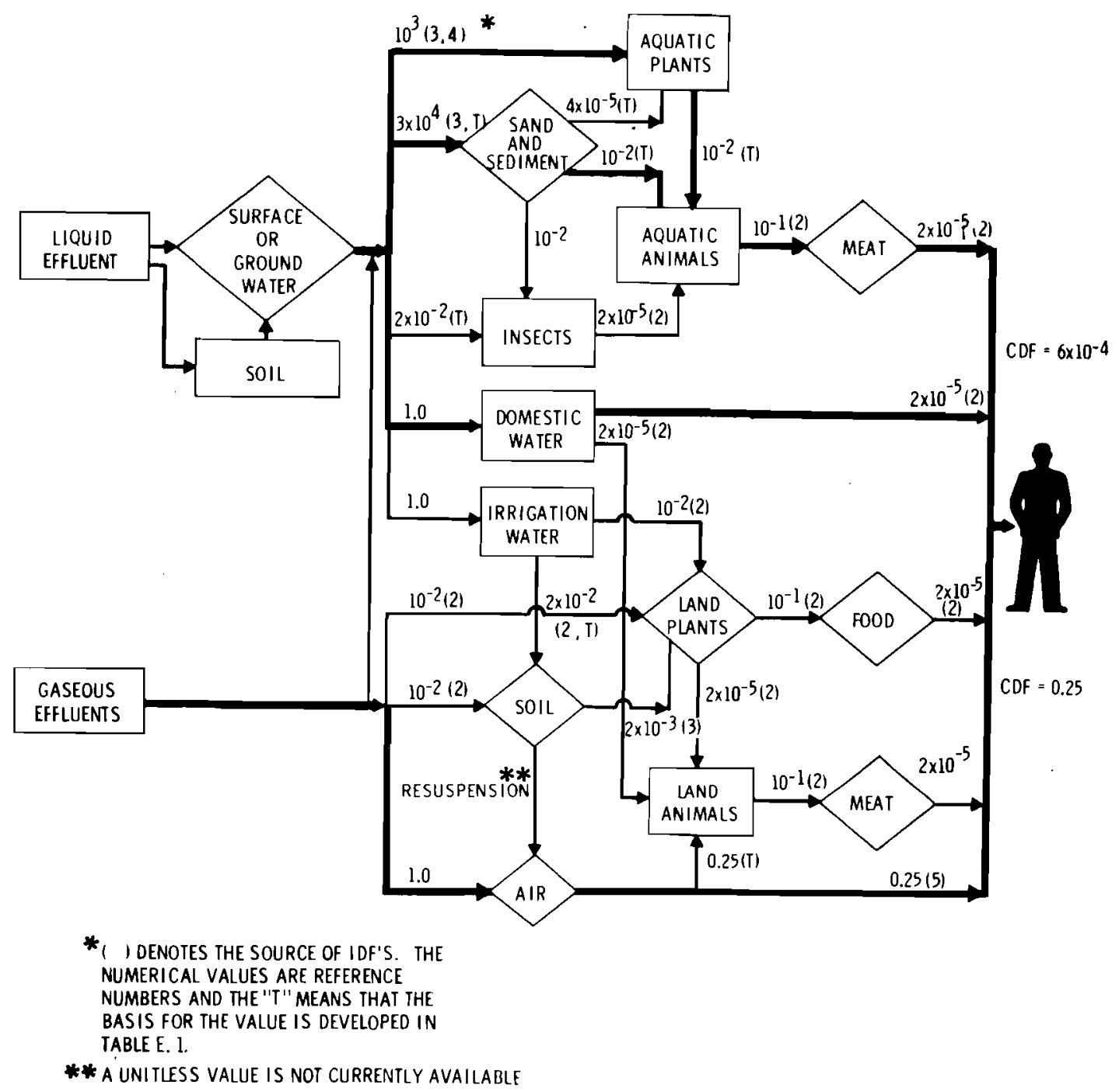

FIGURE E.1 Exposure Pathways and Discrimination Factors for Plutonium in the Biosphere 
routes with CDFs greater than $10^{-5}$ are indicated by heavy 1 ines on the figure. The greatest CDFs for both liquid and gaseous effluent exposure pathways are indicated at the right of the figure.

The relative importance of each critical pathway was deduced by weighing the CDF for each route with quantities related to a) the relative amounts of credible contaminants available to that pathway via environmental release of process materials and $b$ ) the relative extent to which members of each route are used by human populations. By this process, the most important exposure pathway is identified as inhalation of airborne plutonium. The domestic water and aquatic animal pathways are at least four orders of magnitude less significant.

TABLE E.1. Discrimination Factors for Plutonium Pathways

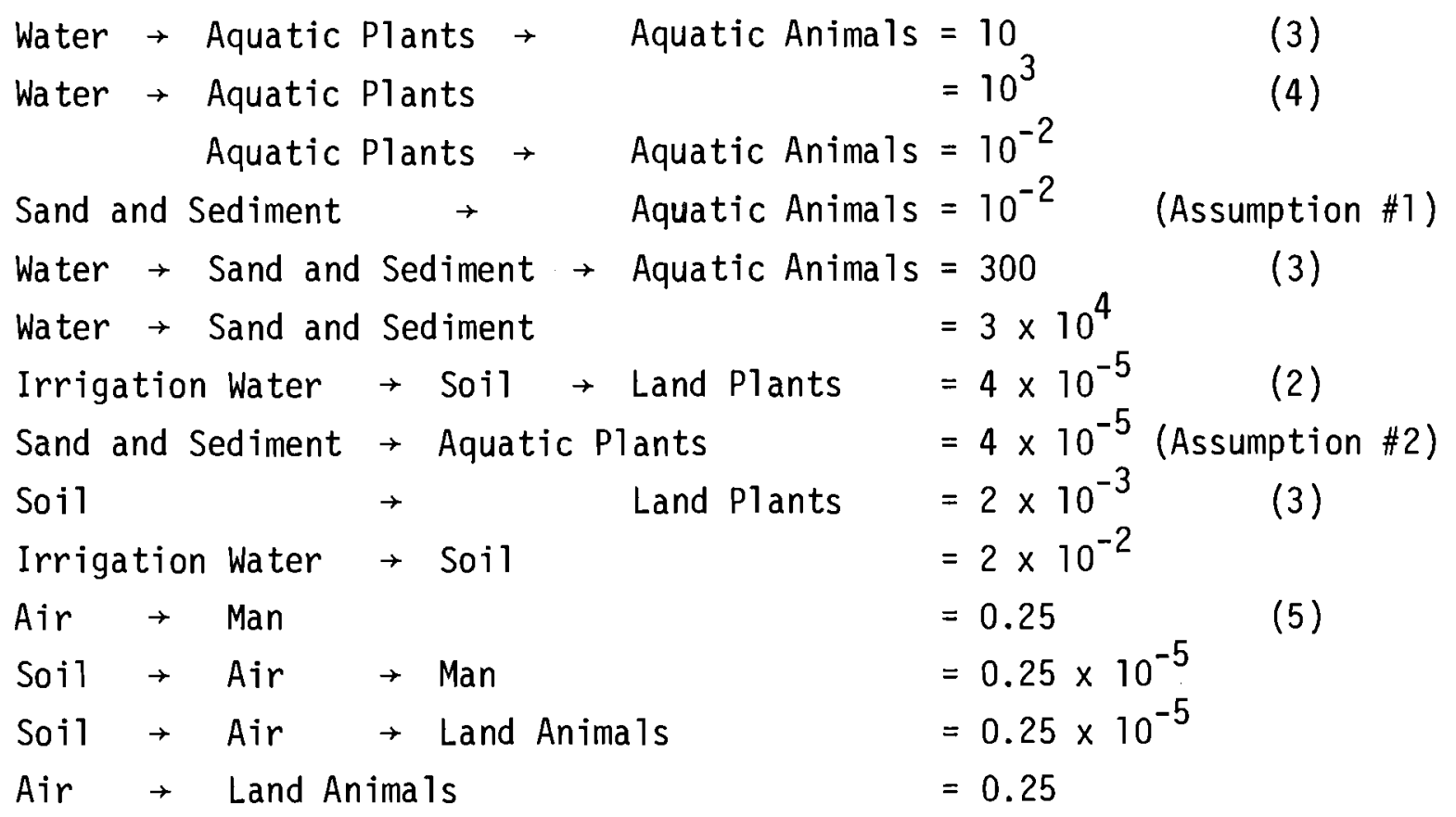




\section{REFERENCES}

1. J. P. Corley, D. A. Waite, and J. W. Johnston, Environmental Surveillance for Fuel Fabrication Plants, BNWL-1723, May 1973.

2. W. H. Langham, "Plutonium Distribution as a Problem in Environmental Science," Proceedings of Environmental Plutonium Symposium, LA4756, 1971 .

3. J. K. Soldat, Private Communication.

4. V. E. Noshkin, "Ecological Aspects of Plutonium Dissemination in Aquatic Environments," Health Physics, vo1. 22, pp. 537-549, 1972.

5. Report of Committee II on Permissible Dose for Internal Radiation, 1959, ICRP Publication 2, Pergamon Press. 
INHALATION MODELS FOR CALCULATING THE DOSE FROM INTERNAL DEPOSITION OF PLUTONIUM

Two lung models have been described by the International Commission on Radiological Protection (ICRP). The initial lung model (ILM), recommended by the International Commission on Radiological Protection, treats the inhaled material as either soluble or insoluble. ${ }^{(1)}$ When the inhaled material is soluble, the uptake by other organs is assumed to be essentially instantaneous. A more sophisticated lung model, recently documented by the ICRP is based on the Task Group Lung Mode1. This model, hereafter referred to as the TGLM, treats inhaled material in a more complex way. The equations derived for estimating the dose to the lung and other organs are considerably more complex than those for the ILM. For this reason, a computer program has been developed for calculating doses using the TGLM. ${ }^{(3)}$

$\underline{\text { ILM }}$

The dose to an organ of interest via inhalation using the ILM, from a radionuclide accidentally released to the atmosphere, is given by:

$$
D=f_{a} k P_{s}\left[1-\exp \left(-\lambda_{e} t\right),\right] \text { rem }
$$

where,

$$
\begin{aligned}
& k=51.1 \mathrm{E} / \mathrm{m} \lambda e, \quad r e m / \mu C i \\
& P_{S}=b c_{a} \tau, \mu C i \\
& D-b\left(f_{a} k\right) c_{a} \tau\left[1-\exp \left(-\lambda_{e} t\right)\right] \text {, rem }
\end{aligned}
$$

where:

$$
\begin{aligned}
& D \text { is dose to organ of interest delivered over time } t \text {, rem } \\
& f_{a} \text { is fractional uptake, via inhalation by organ of interest } \\
& k \text { is dose conversion factor for a particular radionuclide in the organ } \\
& \text { of interest, rem per } \mu C i \text { in organ } \\
& E \text { is effective absorbed energy per disintegration of the radionuclide }
\end{aligned}
$$


$m$ is the mass of the organ, $g$

$\lambda_{e}$ is effective elimination rate constant, $d^{-1}$

$P_{S}$ is quantity inhaled, $\mu \mathrm{Ci}$

$t$ is time following initial intake, $d$

$b$ is ventilation rate for standard man, $\mathrm{cm}^{3} / \mathrm{sec}$

b $=350 \mathrm{~cm}^{3} / \mathrm{sec}(8 \mathrm{hr}$ working rates)

$b=230 \mathrm{~cm}^{3} / \mathrm{sec}$ (24 hr daily rate)

$c_{a}$ is air concentration, $\mu \mathrm{Ci} / \mathrm{cm}^{3}$

$\tau$ is duration of release (exposure), sec.

The dose from inhalation during chronic atmospheric releases is given by:

$$
D=f_{a} k \frac{p}{\lambda_{e}}\left\{\lambda e^{t}-\left[1-\exp \left(-\lambda e^{t}\right)\right]\right\}
$$

where:

$$
\begin{aligned}
& P \text { is daily intake, } \mu \mathrm{Ci} / \text { day } \\
& P-86400 b_{a}
\end{aligned}
$$

When the chronic intake is interrupted at time, $t_{1}$, then the dose is determined by:

$$
D=f_{a} k \frac{p}{\lambda_{e}}\left(\lambda_{e} t_{1}-\left\{\exp \left[-\lambda_{e}\left(t-t_{1}\right)\right]\right\}\left[1-\exp \left(-\lambda_{e} t_{1}\right)\right]\right)(4)
$$

\section{TGLM}

In the TGLM, the respiratory tract is divided into three regions, the nasopharyngeal (NP), the tracheobronchial (TB), and the pulmonary $(P)$. The schematic representation of the respiratory tract used in the development of the mathematical model for the deposition and clearance of inhaled radionuclides is shown in Figure F.1. Deposition is assumed to vary with the aerodynamic properties of the aerosol distribution and is described by the three parameters $D_{3}, D_{4}$, and $D_{5}$. These parameters represent the fraction of the inhaled material initially deposited in the $\mathrm{NP}, \mathrm{TB}$ and $\mathrm{P}$ regions, respectively. Each of the three regions of deposition is further subdivided into two or more subcompartments, each representing the fraction of material initially in a compartment that is sub- 


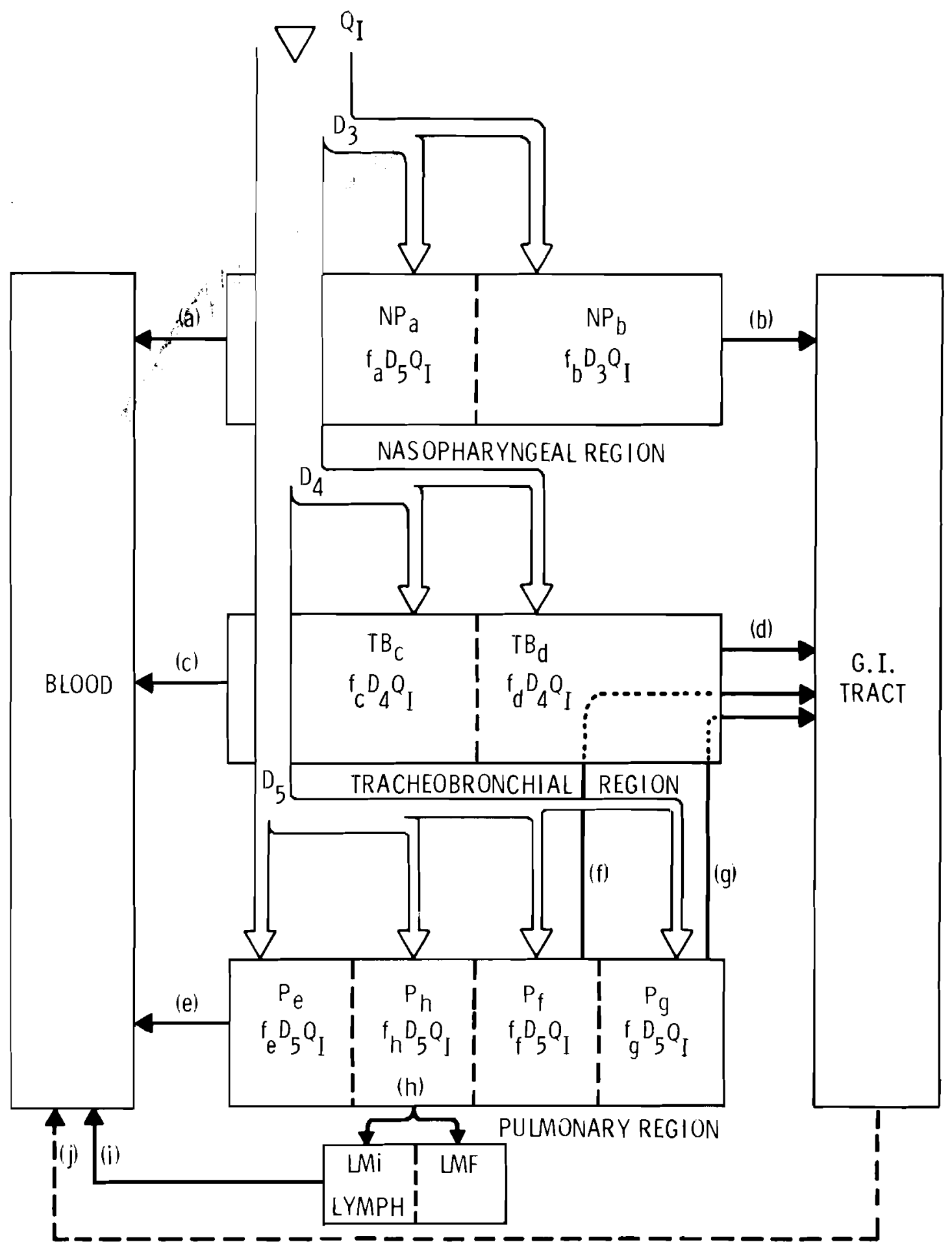

FIGURE F.1. Schematic Diagram of the Task Group Lung Model 
ject to a certain clearance process. This fraction is represented by $f_{k}$, where $k$ indicates the clearance pathway. The quantity of material in the TB region, for example, cleared by process (c) is then represented by the product $f_{c} D_{4} Q_{I}$. Values of the $\left(f_{k}\right)$ and the clearance half times $T_{k}$ for each clearance process for the three translocation classes of aerosols used in the computer code are shown in Table F.1. (2) values of the deposition fractions $D_{3}, D_{4}$, and $D_{5}$ as functions of activity median aerodynamic diameter have been published in the form of a graph. (4)

The respiratory tract model has been incorporated into the simple metabolic mode1. (5) Transport of the radionuclides from the respiratory tract, lymphatic systems, and gastro-intestinal tract to other organs and tissues where significant accumulations of the inhaled radionuclide occur, is assumed to take place via the blood. This translocation from the respiratory tract and lymphatic system to the blood has been described in considerable detail. (4) of the material clearing from the respiratory tract through the GI tract, a constant fraction is assumed to be taken up by the blood. Uptake by the $n^{\text {th }}$ organ or tissue is assumed to be a constant fraction of the amount entering the blood stream at any time. Once in the $n^{\text {th }}$ organ, the activity is assumed to clear the organ and the body at a constant rate.

Notation for the equations found in this section is as follows:

$D_{1 n}\left(T_{1}\right)$ - is the dose equivalent in rem received by the nth organ or tissue by time $T_{1}$ during continuous inhalation of a radioactive aerosol.

$D_{2 n}\left(T_{2}\right)$ - is the dose equivalent in rem received by the nth organ or tissue by time $T_{2}$ following the termination of continuous inhalation of a radioactive aerosol.

$Q_{1 n}\left(T_{1}\right)$ - is the quantity of radioactive material in $\mu \mathrm{Ci}$ present in the nth organ or tissue as a function of time during continuous inhalation of a radioactive aerosol. 
TABLE F-1. Values of the Clearance Parameters for the Task Group Lung Model

COMPARTMENT

TRANSLOCATION CLASS

\begin{tabular}{|c|c|c|c|c|c|c|c|}
\hline \multirow[t]{2}{*}{ RTMENT } & \multirow[b]{2}{*}{$k^{(a}$} & \multicolumn{2}{|c|}{$\mathrm{D}$} & \multicolumn{2}{|c|}{ W } & \multicolumn{2}{|c|}{$\bar{Y}$} \\
\hline & & $T_{k}^{(b)}$ & $f_{k}(c)$ & $\mathrm{T}_{k}$ & $f_{k}$ & $T_{k}$ & $f_{k}$ \\
\hline$N P$ & $a$ & 0.01 & 0.5 & 0.01 & 0.1 & 0.01 & 0.01 \\
\hline & $b$ & 0.01 & 0.5 & 0.40 & 0.9 & 0.4 & 0.99 \\
\hline TB & $c$ & 0.01 & 0.95 & 0.01 & 0.5 & 0.01 & 0.01 \\
\hline & $d$ & 0.2 & 0.05 & 0.2 & 0.5 & 0.2 & 0.99 \\
\hline$p$ & $\mathrm{e}$ & 0.5 & 0.8 & 50 & 0.15 & 500 & 0.05 \\
\hline & $f$ & n.a. & n.a. & 1 & 0.4 & 1 & 0.4 \\
\hline & $g$ & $n \cdot a$ & n.a. & 50 & 0.4 & 500 & 0.4 \\
\hline & $h$ & 0.5 & 0.2 & 50 & 0.05 & 500 & 0.15 \\
\hline$L$ & j & 0.5 & 1 & 50 & 1 & 1000 & 0.9 \\
\hline
\end{tabular}

(a) Metabolic pathways from lung.

(b) Removal half time in days from compartment via pathway $k$.

(c) Fraction removed from compartment via pathway $k$.

$Q_{2 n}\left(T_{2}\right)$ - is the quantity of radioactive material in $\mu C i$ present in the nth organ or tissue following the termination of continuous inhalation of a radioactive aerosol.

$E_{n} \quad-\quad$ is the effective absorbed energy per disintegration in MeV.rem for the nth organ or tissue.

$M_{n}$ - is the mass in grams of the nth organ or tissue over which the dose is to be averaged.

$\lambda_{k}^{b} \quad$ - is the biological removal rate constant for the $k$ th subcompartment of the respiratory tract, sec.

$\lambda$ - is the radiological decay constant of the nuclide of interest, sec. $^{-1}$ 
$\lambda_{k}$ - is the total removal rate constant for the kth subcompartment of the respiratory tract, sec. ${ }^{-1}$ (Note: $\lambda_{k}=\lambda_{k}^{b}+\lambda$ )

$\lambda_{n}^{b} \quad$ - is the biological removal rate constant for the $n$th organ or tissue, sec. $^{-1}$

$\lambda_{n} \quad-\quad$ is the total effective removal rate constant for the $n$th organ or tissue, sec. ${ }^{-1}$ Note: $\lambda_{n}=\lambda_{n}^{b}+\lambda$.

$f_{2}^{\prime}$ - is the fraction of material in the blood that reaches the organ or tissue of interest.

$f_{1}$ - is the fraction of material in the G.I. tract that reaches the blood.

$\mathrm{P}_{0} \quad-\quad$ is the rate at which the radioactive aerosol is inhaled in $\mu \mathrm{Ci} / \mathrm{sec}$.

$f_{k}$ - is the fraction of the material in a deposition region, $N P$, etc., that clears by the kth pathway.

$\mathrm{D}_{3}$ - is the fraction of the material inhaled deposited in the NP region.

$\mathrm{D}_{4}$ - is the fraction of the material inhaled deposited in the TB region.

$D_{5}$ - is the fraction of the material inhaled deposited in the $P$ region.

$T_{1}$ - is the total uptake time in seconds.

$\mathrm{T}_{2}$ - is the time following termination of uptake.

Developing the equations to describe the lung clearance model was divided into two parts. The first part is concerned with describing the organ burdens and the organ doses in the time interval during which the inhalation of radionuclides is taking place. The second part, requiring a different set of equations, describes the organ burdens and the organ doses for the contiguous time interval following the cessation of radionuclide intake. 
During uptake, the equations for computing the quantity of radionuclide in the eight subcompartments of the respiratory tract have the form

$$
Q_{1 P_{e}}(t)=f_{e} D_{5} P_{0} \frac{\left(1-e^{-\lambda} e^{t}\right)}{\lambda_{e}}
$$

The equations for the removable quantity in the pulmonary $7 y m p h$ nodes are complicated by the fact that both equal and unequal rates for transfer paths into and out of the system are involved. This is due to the dependence of transfer rate upon the solubility class of the radionuclide. Thus, two equations are needed to compute the quantity in the lymph compartment.

For the case $\lambda_{h} \neq \lambda_{j}$, i.e., class $Y$ solubility in the current version of the model:

$$
Q_{L M i}(t)=\frac{\lambda_{h}^{b} f_{i} f_{h} P_{0} D_{5}}{\lambda_{h}}\left[\frac{\left(1-e^{-\lambda_{j} t}\right)}{\lambda_{i}}-\frac{\left(e^{-\lambda_{j} t}-e^{-\lambda_{h} t}\right)}{\lambda_{h}-\lambda_{i}}\right],
$$

and for the case $\lambda_{h}=\lambda_{j}$, i.e., class $D$ and $W$ in the current version of the model:

$$
Q_{L M i}(t)=\frac{\lambda_{h}^{b} f_{i} f_{h} P_{0} D_{5}}{\lambda_{h}} \quad\left[\frac{\left(1-e^{-\lambda_{j} t}\right)}{\lambda_{i}}-t e^{-\lambda_{i} t}\right] .
$$

With the preceding equations, the equations describing the quantity of radionuclide in the $n^{\text {th }}$ organ as a function of time during uptake can be derived by:

$$
Q_{1 n}(t)=P_{0}\left\{\sum_{j=a}^{g} f_{2}^{\prime} c_{j}\left[\frac{\left(1-e^{-\lambda_{n} t}\right)}{\lambda_{n}}-\frac{\left(e^{-\lambda_{n} t}-e^{-\lambda_{j} t}\right)}{\left(\lambda_{j}-\lambda_{n}\right)}\right]+L\right\}
$$

where:

$L$ is the contribution to the organ burden from material passing through the lymphatic system,

and:

$$
\begin{aligned}
& c_{a}=\lambda_{a}^{b} f_{a} D_{3} / \lambda_{a} \\
& c_{b}=\lambda_{b}^{b} f_{b} D_{3} f_{1} / \lambda_{b}
\end{aligned}
$$




$$
\begin{aligned}
& c_{c}=\lambda_{c}^{b_{f}}{ }_{c} D_{4} / \lambda_{c} \\
& c_{d}=\lambda_{d}^{b_{f}} D_{4} f_{1} / \lambda_{d} \\
& c_{e}=\lambda_{e}^{b_{f}} D_{5} / \lambda_{e} \\
& c_{f}=\lambda_{f}^{b_{f}} D_{5} f_{1} / \lambda_{f} \\
& c_{g}=\lambda_{g}^{b_{f}} D_{5} f_{1} / \lambda_{g} .
\end{aligned}
$$

The lymph pathway contributions to the $\mathrm{n}^{\text {th }}$ organ burden for the two situations are calculated:

$L=f_{2}^{\prime} C_{h}\left\{\frac{1}{\lambda_{i}}\left[\frac{\left(1-e^{-\lambda_{n} t}\right)}{\lambda_{n}}-\frac{\left(e^{-\lambda_{n} t}-e^{-\lambda_{i} t}\right)}{\left(\lambda_{i}-\lambda_{n}\right)}\right]-\frac{1}{\left(\lambda_{i}-\lambda_{n}\right)}\left[\frac{\left(e^{-\lambda_{n} t}-e^{-\lambda_{j} t}\right)}{\left(\lambda_{i}-\lambda_{n}\right)}\right.\right.$

$$
\left.\left.-\frac{\left(e^{-\lambda_{n} t}-e^{-\lambda_{h} t}\right)}{\left(\lambda_{h}-\lambda_{n}\right)}\right]\right\} \text { for } \lambda_{h} \neq \lambda_{i}
$$

$L=f_{2}^{\prime} C_{h}\left\{\frac{1}{\lambda_{i}}\left[\frac{\left(1-e^{-\lambda_{n} t}\right)}{\lambda_{i}}-\frac{\left(e^{-\lambda_{n} t}-e^{-\lambda_{j} t}\right)}{\left(\lambda_{i}-\lambda_{n}\right)}\right]-\frac{\left(e^{-\lambda_{n} t}-e^{-\lambda_{j} t}\right)\left(\lambda_{i}-\lambda_{n}\right)(t+1)}{\left(\lambda_{j}-\lambda_{n}\right)^{2}}\right\}$ for $\lambda_{h}=\lambda_{j}$

where: $\quad C_{h}=\frac{\lambda_{i} \lambda_{h}{ }{ }_{i} f_{h} D_{5}}{\lambda_{h}}$.

The calculation of the dose equivalents to organs burdened by the radionuclide are based on the following:

$$
D_{1 n}(t)=\frac{5.92 \times 10^{-4} E_{n}}{M_{n}} \int_{0}^{t} Q_{1 n}(\tau) d \tau
$$


where the constant is a combination of the conversion factors:

$$
3.7 \times 10^{4}\left(\frac{\mathrm{dis} / \mathrm{sec}}{\mu \mathrm{Ci}}\right) 1.6 \times 10^{-6}\left(\frac{\mathrm{ergs}}{\mathrm{MeV}}\right) 10^{-2}\left(\frac{\mathrm{rads}}{\mathrm{erg} / \mathrm{g}}\right)=5.92 \times 10^{-4} \text {. }
$$

The dose to the pulmonary lung at the end of inhalation intake of a radionuclide is determined by:

$$
D_{1 p}\left(T_{1}\right)=\frac{5.92 \times 10^{-4} E_{p_{1}}}{M_{p}} P_{0} D_{5} \sum_{j=e}^{h} \frac{f_{j}}{\lambda_{j}}\left(T_{1}-\frac{1-e^{-\lambda_{j} T_{1}}}{\lambda_{j}}\right)
$$

where $M_{p}$ is the mass of the lung in grams

For the $n^{\text {th }}$ organ or tissue, the dose is computed by:

$$
\begin{aligned}
D_{1 n}= & 5.92 \times 10^{-4} \frac{E_{n} P_{0} f_{2}^{\prime}}{M_{n}}\left\{\sum_{j=a}^{g} C_{j}\left[\frac{T_{1}-A_{n}}{\lambda_{n}}\left(\frac{A_{n}-A_{j}}{\lambda_{j}-\lambda_{n}}\right)\right]\right. \\
& +\frac{C_{h}}{\lambda_{i}}\left[\frac{T_{1}-A_{n}}{\lambda_{n}}-\frac{A_{n}-A_{j}}{\left(\lambda_{i}-\lambda_{n}\right)}\right]-\frac{C_{h}}{\left(\lambda_{h}-\lambda_{i}\right)}\left[\frac{A_{n}-A_{j}}{\left(\lambda_{i}-\lambda_{n}\right)}\right. \\
& \left.-\frac{A_{n}-A_{h}}{\lambda_{h}-\lambda_{n}}\right]\left.\right|_{\text {for } \lambda_{h} \neq \lambda_{i}}
\end{aligned}
$$


or:

$$
\begin{aligned}
D_{n}\left(T_{1}\right) & =5.92 \times 10^{-4} \frac{E_{n} P_{0} f^{\prime}}{M_{n}}\left(\sum_{j=a}^{g} C_{j}\left(\frac{T_{1}-A_{n}}{\lambda_{n}}-\frac{A_{n}-A_{j}}{\lambda_{j}-\lambda_{n}}\right)\right. \\
& +\frac{C_{n}}{\lambda_{i}}\left(\frac{T_{1}-A_{n}}{\lambda_{n}}-\frac{A_{n}-A_{i}}{\lambda_{i}-\lambda_{n}}\right)-\frac{C_{n}}{\left(\lambda_{j}-\lambda_{n}\right)^{2}} A_{i}-A_{n} \\
& +\frac{\left(\lambda_{i}-\lambda_{n}\right)}{\lambda_{i}^{2}}\left[1-\left(\lambda_{j} T_{1}+1\right) e^{\left.\left.\left.-\lambda_{i} T_{1}\right]\right\}\right) \text { for } \lambda_{h}=\lambda_{i}}\right.
\end{aligned}
$$

where:

$$
\begin{aligned}
& A_{n}=\frac{1-\exp \left(-\lambda_{n} T_{1}\right)}{\lambda_{n}} \\
& A_{j}=\frac{1-\exp \left(-\lambda_{j} T_{1}\right)}{\lambda_{j}} \\
& A_{i}=\frac{1-\exp \left(-\lambda_{j} T_{1}\right)}{\lambda_{i}} \\
& A_{h}=\frac{1-\exp \left(-\lambda_{h} T_{1}\right)}{\lambda_{h}}
\end{aligned}
$$

and $C_{j}$ and $C_{h}$ are as previously defined.

Now for the time following cessation of radionuclide inhalation, the equations used to calculate the respiratory tract burden and the other organ or tissue burdens become:

$$
Q_{2 j}\left(T_{2}\right)=Q_{1 j}\left(T_{1}\right) e^{-\lambda} T_{2}
$$

where: $Q_{2 j}\left(T_{2}\right)$ is the respiratory tract subcompartment burden at a time $\mathrm{T}_{2}$ following the termination of inhalation uptake. 
$Q_{1 j}\left(T_{1}\right)$ is the respiratory tract subcompartment burderi at the and of inhalation uptake for a time $T_{1}$.

The burden in the $n^{\text {th }}$ organ can be described by:

$$
\begin{aligned}
Q_{2 n}\left(T_{2}\right) & =Q_{1 n}\left(T_{1}\right) e^{-\lambda_{n} T_{2}}+f_{2}^{\prime} \lambda_{i}^{b} Q_{1 L M i}\left(T_{1}\right) \frac{\left(e^{-\lambda i T_{2}}-e^{-\lambda_{n} T_{2}}\right)}{\left(\lambda_{n}{ }^{-\lambda_{j}}\right)} \\
& +f_{2}^{\prime}\left\{\sum_{j=a}^{g} \frac{c_{j}^{\prime}}{\left(\lambda_{j}-\lambda_{n}\right)}\left(e^{-\lambda_{n} T_{2}}-e^{-\lambda_{j} T_{2}}\right)\right. \\
& \left.+c_{n}^{\prime}\left[\frac{\left(e^{-\lambda_{n} T_{2}}-e^{-\lambda_{j} T_{2}}\right)}{\left(\lambda_{i}-\lambda_{n}\right)}-\frac{\left(e^{-\lambda_{n} T_{2}}-e^{-\lambda_{n} T_{2}}\right)}{\left(\lambda_{n}{ }^{-\lambda_{n}}\right)}\right]\right\} \text { for } h_{h}=\lambda_{i}
\end{aligned}
$$

or by:

$$
\begin{aligned}
Q_{2 n}\left(T_{2}\right) & =Q_{1 n}\left(T_{1}\right) e^{-\lambda_{n} T_{2}}=f_{2}^{\prime} \lambda_{i}^{b} Q_{1 L M i}\left(T_{1}\right) \frac{\left(e^{-\lambda_{j} T_{2}}-e^{-\lambda_{n} T_{2}}\right)}{\left(\lambda_{n}-\lambda_{i}\right)} \\
& +f_{2}^{\prime}\left(\sum_{j=a}^{g} \frac{c_{j}^{\prime}}{\left(\lambda_{j}-\lambda_{n}\right)}\left(e^{-\lambda_{n} T_{2}}-e^{-\lambda_{j} T_{2}}\right)\right. \\
& \left.+\frac{c_{n}^{\prime}}{\left(\lambda_{i}-\lambda_{n}\right)}\left\{e^{-\lambda_{n} T_{2}}-e^{-\lambda_{j} T_{2}}\left[\left(\lambda_{i}-\lambda_{n}\right) T_{2}-1\right]\right\}\right) \text { for } h_{i}^{-\lambda_{i}}
\end{aligned}
$$

where:

$$
\begin{aligned}
& c_{a}^{\prime}=\lambda_{a}^{b} Q_{1 a}\left(T_{1}\right) \\
& c_{b}^{\prime}=\lambda_{b}^{b} Q_{1 b}\left(T_{1}\right) f_{1} \\
& c_{c}^{\prime}=\lambda_{c}^{b} Q_{1 c}\left(T_{1}\right) \\
& c_{d}^{\prime}=\lambda_{d}^{b} Q_{1 d}\left(T_{1}\right) f_{1}
\end{aligned}
$$




$$
\begin{aligned}
& c_{e}^{\prime}=\lambda_{e}^{b_{a} Q_{l e}\left(T_{1}\right)} \\
& c_{f}^{\prime}=\lambda_{f}^{b} Q_{l f}\left(T_{1}\right) f \\
& c_{g}^{\prime}=\lambda_{g}^{b} Q_{l g}\left(T_{1}\right) f \\
& c_{h}^{\prime}=f i \lambda_{h}^{b} \lambda_{j}^{b} Q_{l h}\left(T_{1}\right) /\left(\lambda_{h}-\lambda_{j}\right) .
\end{aligned}
$$

The pulmonary lung dose from inhalation of a radionuclide for a time $T_{1}$ followed by no additional radioactive intake for a time $T_{2}$ is determined by:

$$
D_{1 p}\left(T_{2}\right)=5.92 \times 10^{-4} E_{p} P_{0}\left[\sum_{j=e}^{h} \frac{f_{j} D_{5}}{\lambda_{j}^{2}}\left(1-e^{-\lambda_{j} T_{1}}\right)\left(1-e^{-\lambda_{j} T_{2}}\right)\right]+D_{1 p}\left(T_{1}\right)
$$

where: $D_{1 p}\left(T_{1}\right)$ is the effective dose to the pulmonary lung during the uptake period as determined by Equation (11).

The effective dose to the $n^{\text {th }}$ organ as a result of inhalation uptake for a time $T_{1}$ followed by no additional radioactive intake for a time $T_{2}$ is determined by:

$$
\begin{aligned}
D_{2 n}\left(T_{2}\right) & =5.92 \times 10^{-4} \frac{E_{n}}{M_{n}}\left(Q_{1 n}\left(T_{1}\right) B_{n}+f_{2}^{\prime}\left\{\sum_{j=a}^{g} \frac{f_{j} C_{j}^{\prime}}{\left(\lambda_{j}-\lambda_{n}\right.}\right)\left(B_{n}-B_{j}\right)\right. \\
& +\frac{\lambda_{j}^{b_{0} Q_{1 L M i}\left(T_{1}\right)}}{\lambda_{n}}\left(T_{2}-B_{n}\right) \\
& \left.\left.+C_{n}^{\prime}\left(\frac{B_{n}-B_{j}}{\lambda_{j}-\lambda_{n}}-2\right)\right\}\right)
\end{aligned}
$$


where:

$Z=\frac{B_{n}-B_{h}}{\lambda_{h}-\lambda_{i}} \quad$ and $Q_{1 n}$ is determined by Equations $(8,9 a)$ for $\lambda_{i} \neq \lambda_{h}$

or: $z=\frac{B_{i}}{\lambda_{i}}\left(\lambda_{i} T+1\right)$ and $Q_{7 n}$ is determined by Equations $(8,9 b)$ for $\lambda_{i}=\lambda_{h}$

and:

$$
\begin{aligned}
& B_{n}=\frac{1-e^{-\lambda_{n} T_{2}}}{\lambda_{n}} \\
& B_{h}=\frac{1-e^{-\lambda_{h} T_{2}}}{\lambda_{h}} \\
& B_{i}=\frac{1-e^{-\lambda_{j} T_{2}}}{\lambda_{i}} \\
& B_{j}=\frac{1-e^{-\lambda_{j} T_{2}}}{\lambda_{j}}
\end{aligned}
$$

In addition, because the equation for $Q_{7 n}$ is dependent on whether $\lambda_{i}=\lambda_{h}$ or not, the choice of equations for the burden and dose computation must be consistent throughout. 


\section{REFERENCES}

1. Report by Task Group of Committee II, on ICRP, Permissible Dose for Internal Radiation, ICRP Publication 2, Pergamon Press, 1952.

2. Task Group of Committee 2, ICRP, The Metabolism of Compounds of Plutonium and Other Actinides, ICRP Publication 19, Pergamon Press, oxford, 1972 .

3. J. Houston, D. L. Strenge and E. C. Watson, DACRIN Computer Program for Calculations of Organ Dose from Acute or Chronic Radionuclide Inhalation, BNWL-B-389, Battelle, Pacific Northwest Laboratories, Richland, WA, December 1974.

4. Task Group of Committee 2, ICRP, Task Group on Lung Dynamics for Committee II of the ICRP, Health Physics, Vol. 12, p. 173, 1966.

5. Paul G. Voilleque, AERIN, A Code for the Acute Aerosol Inhalation Exposure Calculations, Health Physics, Vol. 19, p. 427, 1970. 
APPENDIX G

\section{CRITICALITY CONSIDERATIONS IN TRANSPORTATION ACCIDENT STUDIES}

The possibility of criticality must be considered in the transportation of fissile material. This appendix provides data required for the evaluation of the importance of criticality as a mechanism for rupturing the containment vesse 1 (the $2 \mathrm{R}$ container for the $6 \mathrm{M}$; the pressure vessel for the $L-10$ ) in an accident.

Data on three packages is presented. These are the $L-10$ plutonium nitrate solution shipping package and the 6M and LLD-1 plutonium oxide powder shipping packages. During transportation of plutonium in these packages, criticality cannot occur if the array of packages is not deformed and if no significant amount of plutonium leaks out of the containment vessel. This is true even if the shipment is somehow flooded with water.

Basic criticality theory says that a system becomes more reactive (closer to critical) if compressed. Therefore in this appendix the criticality aspects of shipping package arrays which have been deformed by crushing are presented. Numerous conservative assumptions were made in the analysis. These include:

1) The arrays were assumed to be uniformly and highly compacted along the line of action of the crush force. In a transportation accident crushing does not result in uniform compaction of packages (e.g. in a front end impact accident the back rows of packages are only slightly deformed, see Appendix J.1).

2) The plutonium assumed for the criticality calculations contained only $5 \mathrm{wt} \%{ }^{240} \mathrm{Pu} .{ }^{240} \mathrm{Pu}$ is a neutron absorber which reduces reactivity. The more ${ }^{240} \mathrm{Pu}$ in the plutonium, the lower the reactivity. The plutonium used in the other portions of the risk analysis contains $24 \mathrm{wt} \% 2{ }^{240} \mathrm{Pu}$.

3) The number of packages assumed to be on the truck was greater than the dose-1 imited number found in Section 11.1. 
4) For the L-10 analysis a truck loading pattern of alternate rows of four packages across and three packages across was used in the criticality calculation. Four packages cannot be put across in a norma 1 width truck. The arrangement used is more reactive than a uniform three package across array.

For the 6M and LLD-1 packages, which are loaded in a square pitch, the deformed array analyzed was one completely compacted (i.e. with inner containment vessels touching) along the long axis of the truck. For the L-10 packages, assumed to be loaded in a hexagonal pitch, the deformed array analyzed has $8 \mathrm{in}$. center-to-center spacing between rows along the long axis of the truck. The likelihood of having these extreme deformations in an accident is discussed in Section 9.1 and is not addressed in this appendix.

\section{RESULTS OF STUDY}

Several plutonium oxide shipping package deformed arrays were studied; all were found to be subcritical. This included LLD-1 and 6M (16 gal) container arrays at their fissile Class III container/vehicle limit under flooded, partially wetted, and dry conditions. The deformation model was to reduce the dimension of each containe $r$ in the array along the long axis of the truck to that of the containment vessel while maintaining the outer vessel dimensions in the transverse and vertical directions.

For the L-10 plutonium nitrate shipping package a deformed array consisting of 18 alternate rows of 4 packages across and 3 packages across was studied; it was found to be subcritical. A center-to-center spacing of 8.0 in. along the long axis of the truck was used. As in the oxide packages the pre-accident transverse spacing was maintained. For the optimally moderated, plutonium nitrate solution used in the calculations, the dry array is known to be more reactive than a partially wetted or flooded array. Therefore only dry array results are reported.

In a 11 cases containment vessel integrity was assumed. 
ASSUMPTIONS AND MODEL ING

Original Loading Pattern

The pre-accident loading pattern is described by Table G.1 and the shape of the loads are shown in Figure G.1. These patterns are based on an $8 \mathrm{ft}$ wide truck bed. The dimensions of the individual packages are given in Table G.2.

TABLE G.1. Loading Pattern for Plutonium Shipping Packages

\begin{tabular}{|c|c|c|c|c|c|}
\hline Package/Class & $\begin{array}{l}\text { Max. No. } \\
\text { Allowed }\end{array}$ & $\begin{array}{c}\text { No. } \\
\text { Across }\end{array}$ & $\begin{array}{l}\text { No. } \\
\text { Deep }\end{array}$ & $\begin{array}{l}\text { No. } \\
\text { High }\end{array}$ & $\begin{array}{l}\text { No. Used } \\
\text { In Model }\end{array}$ \\
\hline L-10/I I I & 64 & $4 / 3^{\star}$ & 18 & 1 & 63 \\
\hline LLD-1/III & 50 & 4 & 4 & 3 & 48 \\
\hline 6M/ I I I & 125 & 5 & 8 & 3 & 120 \\
\hline
\end{tabular}

TABLE G.2. Plutonium Shipping Package Dimensions

\begin{tabular}{|c|c|c|c|c|c|}
\hline Package & ID, in. & $\begin{array}{c}\text { Containment Vesse } 1 \\
0 \mathrm{D} \text {, in. }\end{array}$ & Height, in. & $\begin{array}{l}\text { Outer } \\
O D \text {, in. }\end{array}$ & $\begin{array}{l}\text { Container } \\
\text { Height, in. }\end{array}$ \\
\hline$L-10$ & 4.813 & 5.563 & 52.25 & 24 & 66.75 \\
\hline LLD-1 & 5.047 & 5.563 & 14 & 16 & 25 \\
\hline $\begin{array}{r}\text { gM } \\
\text { ga } 17)^{16}\end{array}$ & 5.047 & 5.563 & 14 & 16.5 & 27.5 \\
\hline
\end{tabular}

\section{Post-Accident Pattern}

The post-accident pattern for the oxide packages was determined by reducing the depth of the array of packages until the inner containment vessels of the respective packages were touching. The vertical and transverse spacing was maintained in the pre-accident dimensions.

The pre-accident model for the L-10 packages is a pattern of a row of 4 packages followed by a row of 3 packages, then 4 and so forth for 18 rows totaling 63 packages. The center-to-center spacing of containers

* Stagger packing of 4 in a row followed by 3 in a row. 


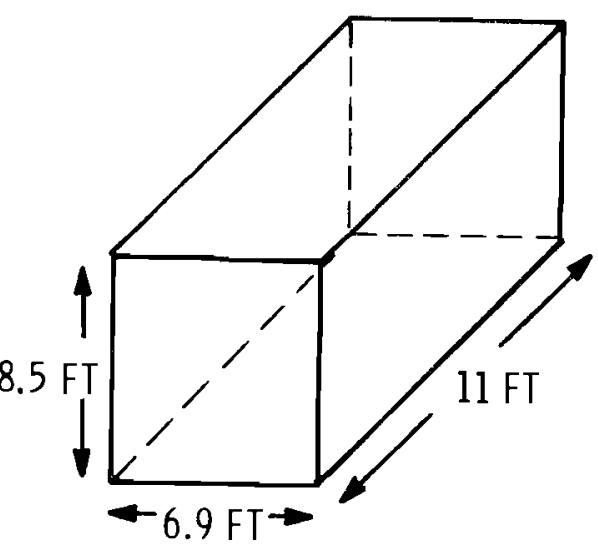

$6 M$
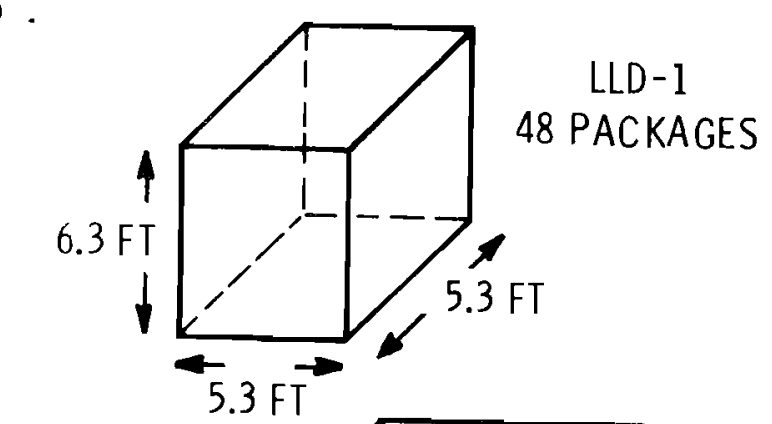

120 PACKAGES

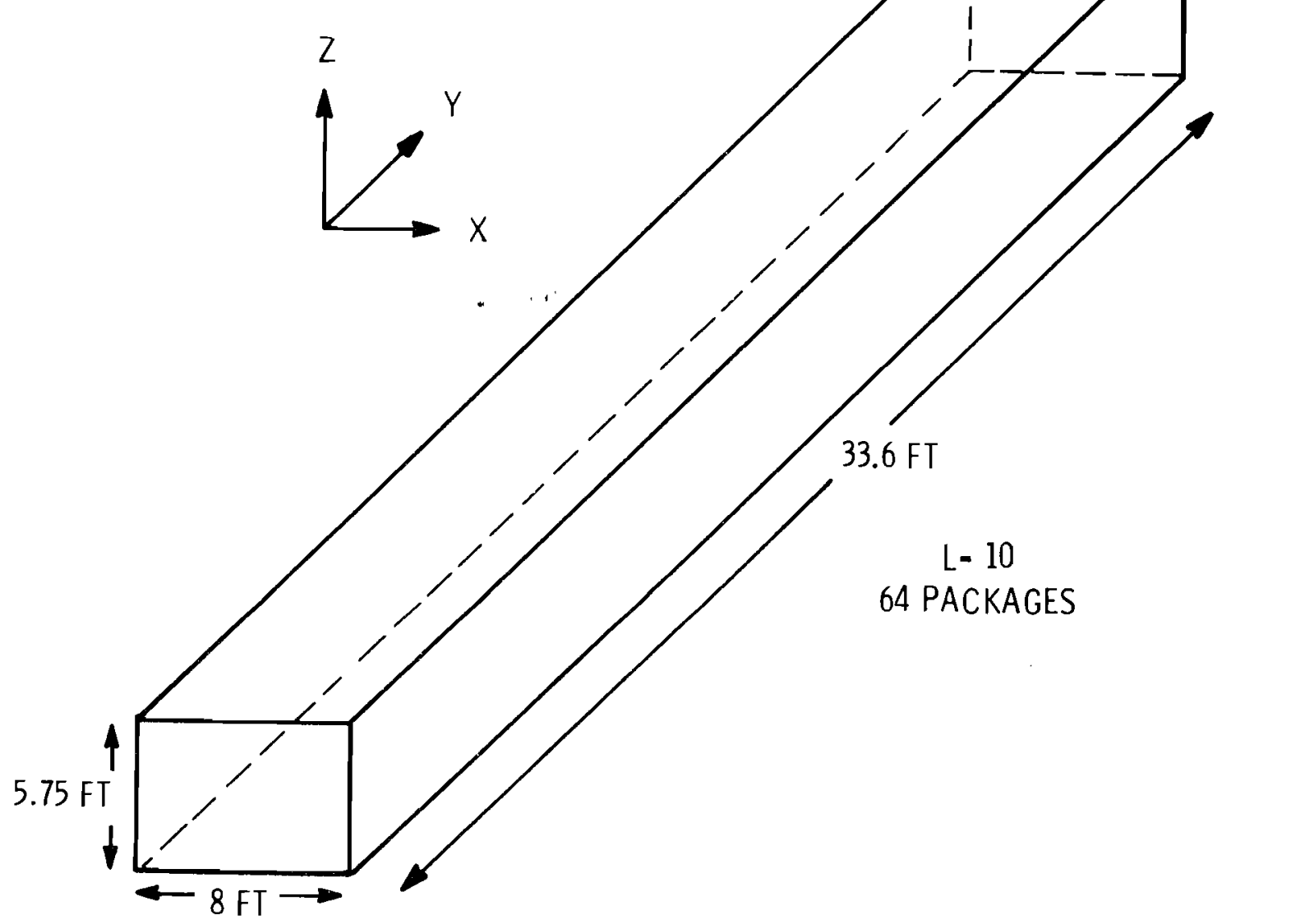

FIGURE G.1. Pre-Accident Truck Loading Patterns 
along the long axis of the vehicle was reduced to $8.0 \mathrm{in}$. The transverse spacing was maintained at the pre-accident condition. The compacting of each vessel type assumed in the analysis is shown in Figure G.2.

It is assumed that all of the inner containment vessels remain intact.

\section{Deformed Container Modeling}

In the calculational modeling, the outer vessel and packing material were neglected. The model consists of the containment vessel and the fissile material within. Each vessel is further described below.

\section{$\underline{\mathrm{L}-10}$}

The $L-10$ is modeled as two concentric cylinders corresponding to the pressure vesse 1 and space within. The height of the plutonium nitrate solution is that required to give the maximum permissible volume of $10.5 \&$ in an $11.1 \mathrm{~cm}$ ID polyethylene bottle (the size bottle normally used in shipment). This height is $108.5 \mathrm{~cm}$. The radius of the solution used in the model was $6.113 \mathrm{~cm}$, that of the interior of the pressure vessel. This results in a conservative volume of 12.7 \& of plutonium nitrate solution, 2.2 \& more than the maximum allowed. The pressure vessel is made from 5 in. schedule 80 stainless steel pipe. Its radius and thickness are modeled accordingly. The thickness of the top and bottom end caps were taken as equal to the $0.95 \mathrm{~cm}$ wall thickness.

The fissile material used in the $\mathrm{L}-10$ model was $\mathrm{Pu}\left(\mathrm{NO}_{3}\right)_{4}$ at $150 \mathrm{~g} \mathrm{Pu} / \mathrm{l}$, the optimum (most reactive) plutonium concentration for the plutonium nitrate solution. The plutonium was assumed to be $95 \mathrm{wt} \%{ }^{239} \mathrm{Pu}$ and 5 wt $240 \mathrm{Pu}$.

\section{$6 \mathrm{M}$ and LLD-1}

The 6M and the LLD-1 plutonium oxide packages share a common containment vesse1--the $2 R$ container. The $2 R$ container and plutonium are modeled as a pancake of plutonium oxide in the center of the steel pressure vessel. The height of the pancake is that required to give $4.5 \mathrm{~kg}$ of $\mathrm{PuO}_{2}$ at a 


\section{PRE-ACCIDENT \\ POST-ACCIDENT}

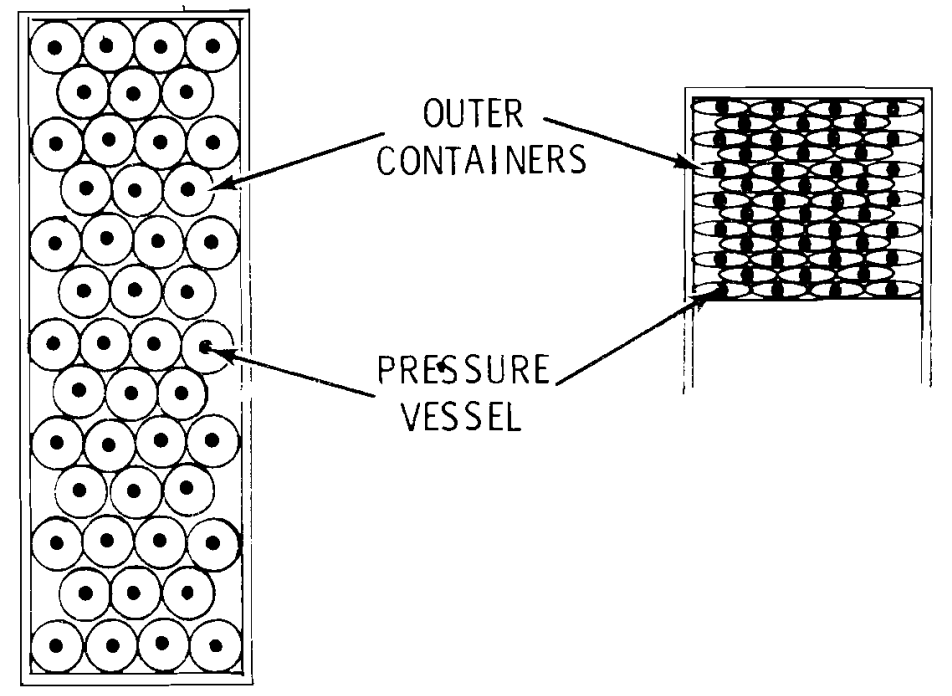

$\mathrm{LLD}-1$

CONPLETE ARRAY - 48 CONTAINERS - $4 \times 4 \times 3$

PRE-ACCIDENT

POST-ACCIDENT

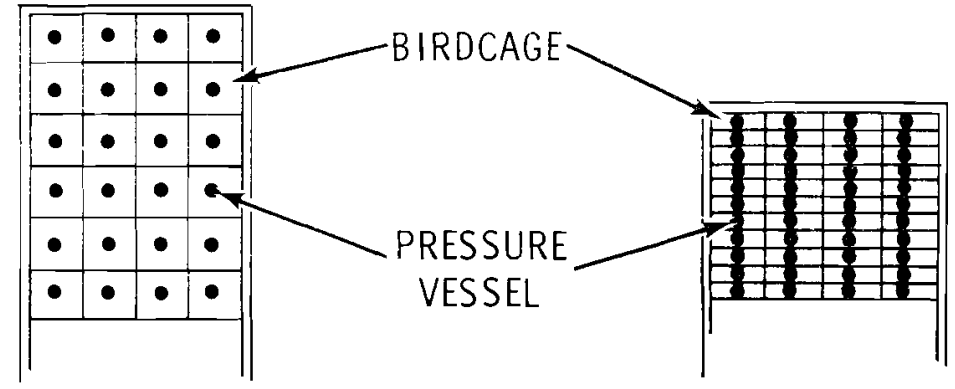

$6 \mathrm{M}$

COMPLETE ARRAY - 120 CONTAINERS - $5 \times 8 \times 3$

PRE-ACCIDENT POST-ACCIDENT

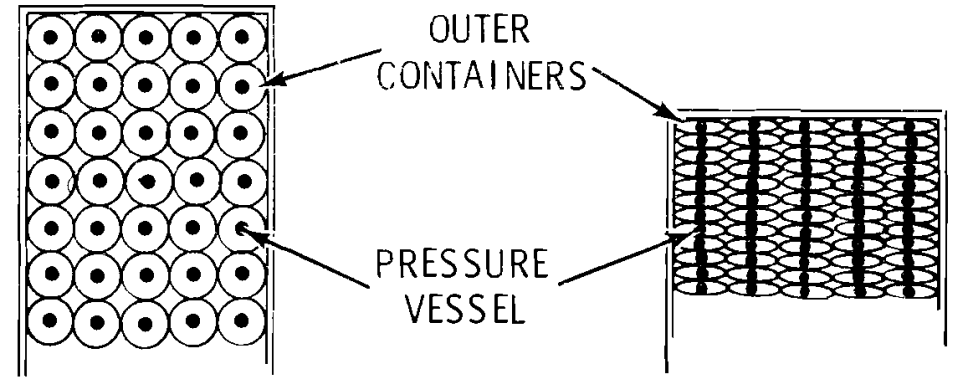

FIGURE G.2. Vessel Compaction Assumed in Analysis 
density of $5.6 \mathrm{~g} / \mathrm{cm}^{3}$ and a diameter of $12.82 \mathrm{~cm}$. This gives a height of $6.23 \mathrm{~cm}$. The $2 R$ pressure vessel has a thickness of $0.66 \mathrm{~cm}$ and an exterior height of $38.10 \mathrm{~cm}$. The actual and modeled $2 R$ containers are sketched in Figure G.3.

The $6 \mathrm{M}$ outer drum diameter is $41.91 \mathrm{~cm}$ and its height is $54.61 \mathrm{~cm}$. The LLD-1 bird cage is a square container $40.64 \mathrm{~cm}$ on a side and $63.50 \mathrm{~cm}$ high. These dimensions were used to give the respective spacings across the vehicle width and in the vertical direction.

FIGURE G.3. Actual and Model 2R* Container

$\underline{\text { Actua } 1}$

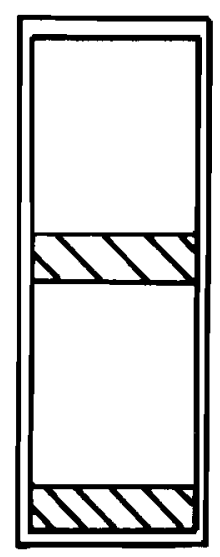

Mode]

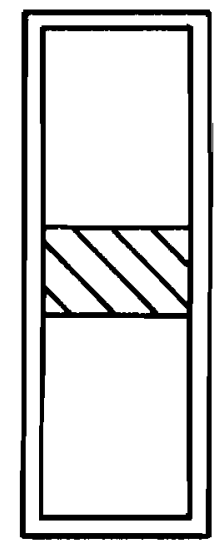

*Containment vessel for LLD-1 and 6M packages.

The fissile material was plutonium oxide at $5.6 \mathrm{~g} \mathrm{PuO} / 2 / \mathrm{cm}^{3}$ with $1 \mathrm{wt} \%$ water, and the ${ }^{240} \mathrm{Pu}$ content was assumed to be $5 \mathrm{wt} \%$.

\section{Other Post-Accident Conditions}

For the L-10 array all space within the array but external to the pressure vessels was considered to be void. This dry condition is more reactive than a case with external moderator between the pressure vessels. 
Since the nitrate solution is already at optinum moderation, external water tends to isolate the individuals $L-10^{\prime} \mathrm{s}$, which reduces interaction and thus the overall reactivity of the array. Test calculations have shown this effect.

For the plutonium oxide containers (6M and LLO-1) in addition to flooded and dry arrays, partially wetted arrays were calculated. This was done because it was felt that while water moderation increased reactivity, full flooding may cause partial vessel isolation. The partially wetted cases were modeled by placing water at reduced density outside the pressure vessels. The arrays were calculated with water at 5\%, 6\% and 7\% of normal density. For both the $6 M$ and the LLD- 1 the $6 \%$ density case proved to give the highest value of $k_{\text {eff. }}$

In all instances the array was surrounded by a $30-\mathrm{cm}$ water reflector. This was done to account for any neutron refiectors that might be encountered in the extreme instance.

\section{METHOD OF CALCULATION}

The calculations were performed using the KENO II Monte Carlo computer program. The 16-group Hansen-Roach neutron cross-section set was used. A differential albedo deck was used to simulate the $30-c m$ water reflector. The $k_{\text {eff }}^{*}$ values for the plutonium oxide package arrays are given in Table G.3.

TABLE G.3. Keff for Deformed Plutonium Oxide Shipping Package Arrays under the Assumed Conditions

\begin{tabular}{|c|c|c|c|}
\hline \multirow[b]{2}{*}{ Package } & \multicolumn{3}{|c|}{$k_{\text {eff }}$} \\
\hline & Flooded & $\begin{array}{c}\text { Partiaily wetted } \\
\text { (6\% Norma } 1 \text { H20 Density) }\end{array}$ & Dry \\
\hline $6 M(16$ ga 1$)$ & $0.560 \pm 0.010$ & $0.636 \pm 0.006$ & $0.609 \pm 0.005$ \\
\hline LLD-1 & $0.529 \pm 0.006$ & $0.537 \pm 0.004$ & $0.534 \pm 0.006$ \\
\hline
\end{tabular}

\footnotetext{
${ }^{*} k$ is a measure of the criticality of a system. $k$ ff $=1.0$ for a cfftical system. Criticality cannot occur in a systert with $k_{\text {eff }}$ 
The results in Table $\mathrm{G} .3$ show that the $\mathrm{PuO}_{2}$ arrays studied were all subcritical. The $6 \mathrm{M}$ package arrays displayed greater reactivity than those of the LLD-1 package; however, both were far subcritical. As expected, the partially wetted arrays gave a slightly higher value of $k_{\text {eff }}$. The $6 \%$ of normal water density was found to be more reactive than the $5 \%$ and $7 \%$ water density cases. The $6 \%$ water density values for $k_{\text {eff }}$ are given in Table G.3. The $k_{\text {eff }}$ values for the $5 \%$ and $7 \%$ cases were lower with the differences near the statistical accuracy of the KENO II code.

The deformed L-10 array is also subcritical. $k_{\text {eff }}=0.970 \pm 0.006$ for the conservatively modelled array. Preliminary calculations showed that if the array were to be flooded $k_{\text {eff }}$ would be reduced to about 0.87 .

It is important to recall that the integrity of the containment vessel was assumed in these calculations. Were multiple vessels to leak and a sufficient amount of the fissile material were to collect in a particular geometry, it is possible that criticality could be achieved with any of the plutonium shipping packages. 
APPENDIX H

STRESS ANALYSIS OF L-10 AND 6M CONTAINERS

The tests performed to license containers are qualification tests (i.e., tests to demonstrate that the container can withstand certain conditions with only nominal damage) and not failure tests. As a result, for most containers, failure points are largely unknown. In the case of the L-10 and 6M containers, tests more extreme than those required for licensing have been performed at Sandia. (1) In addition, containers simi$1 \mathrm{ar}$ to the $6 \mathrm{M}$ and L-10 were in a simulated accident at the Aberdeen Proving Grounds. (2) The analytical results presented here have been compared to the test results and found in general agreement.

This appendix describes the stress analys is methodology used in the determination of the failure drop heights shown in Table 6.1 , Section 6 in the text of this report. This methodology is based primarily on the linear-elastic mathematical treatment of structural behavior under sideloading or impact conditions. It does not include the effect of large deformation and plastic behavior. Inclusion of these effects would undoubtedly give more precise results, but would require a level of analytical effort beyond the scope of this study. However, in practically all cases (a possible exception is given below) the use of linear-elastic theory renders inherently conservative results, i.e., limiting drop heights that are less than those which would actually cause the failures as defined.

In the case, as shown below, where it is assumed that the lid will pop off when a certain elastic deformation of the outer container is reached, some definite degree of uncertainty remains. However, a conservative analys is can still be achieved for this case if some of the load-bearing structures, such as the birdcage space frame, are neglected. It is believed that significant drop energy would be dissipated in localized buckling of the outer container. In this case the omission of large elastic deformation (buckling) or plastic deformation effects would not necessarily lead to conservative 
results. This particular assumption and the actual behavior of the containers undergoing a side drop and impacting in other orientations should be determined from a carefully structured experimental program. In lieu of this internal load-bearing structures were neglected in the analysis for lid removal.

\section{L-10 Container Analysis 1}

Problem Statement: Determine the drop height which results in loss of vermiculite (assuming vermiculite is lost when the container lid comes off). Then determine the length of time required for a fire to pressurize and rupture the inner pressure vessel.

Specification of $L-10$ container:

Weight $(\operatorname{tota} 1)=5101 \mathrm{bs}$

$O D=239 / 16 \mathrm{in}$.

ID $=2213 / 16$ in.

Shell thickness $=0.0478 \mathrm{in}$.

End plate $=0.0598 \mathrm{in}$.

Total length $=66.75 \mathrm{in}$.

Dynamic Flow Stress:

She11: $\sigma_{s}=50,000 \mathrm{psi}^{(3)}$

Vermiculite: $\sigma_{v}=10$ psi (assumed)

It was assumed that the L-10 container was dropped on an unyielding surface. All the energy due to impact would be absorbed by the container. The deformation of the shell versus drop height was calculated using an equation from the "Cask Designer's Guide".

$$
H=\frac{t_{s}{ }^{R L} \sigma_{s}}{W}\left\{\left[F_{1}(\theta)\right]\left[\frac{R}{t_{s}}\left(\sigma_{v} / \sigma_{s}\right)+2(R / L)\left(t_{e} / t_{s}\right)\right]+F_{2}(\theta)\right\}
$$

where

$$
\begin{aligned}
& F_{1}(\theta)=\theta-\frac{1}{2} \sin 2 \theta \\
& F_{2}(\theta)=\sin \theta(2-\cos \theta)-\theta
\end{aligned}
$$




$$
\begin{aligned}
& W=\text { weight of she } 11,1 \text { bs } \\
& R=\text { outer she } 11 \text { radius, in. } \\
& t_{S}=\text { outer she } 11 \text { thickness, in. } \\
& L=\text { length of shel1, in. } \\
& \sigma_{s}=\text { the dynamic flow stress of the shell, psi } \\
& \sigma_{v}=\text { the dynamic flow stress of the vermiculite material, psi } \\
& \theta=\text { the angle associated with the deformed configuration of shell, } \\
& t_{e}=\text { thickness of steel end plate, in. }
\end{aligned}
$$

The equation above was developed for steel-encased solid lead cylinders. An approximation of deformation in a steel-encased cylinder filled with vermiculite was obtained by assuming a value for dynamic flow stress for vermiculite (10 psi) and substituting for the properties of lead in the equation. The assumed value for dynamic flow stress needs experimental verification.

Three different cases were analyzed:

Case I: Ignore the effect of vermiculite material and the bird cage (inner container supporting frames).

Case II: Ignore the effect of the bird cage.

Case III: Include the effect of vermiculite material and the bird cage.

A plot of the deformation of the shell versus drop height is shown in Figure H.I for Cases I, II and III.

The model assumes that the lid will come off when the perimeter of the lid is smaller than the undeformed inside circumference of the clamp ring. Based on this assumption, the drop height for a side drop which would cause the loss of vermiculite material was found to be:

\begin{tabular}{cc} 
Case No. & Drop Height $(\mathrm{ft})$ \\
\cline { 1 - 2 } I & 130 \\
II & 138 \\
III & 181
\end{tabular}




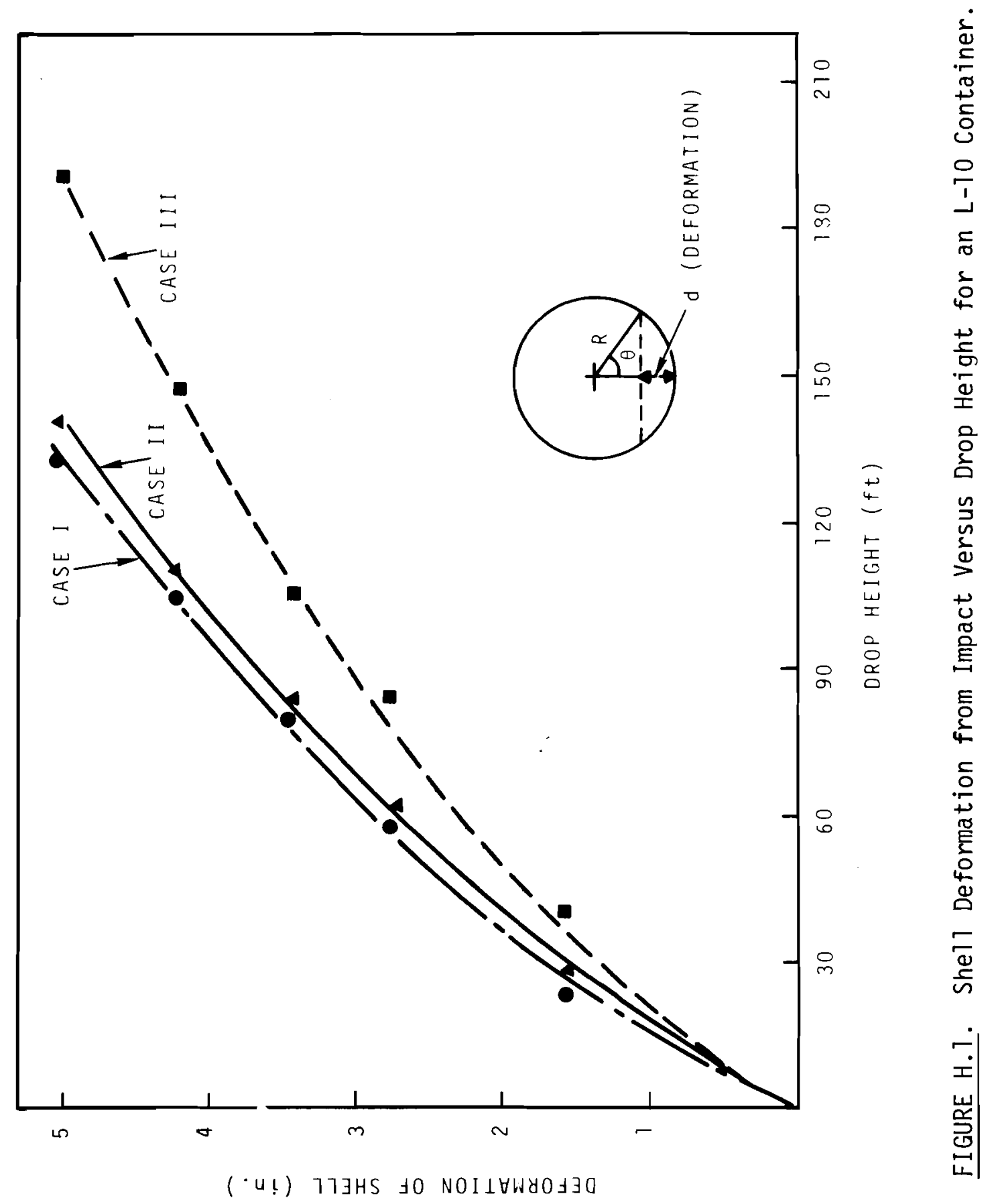




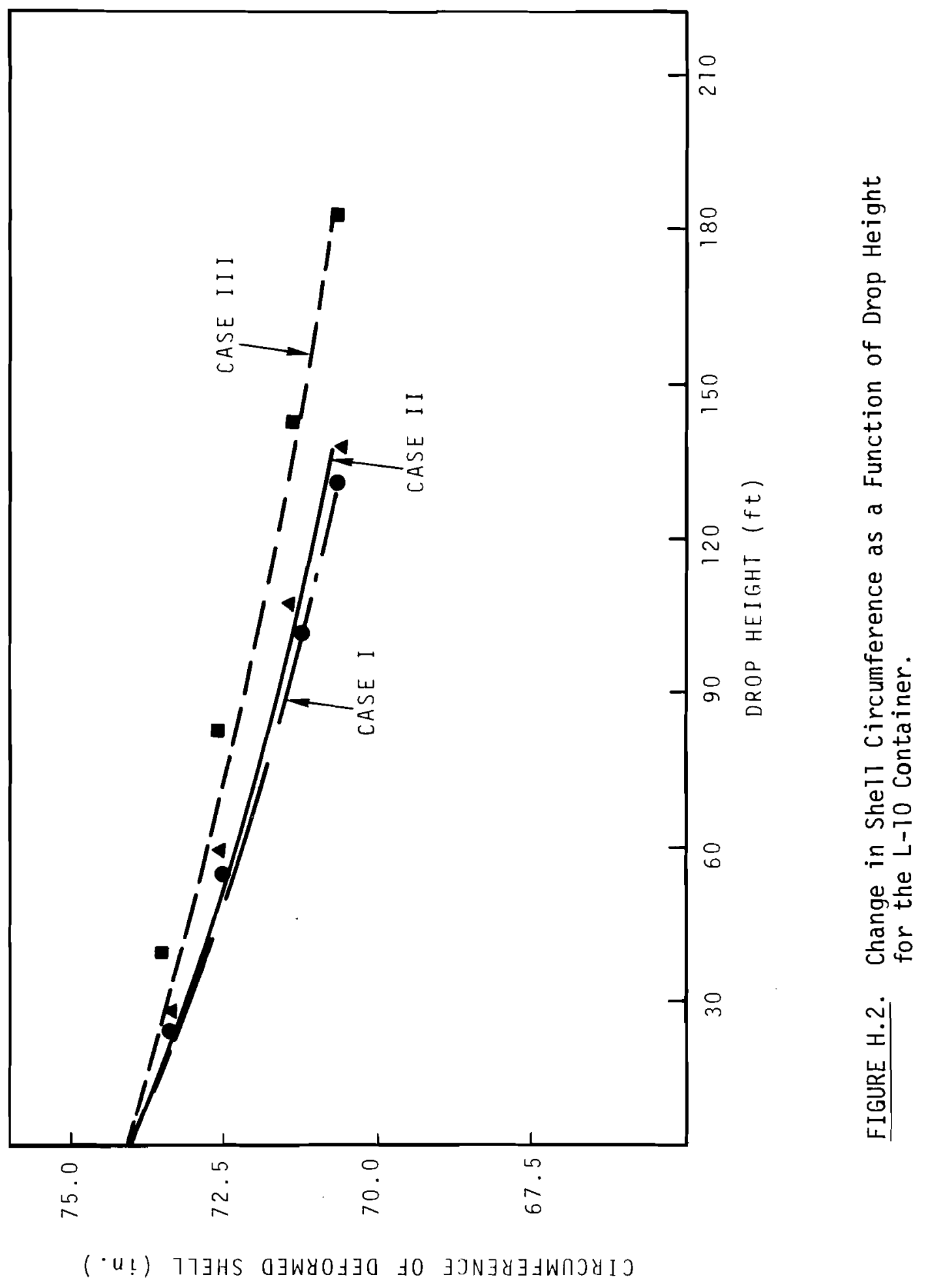

H. 5 
The change of circumference of the shell versus drop height is given in Figure H.2.

The rupture of the inner pressure vessel ( $5 \mathrm{in}$. diameter schedule 80 SS 304 pipe) under fire conditions was determined from two sets of calculations: a) rupture pressure versus temperature and b) vessel internal pressure versus temperature. From these a critical temperature was determined.

a. The rupture pressure versus temperature was calculated using the ASME Section VIII pressure vessel code. ${ }^{(4)}$ The temperature-dependent material properties were obtained from Reference (5). The rupture pressures for these components were calculated:

i) pressure vessel wall (at rupture)

ii) bolts (at yield)

iii) flange (at yield)

The results are shown in Figure H.3.

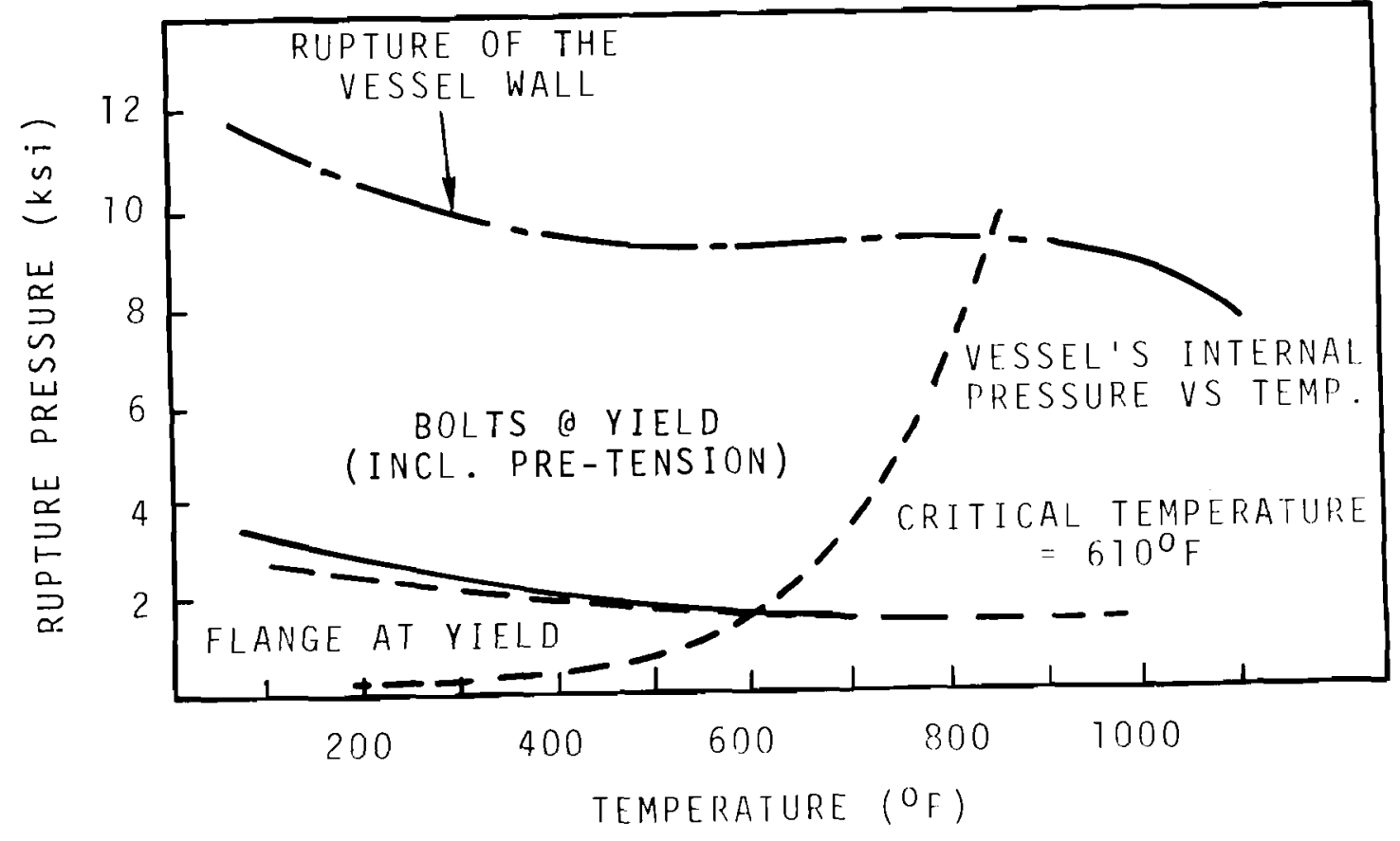

FIGURE H.3. Pressure-Temperature Relationships for the L-10 Container 
b. The internal pressure in the vessel at various temperatures (resulting from a fire incident) was calculated from the equation: ${ }^{(6)}$

$$
\log _{e} P=A-B / T
$$

where $P=$ pressure in ps $i$

$$
\begin{aligned}
& A=\text { constant }=16.6749 \\
& B=\text { constant }=5399.03 \\
& T=\text { temperature in }{ }^{\circ} \mathrm{K}
\end{aligned}
$$

This equation, plotted in Figure H.3, is explained in greater detail in Appendix $D$.

It is evident that the bolts and flange will yield first. The temperature at which the bolts and flange yield is approximately $610^{\circ} \mathrm{F}$. The time required to reach this temperature during a fire incident was determined by a heat transfer analysis reported in Appendix I.

The relative distance between the inner and outer container after drop was determined by Equation $\mathrm{H}-\mathrm{l}$ for use in the heat transfer analysis. The result is shown in Figure H.4.

The final deformed configuration corresponding to Case II is shown in Figure H.5. The effect of the bird cage, however, was included in the calculation for the inner container deformation.

Following impact a deceleration takes place. The deceleration versus drop height for the outer and inner container is shown in Figure H.6.

A separate analysis was made on the inner container closure bolts. It showed that the deceleration rate for this container would not result in bolt failure.

\section{L-10 Container Analysis 2}

Problem Statement: Determine the drop height required to deform the outer container so that a half-hour fire $\left(800^{\circ} \mathrm{C}\right)$ results in sufficient pressure to fail inner pressure vessel. 

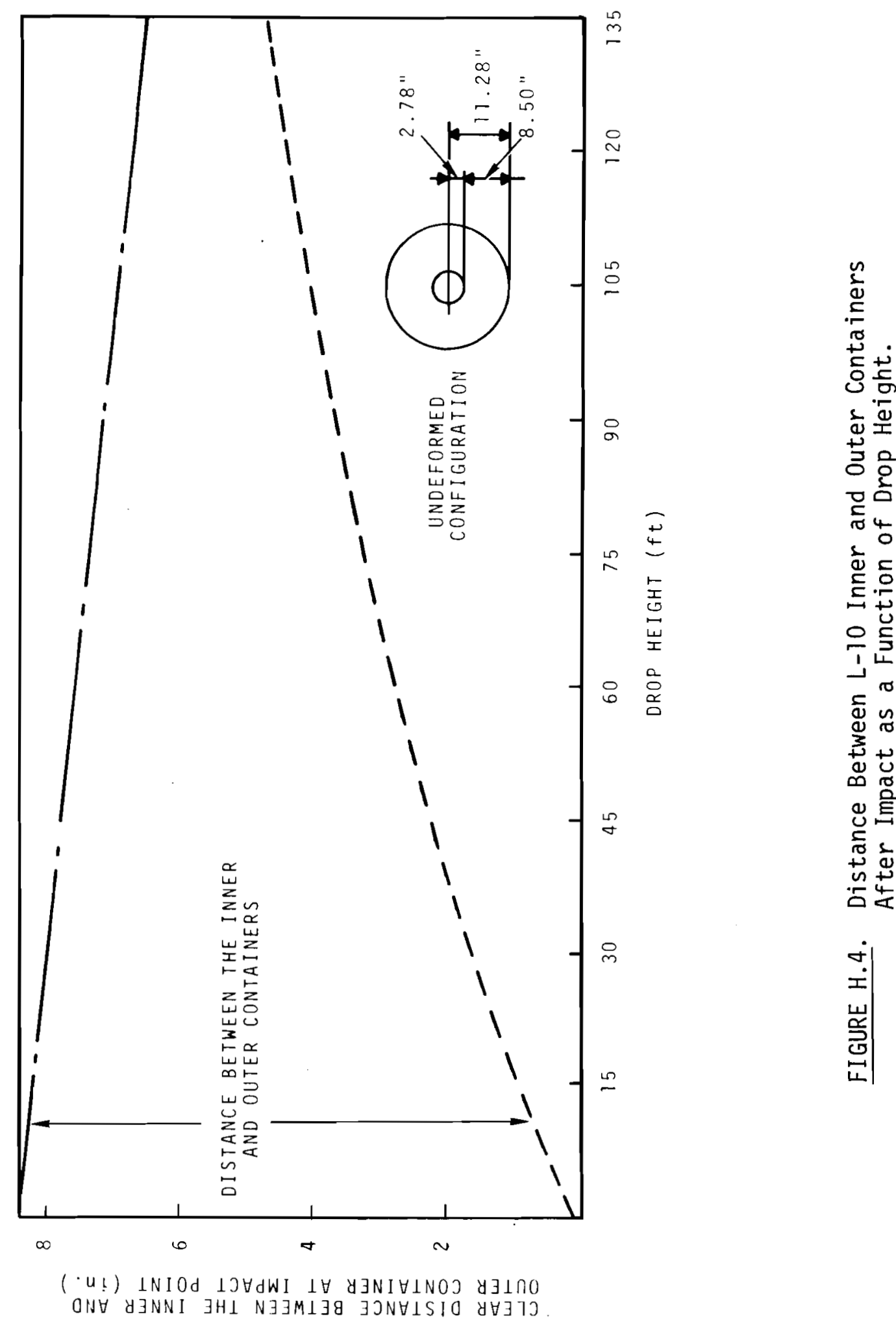

H. 8 
L-10 CONTAINER UNDEFORMED POSITION

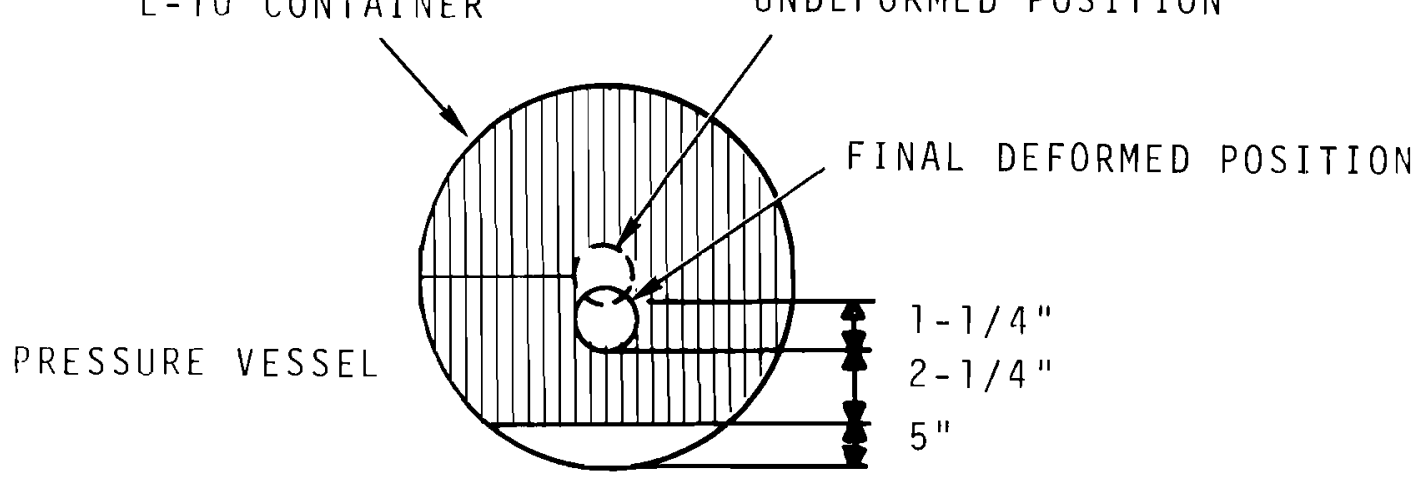

FIGURE H.5. Relative Distance Between Inner and Outer Containers after Case II Drop

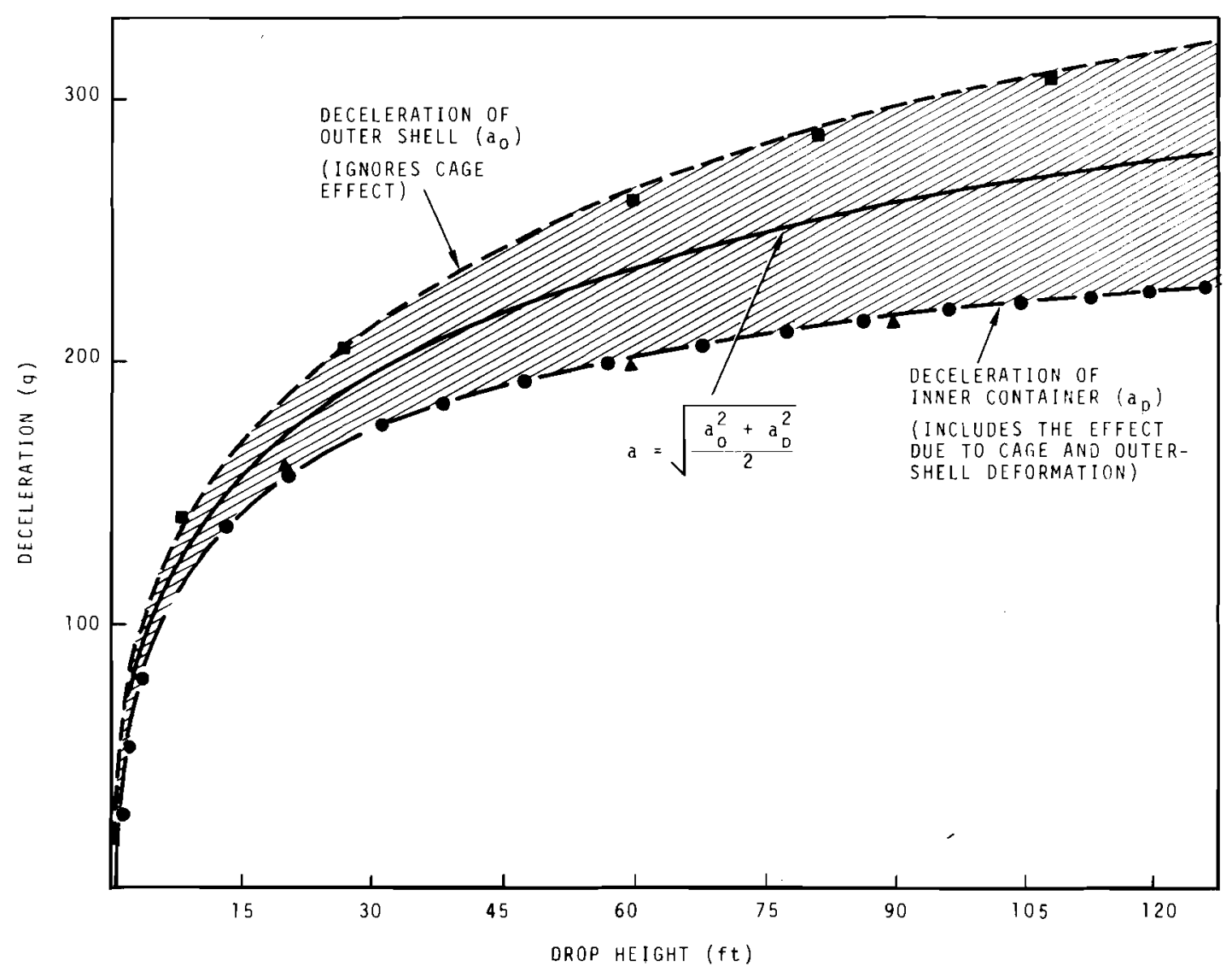

FIGURE H.6. Deceleration of Inner Container and Outer Shell During Impact as a Function of Drop Height 
Based on the thermal analysis in Appendix I, the required vermiculite thickness was found to be $1 / 2$ in. Thus, based on the curves presented in Figure H.4, a drop height greater than $135 \mathrm{ft}$ is required before the container will fail in an $800^{\circ} \mathrm{C}$ fire with a half-hour duration.

6M Container Analysis I

Problem Statement: Determine the drop height which results in rupture of the outer container (side drop).

Specification of 6M Container:

Weight $($ tota 1$)=1601 \mathrm{~b}$

$O D=15.57$ in. $\times 21.25$ in. high (15 ga 1 size $)$

She 11 thickness $=0.0478 \mathrm{in} .(18 \mathrm{GA})$

Pressure Vessel:

ID $=5-1 / 4$ in. $\times 10-1 / 2$ in. high

Wall thickness $=1 / 4 \mathrm{in}$.

Dynamic Flow Stress:

She 11: $\sigma_{S}=50,000$ psi (Reference 3)

Celotex: $\sigma_{C}=100$ psi (assumed)

The deformation of outer container versus drop height (obtained using Equation $\mathrm{H}-1$ ) is shown in Figure $\mathrm{H} .7$. The drop height required to pop off the lid of the outer container was found to be $194 \mathrm{ft}$. Again this was based on the assumption that the lid would come off when the perimeter of the lid in the deformed state is smaller than the undeformed inside circumference of the clamp ring.

6M Container Analysis 2

Problem Statement: Determine the drop height which would cause rupture of the inner container.

It was assumed that the inner pressure vessel would not deform until the outer shell contacted the inner vessel. The drop height to cause this contact was found to be approximately $260 \mathrm{ft}$. 


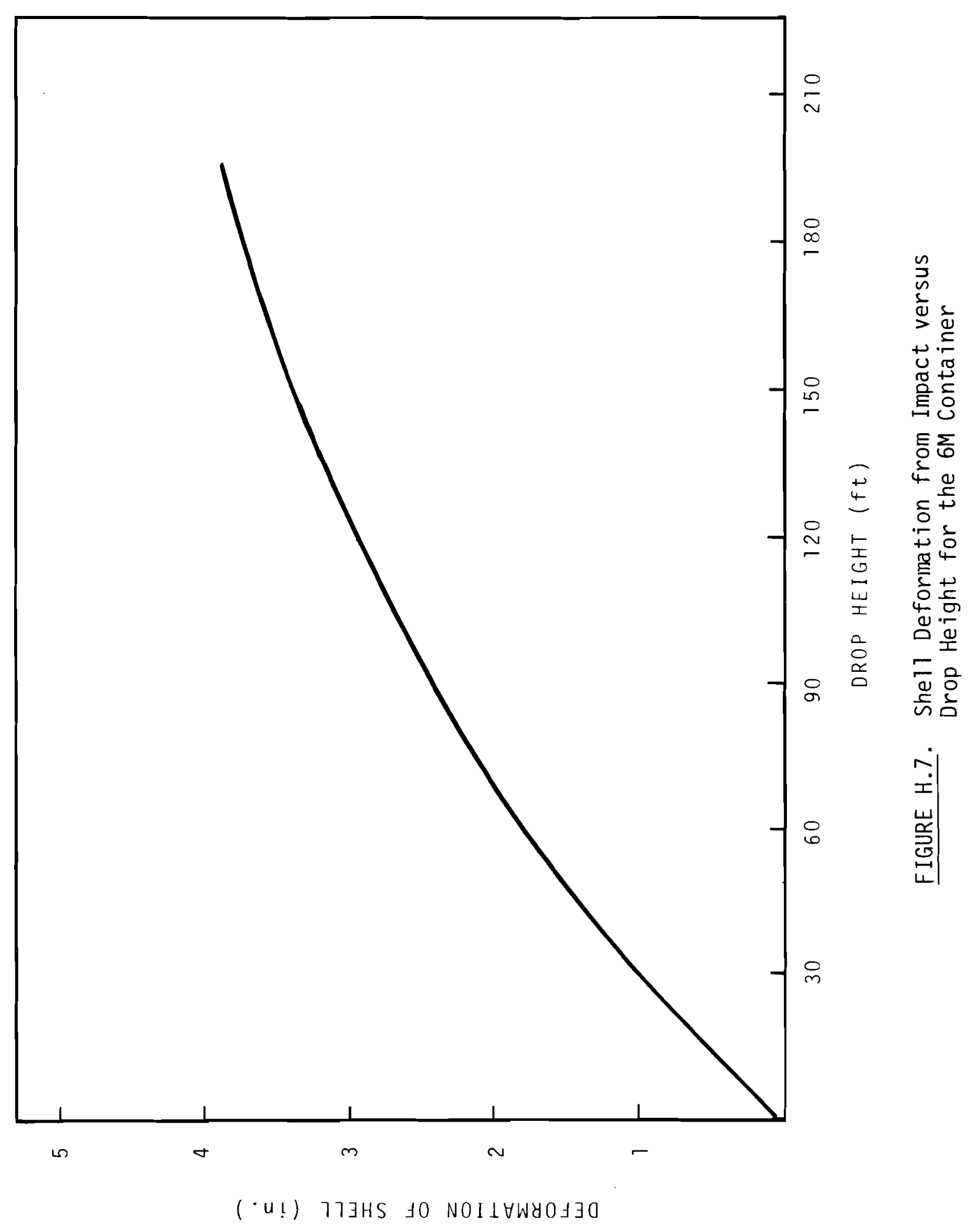

H.11 
The deformation versus drop helght for an inner vessel is shown in Figure H.B. The point at which rupture would occur due to deformation cannot be defined. The solution may only be found by a physical test. The data used in determining deformation using equation $\mathrm{H}-\mathrm{I}$ are:

$$
\begin{aligned}
& t_{e}=\text { Thickness of steel end plate }=1 / 2 \mathrm{in} . \\
& t_{e s}=\text { Thickness of screwed end plug }=1.31 \mathrm{in} . \\
& \sigma_{s}=\text { The dynamic flow stress in steel }=50,000 \mathrm{psi} \\
& t_{s}=\text { The outer shell thickness }=0.25 \mathrm{in} . \\
& R=\text { The outer shell radius }=2.875 \mathrm{in} . \\
& L=\text { The length of shell }=10.5 \mathrm{in} .
\end{aligned}
$$

It was also assumed that the contents of the inner pressure vessel were compressible.

\section{L-10 Container Analys ts 3}

Problem Statement: Determine the drop height onta a 6 in, diam pin required to puncture the $1-10$ outer container and inner container. (Side drop for upended pin.)

The puncture of the L-10 outer and inner container was calculated using the equation:

$$
H=\frac{39(S) t^{1.4}}{\bar{W}}
$$

where

$$
\begin{aligned}
& H=\text { drop height, in, } \\
& S=\text { ultimate tensile stress of container, psi } \\
& t=\text { thickness of container, in, } \\
& \bar{W}=\text { weight of contalner, } 1 \mathrm{~b},
\end{aligned}
$$

For the outer container

$$
\begin{aligned}
& \bar{W}=510 \mathrm{lb} \\
& t=0.0478 \mathrm{in}, \\
& S=50,000 \mathrm{ps} .
\end{aligned}
$$
*For containers less than 30 in, diameter (e.g. the $L-19$ container) $\bar{W}$ in
Equation $\mathrm{H}-2$ should be increased by a factor of 1.3 . $(7)$ 


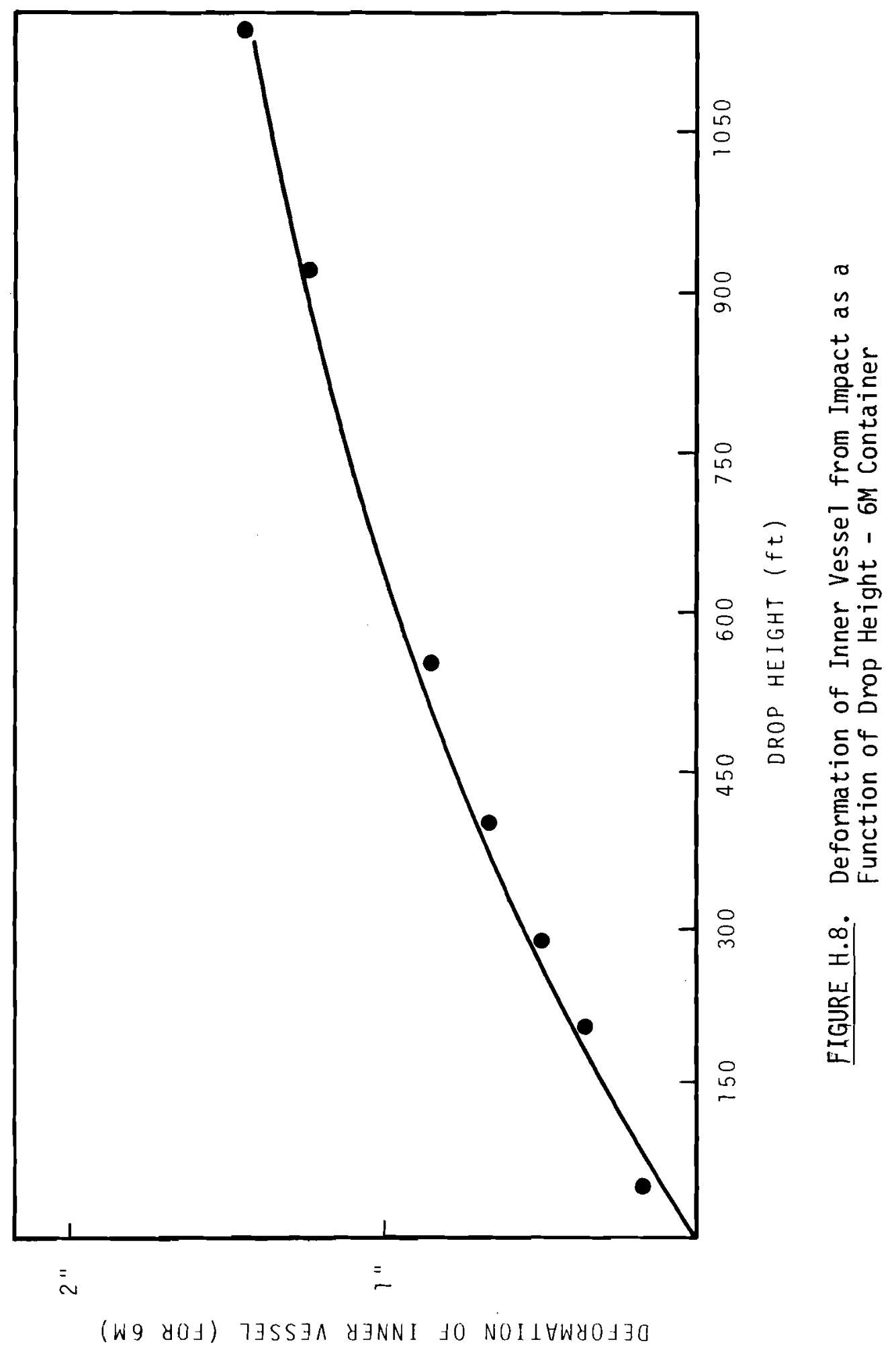

H.13 
The drop height required to puncture the outer container was found to be $42 \mathrm{in}$.

The drop height to puncture the inner container alone (based on the weight of $160 \mathrm{lb}$ ) is $4000 \mathrm{in}$. The inner container alone, however, will fail due to bending at a much lower height. The drop height to cause such failure is $58 \mathrm{in}$. The total height resulting in the rupture of the inner container is, therefore, $42+58=100 \mathrm{in}$. The puncture resistance of vermiculite material was ignored in the analysis.

Correlation of Analysis with Test Results

Additional calculations regarding the puncture of the $6 \mathrm{M}$ container in a side drop onto a 6 in. diameter pin were made using Equation $\mathrm{H}-2$. The drop height required to puncture the outer container is 133 in. The inner container will fail due to bending at a drop height of $37 \mathrm{in.}$ The total drop height required to rupture both the outer and inner containers is $170 \mathrm{in.}$. It is interesting to note that in a controlled drop test carried out by Sandia, ${ }^{(1)}$ a $6 \mathrm{M}$ container was side dropped onto a 6 in. diameter pin from a height of 119 in. without puncturing the outer container. The results of this test tend to verify these calculations. 


\section{$\underline{\text { REFERENCES }}$}

1. L. F. Stravasnik, Special Tests for Plutonium Shipping Containers 6M, SP5795, and L-10, AEC R\&D Report TID-4500, Sandia Report SC-DR-72 0597, September 1972 .

2. 0. A. Kelly, and C. W. C. Stoddart, "Highway Vehicle Impact Studies: Tests and Mathematical Analyses of Vehicle, Package and Tiedown Systems Capable of Carrying Radioactive Materials," ORNL-NSIC-61, Nuclear Safety Information System, Oak Ridge National Laboratory, Oak Ridge, TN, 1970.

3. L. B. Shappert, A Guide to the Design, Fabrication, and Operation of Shipping Cask for Nuclear Applications, ORNL-NSIC-68, February 1970.

4. ASME Boiler and Pressure Vessel Code, Section VIII Pressure Vesse1s, American Society of Mechanical Engineers, New York, Ju1y, 1971.

5. Aerospace Structural Metals Handbook, Vol. 1, Ferrous Alloys, Syracuse University Press, March, 1967.

6. R. D. Scheele, Pressure and Temperature Relationships for $\mathrm{Pu}\left(\mathrm{NO}_{3}\right)_{4}$, HNO3 Aqueous Solutions, Internal Correspondence to T. I. McSweeney, November, 1973.

7. H. A. Nelms, Structural Analysis of Shipping Casks, Vol. 3, Effects of Jacket Physical Properties and Curvature on Puncture Resistance, ORNL-TM-1312, vo1. 3, June 1968.

GENERAL REFERENCES

1. F. B. Seely, and J. 0. Smith, Advanced Mechanics of Material, John Wi ley \& Sons, Inc., New York, October 1963.

2. J. B. Loser et al., Thermophysical Properties of Thermal Insulating Materials, Technical Documentary Report No. ML-TDR-64-5 Midwest Research Institute, Apri1, 1964. 


\section{APPENDIX I}

\section{THERMAL ANALYSIS OF THE L-10 CONTAINER}

Analyses of the thermal characteristics of an L-10 container were performed using the HEATING4 heat conduction computer program to determine:

1) Time for pressure housing failure based on temperature rise resulting from a $1475^{\circ} \mathrm{F}$ fire ${ }^{\star}$ imposed at the surface of the unprotected pressure housing (i.e., in the absence of vermiculite insulating material).

2) Time for pressure housing failure based on temperature rise in a crushed shipping container exposed to a $1475^{\circ} \mathrm{F}$ fire under conditions described in 10 CFR 71.

3) Amount of insulation required with $1475^{\circ} \mathrm{F}$ fire inside container to prevent pressure housing failure for $30 \mathrm{~min}$.

Failure of the pressure housing was determined by correlation of temperature/time history established in this work with the temperature/stress analysis given in Appendix $H$. Using the failure condition of $610^{\circ} \mathrm{F}$ in the SS 304 housing (see Appendix $\mathrm{H}$ ), the following results were obtained:

Case I Failure was predicted to occur between 6 and 7 min after start of fire.

Case II Failure occurs approximately 240 min after start of fire.

Case III Thirty-minute survival requires about $0.38 \mathrm{in.}$ of vermiculite thermal insulation covering the pressure housing.

This appendix summarizes this analys is effort.

*This Appendix uses the hypothetical fire conditions specified in 10 CFR 71 , Appendix B. The $1850^{\circ} \mathrm{F}$ fire environment used in the risk analys is generates a radiant heat flux a factor of two above that generated by a $1475^{\circ} \mathrm{F}$ fire. Thus, in the failure analysis (Section 9) a factor of two reduction in the time to failure was conservatively used to obtain the consequences of the $1850^{\circ} \mathrm{F}$ fire environment following a truck accident. 


\section{PROBLEM STATEMENT}

The type L-10 plutonium nitrate shipping container meets requirements in 10 CFR 71, Appendix B. These include survival under hypothetical accident conditions involving a $1475^{\circ} \mathrm{F}$ radiation environment imposed for 30 minutes. (1) Survival characteristics of the container are of interest for hypothetical accident conditions more severe than those specified in 10 CFR 71, Appendix B. Specific cases to be studied involve the entry of the hypothetical fire into a partially insulated container. The time required for pressure housing failure and the insulation thickness needed to prevent failure for 30 minutes are determined in this study.

\section{ANALYTICAL APPROACH}

Heat transfer analyses using the HEATING4 computer program were performed to evaluate:

1. Time for pressure housing failure based on temperature rise resulting from a $1475^{\circ} \mathrm{F}$ fire imposed at the surface of the unprotected pressure housing.

2. Time for pressure housing failure based on temperature rise in a crushed shipping container exposed to a $1475^{\circ} \mathrm{F}$ fire under fire test conditions described in 10 CFR 71, Appendix B.

3. Amount of insulation required with $1475^{\circ} \mathrm{F}$ fire inside container to prevent pressure housing failure for $30 \mathrm{~min}$.

Case I represents a worst-case condition in which all insulation is expelled from the container and the pressure housing is exposed directly to the fire. Case II considers a crushed container with reduced insulation thickness in the crush zone. Case III concerns a hypothetical accident involving partial loss of insulation.

On the following page is a list of the symbols used in the analyses detailed in the following subsections. 
$C_{p} \quad$ Heat capacity $\left(B t u 1 b^{-1}{ }^{\circ} F^{-1}\right)$

$h_{c}$ Convection heat transfer coefficient (Btu $\min ^{-1}$ in $^{-2}{ }^{\circ} \mathrm{F}^{-1}$ )

$h_{r}$ Radiation heat transfer coefficient (Btu $\min ^{-1} \mathrm{in}^{-2}{ }^{\circ} \mathrm{R}^{-4}$ )

$k$ Thermal conductivity (Btu $\min ^{-1}$ in $^{-1}{ }^{\circ} \mathrm{F}^{-1}$ )

$T$ Temperature $\left({ }^{\circ} \mathrm{F}\right.$ or $\left.{ }^{\circ} \mathrm{R}\right)$

$r, \theta$ Coordinate axes

$\Delta T \quad$ Temperature difference $\left({ }^{\circ} \mathrm{F}\right)$

$X \quad$ Product of Grashof and Prandt1 numbers defined in Reference 12

$\varepsilon_{A} \quad$ Ambient Emissivity

$\varepsilon_{\mathrm{S}} \quad$ Single surface Emissivity

$\varepsilon_{\mathrm{F}} \quad$ Emissivity of Fire

$\rho \quad$ Density $\left(1 \mathrm{~b} \mathrm{in}^{-3}\right)$

o Stephan-Boltzmann Constant $\left(1.983 \times 10^{-13} \mathrm{Btu} \mathrm{min}^{-1} \mathrm{in}^{-2}{ }^{\circ} \mathrm{R}^{-4}\right)$

7 Grey body shape factor

\section{Computer Program}

Thermal analyses of the L-10 shipping container were performed with the HEATING4 computer program. HEATING4, derived from the HEATING3 program, (2) has the added capability of accounting for material phase changes. The program is a generalized steady-state and/or transient heat conduction code written in Fortran II and IV, modified to operate on the CDC-6600 computer. 
The code uses the "extrapolated Liebmann method" and a modification of the "Aitken $\delta^{2}$ extrapolation process" to solve the finite difference equations which approximate the partial differential equations for a steadystate problem. The difference equations for a transient problem involve the first forward time difference, and thus the solution is expressed explicitly in terms of the temperatures at the previous time level.

For transient calculations, a modified explicit method is incorporated into the program as an option which allows the use of an arbitrary time increment while maintaining stability.

The HEATING Programi is designed to solve steady-state and/or transient heat conduction problems in one-, two-, and three-dimensional Cartesian or cylindrical coordinates. Thermal conductivity, density, and specific heat may be dependent on temperature. Heat generation rates may be dependent on position and time, and the boundary temperatures may be time dependent. Boundary conditions may be fixed temperatures or any combination of constant heat flux, forced convection, natural convection, and radiation.

The code requires that the object to be analyzed be divided into regions of like material properties with boundaries parallel to the $x, y, z$ or $r, \theta$, $z$ coordinate planes. Input to the code consists of:

1. Region description (material, coordinates, and boundaries).

2. Region properties (thermal conductivity, heat capacity, and density as functions of temperature).

3. Expressions describing internal heat generation for each region as a function of the coordinates.

4. Tables describing boundary temperature and heat generation rate histories.

5. Driving boundary descriptions (adiabatic, constant heat flux, constant temperature, forced convection, free convection, and/or radiation).

6. Coordinate system. 
The output consists of temperatures at each coordinate lattice intersection or node. The original HEATING4 program could consider 1750 nodes. The capacity of the current PNL version is dependent only on the available core of the computer.

Geometry Models

Geometries for Cases I, II, and III are illustrated in Figures I.1, I.2, and I.3, respectively. The principal assumption in all cases is a twodimensional $(r, \theta)$ heat transfer situation, representing either a symmetrical or conservative case by a quadrant section perpendicular to the axis of the pressure housing.

In Cases I and II the thermal analyses modeled a lower quadrant section with the principal axis of the container horizontal prior to onset of the fire. An upper quadrant (Figure I.3) was modeled in Case III.

Figure I.2 shows a geometry with a 5 -in. vertical crush depth on the carbon steel container and a vertical displacement of 1.25 in. of the stainless steel housing axis below the original major axis of the container. These values correspond to a free fall case studied by Liu ${ }^{(3)}$ and given in Appendix H.

The outer carbon steel container was neglected in a 11 computations, based on anticipation that this would have negligible influence on the heating rate of the pressure vessel. This assumption is obviously valid in Case I, where fire is considered to have entered the container. In Case II inclusion of the container would have complicated the noding of asymmetric regions and have increased computation time too much. Neglect of the container should change the outer boundary temperature distribution in the vermiculite less than $10^{\circ} \mathrm{F}$. The absence of the outer container in Case III is conservative by allowing fire to exist directly at the outer vermiculite boundary.

The material/region boundary dimensions are summarized in Table I.1. 


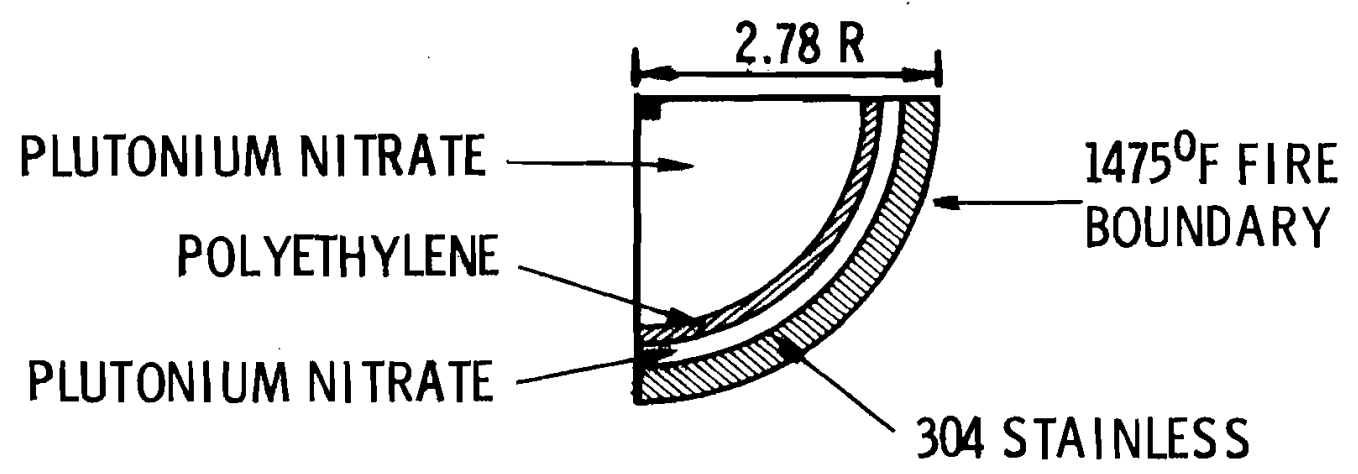

FIGURE I.1 L-10 Case I Geometry

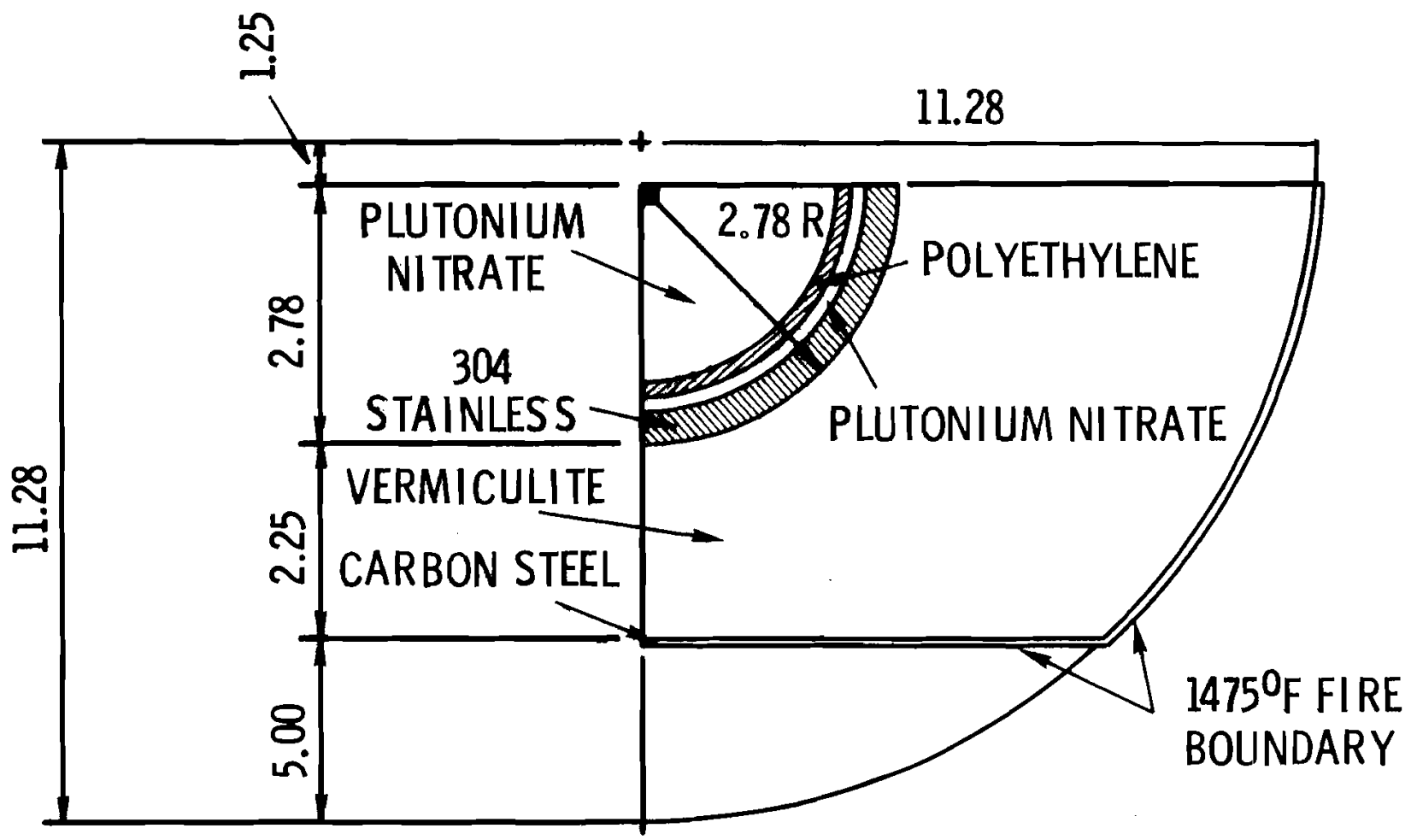

FIGURE I.2 L-10 Case II Geometry

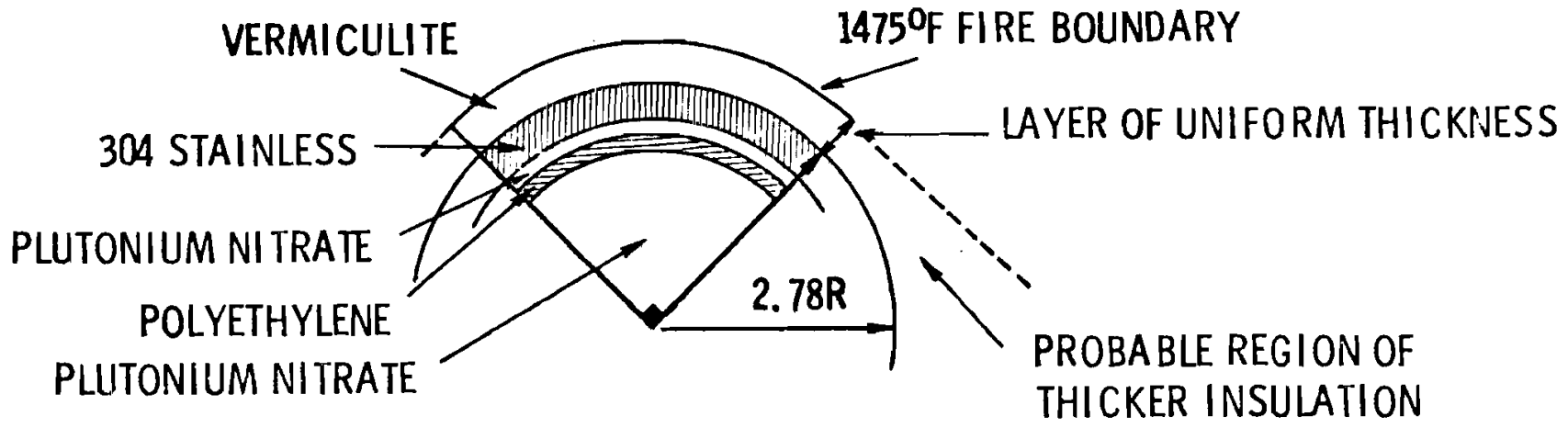

FIGURE I.3 L-10 Case III Geometry 
TABLE I.1 Radial Material Distribution for all Cases

Material

Plutonium Nitrate Solution

Polyethylene

304 Stainless Steel

Vermiculite
Boundary Radius (in.)

Inner Boundary Outer Boundary

0.0

2.25

2.24

2.41

2.78
2.24

2.41

2.25

2.78

$>2.78$

Boundary radi $i$ correspond to dimensions of the L-10 shipping container described in Reference 4 and shown in Appendix A. Plutonium nitrate solution is considered to fill the quadrant inside the polyethylene bottle and the region between the average outer diameter of the bottle and the internal surface of the stainless steel pressure vessel. This configuration allows consideration of plutonium nitrate heat generation in the annular clearance between the polyethylene and the stainless steel. This represents the conservative assumption that the annulus fills by leakage from the bottle after the axis of the container becomes horizontal. The regions containing plutonium nitrate are considered to be full of the solution for conservatism.

The principal difference between cases is contributed by the vermiculite distribution models. In Case I no vermiculite is considered. For the crushed container (Case II) the vermiculite distribution is modeled by five circular segments shown in Figure I.4 assuming the heating to be axisymmetrical. Shading indicates regions which are either external to the flat bottom crush geometry of Figure I.2 or for which no account was taken. The model is considered representative, however, because the exact shape of the crushed surface is unknown. For Case III vermiculite is modeled as a layer of uniform thickness, (Figure I.3) which represents the worst-case region of a vermiculite distribution resulting from partial loss of this material after crushing occurs. It is assumed that thicker layers of vermiculite and, hence, slower heating rates would exist in other regions surrounding the pressure housing (dashed line, Figure I.3). 


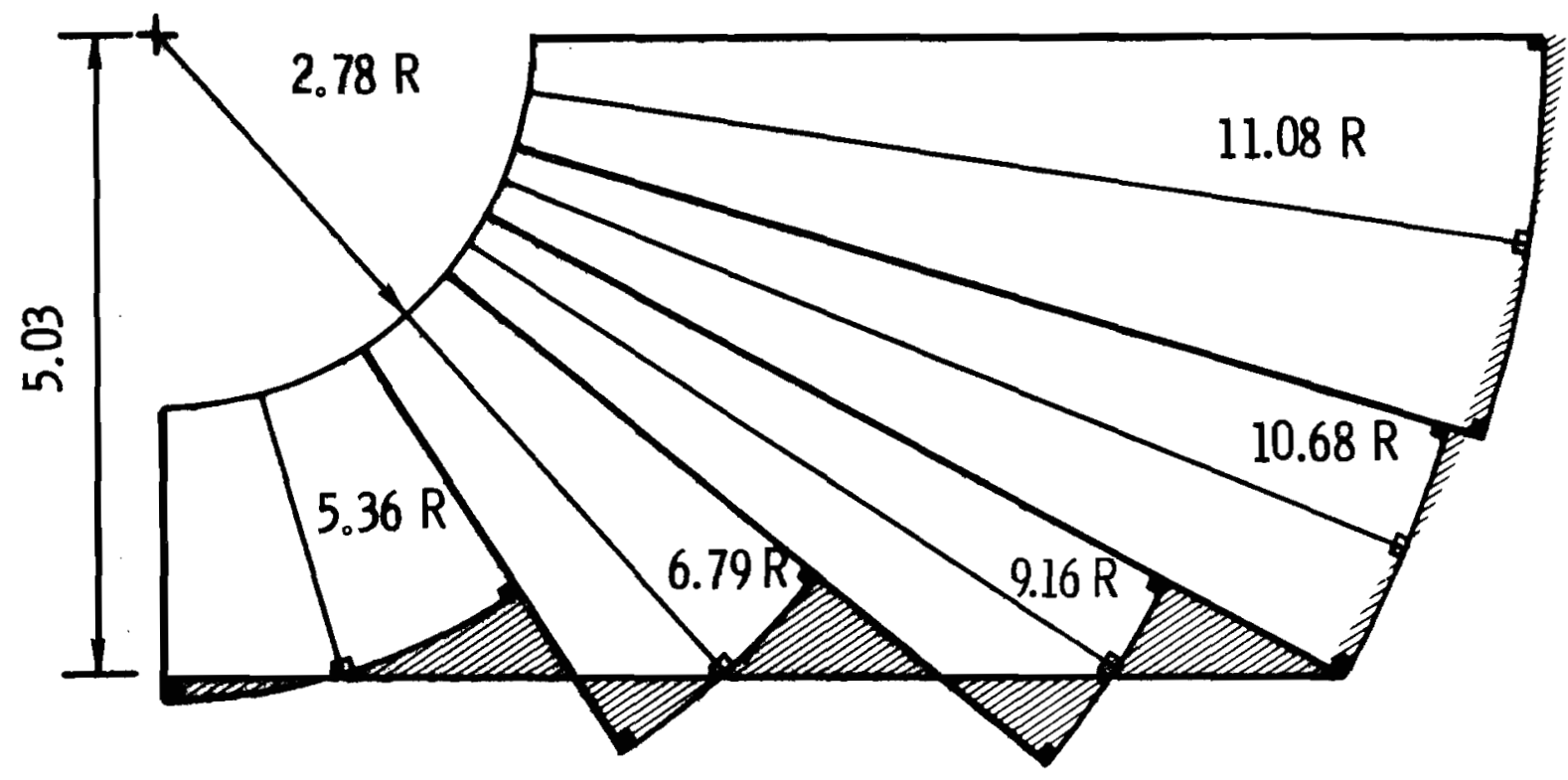

\section{APPROXIMATELY 1/2 SCALE}

DIMENSIONS IN INCHES

\section{FIGURE I.4 L-10 Case II Vermiculite Mode 1}

In all thermal models the influence of the PVC bag in the annulus between the polyethylene bottle and the pressure vessel was considered negligible. Similarly, no account was taken of the thermal characteristics of the case structure.

Material Properties

References 5 through 11 provided thermophysical material properties. Table $I .2$ contains the $C_{p}$, $\rho$ and $k$ values with the appropriate temperature dependences used in these analyses.

The emissivity of stainless stee 1 in Case I was taken as 0.5 to estimate the gray body shape factor. In Case II the gray body factor was computed for the equivalent fire/container interface specified in Reference 1. A value $\varepsilon=0.8$ was assumed for Case III to allow for direct exposure of the vermiculite to the fire. Any error in assumptions relating to radiant heat transfer at the fire boundary were considered to be conservative. In Case I the emissivity of the stainless stee 1 may increase during the fire. 


\section{TABLE I.2 Material Description Data*}

Conductivity as a Function of Temperature.

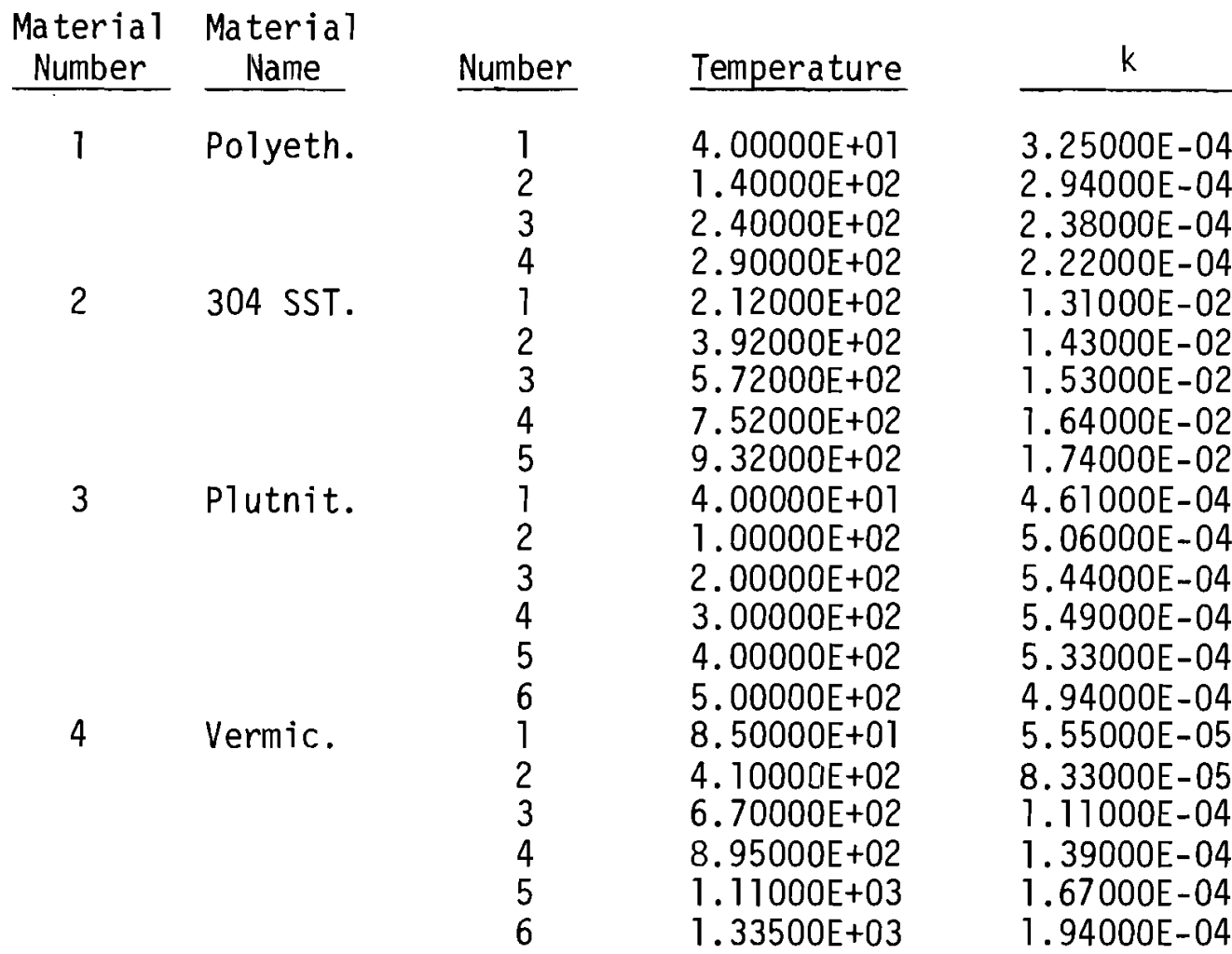

Density as a Function of Temperature.

\begin{tabular}{|c|c|c|c|c|}
\hline $\begin{array}{c}\text { Materia } 1 \\
\text { Number }\end{array}$ & $\begin{array}{c}\text { Material } \\
\text { Name } \\
\end{array}$ & Number & Temperature & $\rho$ \\
\hline 1 & Polyeth. & $\begin{array}{l}1 \\
2 \\
3 \\
4\end{array}$ & $\begin{array}{l}6.80000 E+01 \\
1.40000 E+02 \\
2.12000 E+02 \\
3.02000 E+02\end{array}$ & $\begin{array}{l}3.46000 \mathrm{E}-02 \\
3.35000 \mathrm{E}-02 \\
3.15000 \mathrm{E}-02 \\
2.95000 \mathrm{E}-02\end{array}$ \\
\hline $\begin{array}{l}2 \\
3\end{array}$ & $\begin{array}{l}304 \text { SST. } \\
\text { Plutnit. }\end{array}$ & $\begin{array}{l}1 \\
1 \\
2 \\
3 \\
4 \\
5 \\
6 \\
6 \\
7\end{array}$ & $\begin{array}{l}0 . \\
4.00000 E+01 \\
1.00000 E+02 \\
2.00000 E+02 \\
3.00000 E+02 \\
4.00000 E+02 \\
5.00000 E+02 \\
6.00000 E+02\end{array}$ & $\begin{array}{l}2.90000 \mathrm{E}-01 \\
5.00000 \mathrm{E}-02 \\
4.97000 \mathrm{E}-02 \\
4.82000 \mathrm{E}-02 \\
4.59000 \mathrm{E}-02 \\
4.30000 \mathrm{E}-02 \\
3.93000 \mathrm{E}-02 \\
3.40000 \mathrm{E}-02\end{array}$ \\
\hline 4 & Vermic. & 1 & 0 . & $4.63000 \mathrm{E}-03$ \\
\hline
\end{tabular}

Reference 8 Temperature dependence calculated from specific volume Reference 9 Reference 5 . Temperature dependence proportional to that of water with $\left(\rho 25^{\circ} \mathrm{C}-3\right)=1.385$ $\mathrm{gm} . \mathrm{cm}$ Reference 10 and 11 
TABLE I.2 Material Description Data* (Continued)

Heat Capacity as a Function of Temperature.

\begin{tabular}{|c|c|c|c|c|c|}
\hline $\begin{array}{l}\text { Material } \\
\text { Number } \\
\end{array}$ & $\begin{array}{l}\text { Material } \\
\text { Name } \\
\end{array}$ & Number & Temperature & $C_{p}$ & Derivation $^{(\star \star)}$ \\
\hline 1 & Polyeth. & $\begin{array}{r}1 \\
2 \\
3 \\
4 \\
5 \\
6 \\
7 \\
8 \\
9 \\
10 \\
11\end{array}$ & $\begin{array}{l}5.00000 \mathrm{E}+01 \\
1.00000 \mathrm{E}+02 \\
1.50000 \mathrm{E}+02 \\
2.00000 \mathrm{E}+02 \\
2.25000 \mathrm{E}+02 \\
2.50000 \mathrm{E}+02 \\
2.68000 \mathrm{E}+02 \\
2.87500 \mathrm{E}+02 \\
3.00000 \mathrm{E}+02 \\
4.00000 \mathrm{E}+02 \\
5.00000 \mathrm{E}+02\end{array}$ & $\begin{array}{l}4.78000 \mathrm{E}-01 \\
4.80000 \mathrm{E}-01 \\
4.84000 \mathrm{E}-01 \\
5.11000 \mathrm{E}-01 \\
5.38000 \mathrm{E}-01 \\
6.22000 \mathrm{E}-01 \\
9.22000 \mathrm{E}-01 \\
8.68000 \mathrm{E}-01 \\
8.54000 \mathrm{E}-01 \\
7.82000 \mathrm{E}-01 \\
7.07000 \mathrm{E}-01\end{array}$ & Reference 7 \\
\hline 2 & 304 SST. & 1 & 0 . & $1.20000 \mathrm{E}-01$ & Reference 9 \\
\hline 3 & Plutnit. & 1 & 0. & $1.00000 \mathrm{E}+00$ & $\begin{array}{l}\text { Reference } 6 \\
\text { as for water }\end{array}$ \\
\hline 4 & Vermic. & $\begin{array}{l}1 \\
2\end{array}$ & $\begin{array}{l}3.20000 \mathrm{E}+01 \\
1.40000 \mathrm{E}+03\end{array}$ & $\begin{array}{l}2.00000 \mathrm{E}-01 \\
2.40000 \mathrm{E}-01\end{array}$ & Reference 11 \\
\hline $\begin{array}{l}\text { Material } \\
\text { Number } \\
\end{array}$ & $\begin{array}{l}\text { Ma terial } \\
\text { Name } \\
\end{array}$ & \multicolumn{2}{|c|}{$\begin{array}{c}\text { Melting } \\
\text { Point }\end{array}$} & $\begin{array}{c}\text { Latent } \\
\text { Heat }\end{array}$ & \\
\hline 1 & Polyeth. & \multicolumn{2}{|c|}{$2.66000 E+02$} & $.39700 E+01$ & Reference 8 \\
\hline
\end{tabular}

* Material properties, unless otherwise noted were input to the computer code with the following temperature dependence. Appropriate references are noted.

** The reference for each property is cited once at the beginning of the values for which it is appropriate. 
This tendency would increase the rate of heating and decrease the time for failure. In Cases II and III, the gray body shape factor ( $\mathcal{F}$ ) will have a tendency to be lower than assumed values. Computed failure times will therefore tend to be shorter than may occur in reality, and survival to 30 min may be achieved with a slightly thinner vermiculite layer than the results indicate. It is expected generally that the uncertainty in $\mathcal{F}_{\text {will }}$ cause significantly less perturbation than similar variability in $C_{p}$ and $k$ values found in the literature.

Phase change was anticipated for the polyethylene bottle. Heat of fusion and melting point temperature were obtained from Reference 8. Contact resistance between regions was neglected.

Heat Generation Rate

A constant uniform heat generation rate of $3.26 \times 10^{-3} \mathrm{Btu} \mathrm{min}^{-1} \mathrm{in}^{-3}$ was calculated ${ }^{(6)}$ for all plutonium nitrate solution regions.

Boundary Conditions

Boundary parameters were estimated to provide appropriate initial steady-state and fire-initiated transient conditions.

Steady-state initial conditions were assumed to be controlled by radiation and free convection from the undamaged container in a $130^{\circ} \mathrm{F}$ ambient air environment. A radiation heat transfer coefficient $h_{r}$ was calculated from

$$
h_{r}=\sigma f .
$$

The gray body shape factor (7) was determined by

$$
\mathcal{F}=\left[\frac{1}{\bar{\varepsilon}_{S}}+\frac{1}{\varepsilon_{A}}-1\right]^{-1} \text {. }
$$

Assuming the ambient to be a black body in effect

By substitution in (1)

$$
\mathcal{F}=\left[\frac{1}{0.8}\right]^{-1}=0.8 \text {. }
$$

$$
h_{r}=1.59 \times 10^{-13} \text { Btu. min }{ }^{-1} \cdot i n^{-2} \cdot{ }^{\circ} R^{-4} .
$$


An expression for an appropriate free convection heat transfer coefficient $\left(h_{c}\right)$ for vertical cylinders in air was obtained from Reference 12:

$$
h_{c}=2.2 \times 10^{-5} \Delta T^{1 / 3} .
$$

The validity of this expression is determined by

$$
10^{9}: x<10^{12} \text {. }
$$

A value $x \sim 2.3 \times 10^{9}$ was calculated for steady-state conditions.

Solar energy input was neglected with the assumption that the container is shaded from the sun prior to imposition of the fire.

Consideration was given to the effect of free convection in the plutonium nitrate solution. Using expressions in Reference 12, it was found that the effective conductivity of the solution could be enhanced $29 \%$ by free convection. To provide a conservative estimation of heating rate in the pressure housing this effect was neglected.

A steady-state temperature distribution was established by running the HEATING4 code with the above inputs for heat generation, free convection, and radiation.

In all transient calculations the fire boundary is coupled to the container by radiant energy transfer. A radiation heat transfer coefficient defined in (1) was used with $\mathcal{F}$ variable according to the case. $\mathcal{F}$ was calculated from (2) by substituting $\varepsilon_{F}$ for $\varepsilon_{A}$. Table I.3 indicates $h_{r}$ for each case.

TABLE I.3 Radiation Heat Transfer Coefficient

\begin{tabular}{|c|c|c|c|c|}
\hline Case & $E_{S}$ & $\varepsilon_{\mathrm{F}}$ & 7 & $h_{r}\left(\right.$ Btu $\left.\min ^{-1} i n^{-2}{ }^{-} R^{-4}\right)$ \\
\hline 1 & 0.5 & $0.9 *$ & 0.474 & $9.40 \times 10^{-14}$ \\
\hline 2 & $0.8^{\star}$ & $0.9^{*}$ & 0.734 & $1.46 \times 10^{-13}$ \\
\hline 3 & $0.88^{\star \star}$ & $0.9^{*}$ & 0.80 & $1.59 \times 10^{-13}$ \\
\hline
\end{tabular}
for Transient Fire Conditions 
Results

The results of the $L-10$ shipping container thermal analyses for three hypothetical fire accidents may be summarized as follows:

Case I-Fire on Surface of Stainless Steel Pressure Housing

Figure I.5 shows temperature versus time for the mean diameter of the stainless steel pressure housing with a $1475^{\circ} \mathrm{F}$ fire at the outer diameter. Extrapolation shows incipient failure of the pressure housing after 6.4 min exposure to the fire. Failure temperature was taken as $610^{\circ} \mathrm{F}$ from the analysis in Appendix $\mathrm{H}$. At approximately $600^{\circ} \mathrm{F}$, a $23^{\circ} \mathrm{F} \Delta \mathrm{T}$ exists across the wall of the pressure housing. For the assumed boundary conditions, the corresponding range of uncertainty in the time for failure is \pm 0.19 min.

Case II-Fire on Crushed Container

Using the geometry of Figure I.4, transient heat transfer analysis showed that the pressure housing temperature ranges from $298^{\circ} \mathrm{F}$ to $317^{\circ} \mathrm{F}$ after 56 min of fire exposure. The nodal temperature distribution after a 56-min fire is shown in Figure I.6. The extrapolations plotted in Figure $I .7$ roughly indicate that incipient failure may not be anticipated before approximately $240 \mathrm{~min}$. The computer run was arbitrarily limited to a 60-min fire transient case to avoid excessive computer costs. The computer reached this time 1 imit before the $60 \mathrm{~min}$. transient history was completed.

\section{Case III-Fire with Variable Insulation Thickness}

This situation is shown in Figure I.3. A fire-initiated transient heat transfer analysis was run for several vermiculite insulation thicknesses. Figure I.8 shows temperature versus time for four cases. Using these data, the time for $610^{\circ} \mathrm{F}$ to be reached at the mean diameter of the stainless steel is plotted as a function of vermiculite thickness in Figure I.9. A vermiculite thickness of approximately $0.38 \mathrm{in}$. is shown to be sufficient to prevent pressure housing failure for $30 \mathrm{~min}$ exposure to the hypothetical fire. 


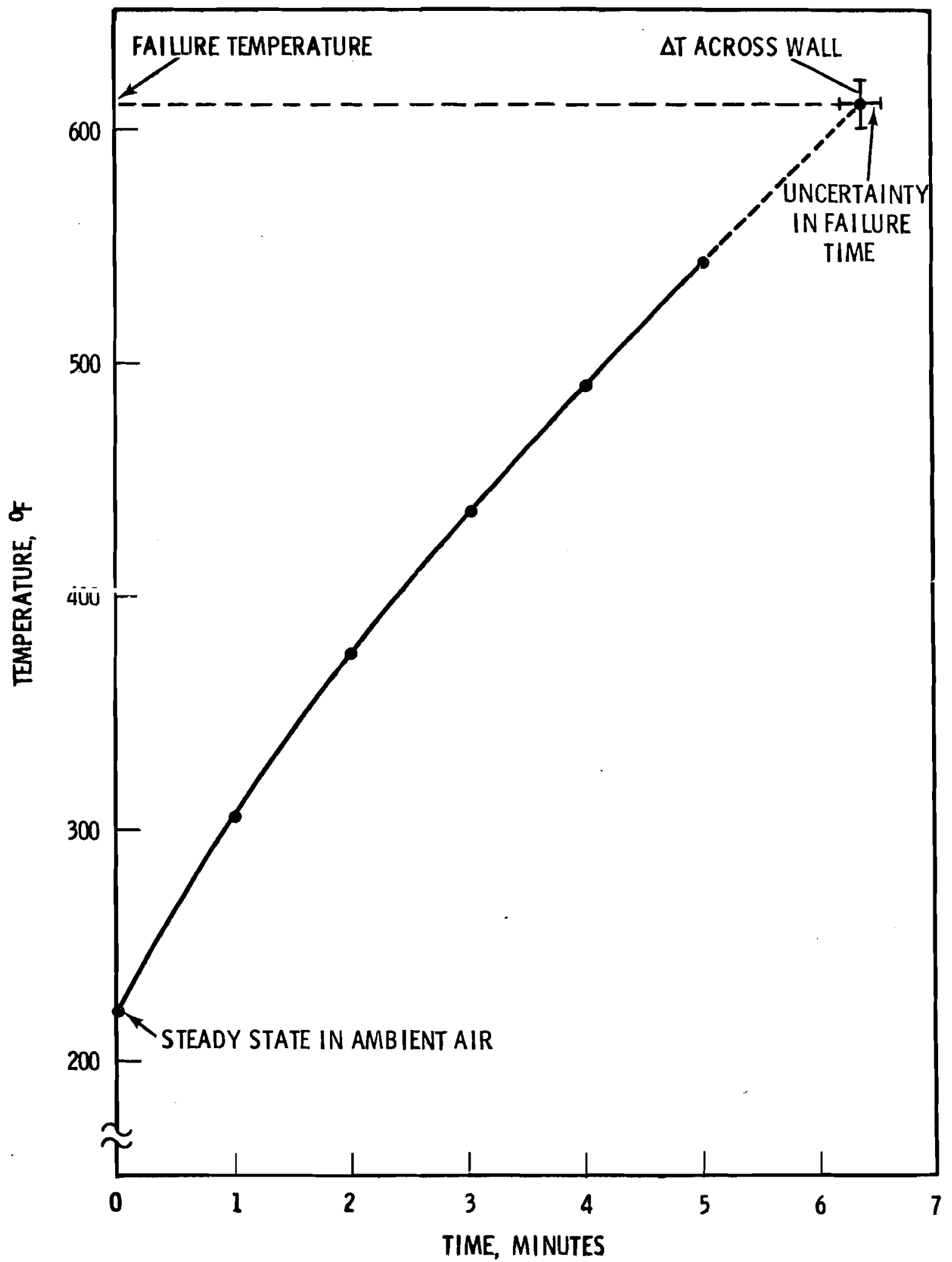

FIGURE I.5 L-10 Case I Temperature versus Time of Pressure Housing Exposed Directly to $1475^{\circ} \mathrm{F}$ Fire 


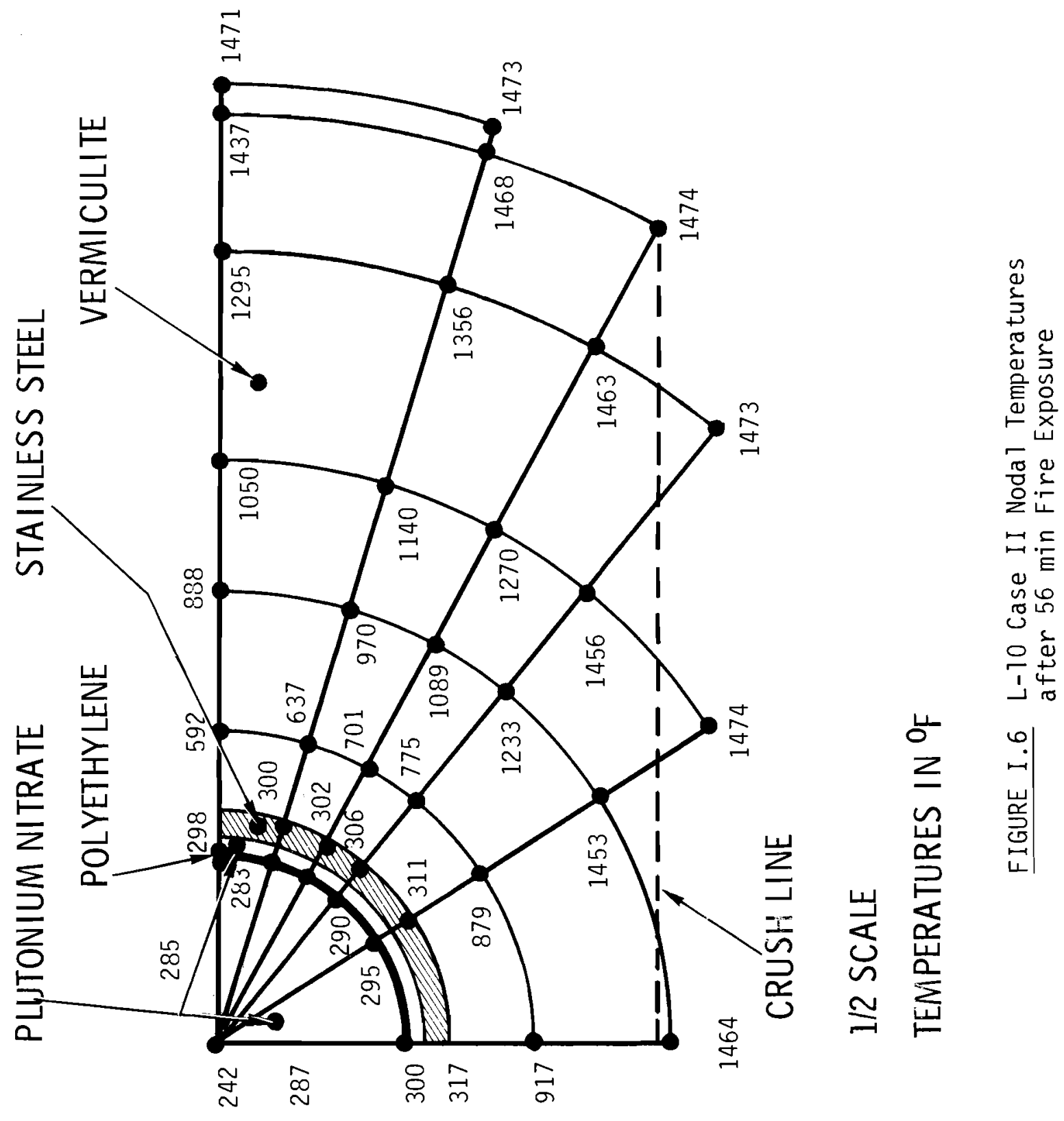




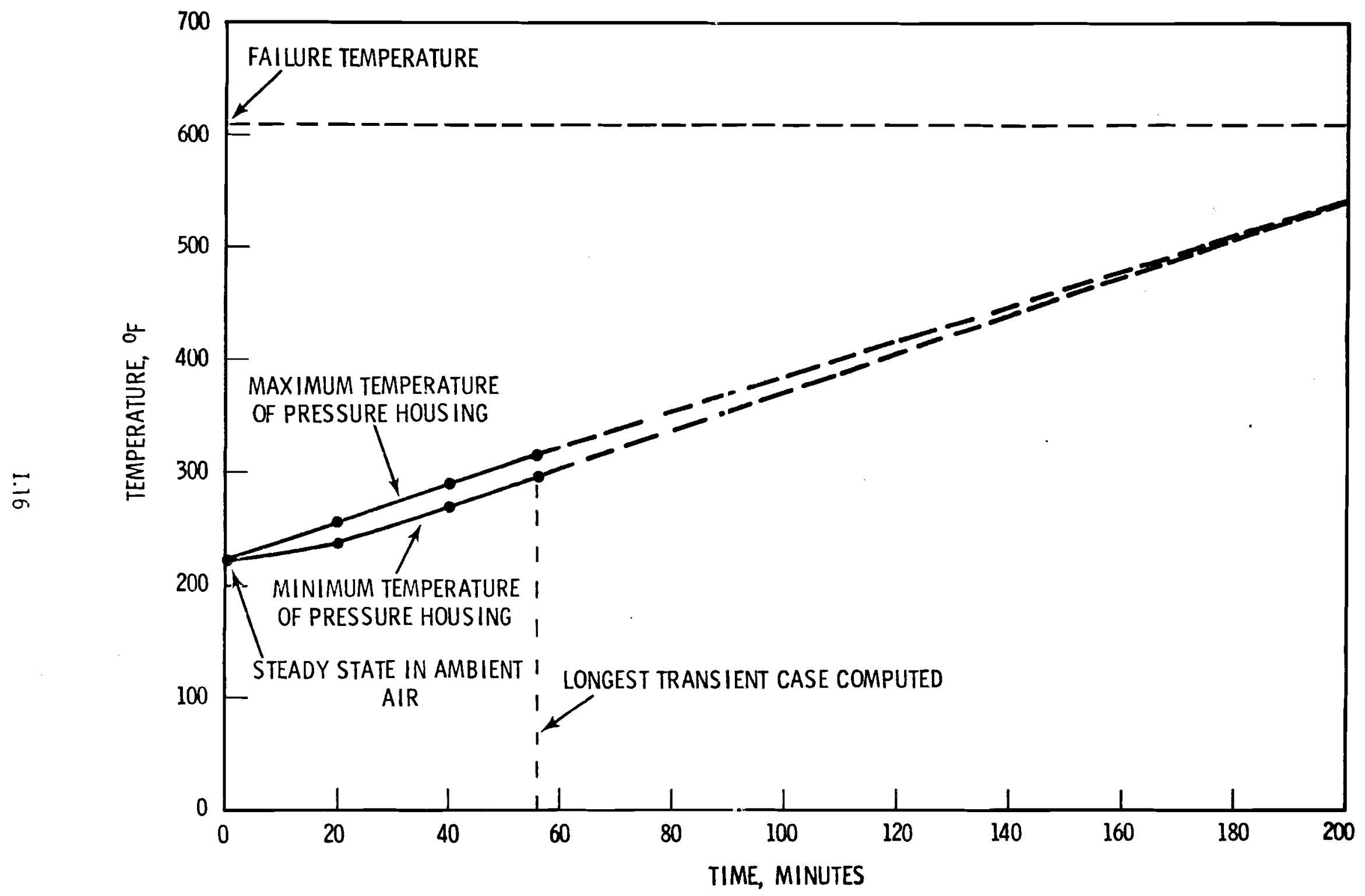

FIGURE I.7 L-10 Case II Temperature versus Time of Pressure Housing in Crushed Container Exposed to $1475^{\circ} \mathrm{F}$ Fire 


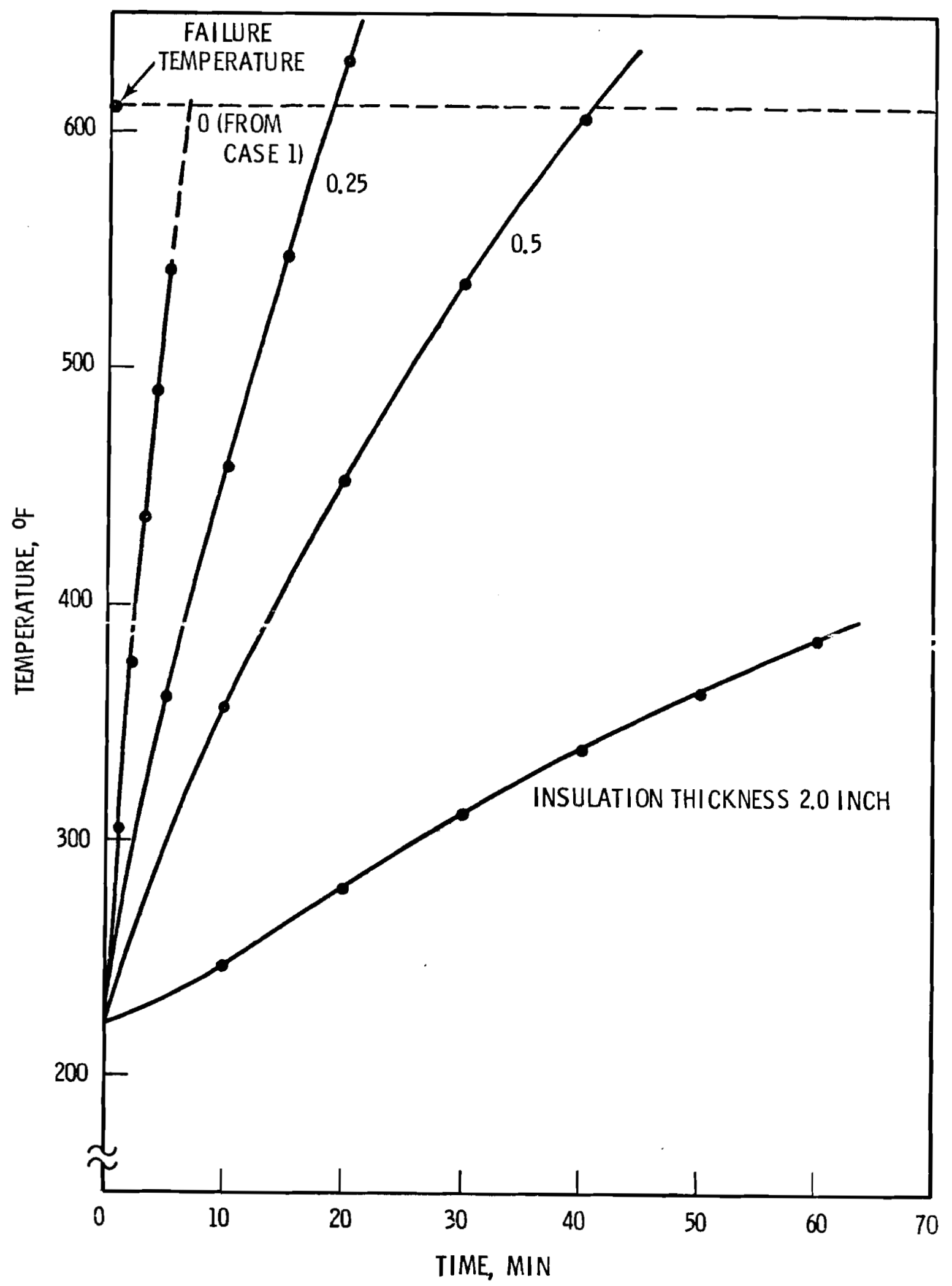

FIGURE I.8 L-10 Case III Temperature versus Time of Pressure Housing with $1475^{\circ} \mathrm{F}$ Fire Inside Container 


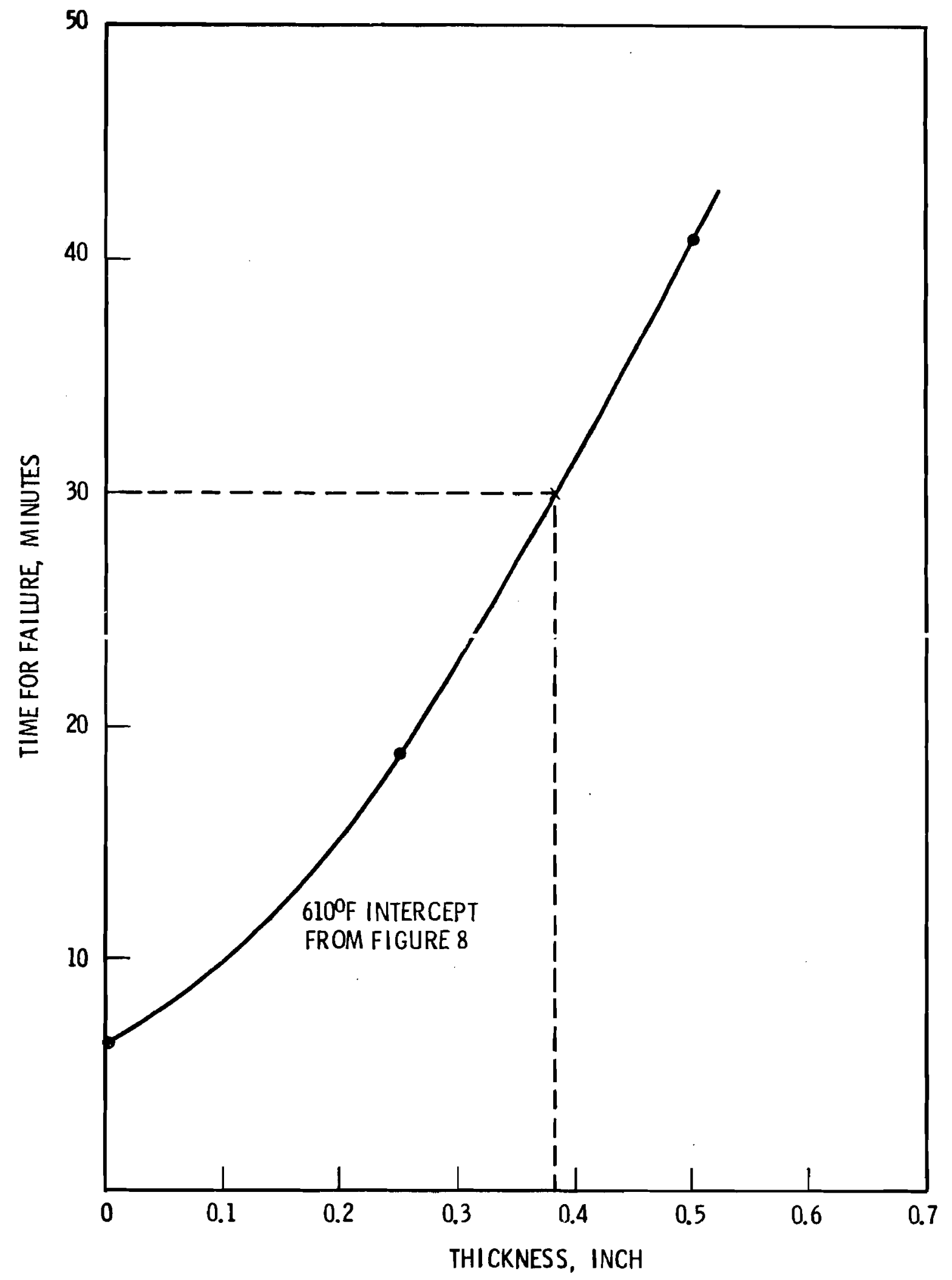

FIGURE I.9 L-10 Case III Time for Pressure Housing Failure versus Vermiculite Insulation Thickness 
Discussion and Conclusions

With the assumed boundary conditions the principal conclusions of this work are:

1) A 5-in. crush depth and associated displacement of the pressure housing does not degrade the $L-10$ container below test fire survival requirements if no loss of vermiculite occurs. The trend indicated by a 56-min transient analysis indicated failure would occur at approximately $240 \mathrm{~min}$.

2) If vermiculite is partially lost, a relatively thin layer ( 20.38 in. thickness) would protect the pressure housing for $30 \mathrm{~min}$ in the hypothetical fire test.

3) The pressure housing alone is predicted to survive between 6 and 7 min if exposed directly to the test fire.

Some uncertainties were generated in Cases I and III by the computational approach. To avoid computer costs, a single fire steady-state boundary condition was computed and applied to all runs. This started some transient computations with initial temperatures as much as $40^{\circ} \mathrm{F}$ different from their probable values. This effect was observed as the thickness of vermiculite was changed in Case III. Linear corrections for these displacements of initial temperature were applied to results plotted in Figures I.5 and I.8. 


\section{REFERENCES}

1. Code of Federal Regulations, Title 10, Part 71, Appendix B-Hypothetica 1 Accident Conditions.

2. W. D. Turner and M. Siman-Tov, HEATING3-An IBM 360 Heat Conduction Program, Oak Ridge National Laboratory Report No. ORNL-TM-3208, February 1971.

3. S. N. Liu, private communication to J. G. DeSteese, both of BattelleNorthwest. (See also Appendix $H$, this report.)

4. E. F. Curren, Evaluation of the Type L-10, Class II Shipping Container for Conformance with AEC Manual Chapter 0529 Appendix, Isochem Inc., Report No. ISO-970, July 1967.

5. T. I. McSweeney et a1. Transportation Safety Studies-The Risk of Plutonium Shipments, Battel1e, Pacific Northwest Laboratories Summary Report No. BNWL-B-295, August, 1973.

6. T. I. McSweeney, private communication to J. G. DeSteese, both of Battelle-Northwest.

7. E. C. Bernhardt, Processing of Thermoplastic Materials, Reinhold Publishing Co., New York, NY, 1959.

8. J. Brandrup and E. H. Immergut, Polymer Handbook, Interscience Publishers, 1966 Edition.

9. Amer. Soc. of Metals, Metals Handbook vol. 1-Properties and Selection of Metals, 8th Edition, 1961.

10. J. B. Loser et al, Thermophysical Properties of Thermal Insulating Materials, TechnicaT Documentary Report No. ML-TDR-64-5, Midwest Research Institute, Kansas City, MO, April 1964.

11. Zonolite Branch Vermiculites, Zonolite Division W. R. Grace and Co. Brochure G-231, 1964.

12. W. H. McAdams, Heat Transmission, McGraw-Hill Book Company, 3rd Edition, 1954. 
APPENDIX J

\section{EVALUATION OF MULTIPLE CONTAINER FAILURES FROM CRUSH}

Throughout this report accident impact forces have been distinguished from crush forces. The major difference is in the time interval over which the force is active. Impact is a sudden blow. Crush is the squeezing action which occurs as the load shifts following the accident. Eventually all the containers will come to rest, however the containers closest to direct involvement in the accident will decelerate first followed by the deceleration of successive rows of containers. The highest crush forces will be experienced by the row which is first to experience deceleration since essentially the entire weight of the cargo presses against the first

row. Successive rows experience smaller crush forces.

Since crush forces result from the action of many containers, the question of multiple container failures in an accident must be considered. The analysis in the body of the report considered container failures to be independent events which are so rare that the likelihood of two containers failing in the same accident is extremely small.

This appendix will evaluate the possibility of more than one container failing in the crush environment. It will be shown that the crush environment for the 6M container results in no outer drum failures. However, for the L-10 container the crush environment wi11 be shown to be severe enough to potentially fail several containers in the same accident. For the L-10 the following accident sequence will be evaluated. An accident occurs and sufficient crush forces are experienced so that several containers lose their outer drum lids. In the accident some of these failed containers are lost from the van, and in the process the vermiculite is lost from the space between the outer drum and the $2 \mathrm{R}$ container. Finally, a fire ensues and after 6 min any containers outside the truck which have no vermiculite will begin to release nitrate solution at approximately 3000 psia and $600^{\circ} \mathrm{F}$.

To show the effect of multiple failures the above sequence will be evaluated two ways. The first case will consider the failures of the containers independently. The independent container evaluation will evaluate a nitrate shipment accident involving 50 containers as if 50 independent accidents occurred instead of one actual accident. The 
second case, a multiple container evaluation, considers the failure of all the containers in the shipment simultaneously. Since the risk results presented in Section 11 are based on an independent container evaluation, the comparison of these two cases is of value in assessing the applicability of the modeling.

This appendix will be divided into two parts. The first part will discuss the effect of crush forces on container integrity. The second part will present the results of the independent container evaluation which was used in Section 11, and then modify these results to obtain the multiple container evaluation.

Evaluation of Crush as a Container Failure Element

The crushing action of multiple containers in a shipment can effectively remove lids from containers if the deformation is sufficient. In the mode 1 described in Section 6.0 and Appendix $\mathrm{H}$, the criterion for lid removal is sufficient deformation of the drum so that the inner circumference of the bolt ring is greater than the deformed circumference of the drum.

The amount of crush required to meet this criterion is dependent on the number of directions in which force is applied. Table J.l shows the crush forces required to meet the lid removal criterion for both the $6 \mathrm{M}$ and $L-10$ containers. The deformations used to obtain these results are based on deformation curves presented in Appendix $H$.

\section{TABLE J.1. Crush Force Required for Lid Removal} of the L-10 and $6 \mathrm{M}$ Containers

$\begin{array}{ccc}\begin{array}{c}\text { No. of Directions } \\ \text { of Applied }\end{array} & \begin{array}{c}\text { Crush Force Required } \\ \text { for L-10 Lid Removal } \\ \text { Force }\end{array} & \begin{array}{c}\text { Crush Force Required } \\ \text { for 6M Lid Removal } \\ (1 \mathrm{bs})\end{array} \\ 1 & 164,000 & 97,000 \\ 2 & 133,000 & 73,000 \\ 4 & 111,000 & 60,000\end{array}$

The number of force directions is dependent on the container loading arrangement. The one-sided crush is equivalent to the force generated in a drop test. The two-sided crush predominates when the containers are arranged in a square 
array. The four-sided crush is dominant when the containers are arranged on a triangular pitch. The normal arrangement of containers is on a triangular pitch. Therefore, only the four-sided forces are considered in this analysis.

The magnitude of the forces obtained in the analysis of the crush environment is very dependent on the force model used. If it is assumed that there is zero sliding friction at the contact points, then the deceleration force is proportional to $1 / \sin \alpha$, where $\alpha$ is $1 / 2$ the apex angle measured between the lines formed from the center of the container in one row to the centers of the two containers in the next row. If friction is considered, the force is proportional to sin $\alpha$. Since $\alpha$ is typically $30^{\circ}$ or less, it is easily seen that the potential range of crush forces is large and strongly dependent on the model. For this analysis the crush force was estimated using a square shipping arrangement but the 1id loss criterion was still based on a four-sided deformation. In the absence of knowledge on the frictional characteristics of contact points in a shipping arrangement, this seemed to be the most straightforward approach to the problem.

As discussed in Section 5, the maximum crush force experienced in an accident was assumed to be no more than 20 times the cargo weight. In terms of forces on individual containers, the force is distributed over the number of containers in a row. For the $6 \mathrm{M}$, the 39 containers are arranged five across and two high. The highest forces are generated by head-on impacts. since the containers are arranged four rows deep in the truck, the resultant crush force is $F_{C}=20 \times 4 \times 160=12,800 \mathrm{lb}$.

Since this force is much less than the minimum force of 60,000 1b required for 1 id removal, the crush forces are not sufficient to cause lid removal.

For the $L-10$, the 50 containers in a shipment are arranged in rows containing 3 containers. This means that there are 17 rows of containers. The maximum crush forces generated in an accident are therefore:

$$
F_{C}=20 \times 17 \times 510=173,4001 \mathrm{~b} .
$$


This force exceeds the value for the drum lid removal criterion and multiple container failures must be considered for the L-10 shipments.

Based on the data presented in Table J.1 and the container arrangement shown above, decelerations of 13 times gravity will exceed the lid removal criterion for the first row of containers. Table $\mathrm{J} .2$ presents the results of an analysis to determine the number of containers which would be expected to fail when the cargo load experiences decelerations between 13 and 20 times normal gravity. Also shown are the expected frequencies of experiencing a given deceleration level in an accident. These data were obtained by differentiating the data summarized in Figure 5.1.

TABLE J.2. Accident Severity Spectrum for Crush Failure in the Accident Environment

\begin{tabular}{ccc}
$\begin{array}{c}\text { Deceleration } \\
\text { Level }\end{array}$ & $\begin{array}{c}\text { Occurrence Frequency } \\
\text { of Deceleration } \\
\text { Gultiples of Gravity) }\end{array}$ & $\begin{array}{c}\text { Number of Containers } \\
\text { Experiencing Crush } \\
\text { Forces in Excess } \\
\text { of } 111,00016\end{array}$ \\
\cline { 2 - 3 } 13 & 0.492 & 3 \\
14 & 0.413 & 6 \\
16 & 0.063 & 12 \\
18 & 0.024 & 18 \\
20 & 0.008 & 21 \\
Total > 13 & 1.000 & Avg. ${ }^{*} 5.31$
\end{tabular}

*0ccurrence Frequency weighted.

The occurrence frequencies in the table are normalized to the $13 \mathrm{~g}$ failure threshold. Based on the results summarized in Figure 5.1 , the $13 \mathrm{~g} \mathrm{de}-$ celeration is expected to be exceeded in $0.7 \%$ of all accidents. Also shown in Table J.2 is the average number of containers expected to fail in an accident which generated deceleration greater than $13 \mathrm{~g}$. 
Comparison of Independent and Multiple Container Failure Analyses

The independent container evaluation considers the following sequence of failure elements, associated occurrence frequencies and titles:

Event Occurrence Number Frequency Event Titles

$\begin{array}{lll}\text { X001 } & 3.80 \times 10^{-3} & \text { Accident occurs } \\ \times 002 & 1.60 \times 10^{-2} & \text { Fire occurs } \\ \times 017 & 7.43 \times 10^{-4} & \text { Accident crush forces cause 1id removal } \\ \times 043 & 1.00 & \text { Bottle fails in accident } \\ \text { X056 } & 0.75 & 1850^{\circ} \mathrm{F} \text { fire with duration greater than } 6 \text { minutes } \\ \text { A069 } & 2.30 \times 10^{-2} & \text { Van breached and failed container lost. }\end{array}$

The expected occurrence frequency for the crush-initiated release sequence is the product of all the expected frequencies for each element. The sequence is expected to occur at a rate of $7.79 \times 10^{-10}$ per container in 1500 miles of travel. To get the annual rate of occurrence for this event during shipment of 18 MT of plutonium 1474 miles in the U.S., this number must be multiplied by the number of containers required to ship 18 MT (9000) and multiplied by the ratio of $1474 / 1500$ to correct the accident frequency for the shorter shipping distance. The resultant multiplier is 8844. These are the values used in the independent container evaluation. The following paragraphs will convert the data for the independent container evaluation to a multiple container evaluation.

In the multiple container analysis, the accident rate is based on 1474 miles, and therefore $x_{001}$ is set at $3.73 \times 10^{-3} /$ shipment. The risk multiplier is 180 since that is the number of shipments which will be made in 1980 to ship 18 metric tons of plutonium. The values of X002, X043 and X056 are the same for either a container or a shipment. However, $X 017$ and $f .69$ must be modified to change the crush release sequence from an individual container basis to a whole shipment basis.

The occurrence frequency for $x 017$ in the independent container evaluation was obtained by multiplying the fraction of accidents resulting in decelerations of greater than 13 times gravity $\left(7 \times 10^{-3}\right)$ times the probability that a container will be one of those failed in the crush environment 
$(5.31 / 50)$. The resultant value used for $x 017$ was $7.43 \times 10^{-4}$. In the multiple container analysis the $7 \times 10^{-3}$ value must be used for $x 017$ and the dependent probability of multiple container failures, shown in Table J.2 must be added to the analysis.

In order to analyze an entire shipment of containers, AEQ must alsn be modified. The value of $2.30 \times 10^{-2}$ used in the single-container analys is was based on the product of an occurrence frequency of $6.8 \%$ that some containers will be lost in an accident and a $1 / 3$ release fraction. To evaluate an entire shipment the $6.8 \%$ value must be used for $\mathrm{A} .69$. Table J.3 compares the occurrence frequencies used for the single container analysis with those used in the shipment evaluation.

TABLE J.3. Comparison of Occurrence Frequencies for Single Container and Shipment Crush Sequence Evaluation

\begin{tabular}{|c|c|c|}
\hline $\begin{array}{c}\text { Risk } \\
\text { Component } \\
\end{array}$ & $\begin{array}{c}\text { Independent } \\
\text { Container } \\
\text { Evaluation }\end{array}$ & $\begin{array}{r}\text { Multiple } \\
\text { Container } \\
\text { Evaluation } \\
\end{array}$ \\
\hline$x 001$ & $0.380 \times 10^{-2}$ & $0.373 \times 10^{-2}$ \\
\hline$x 002$ & $0.160 \times 10^{-1}$ & $0.160 \times 10^{-1}$ \\
\hline$x 017$ & $7.43 \times 10^{-4}$ & $7 \times 10^{-3}$ \\
\hline$x 043$ & 1.00 & 1.00 \\
\hline$\times 056$ & 0.75 & 0.75 \\
\hline 1069 & $0.23 \times 10^{-1}$ & $0.68 \times 10^{-1}$ \\
\hline Risk multiplier & 8844 & 180 \\
\hline Annual release frequency* & $6.89 \times 10^{-6}$ & $3.84 \times 10^{-6}$ \\
\hline
\end{tabular}

*In the analysis year. The assumed number of shipments and shipment distances are given in Section 11.1 .

The only terms missing from the multiple container evaluation are the dependent probability of multiple container failures in an accident shown in Table 3.2 and the probability that a failed container is removed from the van during an accident.

The containers failed are not necessarily released from the van. Sandia $(1)$ estimates that on the average only $1 / 3$ of the containers in the van will actually escape. Ideally, it would be desirable to know the escape 
frequency for containers located at various positions in the truck. However, this information is not available. The alternative is to assume that the containers lost are randomly distributed. The probability that $r$ failed containers will be lost from a truck containing $x$ failed containers when $n$ are released out of a total shipment of $N$ containers is given by the expression:

$$
p(r)=\frac{\left(\begin{array}{l}
x \\
r
\end{array}\right)\left(\begin{array}{l}
N-x \\
n-r
\end{array}\right)}{\left(\begin{array}{l}
N \\
n
\end{array}\right)}
$$

where

$$
\left(\begin{array}{l}
x \\
r
\end{array}\right)=\frac{x !}{r !(x-r) !}
$$

Using this expression, the probability can be developed that $r$ failed containers will be released in an accident which generates decelerations greater than 13 times normal gravity. These are shown in Table J.4 for 1 through 11 failed containers being released. Also shown in Table $\mathrm{J} .4$ is the expected frequency of from one to eleven containers failing from the crush sequence in the analysis year. The release spectrum curve for the multiple container failure analysis can now be obtained using the data in Table J.4 and the crush only risk spectrum curve in Figure J.1. The risk spectrum curve for one failure in the multiple container evaluation can be obtained by multiplying the frequency for each point on the independent container evaluation curve by the ratio of $1.27 \times 10^{-6} / 6.89 \times 10^{-6}$. The first term is the expected occurrence frequency for one container in a shipment failing from the crush initiated release sequence in the analysis year and the second term is the release frequency used in developing the independent container evaluation of crush shown in Table J.3. To get the curves for more than one container failing in the same accident requires adjusting both the frequency and the consequence levels. Thus for three containers failing in the same accident the consequence value for each point on the independent container analysis curve is first multiplied by three, since the consequences of the release are three times greater, and then the frequency of a release for the new curve is adjusted by multiplying each release frequency by the ratio of $4.92 \times 10^{-7} / 6.89 \times 10^{-6}$. 
This procedure is followed for successive numbers of containers failing and then all the resultant curves summed to get the multiple container evaluation curve shown in Figure J.1.

It can be seen that the independent container crush curve closely approximates the multiple failure analysis. The main deviation is at the less frequent higher consequence end of the risk spectrum. Even here the agreement is within a factor of 3 . Thus the use of independent container failure data throughout this evaluation does not significantly underestimate the risk level. 
TABLE J.4. Summary of Multiple Container Failure from Crush, Lost from Van and Subsequent Fire

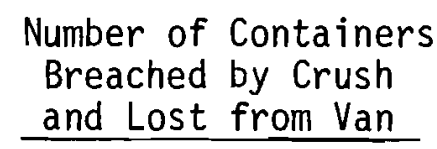

0

1

2

3

4

5

6

7

8

9

10

11 or more

Total

\section{Expected Occurrence} Frequency in a Crush Accident

0.1659

0.3320

0.2641

0.1281

0.0527

0.0246

0.0148

0.0093

0.0052

0.0023

0.0008

0.0002

1.0000
Expected Occurrence

Frequency in Analys is Year

$6.37 \times 10^{-7}$

$1.27 \times 10^{-6}$

$1.01 \times 10^{-6}$

$4.92 \times 10^{-7}$

$2.02 \times 10^{-7}$

$9.45 \times 10^{-8}$

$5.68 \times 10^{-8}$

$3.57 \times 10^{-8}$

$2.00 \times 10^{-8}$

$8.83 \times 10^{-9}$

$3.07 \times 10^{-9}$

$7.68 \times 10^{-10}$

$3.84 \times 10^{-6}$ 


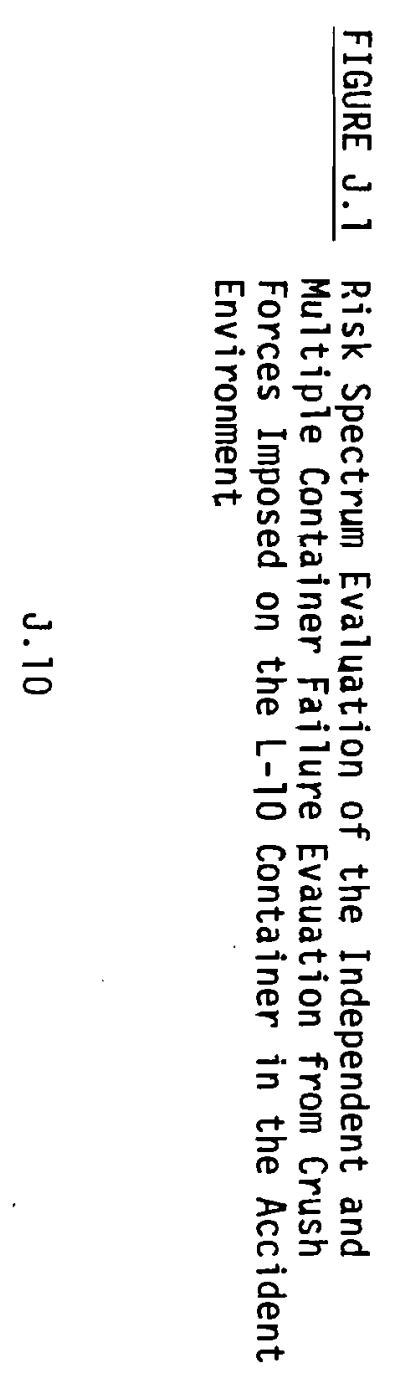

ESTIMATED FREQUENCY

(EVENTS/YEAR RESULTING IN N OR MORE FATALITIES)

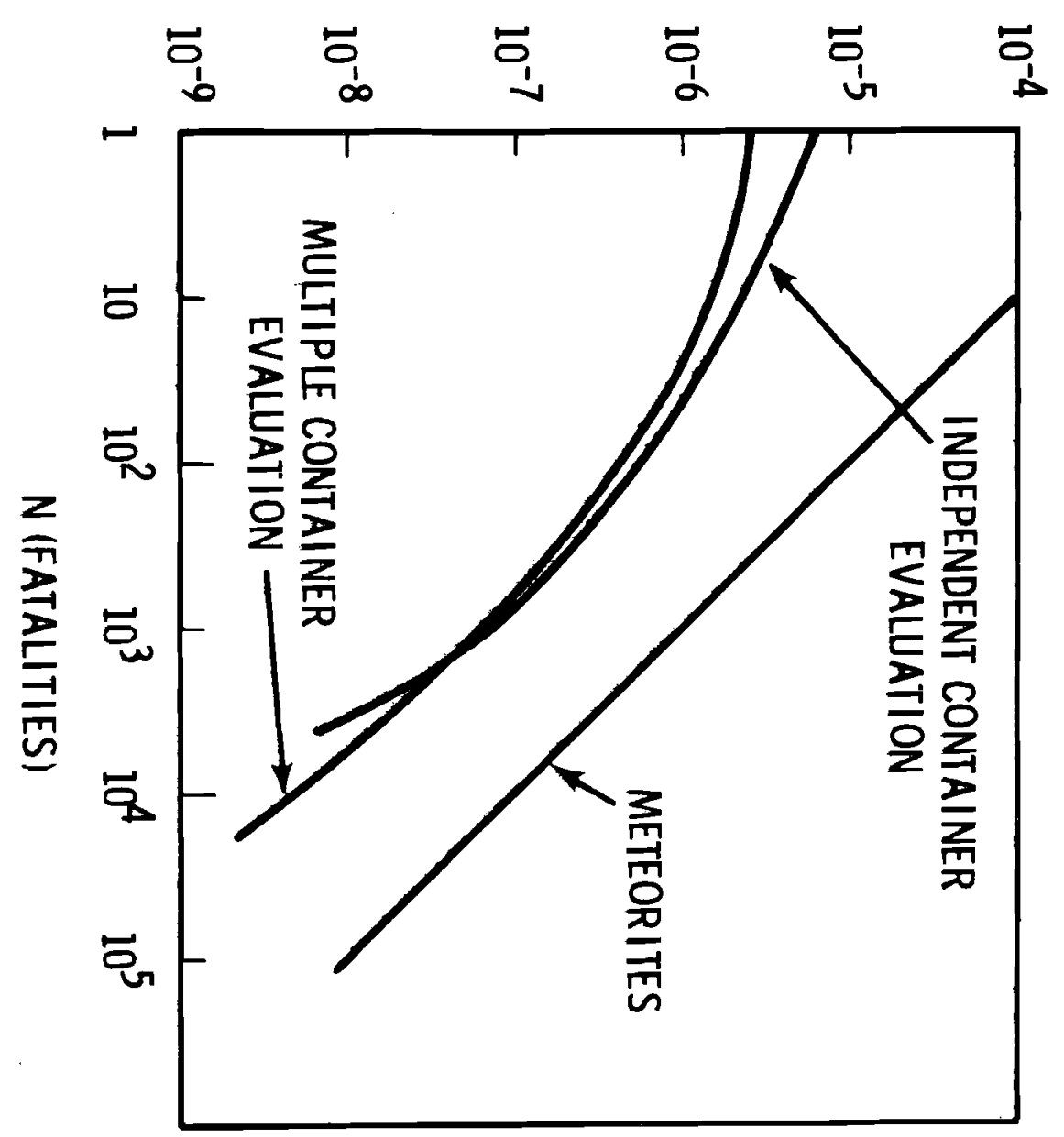




\section{REFERENCES}

1. R. K. Clarke, J. T. Foley, W. F. Hartman and D. W. Larson, Severities of Transportation Accidents, Volume III-Motor Carriers, SLA-74-001, Sandia Laboratories, Albuquerque, New Mexico (to be published). 
BHIVL -1846

UC-71

\section{Distribution}

No. of

Copies

OFFSITE

1 ERDA Chicago Patent Group

Chicago Operations office

9800 South Cass Avenue

Argonne, IL 60439

A. A. Churm

134 ERDA Technical Information Center

1 ERDA Division of Reactor Research

and DeveTopment

USERDA Headquarters

Germantown, MD 20014

K. A. Trickett

27 ERDA Division of Environmental

Control Technology

Transportation Branch

USERDA Headquarters

Washington, D.C. 20545

W. Brobst (25)

W. S. Holman

J. A. Sisler

2 ERDA Chicago Operations Office 9800 South Cass Avenue

Argonne, IL 60439

S. Kops

R. M. Moser

2
ERDA Savannah River Operations Office P.0. Box A

Aiken, South Carolina 29801

R. L. Chandler

N. Stetson
1 ERDA Albuquerque Operations Office Sandia Area Office Sandia Laboratories

P.0. Box 5800

A1buquerque, New Mexico 87115

D. Davis

1 ERDA Holifield National Laboratories Holifield National Laboratories P.0. Box E Oak Ridge, TN 37830

J. J. Schreiber

2 ERDA Idaho Operations Office P. 0 . Box 2108 Idaho Falls, ID 83401

P. G. Bradley

K. K. Kennedy

1 ERDA Albuquerque Operations Office Los Alamos Area Office Los Alamos, New Mexico 87544

T. Keenan

1 ERDA A1buquerque Operations Office Rocky Flats Area Office

P.0. Box 928 Golden, Colorado 80401

W. C. Bright

1 National Transportation Safety Board Washington, D.C. 20591

$L$. Benner 
No. of

Copies

OFFSITE

1 Westinghouse Electric Corp.

P.0.Box 355

Pittsburgh, PA 15230

2 Aerojet Nuclear Company

550 2nd St.

Idaho Fal1s, ID 83401

J. Power

W. W. Hickman

A. J. Nertney

1 Sandia Laboratories

Livermore, Ca 94550

P. J. Eicker

1 Nuclear Fuel Cycle Production ERDA Washington, DC 20545

1 DuPont Company

Wilimgton, DE 19898

W. Voigt

J. W. Langhaar

3 Electrical Power Research Inst.

P.0. Box 10412

Palo Alto, CA 94304

1 Suntac Nuclear

Rockville, MD 20850

C. Starr

C. Comar

James J. Holloway

E. Zebrowski

1 Department of Transportation Office of Hazardous Material Washington, DC 20590

A. Grella

1 Federal Aviation Admin. Dept. of Transportation Washington, DC 20591

E. C. Langford

Combustion Engineering, Inc. Windsor, CT 06095

1 Babcock \& Wilcox Co.

P.0. Box 1260

Lynchburg, VA 24505

J. Desmond

1 Environmental Protection Agcy. 401 M Street Washington, DC 20460

J. Russe11

1 Brookhaven National Labs. Upton, Long Is Iand, NY 11973

3

Hanford Engineering Deve1. Lab. Richland, WA 99352

L. Colton

A. W. DeMerschman

S. Fields

Massachusetts Institute of Technology

Cambridge, Massachusetts 02139

Prof. Norman C. Rasmussen 
No. of

Copies

\section{OFFSITE}

Sandia Laboratories

P.0. Box 5800

Altuquerque, New Mexico

L. Bonzon

J. K. Cole

J. Freedman

W. F. Hartmann (3)

R. M. Jefferson

R. Luna

R. Nickell

T. G. Priddy

A. W. Snyder

R. Yoshimura

4 Savannah River Laboratory

Aiken, South Carolina 29801

J. Groh (4)

10 Nuclear Regulatory Commission

R. F. Barker (3)

S. H. Hanauer

S. Levine

R. B. Minogue

C. McDonald

W. E. Vesely

I. Wa11

2 Argonne National Laboratory

9700 South Cass Avenue

Argonne, IL 60439

W. B. Seefeldt

M. J. Steindler

1
Battelle Memorial Institute

Columbus Operations

505 King Avenue

Columbus, Ohio 43201
1 Genera 1 Atomic

P.0. Box 92138

87115 San Diego, California 92138

D. Pence

1 Holifield National Laboratories P.O. Box X Oak Ridge, Tennessee 37830

L. Shappert

2 Nuclear Fuel Service, Inc. P.0. Box 124 West Valley, NY 14171

N. North

J. Duckworth

1 Kerr-McGee Corporation Oklahoma City, Oklahoma

W. J. Shelley

1 NUMEC

609 Warran Avenue

Apol10, PA 15613

E. Kosiancic

1 Allied Gulf Nuclear Services P.0. Box 847 Barnwe11, SC 29812

R. W. Peterson

1 General Electric Company

T75 Curtner Avenue

San Jose, CA 95125

Art Carson

J. Loomis 
No. of

Copies

OFFSITE

ONSITE

1 Oregon Nuclear \& Thermal

Energy Council

SaTem, OR 97301

W. E. Pollock

1 Western Interstate Nuclear Board

W. M. Rogers

1 U. of Southern California

University Park

Los Angeles, CA 90007

G. P. Jones

1 Holmes \& Narver

400 E. Orangethrope Ave.

Anaheim, CA 92801

C. V. Hodges

ERDA-Richland Operations Office

P. 0. Box 550, Richland, WA 99352

T. A. Bauman

R. F. Garrison

R. B. Goranson

D. J. Squires (4)

Atlantic Richfield Hanford Company

Federal Bldg., Richland, WA 99352

W. G. Bevan

W. A. B1yckert

E. F. Curren

D. A. Hoover, Jr.

D. D. Wodrich

United Nuclear Industries, Inc.

Federal Building, Richland, WA 99352

J. A. Adams

T. E. Dabrowski

Washington Public Power Supply

System

3000 Geo. Washington Way,

Richland, WA 99352

N. Strand

Research and Development Programs Division

B. J. Melton

Exxon Nuclear Company, Inc.

2101 Horn Rapids Road

Richland, HA 99352

Environmenta1, Safety and

Technical Services Division

R. Nilsen

G. Waymire

P. J. Holsted

R. K. Robinson

Dist. -4 
No. of

Copies

ONSITE

41 Battelle-Northwest
F. W. Albaugh
W. J. Bair
C. L. Brown
J. B. Burnham
S. H. Bush
N. E. Carter
J. M. Creer
D. K. Davis
J. G. DeSteese
J. G. Droppo
E. A. Eschbach
D. Haas 1 (Consultant)
R. J. Ha 11
H. Harty
S. W. Heaberl in
H. L. Henry
W. S. Kelly
D. A. Kottwitz
S. N. Liu
T. I. McSweeney
J. Mishima
K. J. Schneider
T. H. Smith
E. C. Watson
R. D. Widrig
L. D. Williams (10)
K. W. Winegardner
N. G. Wittenbrock Technical Information (3)
Technical Publications 